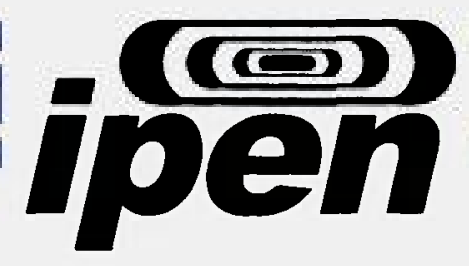

AUTARQUIA ASSOCIADA À UNIVERSIDADE DE SÃO PAULO

ESTUDO DA INFLUÊNCIA DA ADIÇÃO DE POLÍMEROS PRECURSORES CERÂMICOS NA SINTERIZAÇÃO DE SiC e $\mathrm{Al}_{2} \mathrm{O}_{3}$

ANA LÚCIA EXNER GODOY

Tese apresentada como parte dos requisitos para obtenção do Grau de Doutor em Ciências na Área de Tecnologia Nuclear - Materiais.

Orientadora:

Dra. Ana Helena de Almeida Bressiani

São Paulo

2005 
INSTITUTO DE PESQUISAS ENERGÉTICAS E NUCLEARES

Autarquia associada à Universidade de São Paulo

ESTUDO DA INFLUÊNCIA DA ADIÇÃO DE POLÍMEROS PRECURSORES CERÂMICOS NA SINTERIZAÇÃO DE $\mathrm{SiC}$ e $\mathrm{Al}_{2} \mathrm{O}_{3}$

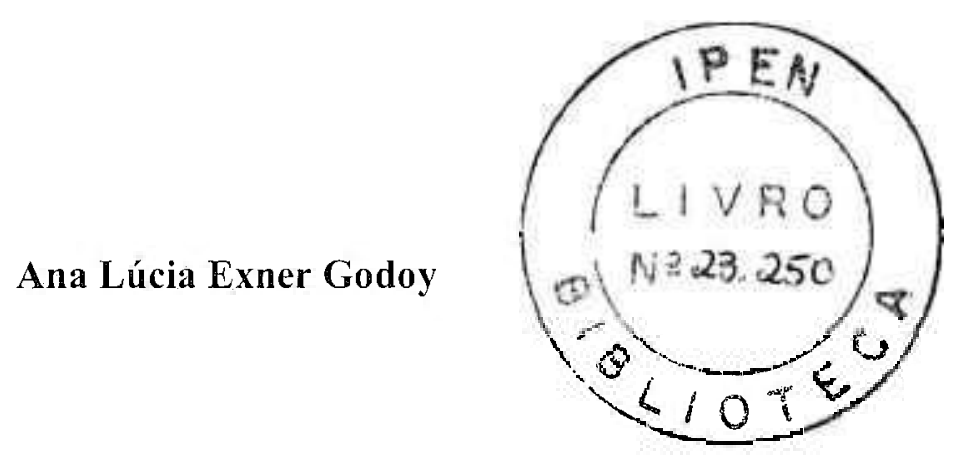

Tese apresentada como parte dos requisitos para obtenção do Grau de Doutor em Ciências na Área de Tecnologia Nuclear- Materiais.

Orientádora:

Dra. Ana Helena de Almeida Bressiani 
Dedico com muito carinho este trabalho aos meus filhos, Rachel e Caio, e aos meus pais, Carlota e Cyro 


\section{AGRADECIMENTOS}

Agradeço meus filhos Caio e Rachel, a quem dedico este trabalho, pela paciência, carinho, apoio e compreensão demonstrada nos momentos dificeis que passamos, nos quais muitas vezes não pude estar próxima.

Sou muito grata a Dr ${ }^{a}$. Ana Helena de Almeida Bressiani, minha orientadora, pelo seu profissionalismo e competência.

Agradeço ao Instituto de Pesquisas Energéticas e Nucleares, IPEN-CNEN/SP, pela oportunidade de desenvolver este trabalho.

Agradeço à Celso, Nildemar, Glauson, Pedro, René, Olandir pela aj̣uda, companherismo e pela amizade durante tantos anos de trabalho no CCTM.

Aos grandes mestres Dra . Ana Helena A. Bressiani, Dr. Arnaldo Homobono, Dr. Ângelo F. Padilha, Dr ${ }^{a}$. Eliana Muccillo, Dr ${ }^{a}$. Helena de Souza Santos (TFUSP), Dr. José Carlos Bressiani, Dr. Lalgudi Ramanathan, Dr. Paulo Iris Ferreina, Dr. Pedro Kyohara (IFUSP), Dr. Reginaldo Muccillo, Dr. Waldemar A. Monteiro, o meu muito obrigada pelos ensinamentos recebidos, que foram de grande valia para minha formação profissional.

Aos meus companheiros de trabalho e amigos, Kenji, Maurício, Valter, Chieko, Rosa, Odília, Hidê, pela ajuda e constante incentivo demonstrado.

À Dolores e Maurício pelo auxílio e discussões no decorrer deste trabalho.

Agradecimento especial à Rejane, minha grande amiga, companheira nos momentos alegres e difíceis.

Ao Laboratório de microscopia eletrônica do IFUSP pela utilização do microscópio eletrônico de transmissão.

Ao laboratório LABMAT do CTMSP-Marinha- ARAMAR em especial ao MSc. Ricardo Gomide e Sandra pelos ensaios de dilatometria.

Ao laboratório de $\mathrm{CCN}$, em especial ao Felipe e ao Davilson.

Agradeço os colegas e amigos do laboratório de cerâmica do IPEN, em especial Luís Gênova e Vanderlei, e a todos que direta, ou indiretamente colaboraram com este trabalho. 
Finalmente sou muito grata ao Carlos, meu companheiro, que tive a felicidade de conhecer, pela paciência, compreensão e carinho demonstrado. 
Em uma época de tanta violência, guerras e injustiças sociais, não diga jamais: É natural! Para que nada passe por imutável. 


\title{
Estudo da influência da adição de polímeros precursores cerâmicos na sinterização
}

\author{
de $\mathrm{SiC}$ e $\mathrm{Al}_{2} \mathrm{O}_{3}$
}

\author{
Ana Lúcia Exner Godoy
}

\section{RESUMO}

Neste trabalho foram avaliados os efeitos da adição de polímeros precursores na sinterização, microestrutura, dureza e na tenacidade à fratura de materiais cerâmicos à base de carbeto de silício e de $\mathrm{Al}_{2} \mathrm{O}_{3}$. As matérias-primas cerâmicas foram caracterizadas por análise semi-quantitativa por espectrometria de fluorescência de raios $\mathrm{X}$, difração por laser, adsorção gasosa e microscopia eletrônica de varredura. Para os polímeros utilizou-se análise termogravimétrica. A cinética de sinterização das amostras compactadas foi estudada por dilatometria. A caracterização dos materiais sinterizados incluiu medidas de densidade aparente pelo princípio de Arquimedes e/ou por picnometria de $\mathrm{He}$, porosimetria por intrusão de $\mathrm{Hg}$, análises de difração de raios $X$, de carbono total, avaliação da microestrutura e por microscopia eletrônica de varredura e de transmissão, análise por espectrometria de raios X por dispersão de energia, ensaios de impressão Vickers para determinação de dureza e tenacidade à fratura. No estudo de cerâmica à base de carbeto de silício foram utilizados os aditivos óxidos $\mathrm{Al}_{2} \mathrm{O}_{3}$ (4\% em peso) e $\mathrm{Y}_{2} \mathrm{O}_{3}$ (4\% em peso) e os aditivos poliméricos PMHS (polimetilhidrogenossiloxano) e polimetilhidrogenossiloxano com $\mathrm{D}_{4} \mathrm{~V}_{i}$. $\mathrm{O}$ processamento envolveu a cura do material, pirólise e sinterização (1850 ${ }^{\circ} \mathrm{C}$ e $1950{ }^{\circ} \mathrm{C} / 1 \mathrm{~h}, \mathrm{Ar}$ ou $\mathrm{N}_{2}$ ). Nas amostras à base de carbeto de silício houve elevada perda de massa, principalmente quando a atmosfera de sinterização foi argônio. As amostras à base de carbeto de silício, com adição de polímeros atingiram densidade de até $3,15 \mathrm{~g} / \mathrm{cm}^{3}$ quando pirolisadas a $900^{\circ} \mathrm{C}$ em $\mathrm{N}_{2}$ e sinterizadas a $1950^{\circ} \mathrm{C}$, em atmosfera de nitrogênio. Para as amostras à base de alumina foram utilizados os aditivos poliméricos PMHS, PMS (polimetilsilsesquioxano) e PPS (polifenilmetilvinilhidrogenosilsesquioxano) e as sinterizações foram realizadas a $1650^{\circ} \mathrm{C}$ e $1700{ }^{\circ} \mathrm{C}$, não havendo variações significativas nas densidades obtidas nas duas temperaturas. Nos materiais com adição de PMHS foram obtidos compósitos de alumina e mulita, sendo que os grãos de mulita foram formados intergranularmente. Nas amostras contendo PMS ou PPS a distribuição das fases formadas, $\mathrm{Si}_{2} \mathrm{Al}_{4} \mathrm{O}_{4} \mathrm{~N}_{4}$ e $\mathrm{Si}_{2} \mathrm{ON}_{2}$, foi bastante heterogênea. $A$ obtenção de compósitos cerâmicos utilizando pequenas adições de polímeros precursores cerâmicos mostrou-se viável para materiais à base de alumina, sendo uma rota simples de conformação, com grande potencial para a obtenção de peças com geometria complexa. 
Influence of the addition of precursor polymers on sintering $\mathrm{SiC}$ and $\mathrm{Al}_{2} \mathrm{O}_{3}$ ceramics

\author{
Ana Lúcia Exner Godoy
}

\begin{abstract}
The effects of the addition of precursor polymers on sintering, microstructure, hardness and fracture toughness of silicon carbide and alumina ceramics were studied. The ceramic raw materials were characterized by semi-quantitative analysis by $\mathrm{X}$-ray fluorescence, particle size by laser diffraction, specific surface area by gas adsorption and microstructural analysis by scanning electron microscopy. The polymers were analyzed by thermogravimetry. The sintering kinetics of cold-pressed specimens was studied by dilatometry. The sintered materials were characterized by evaluation of apparent density by the Archimedes technique and/or helium picnometry, by mercury porosimetry, by X-ray diffraction, by evaluation of total carbon content, by scanning and transmission electron microscopy, by energy dispersion X-ray spectrometry, and by Vickers indentation analysis for determining hardness and fracture toughness. $\mathrm{Al}_{2} \mathrm{O}_{3}$ (4wt.\%) and $\mathrm{Y}_{2} \mathrm{O}_{3}(4 \mathrm{wt} . \%)$ and polymetylhydrogenosiloxane and polymetylhydrogenossiloxane with $\mathrm{D}_{4} \mathrm{~V}_{i}$ were the sintering aids for $\mathrm{SiC}$. The processing procedures were material cure, pyrolysis and sintering $\left(18500^{\circ} \mathrm{C}\right.$ and $1950^{\circ} \mathrm{C} / 1 \mathrm{~h}, \mathrm{Ar}$ or $\left.\mathrm{N}_{2}\right)$. High mass loss was measured in silicon carbide based ceramics, mainly under argon. Silicon carbide based ceramics with polymer sintering aids achieved $3.15 \mathrm{~g} / \mathrm{cm}^{3}$ density after pyrolysis at $900{ }^{\circ} \mathrm{C}$ under $\mathrm{N}_{2}$ and sintering at $1950^{\circ} \mathrm{C}$ under nitrogen. PMHS, PMS and PPS polymer sintering aids were used for alumina based ceramics sintering carried out at $1650^{\circ} \mathrm{C}$ and $1700^{\circ} \mathrm{C}$, without significant difference in the final density. Addition of PMHS yielded alumina and mullite composites, with intergranular mullite grains. Heterogeneous $\mathrm{Si}_{2} \mathrm{Al}_{4} \mathrm{O}_{4} \mathrm{~N}_{4}$ and $\mathrm{Si}_{2} \mathrm{ON}_{2}$ phases were obtained in specimens with PMS or PPS. The preparation of ceramic composites using small amounts of precursor polymers showed a suitable process for alumina-based ceramics, a simple forming route, with high potential for the fabrication of complex shape pieces.
\end{abstract}




\section{SUMÁRIO}

Página

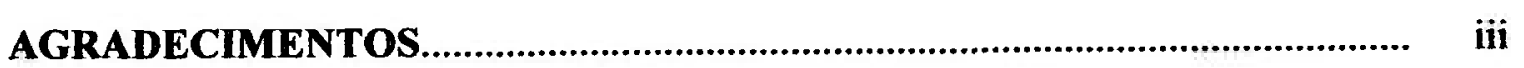

RESUMO

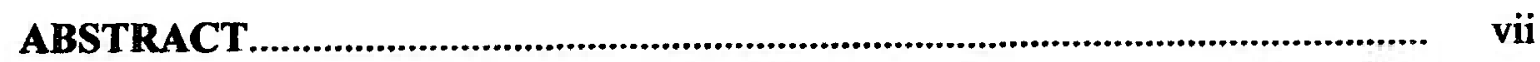

LISTA DE ABREVIATURAS..............................................................................

I- INTRODUÇÃO

II- REVISÃO BIBLIOGRÁFICA .....................................................................

II.1- Carbeto de silício..................................................................................................

II.2- Alumina............................................................................................. 9

II.3- Polímeros precursores........................................................................................ 12

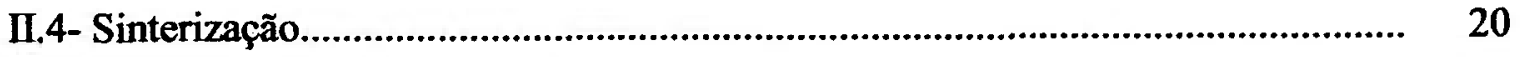

II.4.1- Sinterização no estado sólido...................................................................... 20

II.4.2- Sinterização via fase líquida.......................................................................... 24

II.4.3- Dureza e tenacidade à fratura.......................................................................... 29

III- MATERIAIS E MÉTODOS...............................................................

III.1- Materiais à base de $\mathrm{SiC}$....................................................................................... 37

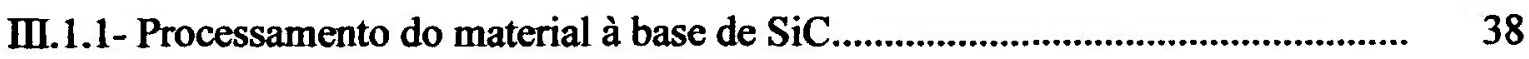

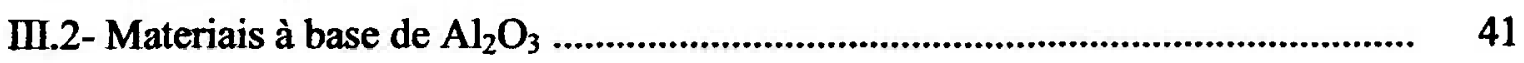

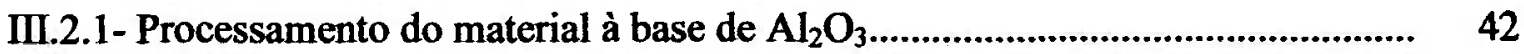

III.3- Métodos de caracterização................................................................................ 45

IV- RESULTADOS E DISCUSSÃO

IV.1- Caracterização das matérias primas................................................................... 51 
IV.2- Caracterização dos polímeros......................................................................... 56

IV.3- Materiais à base de SiC................................................................................... 63

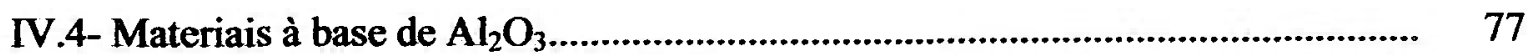

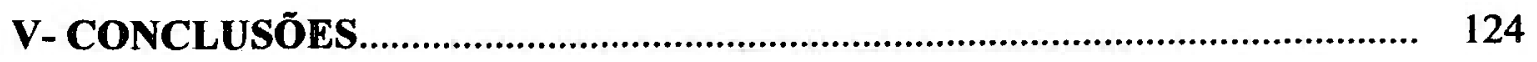

VI- PROPOSTAS PARA TRABALHOS FUTUROS.......................................... 125

REFERÊNCIAS BIBLIOGRÁFICAS............................................................ 126 


\section{ABREVIATURAS}

DRX- difração de raios X

\% DT- porcentagem da densidade teórica

$\mathrm{D}_{4} \mathrm{~V}_{\mathrm{i}}-1,3,5,7$ - tetrametil-1, 3, 5, 7- tetravinilciclotetrassiloxano

EDS- espectrometria de raios $\mathrm{X}$ por dispersão de energia

$\mathrm{H}_{\mathrm{v}}$ - dureza Vickers

ME- microscopia eletrônica

MEV- microscopia eletrônica de varredura

MET- microscopia eletrônica de transmissão

MO- microscopia óptica

PCS- policarbossilano

PM- perda de massa

PMHS- polimetilhidrogenosiloxano

PMP- perda de massa prevista

PMS- polimetilsilsesquioxano

PPS- polifenilmetilvinilhidrogenosilsesquioxano

TG- termogravimetria 


\section{I- INTRODUÇÃo}

O desenvolvimento de cerâmicas de alto desempenho é motivado principalmente pela necessidade de atender a condições de trabalho em temperaturas elevadas. Na Figura I.1 são mostradas as temperaturas máximas de serviço de alguns materiais; a superioridade de materiais cerâmicos é evidente; pode-se notar também que as ligas metálicas estão próximas ao seu limite de aplicabilidade e desenvolvimento, no que se refere à temperatura [1].

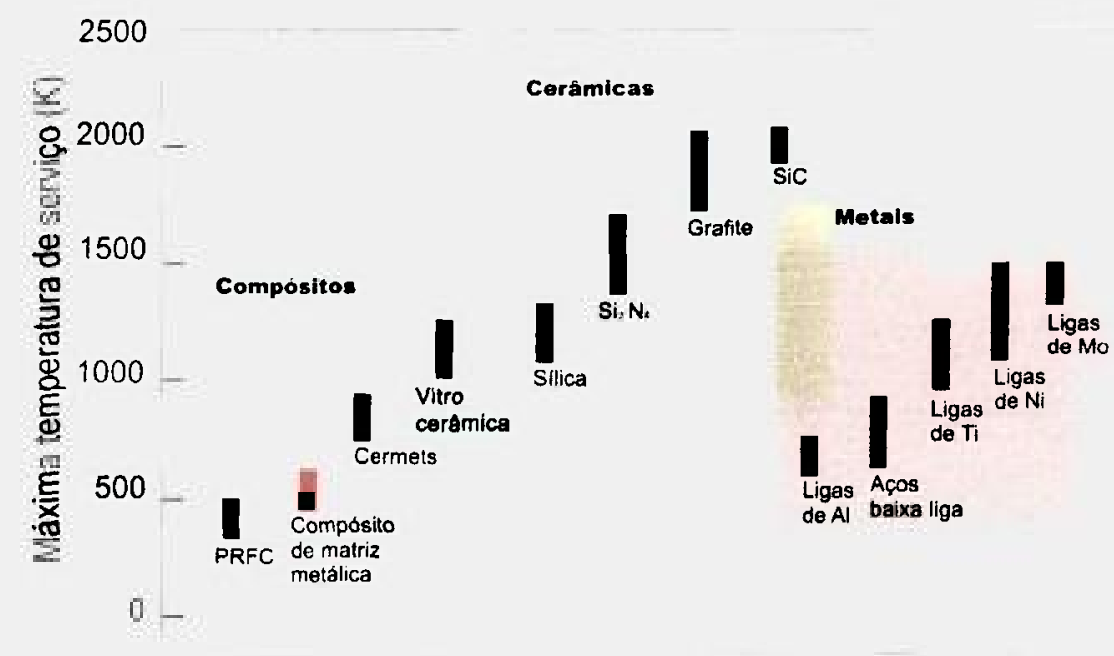

Materiais

Figura I.1- Temperaturas máximas de operação de algumas ligas metálicas, compósitos e cerâmicas [1].

Na Figura I.2 é mostrado um quadro geral das faixas de custo de alguns materiais por unidade de massa (US\$ $/ \mathrm{kg}$ ). A primeira vista, o custo das cerâmicas avançadas e dos compósitos, em relação aos metais, parece antieconômico. Porém é bom ter em mente que muitas vezes trabalhando com materiais cerâmicos há economia na quantidade de material utilizada, que tem efeito cascata sobre vários aspectos ligados a desempenho e a projeto. Como exemplos, a diminuição na quantidade de material em indústria aeronáutica significa possibilidade de aumento de carga paga, gerando maior lucro para a empresa aérea, e na indústria automotiva pode refletir na economia de combustível [1]. 


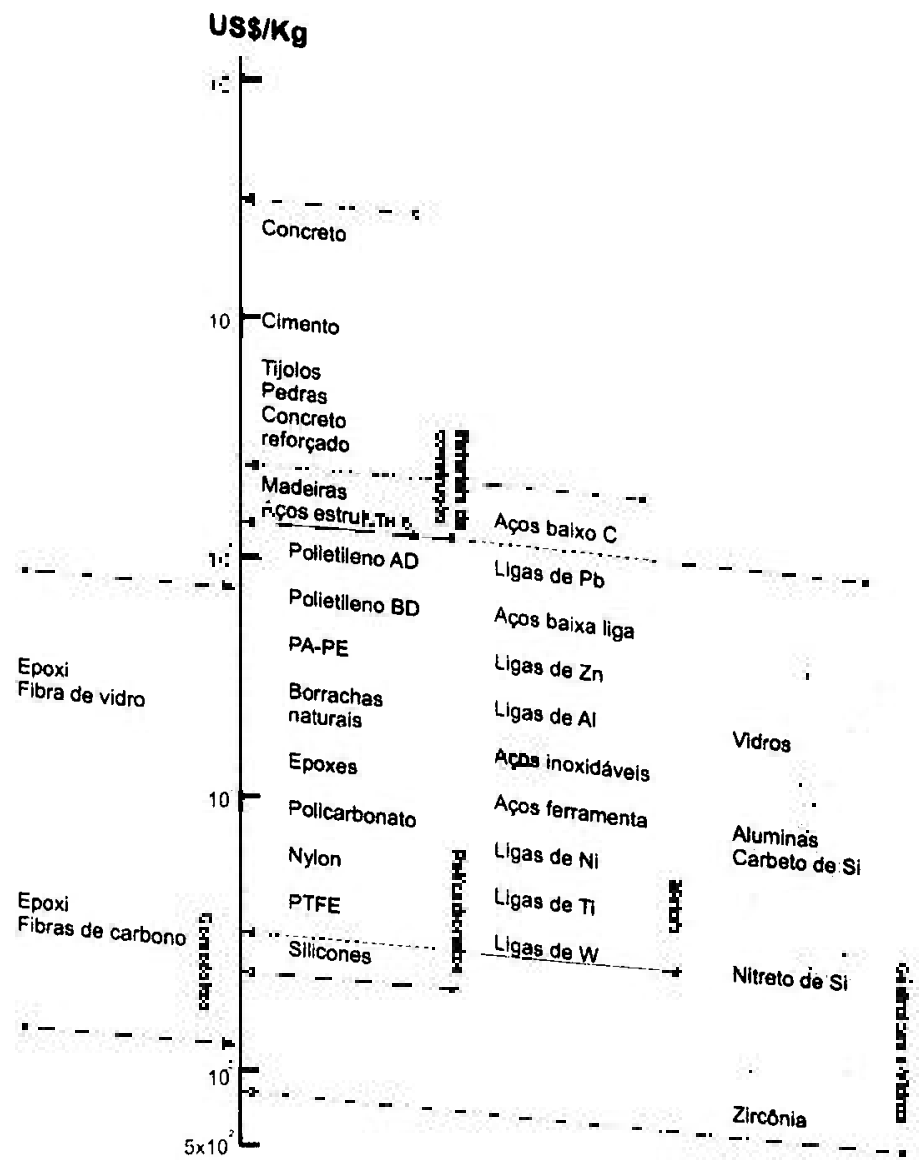

Figura I.2- Faixas de preço, por kg, de materiais cerâmicos, polímeros e ligas metálicas [1].

Neste trabalho foram utilizados, basicamente, dois materiais cerâmicos, $\mathrm{SiC} \mathrm{e}$ $\mathrm{Al}_{2} \mathrm{O}_{3}$, que possuem um custo mais elevado que as cerâmicas convencionais, mas seu desempenho justifica, em situações especiais, seu uso. $O$ importante é o custo/benefício em contraposição ao custo absoluto.

As cerâmicas podem ser definidas como materiais inorgânicos formados, muitas vezes, durante reações à alta temperatura, sendo utilizadas desde a pré-história. A palavra "cerâmica" é originária do grego keramos, que significa peças de barro queimado. Além das cerâmicas tradicionais tais como argila, vidro e cimento, as cerâmicas avançadas mais utilizadas são óxidos, carbetos e nitretos [2].

Dentre os materiais cerâmicos covalentes, nitretos e carbetos são os mais utilizados e o início das pesquisas com estes materiais data da década de 1970. Os carbetos podem ser expressos pela fórmula geral $\mathrm{Me}_{\mathrm{x}} \mathrm{C}_{\mathbf{y}}$ (Me: metal), sendo os mais usados, carbeto 
de silício $(\mathrm{SiC})$, de boro $\left(\mathrm{B}_{4} \mathrm{C}\right)$, de vanádio $(\mathrm{VC})$, de tântalo $(\mathrm{TaC})$, de nióbio $(\mathrm{NbC})$, de titânio (TiC), de molibdênio $\left(\mathrm{Mo}_{2} \mathrm{C}\right)$, e de tungstênio (WC) [3].

Óxidos cerâmicos são muito estudados, mas poucos possuem uma combinação de propriedades necessárias para aplicações à alta temperatura, tais como alto ponto de fusão $\mathrm{e}$ estabilidade quimica. Dentre os mais usados estão: $\mathrm{Al}_{2} \mathrm{O}_{3}, \mathrm{ZrO}_{2}, \mathrm{ThO}_{2}, 3 \mathrm{Al}_{2} \mathrm{O}_{3} .2 \mathrm{SiO}_{2}, \mathrm{SiO}_{2}$ e $\mathrm{MgO}$. $\mathrm{O} \mathrm{Al}_{2} \mathrm{O}_{3}$, que também foi objeto de estudo do presente trabalho, pode ser sinterizado no estado sólido e o $\mathrm{SiC}$ normalmente é sinterizado via fase líquida. $\mathrm{O}$ processo de sinterização será descrito posteriormente.

Polímeros inorgânicos possuem muitas utilidades no processamento cerâmico, seja como auxiliar na conformação de peças ou como precursor cerâmico. Os polímeros precursores permitem, com tratamentos adequados, a obtenção de cerâmicas em diversos sistemas e, ao contrário de polímeros utilizados como auxiliares de conformação, não precisam ser retirados do material, podendo ser preservada até $\sim 90 \%$ da sua massa inicial $[4,5,6]$.

\section{OBJETIVO DO TRABALHO}

O objetivo deste trabalho é o estudo do efeito da adição de polímeros precursores cerâmicos na sinterização, na microestrutura e na dureza de carbeto de silício contendo óxidos de alumínio e ítrio, e de $\mathrm{Al}_{2} \mathrm{O}_{3}$ de alta pureza. 


\section{II- REVISÃo BIBLIOGRÁFICA}

$\mathrm{Na}$ revisão bibliográfica serão abordados aspectos relevantes dos materiais em estudo, carbeto de silício, alumina, polímeros precursores cerâmicos e algumas propriedades como sinterização, dureza e tenacidade das cerâmicas em questão.

\section{II.1- CARBETO DE SILÍCIO}

Segundo K. Yamada e M. Mohri [7], o SiC foi descoberto por E. G. Acheson em 1891, durante uma experiência com síntese de diamantes. Acheson supôs que a substância obtida fosse um composto de carbono e de $\mathrm{Al}_{2} \mathrm{O}_{3}$ ("corundum") contido na argila, que foi denominado carborundum. $\mathrm{O} \mathrm{SiC} \mathrm{raramente} \mathrm{ocorre} \mathrm{na} \mathrm{natureza} \mathrm{e} \mathrm{o} \mathrm{método} \mathrm{de} \mathrm{produção} \mathrm{em}$ massa também foi desenvolvido por Acheson [7].

Atualmente ainda se utiliza este método, que é baseado em redução carbotérmica, de acordo com a equação:

$$
\mathrm{SiO}_{2}+3 \mathrm{C} \rightarrow \mathrm{SiC}+2 \mathrm{CO}
$$

Neste processo areia (sílica) e coque (carbono) são misturados, reagindo em temperaturas superiores a $2400{ }^{\circ} \mathrm{C}$, obtendo-se o $\mathrm{SiC}$ cristalino. $\mathrm{O}$ material produzido é moído, refinado e classificado para a obtenção de pós de SiC adequados à aplicação do mesmo [7]. A descoberta da produção de $\mathrm{SiC}$ conduziu à formação da Carborundum Co., onde inicialmente o $\mathrm{SiC}$ era utilizado como abrasivo, depois como refratário e aditivo metalúrgico. As pesquisas utilizando $\mathrm{SiC}$ cresceram muito, visando a correlação de suas propriedades, métodos de obtenção e características finais do produto obtido. Segundo dados publicados por D. Laughton [8], em 1999, cerca de um milhão de toneladas de SiC são produzidos anualmente. Aproximadamente 500000 toneladas por ano são provenientes de cerca de 125 fábricas existentes na China. A Noruega exporta por volta de 100000 toneladas/ano, enquanto praticamente a mesma quantidade é produzida pelos Estados Unidos e Canadá. A maior parte das 300000 toneladas remanescentes são fabricadas na Europa, Rússia, Índia, Venezuela, Argentina e Brasil [8]. 
O $\mathrm{SiC}$ apresenta dureza elevada, sendo considerado o material mais duro depois do diamante, do nitreto de boro cúbico e do carbeto de boro [7]. Sua estabilidade térmica é alta não sendo possível fundí-lo sob pressão atmosférica. Além da dureza e estabilidade térmica relativamente altas, possui excelente resistência à oxidação, alta condutividade térmica, boa resistência ao desgaste e ao choque térmico e resistência mecânica elevada a altas temperaturas $[9,10]$. O carbeto de silício é protegido contra oxidação por uma camada de $\mathrm{SiO}_{2}$ que se forma na superfície das partículas. Uma das aplicações mais importantes deste material é como refratário, devido a sua estabilidade térmica e resistência à oxidação [11]. Além disso, os materiais à base de $\mathrm{SiC}$ possuem outras aplicações, como, mobília de fornos para indústrias de porcelanas e de sinterização de metais duros, rebolos, pós abrasivos, tubulações para trocadores de calor industriais e componentes para indústria automotiva $[12,13]$.

A unidade básica de todos os politipos do $\mathrm{SiC}$ é um tetraedro de $\mathrm{SiC}_{4}$, com um átomo de silício no centro e 4 átomos de carbono nos vértices, ou $\mathrm{CSi}_{4}$, com um átomo de carbono no centro e 4 átomos de silício nos vértices (Figura II.1).

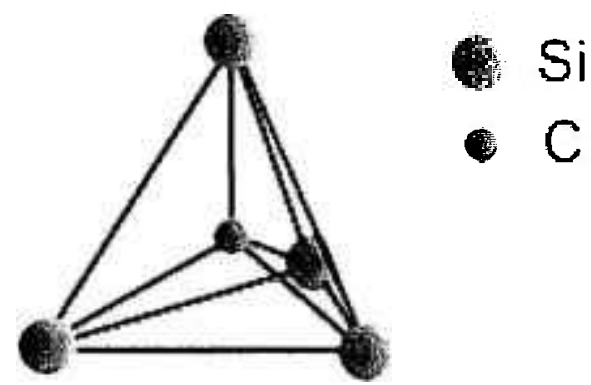

Figura II.1- Representação esquemática da estrutura básica de carbeto de silício [14].

Uma característica marcante do $\mathrm{SiC}$ é o politipismo, ou seja, as estruturas cristalinas possuem camadas idênticas, com diferentes arranjos na direção [0001], hexagonal/ romboédrica ou [001], cúbico. Embora um grande número de politipos seja conhecido, refere-se ao $\beta$-SiC como sendo politipo cúbico e às outras estruturas não cúbicas (hexagonal e romboédrica) como sendo $\alpha$-SiC [14]. Para explicar a formação de politipos de $\mathrm{SiC}$ foi sugerido que a mesma seria controlada por impurezas. Há muitos dados experimentais que demonstram que certas impurezas podem estabilizar alguns politipos 
mais comuns de periodicidade curta, embora esta teoria não seja totalmente aceita, levandose em conta politipos de períodos longos [14]. As impurezas com maior influência na formação de politipos do $\mathrm{SiC}$ são as com elementos dos grupos III e $\mathrm{V}$ da Tabela periódica, ou seja, os receptores eletrônicos ( $\mathrm{Al}, \mathrm{B}$, entre outros) e os doadores de elétrons $(\mathrm{N}, \mathrm{P})$. Um grande número de politipos de $\mathrm{SiC}$ é conhecido e bem documentado, porém poucos são considerados termodinamicamente estáveis. Os diversos tipos de politipos são diferenciados basicamente pelo número de camadas necessárias para que o arranjo se repita, ou seja, o número de camadas por célula unitária. Uma das maneiras de identificar qualquer politipo consiste do número de camadas seguido da letra " $\mathrm{H}$ " se a célula unitária for hexagonal $(2 \mathrm{H}, 4 \mathrm{H}, 6 \mathrm{H})$, "R" se for romboédrica (15R, 21R) e "C" se for cúbica (3C) [15]. Os politipos mais comuns são: $3 \mathrm{C}, 2 \mathrm{H}, 4 \mathrm{H}, 6 \mathrm{H}$ e $15 \mathrm{R}$.

Na Figura Il.2 são mostradas, de maneira esquemática, seqüências de empilhamento de alguns politipos [16].

(a)

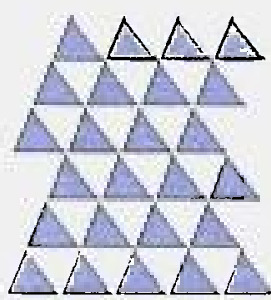

(c)

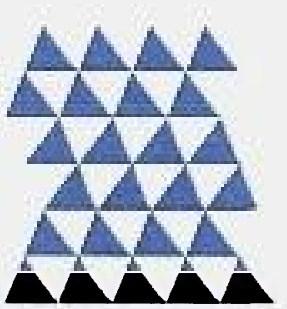

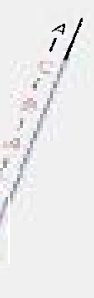

(b)

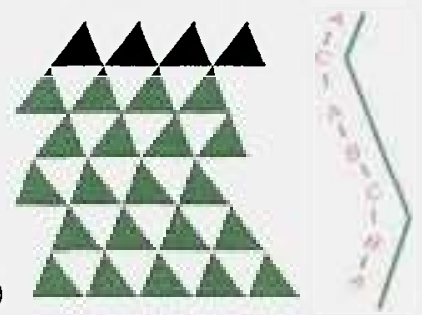

(d)
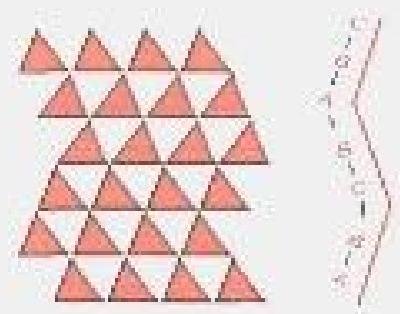

Figura II.2- Seqüência de empilhamento de politipos de $\mathrm{SiC}$ : (a)- 3C; (b)- $6 \mathrm{H}$; (c)- $4 \mathrm{H}$ e (d)- 15R [16].

O carbeto de silício é um material importante para a utilização em cerâmicas estruturais. Na Tabela II.1 são apresentadas algumas propriedades do SiC. 
Tabela II.1- Algumas propriedades do $\mathrm{SiC}$ [7].

\begin{tabular}{|c|c|}
\hline PROPRIEDADES & $\mathrm{SiC}$ \\
\hline Densidade $\left(\mathrm{g} / \mathrm{cm}^{3}\right)$ & 3,21 \\
\hline Módulo de elasticidade $(\mathrm{GPa})$ & 455 \\
\hline Temperatura de decomposição $\left({ }^{\circ} \mathrm{C}\right)$ & $2830 \pm 49$ \\
\hline Resistência à tração $(\mathrm{MPa})$ & 171 \\
\hline Resistência à compressão $(\mathrm{MPa})$ & 1050 \\
\hline Tensão de escoamento $(\mathrm{MPa})$ & 140 \\
\hline Tenacidade $, \mathrm{K}_{\mathrm{Ic}},\left(\mathrm{MPa} \cdot \mathrm{m}^{1 / 2}\right)$ & $2,5 \mathrm{a} 4,0$ \\
\hline
\end{tabular}

A combinação das propriedades do $\mathrm{SiC}$ é determinada pelo forte caráter covalente (até $88 \%$ ) das ligações químicas entre silício e os átomos de carbono, o que dificulta sua densificação. Uma maneira de contornar este problema é a utilização de aditivos, podendo obter $\mathrm{SiC}$ com altas densidades, por sinterização via fase líquida [17].

Prochazka e Scanlau [18] constataram que pequenas quantidades de boro e carbono melhoram a retração do $\mathrm{SiC}$ no processo de sinterização no estado sólido. A sinterização normalmente necessita de temperaturas superiores a $2100{ }^{\circ} \mathrm{C}$ e comumente resulta em crescimento de grão exagerado, o que pode prejudicar as propriedades mecânicas, e em alguns casos inibe a densificação.

Em 1975 F.F. Lange [19] propôs um método para a densificação de cerâmicas à base de carbeto de silício. Este pesquisador obteve $\mathrm{SiC}$ por prensagem a quente, a $1950^{\circ} \mathrm{C}$, utilizando $\mathrm{Al}_{2} \mathrm{O}_{3}$ como aditivo de sinterização. $\mathrm{O} \mathrm{Al}_{2} \mathrm{O}_{3}$ reage com o $\mathrm{SiO}_{2}$ presente na superfície das partículas de $\mathrm{SiC}$ formando um líquido eutético, de forma que a densificação é obtida por sinterização via fase líquida. Böcker et alli [20] estudaram a densificação do $\mathrm{SiC}$ via fase líquida com $\mathrm{Y}_{2} \mathrm{O}_{3}$ e $\mathrm{AIN}$ sinterizando a $1900{ }^{\circ} \mathrm{C}$ e observaram que tanto o $\mathrm{Al}$ como o N difundiram-se nos grãos de SiC. No início da década de oitenta Omori e Takei [21] observaram que muitos aditivos óxidos facilitam a densificação do $\mathrm{SiC}$ também no processo de sinterização via fase líquida. Estes pesquisadores utilizaram grande variedade de óxidos de terras raras em combinação com compostos de alumina e boro para densificar $\mathrm{SiC}$, havendo necessidade que a fase sólida tenha grande solubilidade no 
líquido. Estudos recentes demonstraram que pós de $\alpha-\mathrm{SiC}$ e de $\beta-\mathrm{SiC}$ podem ser densificados a temperaturas relativamente baixas, $1850^{\circ} \mathrm{C}$ a $2000{ }^{\circ} \mathrm{C}$, com a adição de $\mathrm{Al}_{2} \mathrm{O}_{3}$ e $\mathrm{Y}_{2} \mathrm{O}_{3}$ por sinterização via fase líquida [22]. $\mathrm{O}$ interesse por este tipo de sinterização de $\mathrm{SiC}$ cresceu muito nos últimos anos porque tanto sua resistência mecânica quanto sua tenacidade superam as obtidas pelo processo de sinterização convencional [23].

Embora possua excelentes propriedades, o $\mathrm{SiC}$ apresenta tenacidade à fratura relativamente baixa (2,5 a $4 \mathrm{MPa}^{1 / 2}$ ) [24], o que pode limitar suas aplicações. Alguns pesquisadores demonstraram que a tenacidade à fratura pode ser melhorada controlando-se a microestrutura do material por meio da tenacificação "in situ" [14], sendo uma das maneiras de conseguir tenacidade maior é colocar aditivos. A morfologia dos grãos do $\mathrm{SiC}$ depende das condições de sinterização e das características do pó inicial de SiC: politipos $\alpha$ não se transformaram durante a sinterização, obtendo-se microestrutura homogênea com grãos equiaxiais, enquanto grãos de $\beta$-SiC se transformaram em $\alpha$-SiC, ocorrendo crescimento de grão com forma alongada, que, de maneira geral, aumenta a tenacidade do material [22]. A transformação "in situ" foi desenvolvida para materiais à base de $\mathrm{Si}_{3} \mathrm{~N}_{4} \mathrm{e}$ apresenta vantagens em relação aos métodos tradicionais, nos quais são colocados aditivos na forma "whiskers", plaquetas ou mesmo materiais particulados. Algumas das vantagens são não causar dano à saúde, como ocorre com "whiskers", ter potencial para se fabricar componentes grandes com formas complexas, o custo da produção ser relativamente baixo [14], entre outras.

Kim, Mitomo e Hirotsuru [25] estudaram o efeito de sementes de $\alpha$-SiC e de $\beta$-SiC na microestrutura e na tenacidade à fratura de $\mathrm{SiC}$ com $7 \%$ em peso de $\mathrm{Al}_{2} \mathrm{O}_{3}, 2 \%$ em peso de $\mathrm{Y}_{2} \mathrm{O}_{3}$ e $1 \%$ em peso de $\mathrm{CaO}$. $\mathrm{O}$ material foi submetido à prensagem a quente a $1750^{\circ} \mathrm{C} \mathrm{e}$ a tratamento térmico a $1850^{\circ} \mathrm{C}$ para aumentar o tamanho dos grãos. O SiC com sementes de $\beta$-SiC apresentou microestrutura da matriz com grãos pequenos e grãos grandes e alongados. O SiC com sementes de $\alpha$-SiC tem microestrutura mais uniforme que com sementes de $\beta$-SiC. Pela teoria os grãos alongados podem levar a um aumento na tenacidade devido à tenacificação "in situ" nos materiais, embora a tenacidade à fratura obtida foi de 5,5 MPa.m ${ }^{1 / 2}$ para os dois materiais. Segundo os autores a tenacidade pode ser melhorada controlando e otimizando a fração volumétrica dos aditivos, o diâmetro e a taxa de grãos alongados. 


\section{II.2- ALUMINA}

As primeiras pesquisas científicas com óxido de alumínio, $\left(\mathrm{Al}_{2} \mathrm{O}_{3}\right)$, foram feitas no século XIX. O uso comercial da alta alumina, praticamente livre de impurezas, teve início em 1907 e sua produção e aplicação em larga escala começou no final de 1920, começo de 1930. A história do aumento do potencial de utilização da alta alumina está intrinsecamente relacionada ao avanço da tecnologia de fornos de alta temperatura, já que a mesma pode ser usada como cadinho, tubos e mobilia para fornos [26].

A principal fonte de alta alumina é a bauxita, que é encontrada em grandes quantidades por todo o mundo, o que torna este material com custo relativamente baixo. É um material heterogêneo composto principalmente de hidróxido de alumínio e misturas de sílica, óxido de ferro, titânia, silicatos de alumínio e outras impurezas em menor quantidade. A alumina é obtida normalmente pelo processo Bayer que, embora tenha mais de 100 anos, ainda é o método mais econômico. Pós de alumina muito finos e reativos, tornaram-se viáveis a partir de cerca de 1960, havendo, de modo geral, grande melhora nas suas propriedades e aumento nas aplicações de componentes produzidos com este material $[27,28,29]$.

A alumina possui diversas formas cristalográficas, como, $\alpha-\mathrm{Al} 2 \mathrm{O} 3$ e $\gamma$-Al2O3. $\mathrm{O} \alpha$-A12O3, fase termodinamicamente estável, possui superfície específica relativamente baixa, alta dureza, estabilidade química alta, tendo como principais aplicações peças estruturais e refratário. É chamada de corindon e, como monocristal, safira. Quanto a $\gamma$ $\mathrm{Al}_{2} \mathrm{O}_{3}$, devido a sua alta superfície específica, é adequada para utilização em catalisadores [30].

$\mathrm{O} \mathrm{Al}_{2} \mathrm{O}_{3}$ tem relação entre os tamanhos de íons que favorecem o número de coordenação $6 \mathrm{e}$ a estrutura do corindon possui os ions $\mathrm{O}^{2-}$ formando um arranjo com estrutura hexagonal compacta. Os cátions $\left(\mathrm{Al}^{3+}\right)$ preenchem somente $2 / 3$ dos interstícios. Em geral, a forma hexagonal compacta é estável pelo fato da distância mínima entre os cátions ser relativamente grande [31,32]. Na Figura II.3 é mostrada a célula unitária do corindon, mostrando somente a sub-rede do cátion $\mathrm{Al}^{3+}$ e vacâncias, formando uma estrutura hexagonal. Nota-se que esta sub-rede de cátions se repete após 3 camadas. 


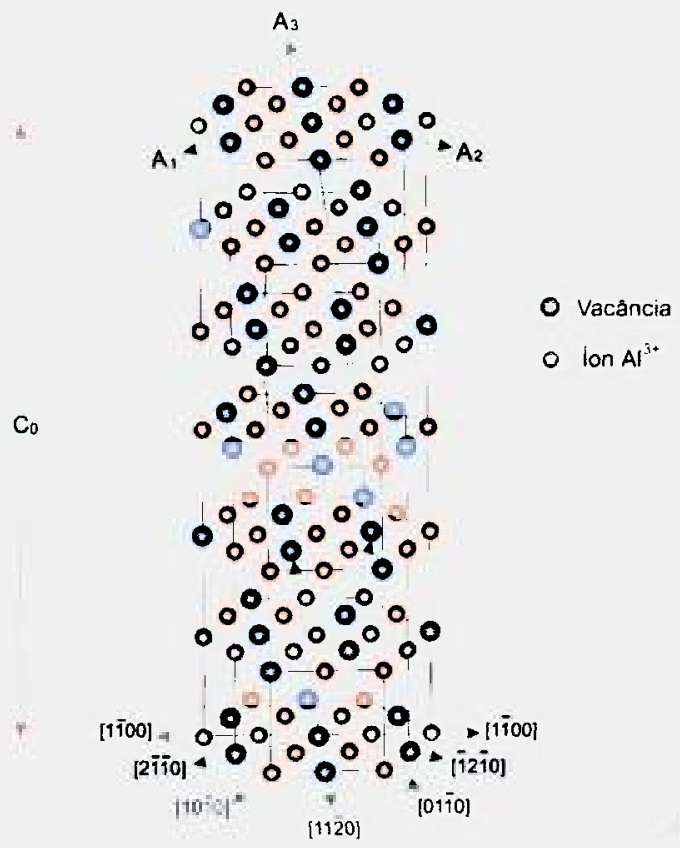

Figura II.3- Representação esquemática da estrutura cristalina do $\alpha-\mathrm{Al}_{2} \mathrm{O}_{3}$, ressaltando as posições de $\mathrm{Al}^{3+}$ e vacâncias [32].

$\mathrm{Al}_{2} \mathrm{O}_{3}$ é um material cerâmico muito utilizado devido à excelente combinação de propriedades fisicas e químicas tais como boa resistência ao calor, ao desgaste, e boa resistência à oxidação. Apresenta grande inércia química, sendo considerado óxido refratário pela sua capacidade de resistir a elevadas solicitações térmicas sem sofrer grandes alterações na sua natureza química [33]. Além destas propriedades possui baixa expansão térmica e alta resistência a choque térmico $[27,34,35]$. Geralmente procura-se obter materiais com baixa porosidade e tamanho de grão pequeno visando alta resistência mecânica. Entretanto, há várias aplicaçōes que não necessitam desta propriedade, como por exemplo, refratários. A maioria dos refratários possuem grãos grandes e alta porosidade para a obtenção das propriedades desejadas tais como baixa condutividade e alta resistência à choque térmico [26].

$\mathrm{Na}$ Tabela II.2 são apresentadas algumas propriedades do $\mathrm{Al}_{2} \mathrm{O}_{3}$. 
Tabela II.2- Algumas propriedades do $\mathrm{Al}_{2} \mathrm{O}_{3}[29,33,36,37,38]$.

\begin{tabular}{|c|c|}
\hline PROPRIEDADES & $\mathrm{Al}_{2} \mathrm{O}_{3}$ \\
\hline Densidade $\left(\mathrm{g} / \mathrm{cm}^{3}\right)$ & 3,98 \\
\hline Módulo de elasticidade $(\mathrm{GPa})$ & 390 \\
\hline Temperatura de decomposição $\left({ }^{\circ} \mathrm{C}\right)$ & 2050 \\
\hline Resistência à tração $(\mathrm{MPa})$ & 206 \\
\hline Resistência à compressão $(\mathrm{MPa})$ & 31000 \\
\hline Tensão de escoamento $(\mathrm{MPa})$ & 262 \\
\hline Tenacidade $, \mathrm{K}_{\mathrm{IC}},\left(\mathrm{MPa} \cdot \mathrm{m}^{1 / 2}\right)$ & $2,5-4,5$ \\
\hline
\end{tabular}

Além das aplicações citadas anteriormente, a alumina é utilizada como cadinhos, tubos para fornos, revestimento cerâmicos, abrasivos, mobília para fornos, esferas como meio de moagem, materiais para polimento, componentes para uso médico e odontológico $[28,35]$, entre outras.

O maior problema em utilizar alumina como material estrutural é sua fragilidade que é uma característica comum em materiais cerâmicos. Com o objetivo de se obter tenacidade à fratura mais elevada de materiais cerâmicos, foram feitos muitos estudos colocando-se aditivos.

A escolha dos aditivos pode promover tanto a densificação, como o crescimento exagerado de grão. A seguir encontram-se exemplos de efeitos provocados pela ação de alguns aditivos em matriz de alumina. $\mathrm{O} \mathrm{MgO}$ promove densificação e impede crescimento exagerado de grão, já que segrega no contorno de grão, reduzindo a mobilidade do mesmo; - $\mathrm{TiO}_{2}$ promove densificação e crescimento exagerado de grão; o $\mathrm{Ni}_{2} \mathrm{O}_{3}$ impede densificação e impede crescimento exagerado de grão e o $\mathrm{SiO}_{2}$ impede densificação e promove crescimento exagerado de grão [26].

Cahoon e Christensen foram os primeiros pesquisadores, em 1956, e alguns anos depois, Coble, que demostraram que o $\mathrm{Al}_{2} \mathrm{O}_{3}$ pode ser sinterizado no estado sólido, até atingir densidades elevadas. Estes autores mostraram que um pré-requisito para completa remoção dos poros é evitar crescimento exagerado de grão, o que pode ser obtido usando como aditivo pequenas quantidades de $\mathrm{MgO}$ [26]. 
Foi apresentado, por vários pesquisadores [37,38,39,40], que impurezas e aditivos influenciam no crescimento de grão e propriedades de cerâmicas à base de $\mathrm{Al}_{2} \mathrm{O}_{3}$. Os autores destes trabalhos utilizaram $\mathrm{MgO}$ para inibir crescimento exagerado de grão.

Compósitos de $\mathrm{Al}_{2} \mathrm{O}_{3}-\mathrm{SiC}$ têm sido estudados principalmente desde o trabalho de Niihara, em 1991 [41]. Jeong, Nakahira, e Niihara [42] também utilizaram MgO, como aditivo de sinterização, que auxilia não só na densificação, como também no controle da microestrutura de nanocompósitos de $\mathrm{Al}_{2} \mathrm{O}_{3}$-SiC. Em trabalho realizado recentemente por Deng et alli [43], foram estudados os efeitos da adição de terras raras no modo de fratura $e$ na tenacidade à fratura de compósitos de $\mathrm{Al}_{2} \mathrm{O}_{3}-\mathrm{SiC}$. Foram preparadas amostras de $\mathrm{Al}_{2} \mathrm{O}_{3}$ $5 \%$ vol. $\mathrm{SiC}$, com pequenas quantidades de terras raras, $800 \mathrm{ppm} \mathrm{de} \mathrm{Y}^{3+}, \mathrm{Nd}^{3+}$ e $\mathrm{La}^{3+}$. As amostras foram prensadas a quente, a $1550{ }^{\circ} \mathrm{C} / 1 \mathrm{~h}, 40 \mathrm{MPa}$ em atmosfera de argônio, apresentaram aproximadamente $99,5 \%$ da densidade teórica e os valores de tenacidade à fratura dos compósitos de $\mathrm{Al}_{2} \mathrm{O}_{3}-\mathrm{SiC}$ dopados com terras raras são mais altos do que dos compósitos sem dopagem, devido a mecanismo tenacificadores, como deflexão de trincas.

\section{II.3- POLÍMEROS PRECURSORES CERÂMICOS}

O desenvolvimento de novos polímeros inorgânicos ou organo-metálicos tem permitido a obtenção de novos materiais, para uso em diversas áreas, principalmente para uso em altas temperaturas e ambientes quimicamente agressivos $[5,44]$.

A síntese de cerâmicas à base de $\mathrm{Si}$ a partir de polímeros precursores, como fibras [45], espumas [46,47], ligantes [48], microtubos [49], recobrimentos [50], filmes finos [51], vidros [52], materiais compactados [53], tem sido alvo de atenção especial por parte de pesquisadores. Os materiais à base de $\mathrm{Si}$ a partir de polímeros precursores possuem aplicações bastante promissoras, e são muito difíceis ou praticamente impossíveis de se obter por rotas convencionais. $O$ desenvolvimento de polímeros inorgânicos e organometálicos para utilização como precursores de materiais cerâmicos de alto desempenho, como carbeto de silício, nitreto de silício, oxinitreto de silício $\left(\mathrm{Si}_{2} \mathrm{ON}_{2}\right)$ e nitreto de boro apresentam várias vantagens em relação aos processos convencionais de processamento; a principal delas é a facilidade de preparação a temperaturas mais baixas que as utilizadas normalmente para estes materiais. 
O conceito deste novo tipo de processamento cerâmico pode ser entendido fazendose uma analogia com o processamento de materiais à base de carbono que, muitas vezes, envolve a pirólise de polímeros. Estes materiais, compostos por $\mathrm{C}$ e $\mathrm{H}$, são submetidos a tratamentos térmicos a algumas centenas de graus centígrados e os átomos de hidrogênio são liberados, deixando apenas a estrutura de carbono do polímero original. $O$ processamento para a transformação de polímeros precursores cerâmicos em produtos cerâmicos, pode envolver a conformação da mistura de pó com o polímero precursor, subsequente cura e pirólise a temperaturas superiores a $800^{\circ} \mathrm{C}$ [44]. Diferentes polímeros precursores possuem comportamentos distintos na pirólise devido, essencialmente, à sua estrutura molecular [54,55]. Existem diversos trabalhos [56-62] envolvendo o uso de polímeros precursores cerâmicos. Misturas de pós e polímeros precursores constituem sistemas com grandes vantagens e potencial para a preparação de compósitos e para a formação de cerâmicas estruturais com formas complexas, devido à facilidade na conformação destes materiais.

Em 1975, Yajima e colaboradores [63] publicaram trabalho sobre a conversão térmica de polissilanos em $\mathrm{SiC}$, iniciando-se assim pesquisas nesta área. Foram preparadas fibras de $\mathrm{SiC}$ pelo método proposto por estes pesquisadores, patenteadas e comercializadas com o nome de NICALON (Nippon Carbon Co. Ltd.-Japão) e TYRANNO (Ube Industries Ltd.-Japão).

A obtenção de materiais cerâmicos a partir de precursores poliméricos geralmente envolve várias etapas, como pode ser observado no fluxograma da Figura II.4.

Este processo consiste na síntese de polímeros a partir de monômeros ou oligômeros, obtendo-se polímero precursor. É feita uma mistura entre o pó cerâmico e o polímero, depois a conformação a quente do material onde ocorre a cura do mesmo. Antes da moldagem e cura o material encontra-se na forma de um líquido viscoso ou de pó. Em seguida faz-se pirólise, em geral a temperaturas superiores a $800^{\circ} \mathrm{C}$, e tratamento térmico para cristalização. 


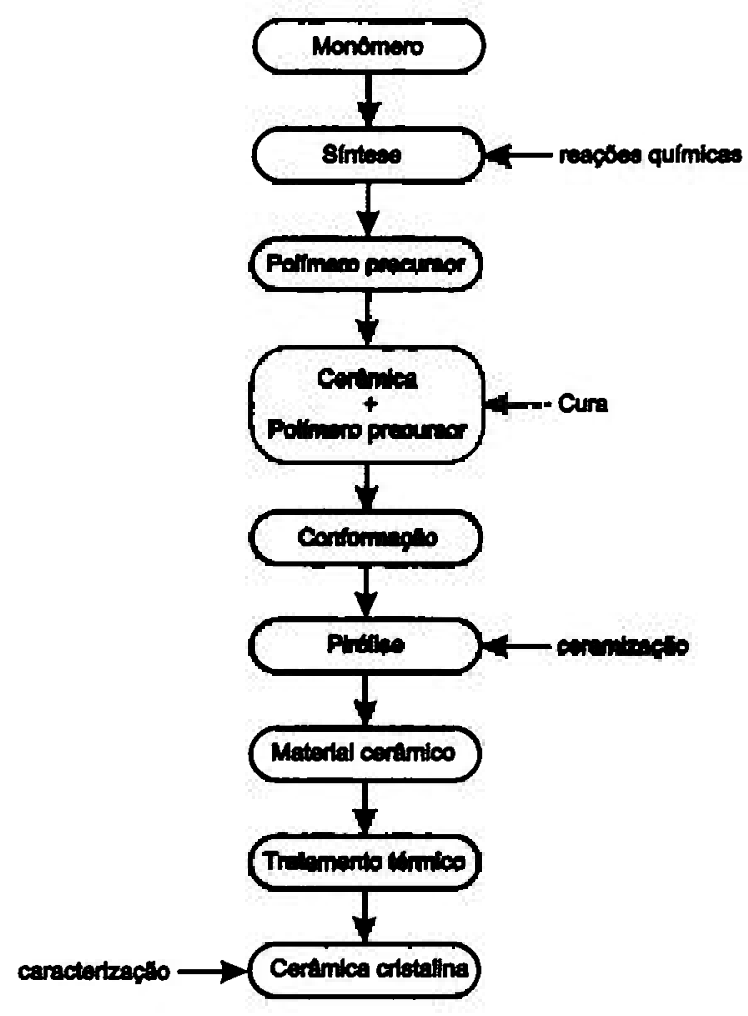

Figura II.4- Fluxograma apresentando a obtenção de materiais cerâmicos a partir de polímeros precursores cerâmicos [64].

Nos últimos anos foram desenvolvidos diversos polímeros inorgânicos. Os mais utilizados, baseados em silício, são [53]:

a) polissiloxanos $\left[-\mathrm{R}_{2} \mathrm{Si}-\mathrm{O}-\right]_{\mathrm{n}}$

b) polissilanos $\left[-\mathrm{R}_{2} \mathrm{Si}-\right]_{\mathrm{n}}$

c) policarbossilanos $\left[-\mathrm{R}_{2} \mathrm{Si}-\mathrm{CH}_{2}-\right]_{n}$

d) polissilazanos $\left[-\mathrm{R}_{2} \mathrm{Si}-\mathrm{NH}-\right]_{\mathrm{n}}$

O comportamento químico do polímero depende da natureza dos grupos funcionais $\mathrm{R}$ ligados aos átomos de $\mathrm{Si}$, os quais podem ser pertencentes aos grupos alquil ou aril, ou até mesmo hidrogênio. Os clorossilanos são precursores dos polissiloxanos e polissilazanos. Polissiloxanos, ou siliconas, são termos utilizado para descrever uma família de compostos baseados em cadeia molecular que alternam átomos de silício e oxigênio [65], como pode se observar na fórmula química mostrada na Figura II.5 (a) [66]. O silício 
pode ter dois grupos funcionais ligados a ele, como por exemplo, grupos metílícos e fenílicos, Figura II.5 (b).

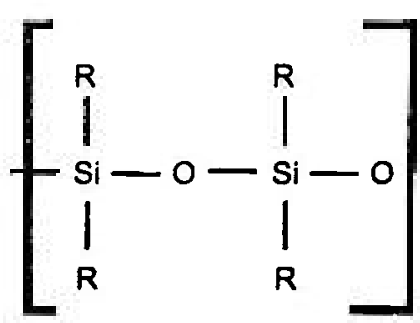

polissiloxano

(a)

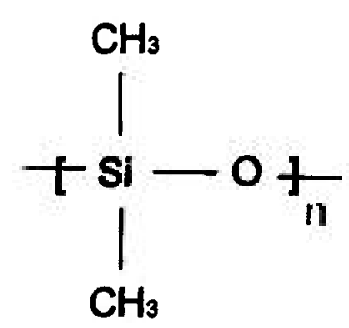

Polidimetilsiloxano

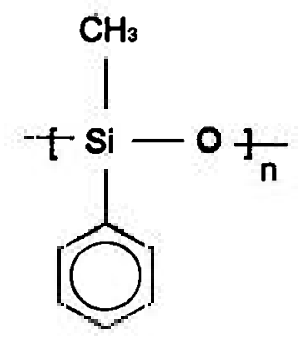

Polimetilfenilsiloxano

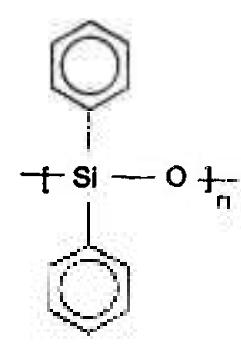

Polidifenilsiloxano

(b)

Figura II.5- (a)- Cadeia molecular alternando átomos de silício e oxigênio [66]; (b)- Exemplos de grupos orgânicos ligados na cadeia principal das siliconas [67].

A ligação entre os átomos de $\mathrm{Si}$ e $\mathrm{O}$ na silicona é forte, porém flexível, de forma que este material tenha alta resistência térmica, sem se decompor. $\mathrm{O}$ ângulo formado pelas ligacoões entre o Si e o O pode abrir e fechar, Figura II.6, o que faz com que a cadeia principal tenha bastante flexibilidade [67,68]. Dependendo do comprimento da cadeia e dos grupos orgânicos ligados aos átomos de silício, pode-se obter desde óleos pouco viscosos até graxas, gels, borrachas, resinas sólidas, selantes, óleos lubrificantes, fluidos para uso em hidráulica, biomateriais, cosméticos, entre outros [65]. Siliconas, que não são derivadas do petróleo, têm sido comercializadas desde meados dos anos 1940, e desde então tem aplicações em muitas grandes indústrias [65]. Podem resultar também em materiais 
cerâmicos do tipo $\mathrm{Si} / \mathrm{C} / \mathrm{O}$, chamados oxicarbetos de silício, oferecendo uma rota fácil e barata $[54,69]$ na formação deste sistema.
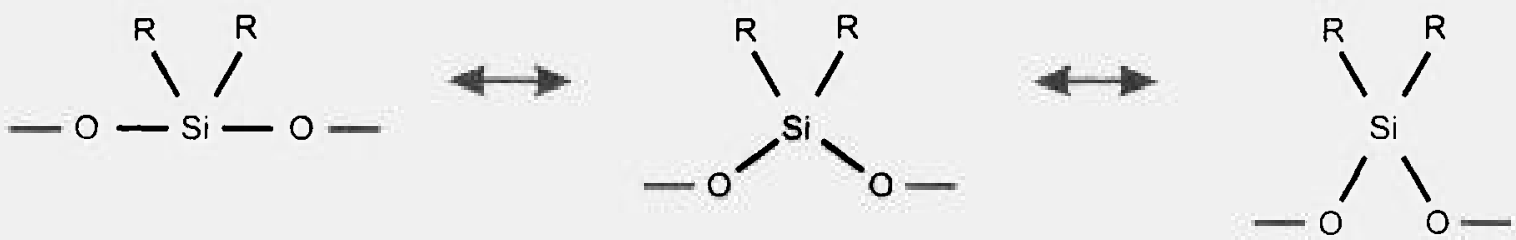

Figura II.6- Esquema representando o movimento da cadeia principal de siliconas, conferindo flexibilidade ao material [67].

Polissilazanos produzem carbonitretos de silício, que são materiais à base de $\mathrm{Si} / \mathrm{C} / \mathrm{N}$. Polissilanos e policarbossilanos são materiais interessantes na produção de SiC. Para cerâmicas à base de $\mathrm{SiC}$ tem sido muito utilizado policarbossilano (PCS), obtendo-se pós finos, "recobrimentos" e fibras.

Na Figura II.7 é mostrada a representação esquemática das transições moleculares e microestruturais que ocorrem a partir de polímeros precursores, durante a preparação de materiais cerâmicos [70].

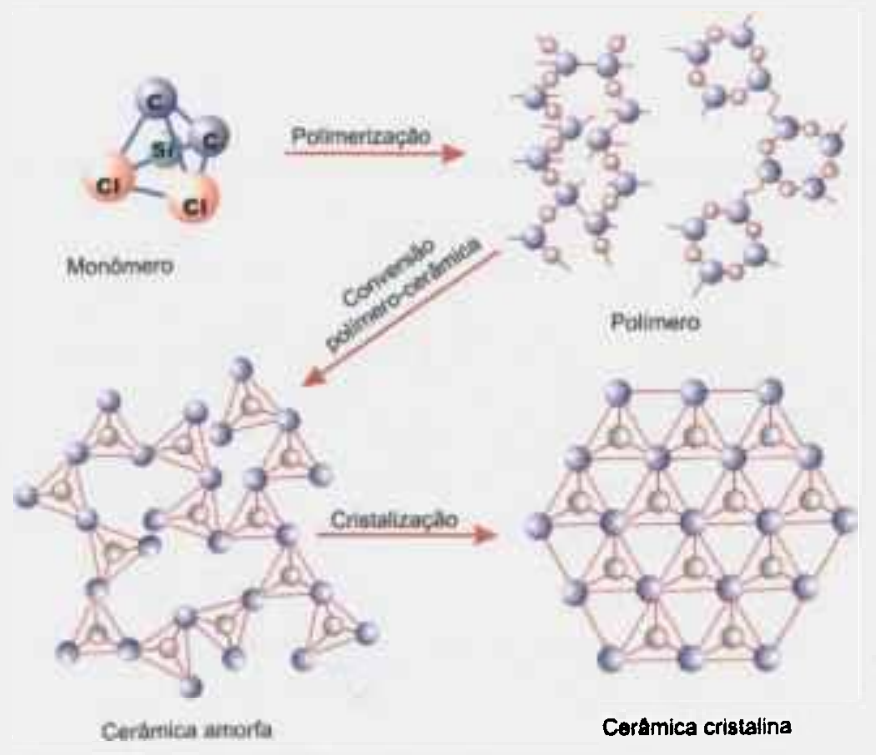

Figura II.7- Representação esquemática de transições moleculares e microestruturais que ocorrem durante a preparação de materiais cerâmicos a partir de polímeros precursores [70]. 
A microestrutura dos materiais produzidos a partir de polímeros precursores pode variar de amorfa a nanocristalina, dependendo das matérias-primas e da temperatura de tratamento térmico utilizada. Tanto a composição química quanto a microestrutura do produto final são fortemente influenciadas pela composição do polímero empregado, temperatura de tratamento térmico e pela atmosfera [71,72]. Segundo Hörz et alli [73], a conversão polímero-cerâmica geralmente é acompanhada por retração alta, e volatilização de orgânicos causando perda de massa.

Nas Figuras II.8 e II.9 são mostrados alguns exemplos de microestruturas de materiais preparados com polissiloxanos e policarbossilano, podendo observar as diferenças entre os mesmos, dependendo dos materiais e das condições empregadas na preparação.

Nas Figuras II.8 (a) e (b) são mostradas as microestruturas de amostras de alumínio / polissiloxano (PA), 35\% vol de $\mathrm{Al}$, e $65 \%$ vol de polidimetilssiloxano e de alumínio / alumina / polissiloxano (PAAO), 19\% vol de $\mathrm{Al}, 19 \%$ vol de $\alpha-\mathrm{Al}_{2} \mathrm{O}_{3}$ e $62 \%$ vol de polidimetilsiloxano, respectivamente. Estas amostras foram sinterizadas a $1550^{\circ} \mathrm{C}$ por 3 horas, polidas e atacadas termicamente. Houve formação de mulita e pode-se observar nas micrografias que a PA possui muitos poros grandes e a PAAO apresenta poros pequenos, com distribuição homogênea. Com resultados de MET, observou-se que a mulita possui grãos extremamente finos e, devido a este fato, a temperatura de mulitização diminuiu em aproximadamente $200^{\circ} \mathrm{C}$ [74].

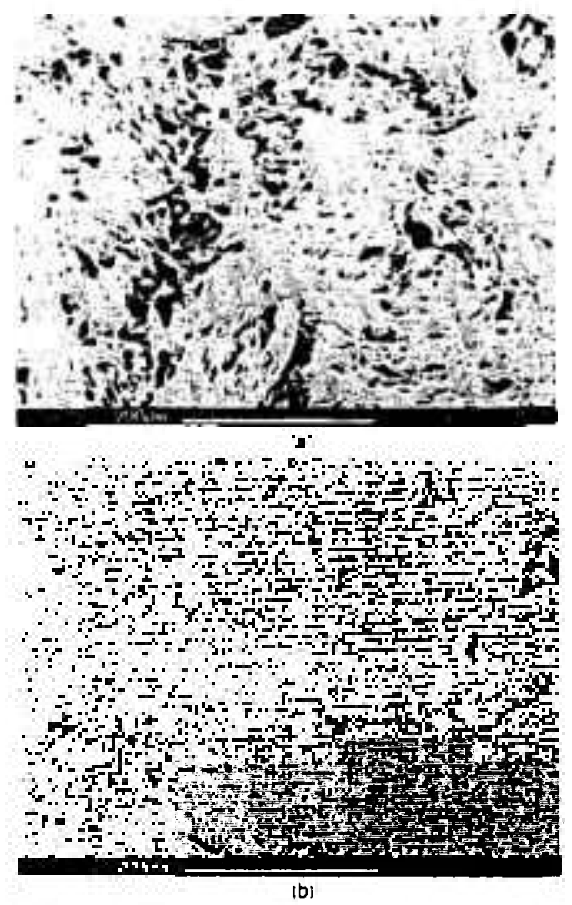

Figura II.8- MEV da superfície de fraturas das amostras: (a)- PA, (b)- PAAO [74]. 
Na Figura II.9 é mostrada uma micrografia da superficie de fratura de amostra de polissiloxano com carga ativa de a-alumina (Alcoa, A16SG). Segundo Sorarù et al. [6], a distribuição da alumina foi uniforme, com tamanho de grão menor que $1 \mu \mathrm{m}$ (grãos claros) e após pirólise a $1500^{\circ} \mathrm{C}$ obteve-se nanocompósitos de mulita-SiC.

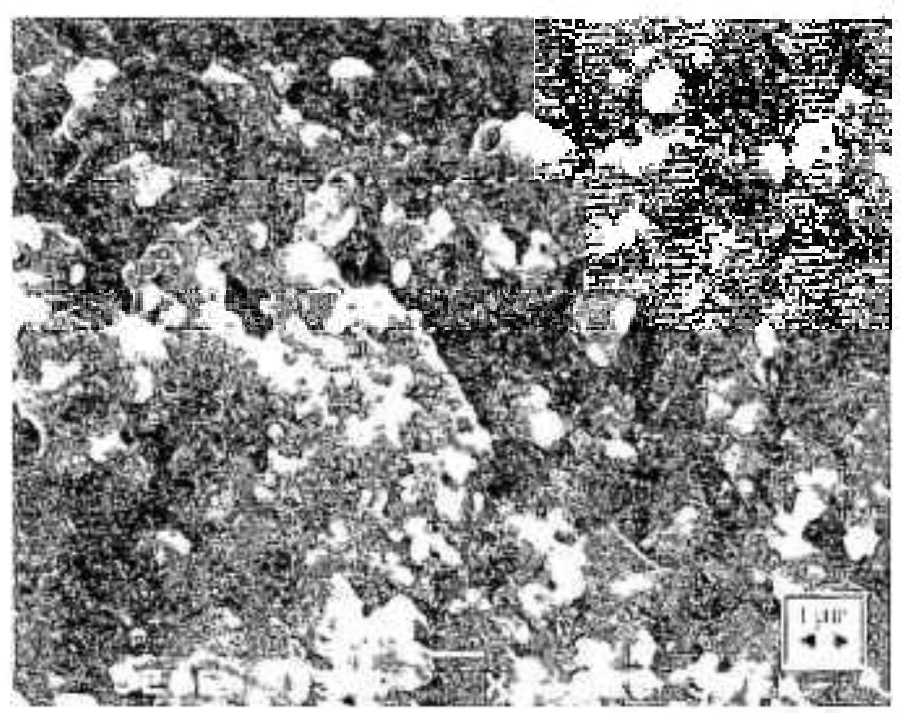

Figura II.9- Micrografia obtida por MEV de superfície de fratura de amostra de polissiloxano com carga de $\alpha-\mathrm{Al}_{2} \mathrm{O}_{3}[6]$.

\section{$\mathrm{SiC}$ e $\mathrm{Al}_{2} \mathrm{O}_{3}$ utilizando precursores poliméricos}

Em trabalho publicado por $\mathrm{Ha}$ et alli [75], com $\mathrm{Al}_{2} \mathrm{O}_{3} / \mathrm{SiC}$, foi investigado um novo método de obtenção de nanocompósitos modificando a rota de introdução do polímero precursor cerâmico. Uma solução de hexano e policarbossilano (PCS) foi infiltrada em amostras porosas de $\mathrm{Al}_{2} \mathrm{O}_{3}$, que foram sinterizadas a $1600{ }^{\circ} \mathrm{C}$ por $2 \mathrm{~h}$, em atmosfera de nitrogênio ou argônio. As fases formadas se mostraram dependentes da atmosfera utilizada. Com argônio obteve-se $\mathrm{SiC}(3 \mathrm{C}$ e $2 \mathrm{H})$ e com nitrogênio constatou-se a presença de $\beta-\mathrm{Si}_{3} \mathrm{~N}_{4}, 15 \mathrm{R}$ SiAlON, além de $\mathrm{SiC}$. O material mais denso foi obtido para amostras com $20 \%$ em peso de PCS. A maior densidade final obtida foi $93 \%$ da densidade teórica. As partículas de $\mathrm{SiC}$, com aproximadamente $400 \mathrm{~nm}$, ficaram localizadas tanto inter como intragranularmente. Os autores sugeriram que para obter melhores resultados de densidade pode-se usar temperatura de sinterização mais alta $\left(1800^{\circ} \mathrm{C}\right.$, por exemplo) e pós 
de alumina mais finos. Foi estudado como a concentração da solução precursora, PCS, e as condições de sinterização afetaram a quantidade de $\mathrm{SiC}$, a densificação, as fases formadas e a microestrutura. Concluiu-se que a quantidade de SiC das amostras infiltradas com PCS aumentou proporcionalmente com a concentração de PCS na solução. É possível aumentar a quantidade de $\mathrm{SiC}$ para $5 \%$ vol repetindo-se o processo de infiltração, e/ou usar solução de hexano com maior concentração de PCS.

Trabalho realizado por Schiavon [76] envolveu a preparação de diferentes polímeros precursores cerâmicos, polissiloxano e polissilazano, e suas conversões, por pirólise em atmosfera controlada, a materiais amorfos de oxicarbeto de silício (SiOC) e carbonitreto de silício ( $\mathrm{SiCN}$ ), respectivamente. Compósitos de matriz cerâmica, como $\mathrm{SiC} / \mathrm{SiC}_{\mathrm{x}} \mathrm{O}_{4-\mathrm{x}}$ e $\mathrm{Si}_{3} \mathrm{~N}_{4} / \mathrm{SiC}_{\mathrm{x}} \mathrm{O}_{4-\mathrm{x}}$, foram preparados utilizando polissiloxano e cargas inertes de $\mathrm{SiC}$ e $\mathrm{Si}_{3} \mathrm{~N}_{4}$. As misturas dos polímeros com $\mathrm{CrSi}_{2}$, como carga reativa, gerou os compósitos $\mathrm{SiC} / \mathrm{CrSi}_{2}$ e $\mathrm{Si}_{3} \mathrm{~N}_{4} / \mathrm{Cr}_{3} \mathrm{C}_{2}$, em atmosferas de argônio e nitrogênio, respectivamente. $\mathrm{O}$ polissiloxano atuou como agregante das partículas do pó e como precursor da fase cerâmica rica em SiC. Estes materiais apresentaram boas propriedades mecânicas e boa resistência à abrasão.

O processo AFCOP (“Active Filler Controlled Polymer Pyrolysis"), isto é, pirólise controlada de polímeros e carga ativa tem sido bastante estudado, com a utilização de diferentes cargas, ativas ou inertes [53]. Nesse método a pirólise dos polímeros precursores cerâmicos com as cargas é realizada em temperaturas entre $1000{ }^{\circ} \mathrm{C}$ e $1600{ }^{\circ} \mathrm{C}$, em atmosfera adequada, por exemplo, nitrogênio ou ar, permitindo que ocorra a reação dos produtos de decomposição dos polímeros com as cargas ativas e/ou com a atmosfera, reduzindo a perda de massa do material. Cerâmicas no sistema Si-Al-O-N-C foram obtidas a partir de polissiloxanos, cargas ativas e inertes, $\mathrm{Si}, \mathrm{Al}, \mathrm{Al}_{2} \mathrm{O}_{3}$ e $\mathrm{SiC}$, e atmosfera de nitrogênio contendo as fases: $\beta$-SiC, $\beta$-SiAlON, O' SiAlON, politipóide-SiAlON, XSiAlON, $\mathrm{Si}_{2} \mathrm{ON}_{2}, \mathrm{AlN}, \mathrm{Al}_{2} \mathrm{O}_{3}$ e mulita. $\mathrm{A}$ metodologia adotada permitiu a obtenção de pastilhas (por prensagem), substratos (por "tape casting") e espumas (expansão por irradiação com feixe eletrônico), mostrando a sua versatilidade [67]. 


\section{II.4- SINTERIZAÇÃO}

Nesta revisão são abordados resumidamente os processos de sinterização, por serem importantes neste estudo. A sinterização pode ser definida como um processo no qual partículas em contato agregam-se quando aquecidas a uma temperatura adequada [77]. $O$ processo é termicamente ativado, envolve transporte de matéria, podendo ocorrer tanto no estado sólido ou via fase líquida. A sinterização é um dos processos mais antigos de fabricação de corpos sólidos e cerâmicos, sendo utilizada há milhares de anos. Os egípcios utilizavam materiais sinterizados (metálicos e cerâmicos) por volta de 3000 a. C. Um dos primeiros produtos sinterizados que se tem notícia é tijolo submetido à tratamento térmico para aumentar sua resistência. Outro uso histórico deste processo foi na confecção de moedas a partir de pó de cobre e de prata. Já na era moderna, a sinterização foi usada por Coolidge para fabricar, com pó de tungstênio, filamentos de lâmpadas mais duráveis, a pedido de Thomas Edison. Atualmente a sinterização é utilizada na produção da maioria de materiais çerâmicos como refratários, tijolos, porcelanas, materiais para construção, peças para indústria automobilística, implantes dentários, próteses ortopédicas, combustíveis nucleares entre outros [78].

O processo de sinterização é influenciado por vários parâmetros como:

- temperatura e tempo de sinterização,

- tamanho e distribuição de partículas e poros na amostra,

- homogeneidade da mistura,

- composição do material, incluindo-se aditivos,

- atmosfera de sinterização,

- pressão de compactação.

\section{II.4.1- Sinterização no estado sólido}

A força motriz para a sinterização é a redução da energia livre do sistema que é possível pela diminuição das áreas específicas e interfaces da amostra. Pode ocorrer pela densificação e crescimento de grão. A densificação se dá com a mudança de interface sólido-gás, partícula-poro, para interface sólido-sólido de menor energia. $\mathrm{O}$ crescimento de 
grão acontece com a transformação de muitos grãos pequenos, originários das partículas do compactado, para um número menor de grãos maiores, Figura II.10. Portanto, as modificações na microestrutura durante a sinterização são devido à combinação da densificação e crescimento de grão, obtendo-se, em condições adequadas, amostras densas, sem crescimento exagerado de grãos [79].

$\mathrm{Na}$ Figura II.10 é mostrado o esquema das mudanças microestruturais durante o processo de sinterização, densificação e crescimento de grão [80].

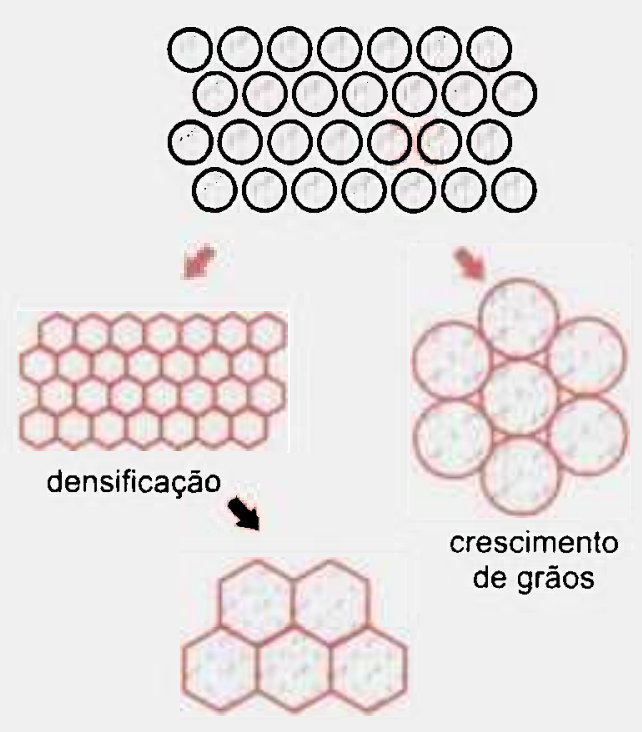

Figura II.10- Representação esquemática de mudanças microestruturais durante a sinterização devido à densificação e crescimento de grãos [80].

Segundo vários pesquisadores $[81,82,83,84]$, no processo de sinterização pode-se distinguir três estágios, de acordo com a forma característica assumida pelos poros durante a densificação de um aglomerado de partículas.

No estágio inicial de sinterização ocorre o arredondamento das partículas, a formação de pescoço, ou seja, há um aumento na área de contato entre as partículas. Durante este estágio as partículas iniciais de pó ainda são distinguiveis. Há pouco crescimento de grão, significativa redução na área específica de superficie e na porosidade.

No estágio intermediário, a inibição à movimentação do contorno de grão desaparece, depois de um crescimento considerável do pescoço, sendo possível o 
crescimento de grão. Durante este estágio as partículas individuais perdem suas identidades, há fechamento de poros acompanhado de densificação devido à ação das respectivas energias de tensões superficiais. Ainda neste estágio ocorre a maior parte da densificação.

No estágio final pode ocorrer a remoção completa dos poros remanescentes, conduzindo à densificação completa do material. Porém, pode ocorrer um crescimento descontínuo dos grãos maiores às custas dos menores [82], e é possível que os poros fechados, como conseqüência, fiquem isolados nos contornos de grãos, localizando-se no interior dos mesmos. Se isto acontecer, a densificação completa torna-se extremamente difícil.

Pode-se associar os estágios de sinterização às curvas de retração linear em função do tempo ou temperatura. Na Figura II.11 é mostrado um esquema da curva de retração linear $\Delta \mathrm{L} / \mathrm{L}_{0}$ até a densidade teórica e, paralelamente, é representada a variação microestrutural do material cerâmico durante o processo de sinterização [84].

Na Figura II.11 é mostrada uma fase (1) na qual há pequena retração linear variando de $0 \%$ a aproximadamente $3 \%$, seguida do estágio inicial (2) de $3 \%$ a $10 \%$, passandó pela fase intermediária (3) de $10 \%$ até cerca de $22 \%$ e o estágio final (4) no qual a retração linear varia de aproximadamente $22,5 \%$ a $25 \%$.

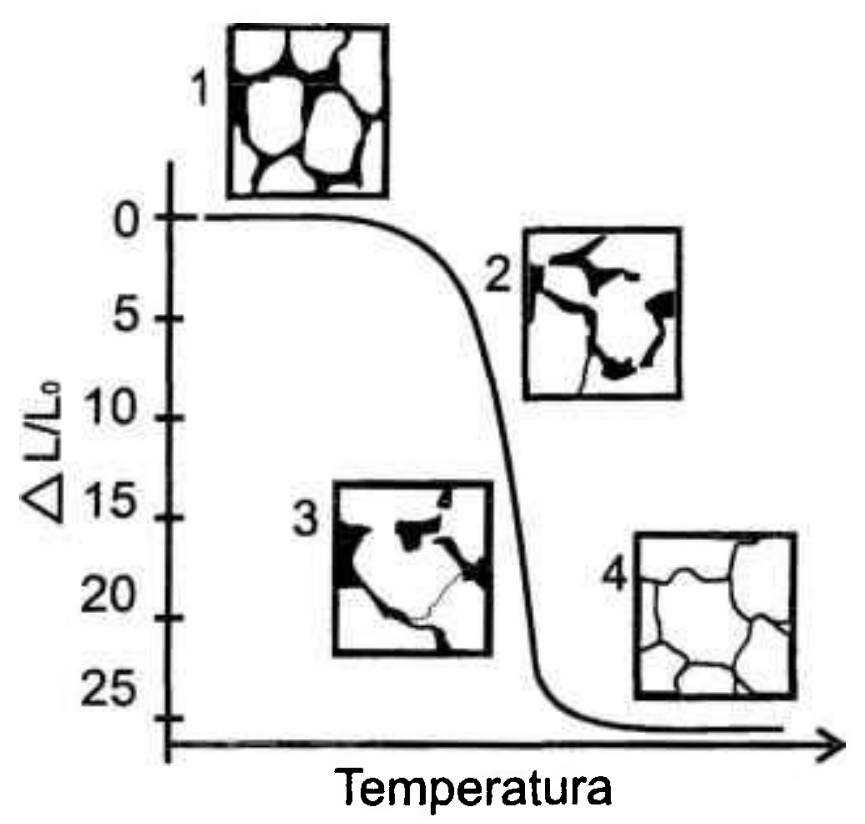

Figura II.11- Representação esquemática de crescimento de grãos, pescoços e redução de poros do processo de sinterização, quando comparado à curva de retração linear [84 ]. 
No processo de sinterização no estado sólido são identificados 6 mecanismos de transporte de matéria, Tabela II.3, que indicam os caminhos do fluxo de massa devido à força motriz [81].

Tabela II.3- Caminhos de transporte de matéria durante 0 estágio inicial de sinterização [81].

\begin{tabular}{|c|c|c|c|}
\hline Mecanismos & Meios de Transporte & Fonte & Absorvedor \\
\hline 1 & Difusão superficial & Superficie & Pescoço \\
\hline 2 & Difusão pelo reticulado & Superficie & Pescoço \\
\hline 3 & Transporte de vapor & Superficie & Pescoço \\
\hline 4 & Difusão contorno de grão & Contorno de grão & Pescoço \\
\hline 5 & Difusão pelo reticulado & Contorno de grão & Pescoço \\
\hline 6 & Difusão pelo reticulado & Discordâncias & Pescoço \\
\hline
\end{tabular}

Na Figura II.12 são mostrados os caminhos de transporte de matéria durante o estágio inicial de sinterização, com as possíveis fontes, caminhos e absorvedores de matéria. Estes mecanismos contribuem para a formação do pescoço e para a densificação do material. As partículas de pós raramente são esféricas, mas utiliza-se esta simplificação para facilitar o entendimento da cinética de sinterização.

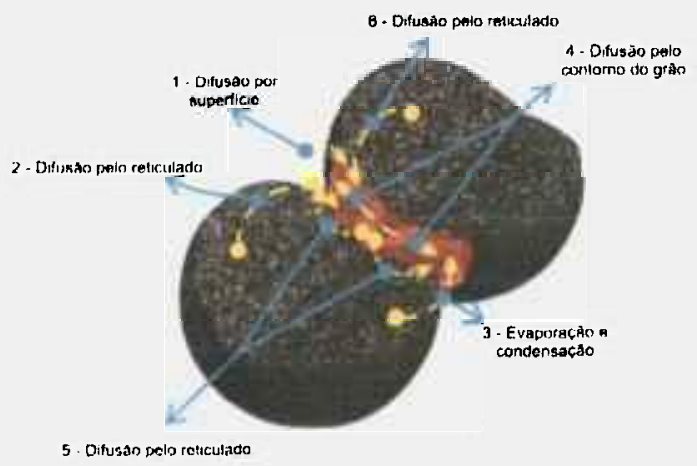

Figura II.12- Caminhos de transporte de matéria entre duas partículas durante o estágio inicial da sinterização [81]. 
Todos os mecanismos podem contribuir simultaneamente para o crescimento do pescoço. Porém, somente os mecanismos 4, 5 e 6 (Figura 11.12) conduzem à densificação, já que o material não é proveniente da superficie. Normalmente, em temperaturas relativamente baixas o mecanismo predominante é a difusão por superficie enquanto que a difusão volumétrica e por meio de contorno de grão predomina em temperaturas elevadas [85]. Um problema na sinterização no estado sólido é a possibilidade de crescimento exagerado de grão no estágio final, com aprisionamento de poros no seu interior, o que dificulta a eliminação da porosidade remanescente. Alguns aditivos permitem o controle da difusão, evitando o crescimento exagerado de grãos. Muitos materiais cerâmicos são obtidos por sinterização no estado sólido, principalmente óxidos tais como $\mathrm{Al}_{2} \mathrm{O}_{3}, \mathrm{BeO}$, $\mathrm{Y}_{2} \mathrm{O}_{3}, \mathrm{UO}_{2}, \mathrm{ThO}_{2}, \mathrm{ZrO}_{2}$, entre outros [37].

\section{II.4.2- Sinterização via fase líquida}

Cerâmicas estruturais covalentes, como $\mathrm{SiC}$ e $\mathrm{Si}_{3} \mathrm{~N}_{4}$, são difíceis de serem sinterizadas no estado sólido, mesmo a altas temperaturas, sendo freqüentemente sinterizadas via fase líquida, usando aditivos óxidos. Para os dois tipos de sinterização o efeito de aditivos em cerâmicas vem sendo pesquisado há muitos anos, sendo hoje, objeto de intensos estudos.

A sinterização via fase líquida envolve a presença de um líquido viscoso na temperatura de sinterização e é muito utilizada na densificação da maior parte de cerâmicas covalentes. A quantidade de aditivos afeta diretamente a fração volumétrica de líquido, que influencia a taxa de sinterização e a microestrutura do material. Características tais como tamanho e forma dos grãos, proximidade entre os mesmos, dependem da quantidade de fase líquida [86]. O principal fator para que este processo ocorra é haver boa molhabilidade do líquido no sólido, de forma que este envolva a parte sólida. Outro fator importante é a solubilidade do sólido no líquido. A taxa de sinterização via fase líquida é controlada pelo tamanho e distribuição das partículas, pela viscosidade do líquido formado e pela tensão superficial do mesmo. As caracteristicas de cerâmicas sinterizadas via fase líquida são influenciadas não só pela morfologia dos grãos mas também pelo tipo, quantidade de fases e sua homogeneidade no material [87]. 
Neste processo, o pó compactado é aquecido a uma temperatura na qual há formação de líquido que, normalmente, é proveniente de uma composição eutética. Durante o aquecimento, antes da formação da fase líquida inicial, há transporte de massa no estado sólido devido, em parte, ao gradiente de potencial químico no material. Na difusão no estado sólido há, freqüentemente, densificação considerável antes da formação do líquido. Uma vez que o líquido se forma ele flui de forma a molhar as partículas. A quantidade de fase líquida presente e a molhabilidade do líquido no sólido determinam o grau de sinterização até o final do processo [86].

\section{Molhabilidade}

Quando o líquido é formado, normalmente, existem três fases: sólida, líquida e vapor. Da mesma forma que na sinterização no estado sólido a superfície livre de um material e os contornos entre as fases, tem energias associadas $(\gamma)$, como sólido-sólido, $\gamma_{\mathrm{SS}}$, sólidovapor, $\gamma_{\mathrm{SV}}$, sólido-líquido, $\gamma_{\mathrm{SL}}$, líquido-vapor, $\gamma_{\mathrm{LV}}$. A energia de interface, $\gamma$, é definida como a energia necessária para formar uma unidade de área de nova interface no sistema. A relação entre a superfície e as energias interfaciais determina a extensão da molhabilidade de um líquido no sólido. A molhabilidade está associada também às reações químicas na interface e depende da solubilidade do sólido no líquido, da formação de compostos intermediários e de interdifusão.

A molhabilidade define o equilíbrio entre as três fases de forma que a energia de interface total dos grãos presentes seja mínima. $O$ ângulo de contato, $\theta$, é uma característica física que representa o balanceamento entre as energias de interface, (Figura II.13). Para um líquido molhar um sólido, deve haver um decréscimo na energia livre total. Quando a energia de interface sólido-líquido $\left(\gamma_{\mathrm{SL}}\right)$ é alta, o líquido forma um semi-círculo, apresentando uma área de interface sólido-líquido pequena (Figura II.13.a). Neste caso há pouca molhabilidade e $\theta>90^{\circ}$. Quando $\theta<90^{\circ}$ há molhabilidade (Figura II.13.b). $\theta=90^{\circ}$ é definido como o limite entre a condição de molhabilidade e a de não molhabilidade. Quando $\theta=0^{\circ}$ ocorre espalhamento, ou seja, o líquido cobre completamente a superfície do sólido (Figura II.13.c) [27]. 


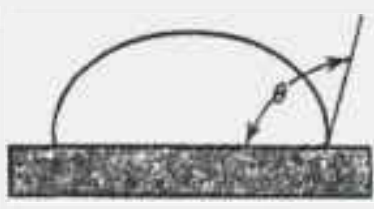

(a)

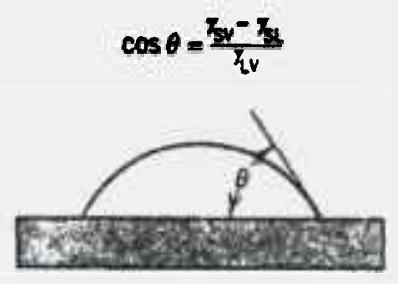

(b)

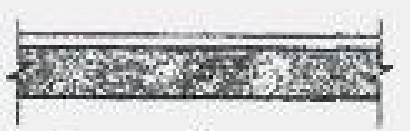

(c)

Figura II.13- Molhabilidade de um líquido em um sólido: (a)- não há molhabilidade $\left(\theta>90^{\circ}\right)$; (b)- há molhabilidade $\left(\theta<90^{\circ}\right)$; (c)- quando $\theta=0^{\circ}$ há espalhamento do líquido no sólido [27].

Um parâmetro importante na microestrutura de corpos policristalinos é o contato entre grãos e fase líquida, representado pelo ângulo diedro $\phi$, Figura II.14. O ângulo diedro $\phi$ é determinado pela razão entre as energias dos contornos de grãos e as das superfícies sólido-líquido ou energia de interface sólido-vapor [86].

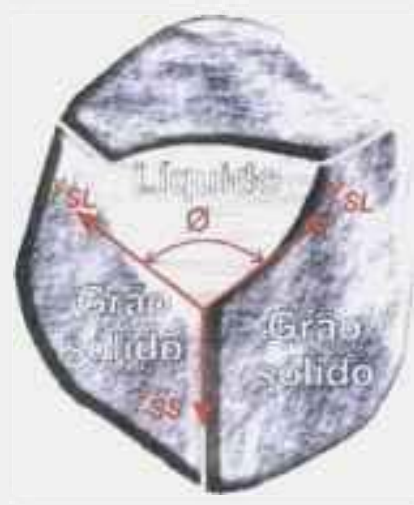

Figura II.14- Ângulo diedro $\phi$ em equilíbrio onde o contorno de grão encontra a superfície.

Na Figura II.15 são mostrados alguns exemplos de sistemas de três grãos com o líquido no ponto triplo. As partículas separadas por contornos de grão de baixo ângulo freqüentemente entram em contato direto uma com as outras durante a sinterização via fase líquida. Este contato conduz a uma possível coalescência dos grãos, resultando em tamanhos de grãos maiores à medida que o processo continua. 


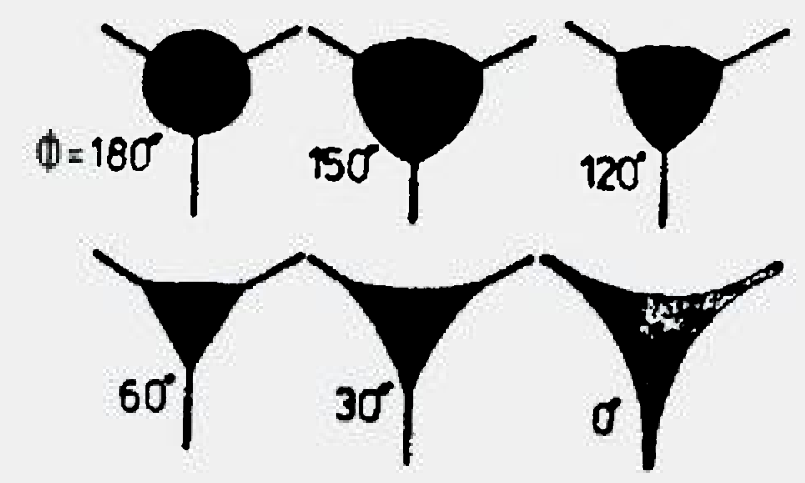

Figura II.15- Efeito do ângulo diedro $\phi$ na forma da fase líquida na interseç̧ão de três ângulos sólidos [86].

Na Figura II.16 é mostrada, resumidamente, a sinterização via fase líquida, com um esquema de processos de densificação em função do volume de líquido. Tem-se inicialmente a densidade a verde do material compactado. Durante o aquecimento ocorre a formação de líquido, rearranjo de partículas, solução-reprecipitação. A influência de cada um desses processos vai depender da quantidade de líquido presente. Observando-se a Figura II.16, nota-se que se a quantidade de líquido for excessiva não haverá o processo de solução-reprecipitação, ocorrendo somente sinterização por rearranjo.

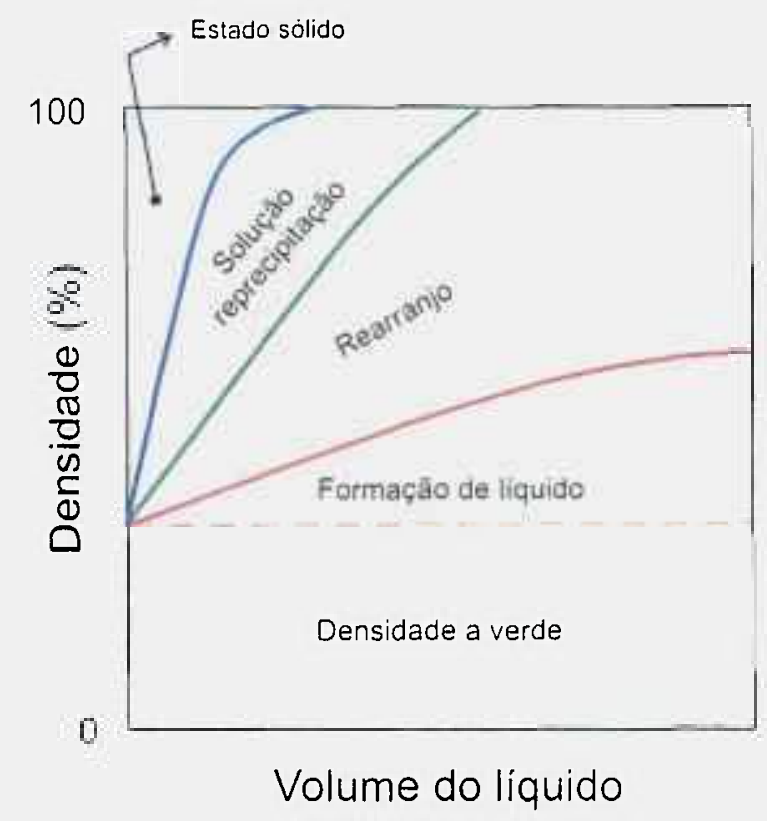

Figura II.16- Variação da densidade em função do volume de líquido mostrando os estágios de sinterização [35]. 
$\mathrm{Na}$ sinterização via fase líquida, mostrada esquematicamente na Figura II.17, podem ocorrer 3 estágios distintos, com diferentes taxas de densificação, resumidos a seguir:

- rearranjo das partículas,

- solução-reprecipitação,

- coalescência.

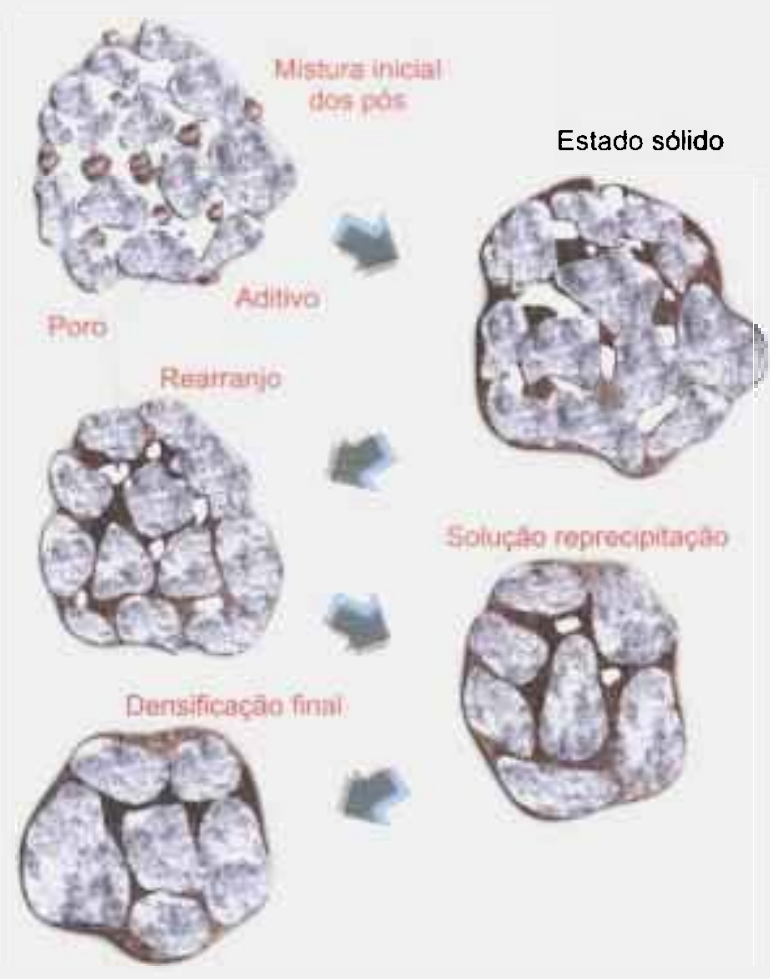

Figura II.17- Estágios da sinterização via fase líquida [35].

No estágio inicial (escoamento líquido e rearranjo) a presença de fase líquida é devido à formação de líquido eutético que, dependendo da molhabilidade na fase sólida, pode promover o rearranjo do sistema.

O segundo estágio é caracterizado pelo arredondamento e crescimento dos grãos, dissolução de grãos pequenos, formação de um esqueleto rígido pela fase sólida e densificação. O processo predominante é o de solução-reprecipitação, que tem como força motriz o gradiente químico e a diminuição da área específica de superfície das partículas. Por meio da difusão no líquido ocorre a dissolução das partículas menores e reprecipitação 
nas partículas maiores. Este mecanismo possibilita maior densificação, pois a velocidade de transporte de matéria pela fase líquida é maior que no estado sólido, desde que haja solubilidade da matriz no líquido.

O terceiro estágio tem como características principais o crescimento de grão e o fechamento de poros, sendo quase uma extensão do processo de solução-reprecipitação. Nesta fase o transporte de matéria ocorre no estado sólido, por difusão volumétrica e por meio dos contornos de grão e, conseqủentemente, a taxa de densificação é bem menor que nas outras etapas $[27,35,78]$.

Se a quantidade de líquido no sistema for suficiente e apresentar boa molhabilidade em relação ao sólido, pode-se obter densidades elevadas durante o rearranjo. $O$ líquido concentrado nos pontos de contato entre as partículas é equivalente ao pescoço formado na sinterização no estado sólido.

$\mathrm{Na}$ sinterização via fase líquida é muito importante que tanto o líquido quanto os pós estejam distribuídos homogeneamente, acarretando, assim, boas propriedades no material sinterizado. A quantidade de aditivo influencia diretamente a fração volumétrica do líquido, que por sua vez influencia a taxa de sinterização e a microestrutura do material.

A atmosfera, ou o tipo de gás utilizado, tem efeito na sinterização, podendo envolver reações de oxidação e redução. Sinterizar $\mathrm{SiC}, \mathrm{Si}_{3} \mathrm{~N}_{4}$, ou outros materiais que não óxidos, ao ar resultará em oxidação. Por outro lado, sinterizar óxidos em atmosfera redutora ou que contenha carbono pode ocorrer redução. Por exemplo, sinterizar $\mathrm{ZrO}_{2}$ em atmosfera redutora, o material terá deficiência de oxigênio resultando em $\mathrm{ZrO}_{2-x}$, mudando sua coloração (poderá ser cinza escuro ou preto).

\section{II.4.3- Dureza e Tenacidade à Fratura}

\section{Dureza}

A dureza é uma propriedade mecânica importante a ser considerada, independente de seus valores serem utilizados para medidas de tenacidade. Pode ser definida como a medida da resistência à deformação do material por indentação superficial [77]. Antigamente os testes de dureza eram baseados somente na habilidade de alguns minerais naturais riscarem outros mais moles. A escala empregada era Mohs e variava de 1 para o 
material mais mole até 10 para o mais duro, diamante. As técnicas de medida de dureza foram se desenvolvendo ao longo dos anos e, atualmente, utiliza-se um pequeno indentador, que aplica uma força na superficie do material a ser submetido ao ensaio, sob condições controladas de carga e tempo de aplicação [77]. A medida de dureza Vickers é associada a um valor numérico, é simples e é a mais utilizada para materiais cerâmicos. Esta técnica foi introduzida em 1925 por Smith e Sandland e tem este nome devido à Companhia Vickers-Armstrong Ltd., que fabricava as máquinas mais conhecidas para a obtenção destas medidas [88]. É importante que se determine a carga crítica a ser aplicada, pois cargas muito baixas levam a valores muito elevados, que não refletem a dureza do material.

Os testes de dureza dependem de vários parâmetros: (a) carga crítica- aplicando-se cargas muito baixas a impressão é muito superficial; (b) superfície- deve ser plana e muito bem polida; (c) tamanho de grão- de maneira geral, quanto menor o tamanho de grão mais duro é o material; (d) pureza do material- impurezas podem causar o endurecimento do material ou se houver fase secundária vítrea pode acarretar a diminuição da dureza; (e) porosidade- a densidade é um fator muito importante; amostra com alta porosidade possui dureza reduzida [89].

A tenacidade à fratura é definida como a medida da quantidade de energia absorvida por um material até que o mesmo frature [77]. É fortemente influenciada pela microestrutura da cerâmica e pelo caminho da trinca à medida que a mesma se propaga pelo material. Esta propriedade mecânica, característica de cada material, é representada por $\mathrm{K}_{\mathrm{Ic}}$, que é o fator crítico de intensidade de tensão e é um indicativo do estado de tensão na ponta da trinca no momento da fratura. $O \mathrm{~K}_{\mathrm{Ic}}$ pode ser determinado aplicando-se uma carga, gerando trincas nas extremidades da indentação, que serão medidas e aplicadas em uma equação que depende do tipo de impressão obtida. A zona de deformação e a propagação das trincas são observadas depois de retirada a carga.

Há 2 tipos principais de trinca radial formadas no ensaio de impressão Vickers, cujo esquema idealizado é mostrado na Figura II.18. As trincas do tipo Palmqvist são radiais, geradas devido à aplicação de cargas baixas e têm início nos vértices da impressão permanecendo próximas à superfície. Aplicação de carga adicional conduziria à formação de outro tipo de trinca, a radial-mediana, que sob ação de cargas suficientemente elevadas 
determina o comportamento de fratura. As trincas tipo radial-mediana são geradas na forma de círculos, abaixo da região deformada pelo indentador $[90,91]$.

Há discussão entre pesquisadores se as trincas do tipo Palmqvist sempre antecedem a formação de trincas tipo radial-mediana e, portanto, antes dos círculos característicos deste tipo de trinca poderia se observar segmentos circulares típicos de trincas do tipo Palmqvist [94].

Na Figura II.18 são mostrados os esquemas de trincas radial-mediana e Palmqvist.

Sabe-se que a microestrutura é determinante nas propriedades macroscópicas dos materiais e é função do processamento. Isto torna a caracterização microestrutural um controle efetivo do processo de fabricação, podendo-se fazer uma pré-avaliação das propriedades mecânicas dos materiais. Controlando-se a microestrutura, por intermédio de mecanismos tenacificadores, é possível impedir, ou pelo menos dificultar, a propagação de trincas, aumentado a tenacidade do material.

\section{Tenacidade à Fratura}

A tenacidade é de extrema importância para a área de materiais. A tenacificação ocorre quando o campo de tensão na ponta da trinca diminui. Este comportamento é devido à tensão na ponta da trinca, que é reduzida por mecanismos tenacificadores, acarretando aumento da resistência à fratura. Há vários mecanismos, Figura II.19, que podem resultar em aumento de tenacidade, tais como:

- deflexão de trincas,

- ramificação de trincas,

- descolamento e arrancamento de grãos,

- ponteamento na cauda da trinca,

- microtrincas,

- tenacificação por transformação de fases. 


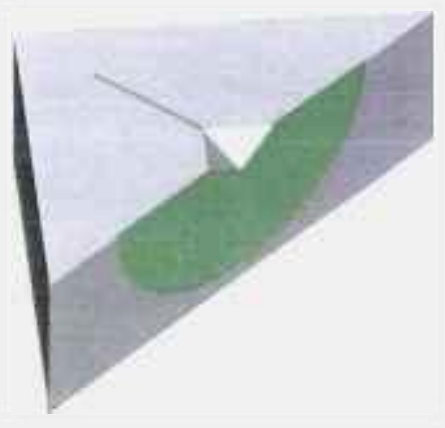

(a)

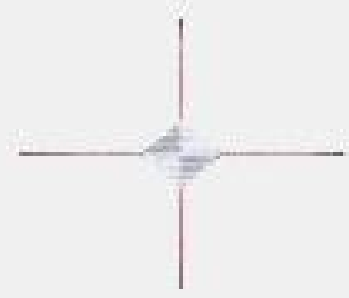

(b)

(e)

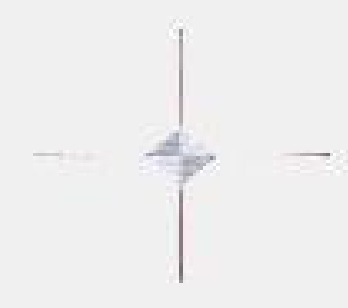

(c)

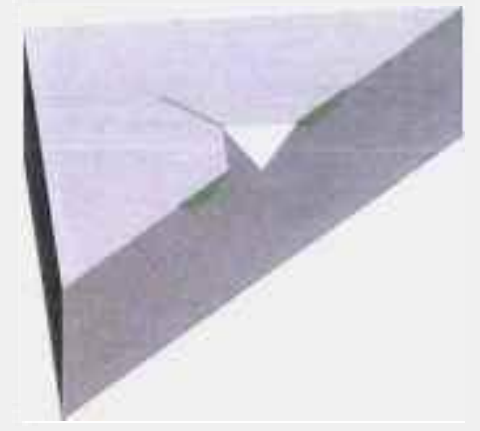

(d)

Figura II. 18- Sistema de trincas tipo radial-mediana (a) e Palmqvist (d): As vistas de topo das impressões, antes e após polimento realizado para identificação do tipo de trinca, são mostradas, respectivamente, para as trincas radial-mediana (b) e (c) e Palmqvist (e) e (f) [92]. 


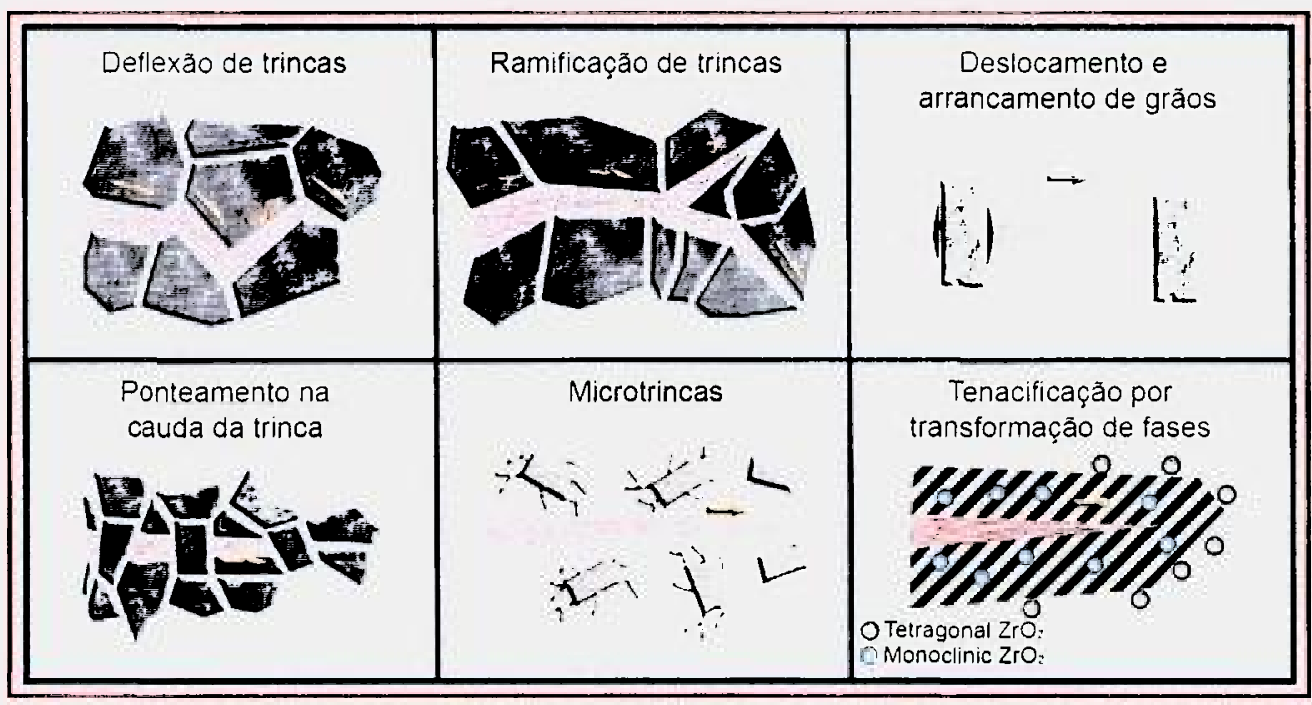

Figura II.19- Mecanismos de tenacificação utilizados para alguns tipos de cerâmica [32].

\section{Deflexão de trincas ("crack deflection")}

A maioria dos materiais cerâmicos para uso comercial é policristalino e geralmente um grão tem orientação cristalográfica diferente dos grãos adjacentes. A trinca pode caminhar pelos contornos de grão e fraturar outros grãos. Pode perder energia, deixar de caminhar, aumentando assim a tenacidade do material [35].

Este mecanismo ocorre quando há deflexão de uma trinca intergranular em um material policristalino. Pode haver deflexão da frente da trinca tanto por inclinação quanto por torção e as duas maneiras irão mudar o modo de fratura e a forma do grão terá um efeito importante na tenacificação. A microestrutura pode ser modificada de modo que se tenha aumento na tenacidade, adicionando-se "whiskers", fibras, uma outra fase, induzindo crescimento de grão com a morfologia desejada. Uma das maneiras mais eficientes de se conseguir aumento na tenacidade é controlar a microestrutura, de forma que se tenha grãos alongados, com alta razão de aspecto.

\section{Ramificação de trincas ("crack branching")}

Quando uma trinca se ramifica em duas ou mais trincas menores, há redução na intensidade de tensão nas pontas das mesmas e perda de energia, dificultando a propagação 
das mesmas. Estas ramificações das trincas podem ser provocadas pela presença de aditivos, aumentando a tenacidade do material, tendo sido observadas em $\mathrm{Al}_{2} \mathrm{O}_{3}$ reforçado com "whiskers" de $\mathrm{SiC}, \mathrm{Si}_{3} \mathrm{~N}_{4}$ reforçado com aditivos, entre outros.

Este mecanismo dificilmente ocorre sozinho. Normalmente resulta da combinação de deflexão de trincas e formação de microtrincas [93].

\section{Descolamento e arrancamento de grãos ("debonding and pull-out")}

Descolamento de grãos, de partículas ou fibras, é um requisito necessário para o arrancamento dos mesmos e formação de ponte. $O$ descolamento necessita interface suficientemente fraca, isto é, mais fraca que as fases que estão ao seu redor, em um determinado campo de tensão aplicado. Durante o descolamento e a abertura da trinca, uma partícula ou fibra pode ser arrancada e a energia é, então, dissipada, aumentando a tenacidade do material.

$\mathrm{O}$ arrancamento e descolamento é um mecanismo importante para melhorar a tenacidade de compósitos de matriz cerâmica reforçada com fibras. A natureza da interface fibra-matriz é crítica. Se a ligação for muito forte, a trinca caminha através da fibra, não ocorre arrancamento, e a tenacidade do material não será afetada [35].

\section{Ponteamento na cauda da trinca ("bridging")}

O ponteamento na cauda da trinca envolve uma microestrutura na qual a ponta da trinca caminha, atrás de alguns grãos da mesma, aplicando-se uma força relativamente grande, dificultando ou até impedindo sua propagação.

Neste mecanismo ocorre formação de ponte entre as superficies na cauda da trinca por "whiskers", fibras ou matriz com grãos alongados e pode conduzir a uma tenacificação substancial do material. Em estudo feito com adição de $\mathrm{Al}_{2} \mathrm{O}_{3}$ em $\mathrm{Si}_{3} \mathrm{~N}_{4}$ obteve-se alta tenacidade, que foi atribuída aos mecanismos de deflexão de trincas e formação de ponte na cauda da trinca [ 32]. 


\section{Microtrincas ("microcracking")}

A formação de microtrincas pode ser induzida pela adição de partículas de $\mathrm{ZrO}_{2}$ tetragonal, por exemplo, em matriz cerâmica, de tal maneira que as partículas de $\mathrm{t}-\mathrm{ZrO}_{2}$ se transformem em monoclínicas durante o resfriamento, causando expansão volumétrica. Esta expansão induz a um aumento no estado de tensão ao redor das partículas e à formação de microtrincas. Estas microtrincas irão, durante o processo de desenvolvimento da trinca absorver energia da mesma, aumentando a tenacidade do material.

\section{Tenacificação por transformação de fase ("transformation toughening")}

Neste caso será citado novamente $\mathrm{ZrO}_{2}$, como exemplo. Inclusões de $\mathrm{t}-\mathrm{ZrO} \mathrm{Z}_{2}$ podem ser mantidas em estado meta-estável, abaixo da temperatura esperada para a transformação martensítica, por meio da força de compressão da matriz. No entanto, durante a propagação de uma trinca no material há formação de campos de tensão ao redor, e na ponta da trinca, capazes de induzir à transformação martensítica. Assim, as partículas de $\mathrm{t}-\mathrm{ZrO}_{2}$ submetidas a essas tensões sofrerão transformação, a qual está associada a uma expansão volumétrica, resultando em compressão sobre a matriz, o que dificulta a propagação da trinca. Tanto o mecanismo de microtrincas quanto o de tenacificação por transformação de fases, são utilizados adicionando-se $\mathrm{ZrO}_{2}$ em matriz de $\mathrm{Al}_{2} \mathrm{O}_{3}, \mathrm{Si}_{3} \mathrm{~N}_{4}, \mathrm{SiC}$, mulita, entre outros.

Alguns destes mecanismos tiveram origem na engenharia metalúrgica e depois estenderam para materiais cerâmicos. Dentre os materiais cerâmicos de alto desempenho poucos apresentam potencial de aplicação tão grande quanto aqueles à base de $\mathrm{SiC}, \mathrm{Si}_{3} \mathrm{~N}_{4} \mathrm{e}$ $\mathrm{ZrO}_{2}$. Para estes materiais, existe a possibilidade de se colocar uma série de aditivos tais como fibras, "whiskers", partículas de segunda fase, podendo aumentar a tenacidade do material.

$\mathrm{Na}$ tenacificação "in situ" há formação de grãos alongados durante a transformação $\beta$-SiC para $\alpha$-SiC. Os grãos grandes e alongados causam aumento na tenacidade do $\mathrm{SiC}$ por ponteamento na cauda da trinca ("crack bridging") ou deflexão de trincas ("crack deflection"), mas podem acarretar um decréscimo na resistência mecânica. Para se otimizar a microestrutura, deve-se fazer cuidadosa seleção dos aditivos de sinterização bem como a 
quantidade dos mesmos, que influenciam a fase líquida das cerâmicas resultantes, de forma que se tenha alta tenacidade à fratura e alta resistência mecânica. Os dados encontrados na literatura são, algumas vezes, discrepantes, embora nota-se grande influência da temperatura dos tratamentos térmicos e dos aditivos utilizados, na microestrutura e nas propriedades mecânicas dos materiais. A escolha dos melhores aditivos e suas quantidades estão constantemente em estudo.

$\mathrm{Na}$ Tabela II.4 são apresentados os valores de tenacidades à fratura de alguns materiais cerâmicos e metálicos.

Tabela II.4- Valores de dureza e tenacidade à fratura de alguns materiais $[27,36,38,94,95,96,97,98]$.

\begin{tabular}{|c|c|c|}
\hline Materiais & $\begin{array}{c}\mathbf{H}_{\mathbf{v}} \\
(\mathrm{GPa})\end{array}$ & $\begin{array}{c}\mathrm{K}_{\mathrm{lc}} \\
\left(\mathrm{MPa}_{\mathrm{m}} \mathrm{m}^{1 / 2}\right)\end{array}$ \\
\hline Vitro cerâmica & $\sim 8,5$ & $\sim 2,5$ \\
\hline $\mathbf{A l}_{2} \mathbf{O}_{3}$ & $18-23$ & $2,5-4,5$ \\
\hline AlN & $8-13$ & $2-3,5$ \\
\hline $\mathrm{ZrO}_{2}$ & $10-15$ & $6-12$ \\
\hline SiC & $\sim 22$ & $2,5-4$ \\
\hline $\mathbf{S i}_{3} \mathbf{N}_{4}$ & $8-19$ & $3-8$ \\
\hline $\begin{aligned} \mathbf{S i}_{3} \mathbf{N}_{4}: \mathbf{A l}_{2} \mathbf{O}_{3}: \mathbf{Y}_{2} \mathbf{O}_{3} \\
T_{\text {sinterizaçáa }}=1800^{\circ} \mathrm{C}\end{aligned}$ & $\sim 16$ & $\sim 5,5$ \\
\hline Aços & $\sim 1,1$ & $40-60$ \\
\hline $\mathrm{Al}_{2} \mathrm{O}_{3}: \mathrm{SiC}: \mathrm{PCS}$ & $\sim 18,0$ & $\sim 3,0$ \\
\hline
\end{tabular}

Observando-se os valores de $\mathrm{K}_{\mathrm{IC}}$, nota-se que a tenacidade à fratura dos metais é muito superior à dos materiais cerâmicos. No entanto dentre as cerâmicas da Tabela II.4 pode-se observar que é possivel aumentar a tenacidade colocando-se aditivos adequados, pois os mesmos agem na microestrutura acionando mecanismos tenacificadores. 


\section{III- MATERIAIS E MÉTODOS}

Como foram utilizados dois materiais para o estudo de sinterização, $\mathrm{SiC} \mathrm{e} \mathrm{Al}_{2} \mathrm{O}_{3}$, com processamentos e características bastante distintos, o trabalho foi dividido em duas partes:

- sinterização via fase líquida de pastilhas cerâmicas à base de $\mathrm{SiC}$, contendo aditivos óxidos e adição de PMHS e de PMHS: $\mathrm{D}_{4} \mathrm{~V}_{\mathfrak{i}}$

- sinterização de pastilhas de alumina, com adição de PMHS, de PMS e de PPS

\section{III.1- Materiais à base de SiC}

As matérias-primas utilizadas nesta etapa do trabalho foram:

- Carbeto de silício- SiC grau BF 17- H.C. Starck, contendo 91,1\% de B-SiC, 8,9\% de a-SiC; $1,45 \%$ de oxigênio.

- Óxido de alumínio- $\mathrm{Al}_{2} \mathrm{O}_{3}$ - A-16 SG- Alcoa, grau de pureza 99,8\%.

- Óxido de ítrio- $\mathrm{Y}_{2} \mathrm{O}_{3}$ - Aldrich, grau de pureza 99,9\%.

- Polimetilhidrogenossiloxano- PMHS 1107 Fluid: líquido, incolor, inodoro, peso especifico a $25{ }^{\circ} \mathrm{C}, 0,99 \mathrm{~g} / \mathrm{cm}^{3}$, viscosidade a $25^{\circ} \mathrm{C}, 30 \mathrm{cSt}$; fórmula geral $\left[\left(\mathrm{CH}_{3}\right)(\mathrm{H}) \mathrm{SiO}\right]_{\mathfrak{n}}-$ Dow Corning.

- Catalisador- Z- 6020 (fase líquida)- Dow Corning; utilizado somente para o PMHS

- $\mathrm{D}_{4} \mathrm{~V}_{\mathrm{i}}-1,3,5,7$ - tetrametil-1, 3, 5, 7-tetravinilciclotetrassiloxano; fórmula geral: $\left[\left(\mathrm{CH}_{3}\right)\left(\mathrm{CH}_{2}\right)=(\mathrm{CH}) \mathrm{SiO}_{4}-\right.$ Dow Corning.

- Catalisador de Pt- dicloro - 1,3 - divinil - 1,1, 3, 3, - tetrametildissiloxano platina, aproximadamente $1 \%$ de platina; divinilcomplexo de platina - Hüll.

Foi estudada a adição dos precursores PMHS (1\% e 5\% em peso) utilizando catalisador Z-6020 e PMHS: $\mathrm{D}_{4} \mathrm{~V}_{\mathrm{i}}(1 \%, 5 \%$ e $10 \%$ em peso) utilizando catalisador de $\mathrm{Pt}$, na sinterização via fase líquida de $\mathrm{SiC}: \mathrm{Al}_{2} \mathrm{O}_{3}: \mathrm{Y}_{2} \mathrm{O}_{3}$. 
As principais etapas do procedimento experimental adotado para $\mathrm{SiC}: \mathrm{Al}_{2} \mathrm{O}_{3}: \mathrm{Y}_{2} \mathrm{O}_{3}$ são mostradas no fluxograma da Figura III.1:

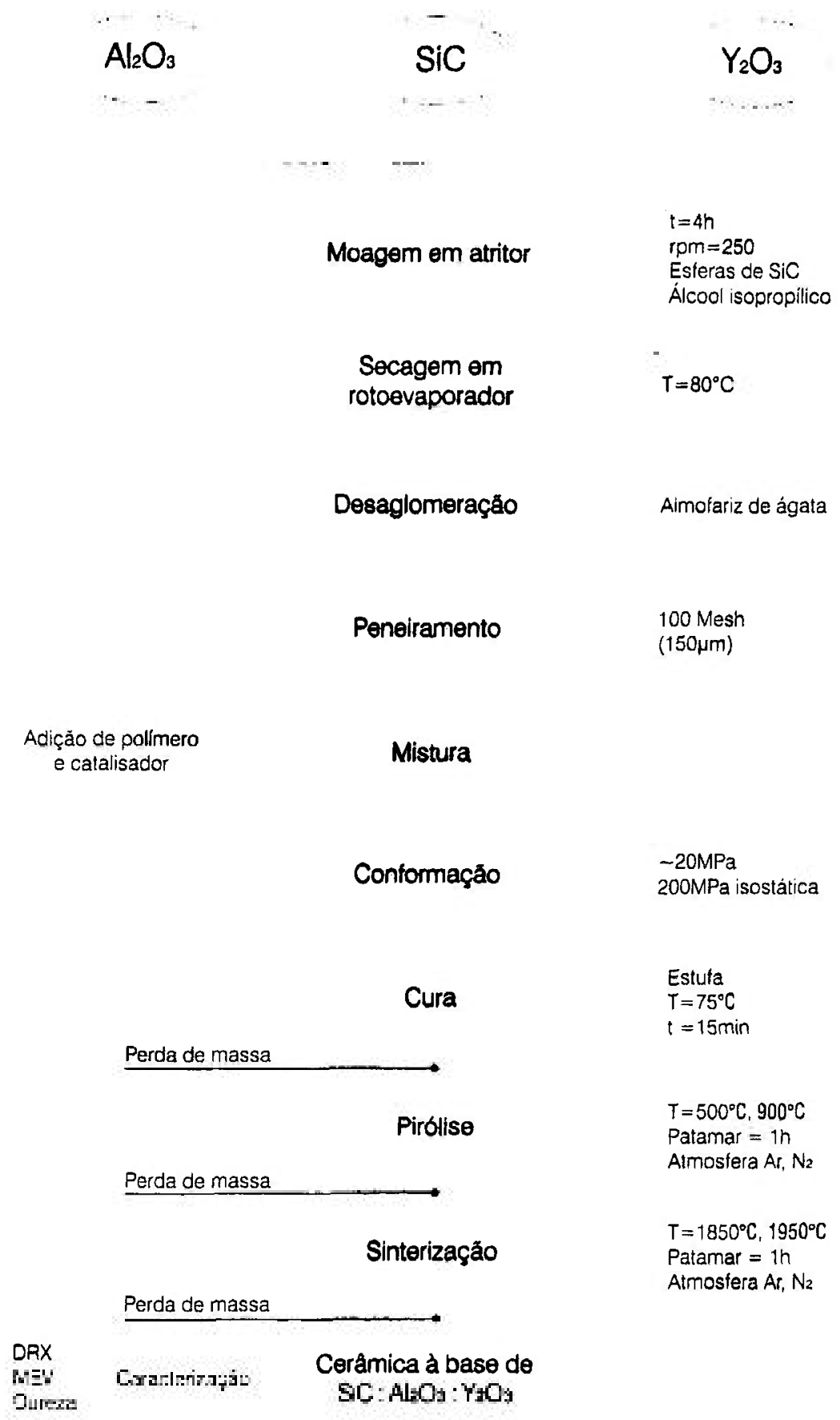

Figura III.1- Fluxograma das etapas de processamento de $\mathrm{SiC}: \mathrm{Al}_{2} \mathrm{O}_{3}: \mathrm{Y}_{2} \mathrm{O}_{3}$ contendo polímero e catalisador. 
Foi preparada uma composição base, SAY0, contendo $92 \%$ em peso de $\mathrm{SiC}, 4 \%$ em peso de $\mathrm{Al}_{2} \mathrm{O}_{3}$ e $4 \%$ em peso de $\mathrm{Y}_{2} \mathrm{O}_{3}$. A moagem da mistura SiC: $\mathrm{Al}_{2} \mathrm{O}_{3}: \mathrm{Y}_{2} \mathrm{O}_{3}$ foi feita em moinho tipo atritor, com álcool isopropílico, haste, jarro e esferas de $\mathrm{SiC}$, por 4 horas. Moinho tipo atritor é altamente eficiente, podendo obter baixa aglomeração dos pós, tamanho de partícula bem abaixo de $1 \mu \mathrm{m}$ e, em geral, distribuição de tamanho de partícula estreita devido, principalmente, à alta rotação, alta energia e grande freqüência de impactos. $O$ material foi submetido a processo de secagem em rotoevaporador e posteriomente colocado em estufa, para eliminação da umidade residual. A mistura foi desaglomerada em almofariz de ágata e passada em peneira (malha 100 Mesh). As amostras padrão, utilizadas como material de referência, $\mathrm{SAY} 0,\left(\mathrm{SiC}: \mathrm{Al}_{2} \mathrm{O}_{3}: \mathrm{Y}_{2} \mathrm{O}_{3}\right)$, foram compactadas uniaxialmente a aproximadamente $20 \mathrm{MPa}$ e isostaticamente a $200 \mathrm{MPa}$, e sinterizadas a $1850{ }^{\circ} \mathrm{C}$ ou $1950^{\circ} \mathrm{C}$.

Para a preparação de amostras contendo $1 \%$ ou $5 \%$ de PMHS foram colocadas 2 gotas de catalisador Z-6020 diluído em álcool isopropílico e adicionada esta mistura no PMHS. Esta solução foi adicionada aos pós e colocada em misturador tipo túrbula por 30 minutos. Foi feita compactação uniaxial, em matriz de $10 \mathrm{~mm}$ de diâmetro, a aproximadamente $20 \mathrm{MPa}$ e compactação isostática a frio, a $200 \mathrm{MPa}$. Após a compactação das amostras foi feita a cura das mesmas a $75^{\circ} \mathrm{C}$, por 15 minutos, em estufa. Estas amostras foram submetidas ao processo de pirólise a $500^{\circ} \mathrm{C}$ ou a $900^{\circ} \mathrm{C}$, por 1 hora, em forno tubular, com atmosfera dinâmica de argônio, Figura III.2.

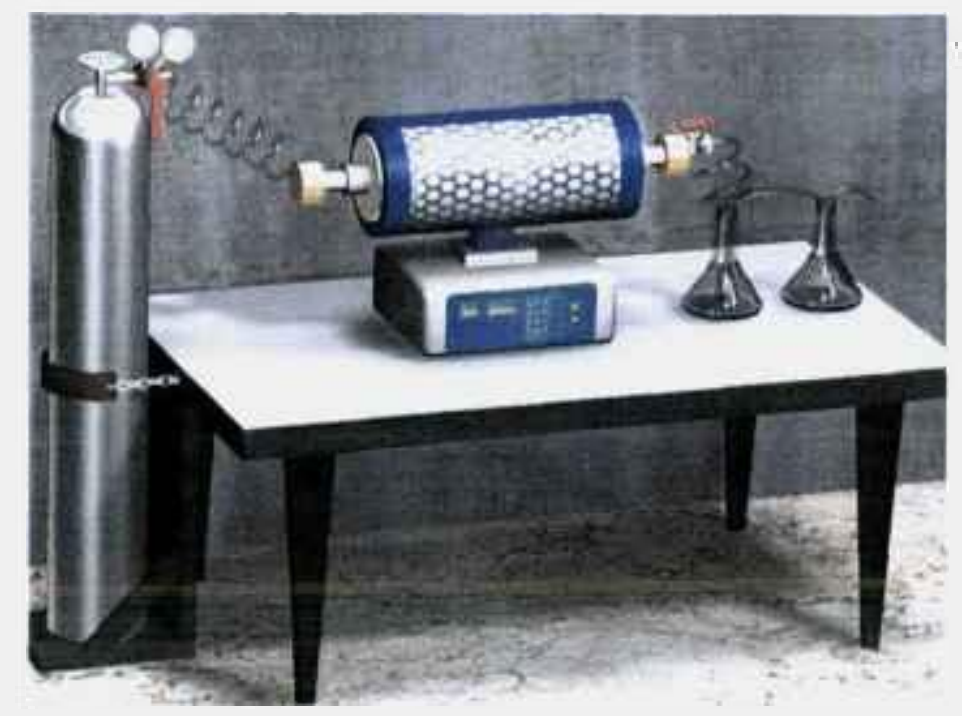

Figura III.2- Montagem experimental utilizada para a pirólise, em atmosfera controlada, das amostras cerâmicas com diferentes precursores poliméricos. 
A sinterização do $\mathrm{SiC}: \mathrm{Al}_{2} \mathrm{O}_{3}: \mathrm{Y}_{2} \mathrm{O}_{3}$ com PMHS foi realizada em forno de resistência de grafite (Astro), com cama protetora de $\mathrm{SiC}: \mathrm{Al}_{2} \mathrm{O}_{3}: \mathrm{Y}_{2} \mathrm{O}_{3}$ e atmosfera de argônio. Foi utilizado cadinho fechado e cama, com o intuito de minimizar a perda de massa. Foram definidas duas temperaturas para a sinterização: $1850^{\circ} \mathrm{C}$ e $1950^{\circ} \mathrm{C}$, com patamar de 1 hora. A taxa de aquecimento foi de $5^{\circ} \mathrm{C} / \mathrm{min}$ até $400{ }^{\circ} \mathrm{C}$, e $20^{\circ} \mathrm{C} / \mathrm{min}$ de $400{ }^{\circ} \mathrm{C}$ até a temperatura de patamar.

Amostras de $\mathrm{SiC}: \mathrm{Al}_{2} \mathrm{O}_{3}: \mathrm{Y}_{2} \mathrm{O}_{3}$ com adição dos polímeros (PMHS: $\mathrm{D}_{4} \mathrm{~V}_{\mathrm{i}}$ ) foram preparadas utilizando catalisador de Pt diluido em álcool isopropilico. Esta mistura, levemente pastosa, sofreu agitação por $5 \mathrm{~min}$. em agitador magnético, a $40^{\circ} \mathrm{C}$, para tirar o excesso de álcool. A compactação do material foi realizada em prensa a quente (Marconi modelo MA 098/A), Figura III.3, $80^{\circ} \mathrm{C}$, por 2 horas, a $40 \mathrm{MPa}$. A pirólise foi feita em atmosfera de argônio, a $900^{\circ} \mathrm{C}$, com patamar de 1 hora em forno tubular. A sinterização foi feita a $1950^{\circ} \mathrm{C}$, com patamar de 1 hora, nas mesmas condições que para as amostras preparadas somente com PMHS.

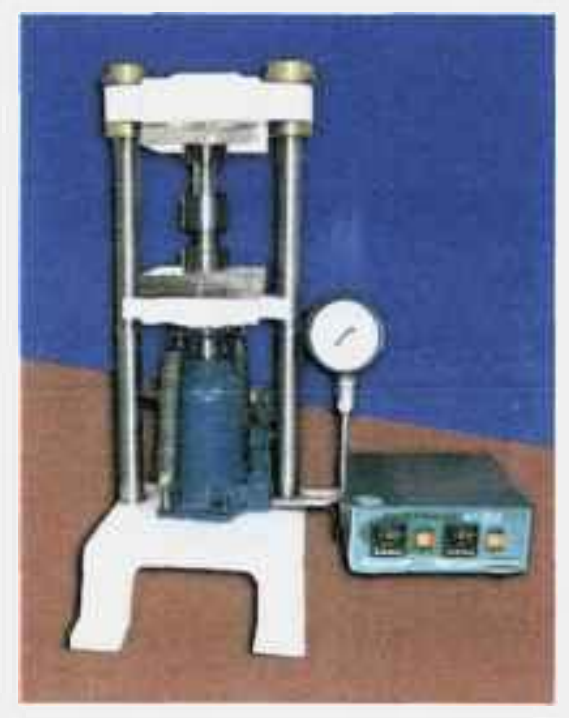

Figura III.3- Prensa a quente utilizada para compactação das amostras contendo precursores poliméricos.

As amostras foram codificadas para facilitar a sua identificação. Os códigos contém: composição, \% de polímero adicionado, tipo de polímero, temperatura e atmosfera de pirólise, temperatura e atmosfera de sinterização.

Exemplos: 
A amostra padrão, $\mathrm{SiC}: \mathrm{Al}_{2} \mathrm{O}_{3}: \mathrm{Y}_{2} \mathrm{O}_{3}$, sem adição de polímero, recebeu o código SAY01950A ou SAY01950N, como:

\section{SAY01950N:}

$\mathrm{SAY} \rightarrow$ material $\left(\mathrm{SiC}: \mathrm{Al}_{2} \mathrm{O}_{3}: \mathrm{Y}_{2} \mathrm{O}_{3}\right) ; 0 \rightarrow$ sem adição de polímero; $1950 \rightarrow$ temperatura $\left({ }^{\circ} \mathrm{C}\right)$ de sinterização e $\mathbf{N} \rightarrow$ atmosfera de sinterização $(\mathbf{N} \rightarrow$ nitrogênio, no caso).

\section{Amostras com PMHS}

SAY1H-9A-1950N, tendo-se:

SAY $\rightarrow$ material ( $\mathrm{SiC}: \mathrm{Al}_{2} \mathrm{O}_{3}: \mathrm{Y}_{2} \mathrm{O}_{3}$ ); $1 \rightarrow \%$ em peso do polímero utilizado; $\mathbf{H} \rightarrow$ aditivo polimérico PMHS; 9A $\rightarrow$ temperatura $\left(900^{\circ} \mathrm{C}\right)$ e atmosfera de pirólise $(\mathrm{A} \rightarrow$ argônio); 1950N $\rightarrow$ temperatura $\left({ }^{\circ} \mathrm{C}\right)$ e atmosfera de sinterização $(\mathrm{N} \rightarrow$ nitrogênio $)$.

\section{Amostras com PMHS:D㫏}

SAY10HD-9A-1950A, tendo-se:

$\mathrm{SAY} \rightarrow$ material $\left(\mathrm{SiC}: \mathrm{Y}_{2} \mathrm{O}_{3}: \mathrm{Al}_{2} \mathrm{O}_{3}\right) ; \mathbf{1 0} \rightarrow \%$ em peso do polímero utilizado; $\mathrm{HD} \rightarrow$ aditivo polimérico PMHS: $\mathrm{D}_{4} \mathrm{~V}_{\mathrm{i}} ; \mathbf{9 A} \rightarrow$ temperatura $\left(900^{\circ} \mathrm{C}\right)$ e atmosfera de pirólise $(\mathrm{A} \rightarrow$ argônio); 1950A $\rightarrow$ temperatura $\left({ }^{\circ} \mathrm{C}\right)$ e atmosfera de sinterização $(\mathrm{A} \rightarrow$ argônio).

\section{III.2- Materiais à base de $\mathrm{Al}_{2} \mathrm{O}_{3}$}

As matérias-primas utilizadas nesta etapa foram:

- Óxido de alumínio- $\mathrm{Al}_{2} \mathrm{O}_{3}-\mathrm{A}-16 \mathrm{SG}-\mathrm{Alcoa}$, grau de pureza $99,8 \%$.

- Polimetilhidrogenossiloxano (PMHS)- 1107 Fluid- Dow Corning. 
- Polimetilsilsesquioxano (PMS)- MK- Wacker Chemie: resina MK, na forma de pó à temperatura ambiente, fórmula geral $\left(\mathrm{CH}_{3} \mathrm{SiO}_{1,5}\right)_{\mathrm{n}}$, com $\mathrm{n}$ variando de 130 a 150 ; densidade de $1,2 \mathrm{~g} / \mathrm{cm}^{3}$.

- Polifenilmetilvinilhidrogenosilsesquioxano (PPS)- H62C, líquido de baixa viscosidade na temperatura ambiente, $1,4.10^{-3} \mathrm{~m}^{2} \cdot \mathrm{s}^{-1}$, composição molecular aproximada de $\left(\mathrm{RSiO}_{1,5}\right)_{\mathrm{n}}$ onde $\mathrm{R}$ é $\left[\left(\mathrm{C}_{6} \mathrm{H}_{5}\right)_{2,8},\left(\mathrm{CH}_{3}\right)_{1,5},\left(\mathrm{CH}_{2}=\mathrm{CH}\right),(\mathrm{H})\right]$ - MKWacker Chemie.

- Catalisador-dicloro - 1,3-divinil-1,1,3,3,- tetrametildissiloxano platina, aproximadamente $1 \%$ de platina; divinilcomplexo de platina - Hüll; utilizado para os três compostos, PMHS, PMS e PPS.

\section{III.2.1- Processamento do material à ase de $\mathrm{Al}_{2} \mathrm{O}_{3}$}

O fluxograma da Figura III.4 apresenta a preparação da alumina, antes da adição do polímero precursor.

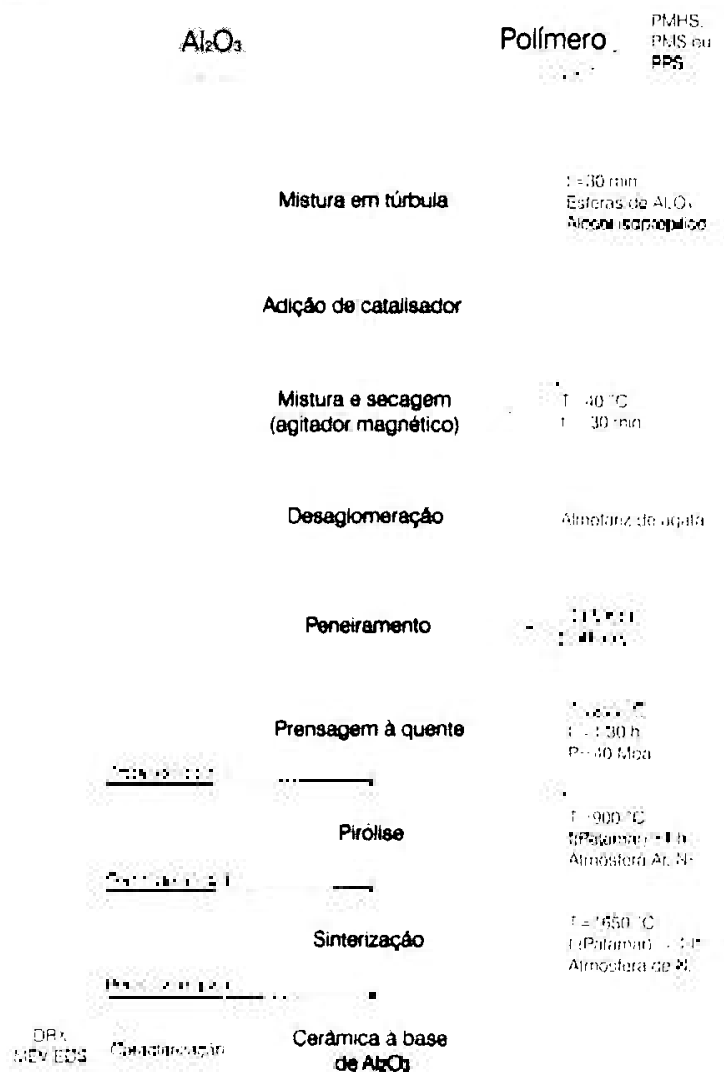

Figura III.4- Fluxograma das etapas de processamento da alumina, antes da adição do polímero precursor. 
Foram feitas adiç̃es no $\mathrm{Al}_{2} \mathrm{O}_{3}$, de $1 \%, 5 \%$ e $10 \%$ em peso de polímeros, utilizando catalisador de platina.

As principais etapas do procedimento experimental de $\mathrm{Al}_{2} \mathrm{O}_{3}$ contendo polímeros são mostradas no fluxograma da Figura WI.5.
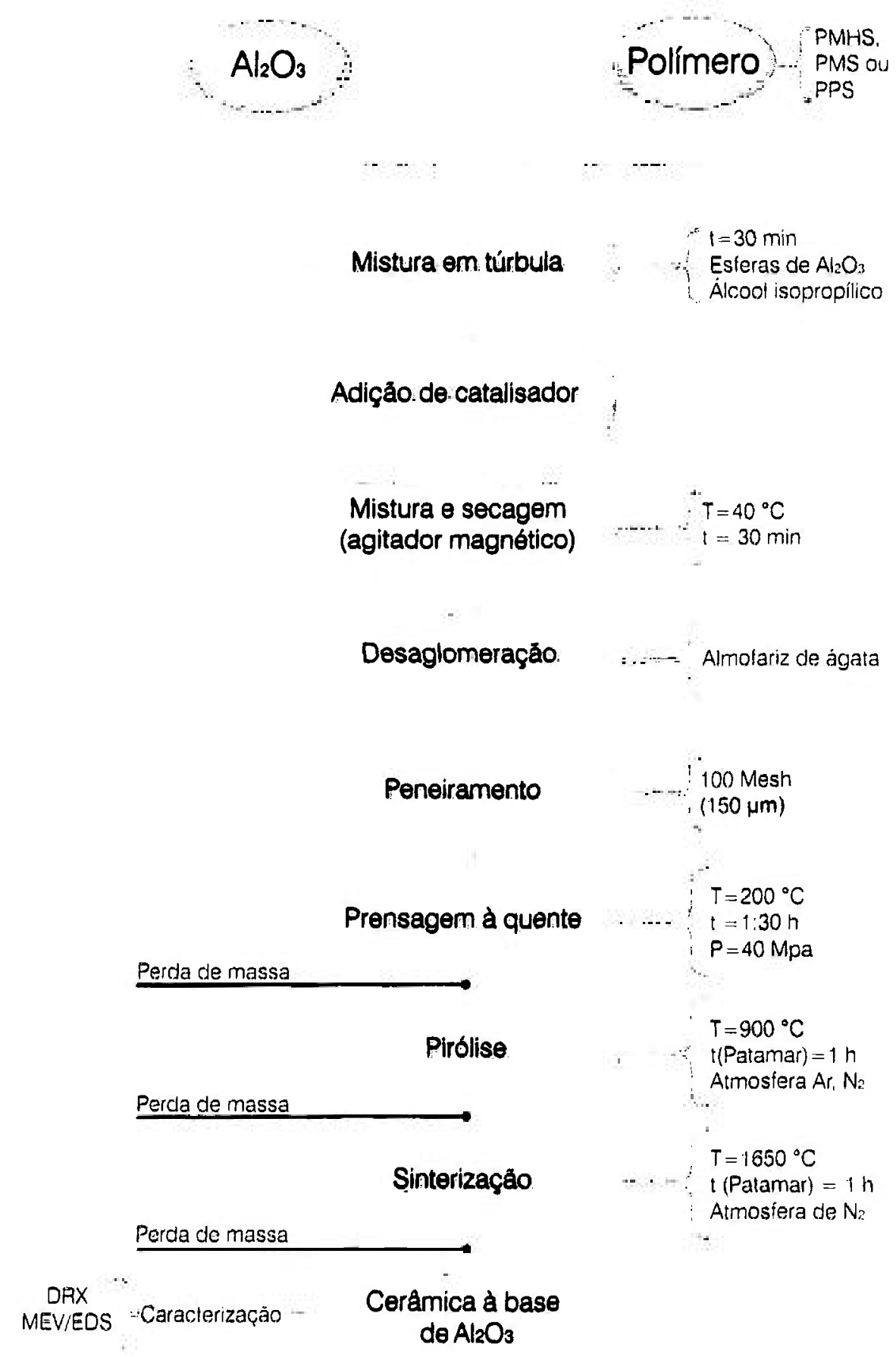

Figura III.5- Fluxograma das etapas de processamento de $\mathrm{Al}_{2} \mathrm{O}_{3}$ contendo precursores poliméricos. 
A codificação utilizada para as amostras à base de alumina é similar à das amostras contendo carbeto de silício.

\section{Amostra padrão}

A01650A ou A01650N $\rightarrow$ padrão (sem adição de polímero), exemplo:

A01650A, sendo:

$A \rightarrow$ material $\left(\mathrm{SiC}: \mathrm{Al}_{2} \mathrm{O}_{3}: \mathrm{Y}_{2} \mathrm{O}_{3}\right) ; 0 \rightarrow$ sem adição de polímero; $1650 \rightarrow$ temperatura $\left({ }^{\circ} \mathrm{C}\right)$ de sinterização e $\mathbf{A} \rightarrow$ atmosfera de sinterização $(\mathbf{A} \rightarrow$ argônio, no caso).

A5M-9N-1650N, tendo-se:

$\mathbf{A} \rightarrow \mathrm{Al}_{2} \mathrm{O}_{3}$ (material); $\mathbf{5} \rightarrow \%$ em peso do polímero utilizado; $\quad \mathbf{M} \rightarrow$ aditivo polimérico PMS; $9 \mathrm{~N} \rightarrow$ temperatura de pirólise $\left(900^{\circ} \mathrm{C}\right)$ e atmosfera de pirólise $(\mathrm{N} \rightarrow$ nitrogênio); $1650 \mathrm{~N} \rightarrow$ temperatura de sinterização $\left({ }^{\circ} \mathrm{C}\right)$ e atmosfera de sinterização $(\mathrm{N} \rightarrow$ nitrogênio).

$\mathrm{O}$ processamento das amostras inclui moagem de $\mathrm{Al}_{2} \mathrm{O}_{3}$ em moinho atritor, com álcool isopropílico, haste, jarro e esferas de $\mathrm{Al}_{2} \mathrm{O}_{3}$, por 4 horas. $\mathrm{O}$ material foi seco em rotoevaporadorador, desaglomerado em almofariz de ágata e passado em peneira (malha $100 \mathrm{Mesh}$ ). A amostra padrão, A0, foi compactada em prensa a quente a $80^{\circ} \mathrm{C}$ por 2 horas, a pressão de $40 \mathrm{MPa}$, depois em prensa isostática a $200 \mathrm{MPa}$ e sinterizada no forno Astro em atmosfera de argônio ou nitrogênio.

$\mathrm{O}$ catalisador de $\mathrm{Pt}$, diluído em álcool isopropílico, foi adicionado ao polímero e ao $\mathrm{Al}_{2} \mathrm{O}_{3}$. No caso do polímero na forma de pó adicionou-se uma quantidade maior de álcool isopropílico. A mistura foi feita em misturador (túrbula, modelo T 2C) por $30 \mathrm{~min}$ e colocada em agitador magnético, a $40^{\circ} \mathrm{C}$, para evaporar o excesso do álcool isopropílico. $\mathrm{O}$ material foi compactado uniaxialmente em prensa a quente, a $200^{\circ} \mathrm{C}$, por 2 horas, a pressão de $40 \mathrm{MPa}$. As amostras foram submetidas ao processo de pirólise a $900{ }^{\circ} \mathrm{C}$, com patamar de 1 hora, em forno tubular, sob atmosfera dinâmica, de nitrogênio, ou argônio. 
A sinterização foi realizada em forno de resistência de grafite (Astro) a $1650^{\circ} \mathrm{C}$ ou $1700^{\circ} \mathrm{C}$, com patamar de 1 hora, pressão positiva de nitrogênio. Este tratamento térmico foi feito em cadinho fechado e cama protetora de $\mathrm{Al}_{2} \mathrm{O}_{3}$. A taxa de aquecimento foi $5^{\circ} \mathrm{C} / \mathrm{min}$ até $400^{\circ} \mathrm{C}$, e $20^{\circ} \mathrm{C} / \mathrm{min}$ de $400^{\circ} \mathrm{C}$ até a temperatura de sinterização.

\section{III.3- Métodos de caracterizaçăo}

\section{Análise química}

$A$ análise química semi-quantitativa dos pós $\mathrm{Al}_{2} \mathrm{O}_{3}, \mathrm{Y}_{2} \mathrm{O}_{3}$ e $\mathrm{SiC}$ foi realizada por espectrometria de fluorescência de raios X (Rigaku, RIX-3000).

Foi utilizado analisador de carbono total via absorção de radiação infravermelho acoplado a um forno de radiofrequêência, (LECO, modelo CS400), para análise da quantidade de carbono das amostras de $\mathrm{Al}_{2} \mathrm{O}_{3}: \mathrm{PMHS}, \mathrm{Al}_{2} \mathrm{O}_{3}: \mathrm{PMS}$ e $\mathrm{Al}_{2} \mathrm{O}_{3}: \mathrm{PPS}$, após sinterização.

\section{Área especifica}

Os valores de área específica dos pós cerâmicos, utilizados como matérias-primas, foram determinados utilizando a técnica de adsorção gasosa pelo método de BET, (Brunauer, Emmett, Teller), em equipamento Micromeritics, modelo ASAP 2010.

\section{Distribuição granulométrica dos pós}

A distribuição granulométrica dos pós foi determinada por difração de laser (CILAS 1064), utilizando como agente dispersante duramax.

\section{Microscopia eletrônica de varredura}

A observação da forma das partículas e/ou aglomerados, foi feita por microscopia eletrônica de varredura (Philips XL-30). Os pós foram depositados em fita adesiva dupla 
face colocada no porta-amostra do MEV e recobertos com ouro, utilizando "sputerring" , BAL-TEC, modelo SCD 050.

\section{Caracterização das pastilhas}

\section{Variação de massa durante o processo}

As perdas de massa das amostras foram avaliadas pesando as mesmas antes e após cada etapa do processo (pirólise, sinterização). A pesagem foi feita em balança analítica de precisão, e a equação utilizada foi:

$$
\left(\Delta m / m_{0}\right) \%=\left[\left(m_{0}-m_{f}\right) / m_{0}\right] .100
$$

em que $: m_{0} \rightarrow$ massa inicial das amostras

$\mathrm{m}_{\mathrm{f}} \rightarrow$ massa após pirólise, ou sinterização

\section{Análise termogravimétrica}

Foram realizadas análises termogravimétricas (TG) para verificar a variação de massa, em função da temperatura, dos polímeros PMHS, PMHS: $\mathrm{D}_{4} \mathrm{~V}_{i}$, PMS e PPS, em termobalança, Shímadzu, TGA 50H. Nesta técnica a variação da massa da amostra (perda ou ganho) é determinada em função da temperatura e/ou tempo, enquanto o material é submetido a uma programação controlada de temperatura $[99,100]$. As amostras foram aquecidas até $1200^{\circ} \mathrm{C}$, ou $1350^{\circ} \mathrm{C}$, com taxa de aquecimento de $10^{\circ} \mathrm{C} / \mathrm{min}$, sob fluxo constante $(10 \mathrm{ml} / \mathrm{min})$ de ar sintético, argônio, ou nitrogênio de alta pureza.

\section{Densidade aparente}

A densidade aparente das amostras sinterizadas foi determinada pelo método da imersão utilizando o princípio de Arquimedes ou por picnometria de He (Micromeritics, modelo 1330). As medidas de densidade aparente pela segunda técnica foram realizadas em 
picnômetro de deslocamento de gases, utilizando He como gás de arraste. Foram realizadas pelo menos 10 medidas de cada amostra.

Para o cálculo de densidade pelo método de Arquimedes, foi utilizada, a equação II.2.

$$
\rho_{\text {amastra }}=M_{\mathbf{s}} X \rho_{\text {água }} /\left(M_{\mathbf{u}}-M_{i}\right)
$$

em que: $\rho \rightarrow$ densidade $\left(\mathrm{g} / \mathrm{cm}^{3}\right)$

$\mathrm{M}_{\mathrm{g}}, \mathrm{M}_{\mathrm{u}}, \mathrm{M}_{\mathrm{i}} \rightarrow$ massa da amostra seca, úmida e imersa, respectivamente $(\mathrm{g})$

As perdas de massa das amostras foram comparadas com as perdas de massa previstas, calculadas levando-se em conta as perdas de massa da amostra padrão, as porcentagens do material $e$ de polímeros adicionados e resultados da análise termogravimétrica.

\section{Dilatometria}

Foram feitos ensaios de dilatometria para amostras de $\mathrm{Al}_{2} \mathrm{O}_{3}$ contendo $10 \%$ de polímeros. As amostras A10H-9N-1650N, A10M-9N-1650N e A10P-9N-1650N foram submetidas a programa controlado de temperatura, com etapas de aquecimento, estágio isotérmico e resfriamento. A variação do comprimento em função da temperatura é acompanhada de mudanças irreversíveis no material. As transformações de fases, cristalização e densificação produzem alterações no comprimento da amostra.

Corpos de prova cilíndricos, diâmetro de $7 \mathrm{~mm}$ e $12 \mathrm{~mm}$ de comprimento, foram sinterizados em dilatômetro de alta temperatura (Netzsch Thermal Analysis, DIL/C7,), sob fluxo de $\mathrm{N}_{2}$ em porta amostra e tubo de alumina. A taxa de aquecimento utilizada foi $10^{\circ} \mathrm{C} /$ min. até $1650^{\circ} \mathrm{C}$, patamar de 1 hora e resfriamento de $10^{\circ} \mathrm{C} / \mathrm{min}$.

\section{Porosimetria por intrusão de $\mathrm{Hg}$}

Porosimetria é um dos métodos mais utilizados para a determinação da porosidade e da distribuição de tamanho de poros em materiais cerâmicos; é baseada na relação inversa 
entre a pressão necessária para forçar a intrusão de $\mathbf{H g}$ metálico dentro de um poro cilíndrico e a dimensão deste; é importante ressaltar que em todos os métodos disponíveis para se calcular a distribuição de tamanho de poros, como os utilizados neste trabalho, somente geometrias regulares de poros são consideradas; a mais comum é geometria cilíndrica; é então um modelo aproximado ao sistema aqui discutido, onde a morfologia dos poros é irregular e pode diferir bastante da forma geométrica cilíndrica.

\section{Difração de raios $X$}

Para a análise das matérias-primas, pós, e das fases cristalinas presentes nas amostras sinterizadas foi utilizado difratômetro de raios X (Rigaku, modelo Multiflex), com radiação de $\mathrm{CuK}_{a}(\lambda=0,15418 \AA)$. As pastilhas foram seccionadas no sentido longitudinal. A identificação das fases cristalinas foi feita comparando-se a distância interplanar (d) com os valores das fichas JCPDS ("Joint Committee on Powder Diffraction Standards").

\section{Análise microestrutural}

A microestrutura foi observada em microscópio óptico (Leitz, ORTHMAT), para acompanhar o polimento, e em eletrônico de varredura (Philips XL-30), sendo utilizados elétrons retroespalhados e/ou secundários. Para observação em microscópio eletrônico de varredura (MEV), as amostras foram embutidas, polidas em pasta de diamante até 1 um e recobertas com ouro. Foram feitas também análises por espectrometria de raios $\mathrm{X}$ por dispersão de energia (EDS- acoplado ao MEV).

As amostras preparadas com $\mathrm{Al}_{2} \mathrm{O}_{3}:$ PMHS foram submetidas a ataque térmico a vácuo, em forno tubular a $1550^{\circ} \mathrm{C}$, por $15 \mathrm{~min}$. para que os grãos fossem revelados.

A verificação das fases presentes no material e sua localização foi feita por microscopia eletrônica de transmissão. A preparação de amostras cerâmicas para observação em microscópio eletrônico de transmissão (MET) seguiu um procedimento padrão, isto é, fazer corte de cilindos de $3 \mathrm{~mm}$ de diâmetro (SBT, 360), desbaste, "dimpling" (Gatan, 656), afinamento com canhão de íons de argônio até sua perfuração 
(Edwards, IBT 200) e recobrimento com carbono para minimizar cargas eletrostáticas sob o feixe de elétrons utilizando um pulverizador catódico ("sputtering", BAL-TEC, SCD 050).

As amostras foram analisadas em MET (Jeol, 200C) para identificação de fases por padrões de difração e MET (Philips CM-200) para análise química com EDS (EDAX).

A identificação das estruturas cristalinas e orientações cristalográficas das fases presentes foi realizada utilizando-se o programa DIFPAT, desenvolvido por Graham Carpenter e Laris Benkis do Metalurgical Laboratory, CANMET, Canada. Este programa determina a direção do eixo zonal e indexa os pontos do padrăo de difração a partir dos dados experimentais, das distâncias dos pontos do padrão de difração em relação ao feixe transmitido e dos ângulos formados entre os pontos.

\section{Dureza Vickers}

Para o ensaio de impressão Vickers, as amostras foram embutidas em baquelite e polidas com pastas de diamante com granulometrias de até $1 \mu \mathrm{m}$, de modo a fornecer uma superficie plana para minimizar as tensões superficiais pré-existentes, originadas nas etapas de corte e desbaste. As amostras polidas foram ensaiadas em máquina de dureza Vickers, (Buehler, VMT-7) cujo penetrador é de diamante (prisma de base quadrada), com ângulo de $136^{\circ}$ entre as faces opostas. Variou-se a carga de $10 \mathrm{~N}$ a $200 \mathrm{~N}$ para determinação da carga mais adequada para a medida de dureza. A carga selecionada foi a de 98,07 N. Foram feitas cerca de 10 impressð̃es em cada amostra observando-se o distanciamento adequado sugerido por Ponton e Rawlings [93], que é de aproximadamente 4 vezes o comprimento das trincas para impressð̃es adjacentes; as impressões também não foram realizadas próximas à borda, pois podem fornecer resultados incorretos. As medidas dos comprimentos das trincas e as diagonais das indentaçðes produzidas no ensaio foram feitas em um microscópio óptico acoplado ao próprio equipamento, que também fornece as medidas de $\mathrm{H}_{\mathrm{v}}$.

A equação utilizada para o cálculo de $\mathrm{H}_{\mathrm{v}}$ é:

$H_{v}=2 L \operatorname{sen}(\alpha / 2) / d^{2} \quad H_{v}=1,8544 L / d^{2}$ 
onde: $\mathrm{H}_{\mathrm{v}} \rightarrow$ dureza Vickers (GPa)

$\mathrm{d} \rightarrow$ diagonal

$\mathrm{L} \rightarrow$ carga aplicada $(\mathrm{N})$

$\alpha \rightarrow$ ângulo da face do cristal $\left(136^{\circ}\right)$

Na Figura III.6 é ilustrada, de maneira esquemática, o processo de indentação, sendo $h$ a profundidade de penetração do prisma.

Postçato de operaça

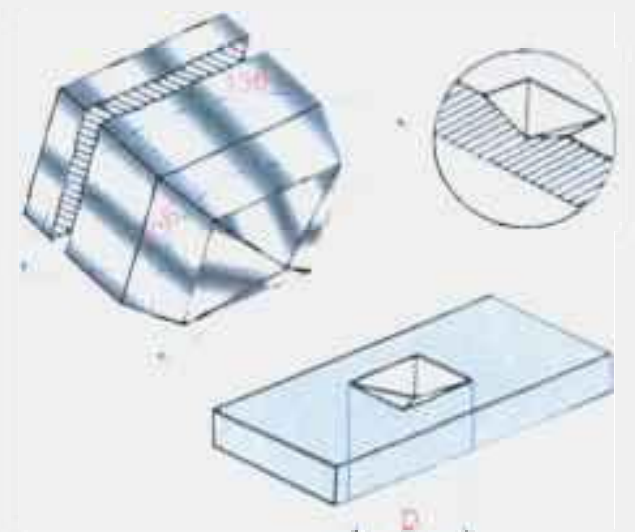

Figura III.6- Esquema do processo de indentação Vickers [36].

Para a verificação do tipo das trincas decorrente das impressões Vickers foi feito polimento das amostras em pasta de diamante $6 \mu \mathrm{m}$ por $2 \mathrm{~min}$. A equação utilizada para o cálculo da tenacidade à fratura para trinca fratura radial-mediana é [36]:

$$
\mathrm{K}_{\mathrm{Ic}}=0,0154(\mathrm{E} / \mathrm{H})^{1 / 2}\left(\mathrm{P} / \mathrm{c}^{3 / 2}\right)
$$

sendo:

$\mathrm{K}_{\mathrm{Ic}} \rightarrow$ tenacidade a fratura (MPa.m ${ }^{1 / 2}$ )

$\mathrm{E} \rightarrow$ módulo de elasticidade (GPa)

$\mathrm{H} \rightarrow$ dureza Vickers (MPa)

$\mathrm{P} \rightarrow$ carga aplicada $(\mathrm{N})$

$c \rightarrow$ comprimento da trinca $(\mu \mathrm{m})$ 


\section{IV- RESULTADOS E DISCUSSÃo}

\section{IV.1- Caracterizaçăo das matérias-primas}

Como as características das matérias-primas, como a morfologia das partículas e a pureza, podem exercer grande influência no processo de fabricação e no produto final, foi feita a caracterização fisica e química das matérias-primas. Os resultados da análise semiquantitativa por espectrometria de fluorescência de raios $\mathrm{X}$ do $\mathrm{SiC}, \mathrm{Y}_{2} \mathrm{O}_{3}$ e $\mathrm{Al}_{2} \mathrm{O}_{3}$ encontram-se na Tabela IV.1.

Os valores obtidos pela análise semi-quantitativa por espectrometria de fluorescência de raios $\mathrm{X}$ foram próximos aos fornecidos pelos fabricantes, levando-se em conta o desvio padrão, embora com algumas diferenças, como na análise por fluorescência de raios $\mathrm{X}$ não foi detectado $\mathrm{Mg}$ na $\mathrm{Al}_{2} \mathrm{O}_{3}$ e a análise química fornecida pela Alcoa constatou a presença de $0,030 \pm 0,002 \%$ em peso de $\mathrm{Mg}$.

Tabela IV.1- Análise semi-quantitativa obtida por espectrometria de fluorescência de raios $\mathrm{X}$.

\begin{tabular}{|c|c|c|c|}
\hline Elementos & $\begin{array}{c}\mathrm{SiC} \\
\text { (\% peso) }\end{array}$ & $\begin{array}{c}\mathrm{Al}_{2} \mathrm{O}_{3} \\
\text { (\% peso) }\end{array}$ & $\begin{array}{c}\mathrm{Y}_{2} \mathrm{O}_{3} \\
\text { (\% peso) }\end{array}$ \\
\hline $\mathrm{Al}_{2} \mathrm{O}_{3}$ & - & $99,93 \pm 0,05$ & - \\
\hline $\mathrm{Y}_{2} \mathrm{O}_{3}$ & - & - & $99,95 \pm 0,05$ \\
\hline $\mathrm{Si}$ & $76,9 \pm 0,8$ & $0,012 \pm 0,003$ & - \\
\hline $\mathrm{C}$ & $22,62 \pm 1,87$ & - & - \\
\hline $\mathrm{Fe}$ & $0,003 \pm 0,005$ & $0,015 \pm 0,003$ & $0,025 \pm 0,003$ \\
\hline $\mathrm{Al}$ & $0,041 \pm 0,005$ & & $0,021 \pm 0,005$ \\
\hline $\mathrm{Ca}$ & - & $0,030 \pm 0,005$ & - \\
\hline $\mathrm{S}$ & $0,014 \pm 0,003$ & $0,008 \pm 0,002$ & - \\
\hline $\mathrm{Ni}$ & $0,013 \pm 0,003$ & & - \\
\hline
\end{tabular}

Os valores dos tamanhos de partículas a $10 \%\left(\Phi_{10}\right), 50 \%\left(\Phi_{50}\right)$ e $90 \%\left(\Phi_{90}\right)$ das matérias-primas obtidos pelo método de difração de laser e das áreas de superfícies 
específicas pela técnica de adsorção gasosa, método de BET, das partículas dos pós, utilizados como matérias-primas, $\mathrm{SiC}, \mathrm{Al}_{2} \mathrm{O}_{3}, \mathrm{Y}_{2} \mathrm{O}_{3}$, são apresentados na Tabela IV.2.

Tabela IV.2- Diâmetros a $10 \%\left(\Phi_{10}\right), 50 \%\left(\Phi_{50}\right)$ e $90 \%\left(\Phi_{90}\right)$ das matérias-primas utilizadas, $\mathrm{SiC}, \mathrm{Al}_{2} \mathrm{O}_{3}, \mathrm{Y}_{2} \mathrm{O}_{3}$, da mistura $\mathrm{SiC}: \mathrm{Al}_{2} \mathrm{O}_{3}: \mathrm{Y}_{2} \mathrm{O}_{3}$ por difração de laser, e as respectivas áreas de superficies específicas (S), obtidas pelo método de BET.

\begin{tabular}{|c|c|c|c|c|}
\hline Material & $\Phi_{10}(\mu \mathrm{m})$ & $\Phi_{50}(\mu \mathrm{m})$ & $\Phi_{90}(\mu \mathrm{m})$ & $\mathrm{S}\left(\mathrm{m}^{2} / \mathrm{g}\right)$ \\
\hline $\mathrm{SiC}$ & 0,11 & 0,39 & 0,88 & 16,7 \\
\hline $\mathrm{Al}_{2} \mathrm{O}_{3}$ & 0,11 & 0,64 & 1,88 & 9,0 \\
\hline $\mathrm{Y}_{2} \mathrm{O}_{3}$ & 0,18 & 0,70 & 3,99 & 15,1 \\
\hline $\mathrm{SiC}: \mathrm{Al}_{2} \mathrm{O}_{3}: \mathrm{Y}_{2} \mathrm{O}_{3}$ & 0,11 & 0,49 & 1,36 & - \\
\hline
\end{tabular}

Os diâmetros médios das partículas interferem diretamente na compactação e na sinterabilidade de sistemas particulados. Os diâmetros médios das partículas dos pós utilizados foram inferiores a $1 \mu \mathrm{m}$, inclusive para a mistura SiC: $\mathrm{Al}_{2} \mathrm{O}_{3}: \mathrm{Y}_{2} \mathrm{O}_{3}$. De forma geral, quanto menor o tamanho das partículas, menor a temperatura de sinterização necessária para se obter boa densificação do material. Segundo pesquisadores [39], em trabalho sobre prensagem a quente de nanopartículas de alumina, obteve-se $100 \%$ D.T. a $1100^{\circ} \mathrm{C}$ e $21 \mathrm{GPa}$ de dureza Vickers.

Na Figura IV.1 é mostrada a análise morfológica que foi feita por MEV, dos pós utilizados com matérias primas, $\mathrm{SiC}, \mathrm{Al}_{2} \mathrm{O}_{3}, \mathrm{Y}_{2} \mathrm{O}_{3}$ e mistura SiC: $\mathrm{Al}_{2} \mathrm{O}_{3}: \mathrm{Y}_{2} \mathrm{O}_{3}$.

Nota-se que todos os pós são finos e muitas partículas estão aglomeradas. As partículas de $\mathrm{SiC}$ e de $\mathrm{Al}_{2} \mathrm{O}_{3}$ são arredondadas e o pó de $\mathrm{Y}_{2} \mathrm{O}_{3}$ possui partículas mais alongadas. Estes pós foram observados como recebidos. Com certeza após moagem por atritor ficaram mais finos.

$\mathrm{Na}$ Figuras IV.2 são mostradas as micrografias das misturas do pós de $\mathrm{Al}_{2} \mathrm{O}_{3}$ com $10 \%$ dos polímeros PMHS, PMS e PPS, após secagem do material. 


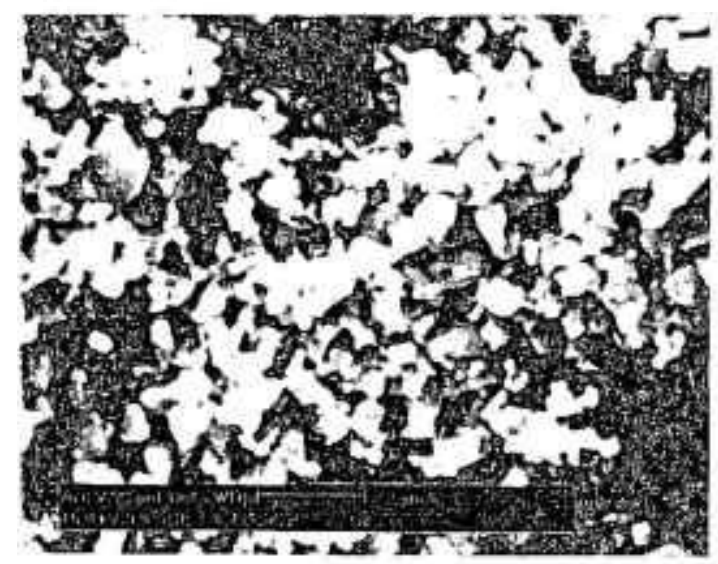

(a)

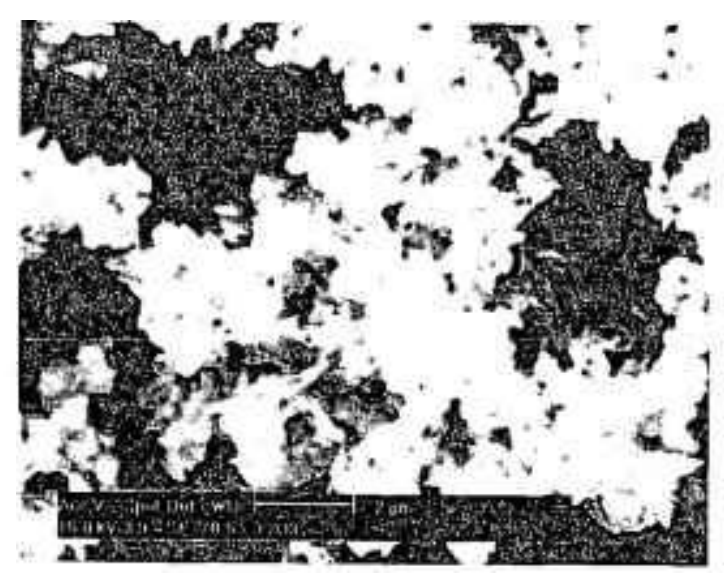

(c)

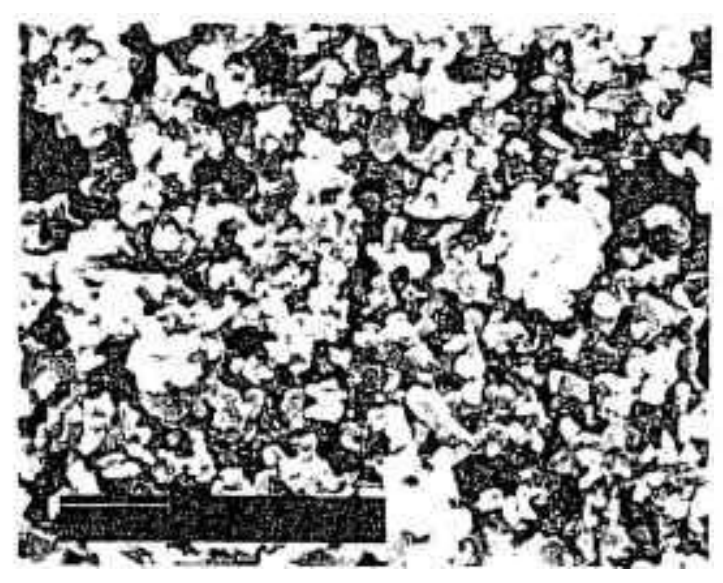

(b)

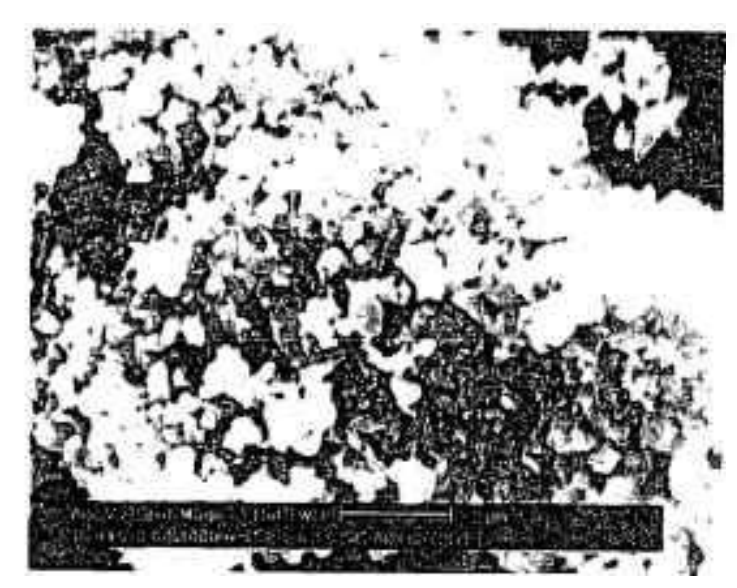

(d)

Figura IV.1- Micrografias de pós, utilizados como matéria-prima, obtidas por microscopia eletrônica de varredura: (a)- $\mathrm{SiC}$; (b)- $\mathrm{Al}_{2} \mathrm{O}_{3} ;$ (c)- $\mathrm{Y}_{2} \mathrm{O}_{3}$; (d) mistura $\mathrm{SiC}: \mathrm{Al}_{2} \mathrm{O}_{3}: \mathrm{Y}_{2} \mathrm{O}_{3}$. 


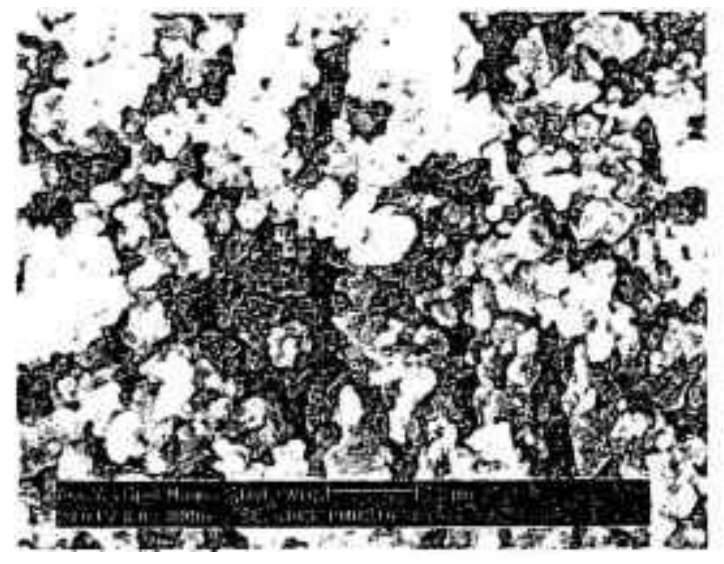

(a)

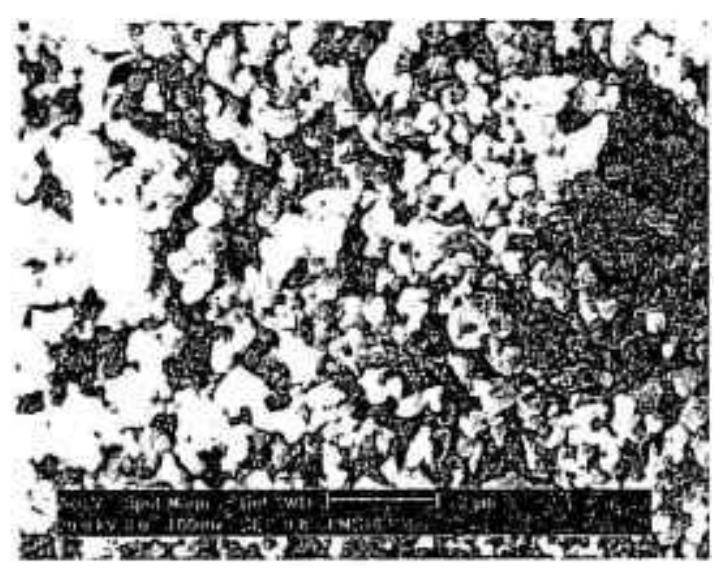

(b)

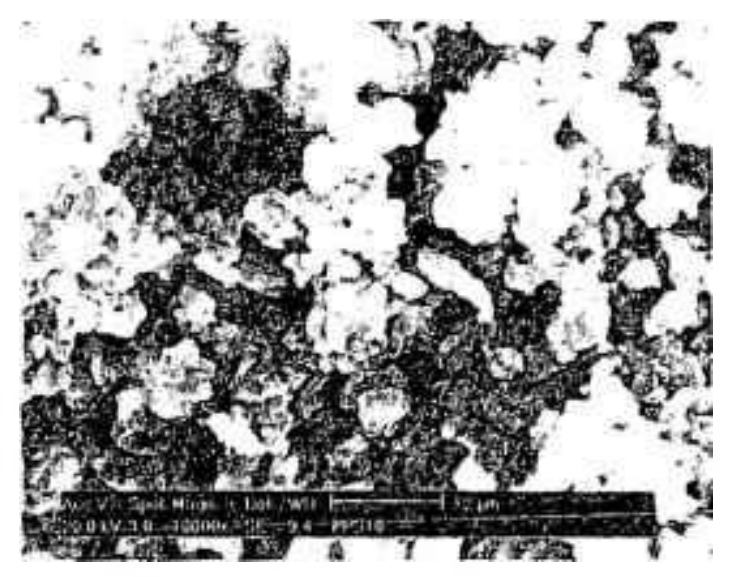

(c)

Figura IV.2- Micrografias de mistura de pós com polímeros, obtidas por microscopia eletrônica de varredura: (a)- mistura $\mathrm{Al}_{2} \mathrm{O}_{3}: 10 \%$ PMHS; (b)- mistura $\mathrm{Al}_{2} \mathrm{O}_{3}: 10 \%$ PMS; (c)- mistura $\mathrm{Al}_{2} \mathrm{O}_{3}: 10 \%$ PPS.

A análise morfológica do $\mathrm{Al}_{2} \mathrm{O}_{3}: 10 \%$ PMHS, $\mathrm{Al}_{2} \mathrm{O}_{3}: 10 \%$ PMS e $\mathrm{Al}_{2} \mathrm{O}_{3}: 10 \%$ PPS apresenta características semelhantes às partículas dos pós observados na Figura IV.1-(b), a não ser pelo fato que, com a adição de polímero, as mesmas encontram-se mais aglomeradas. 
Os difratogramas de raios $\mathrm{X}$ dos pós utilizados como matérias-primas, são mostrados na Figura IV.3.

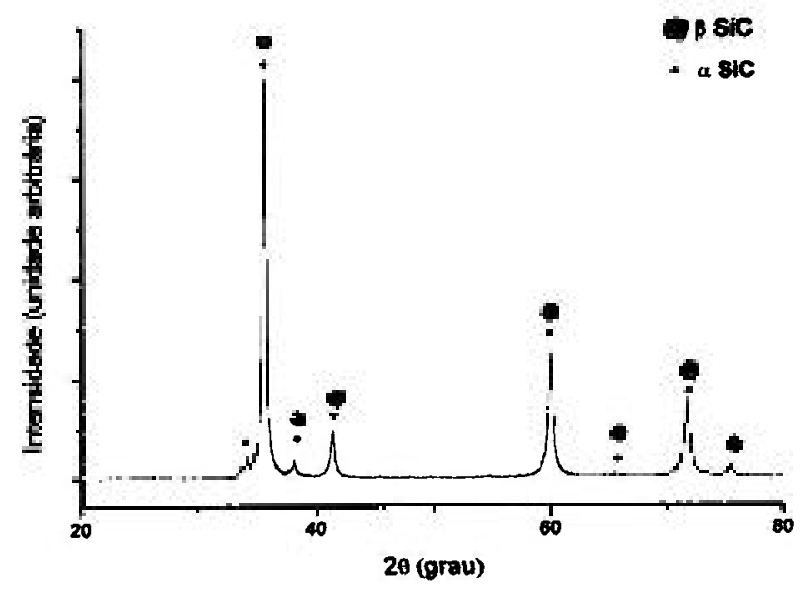

(a)

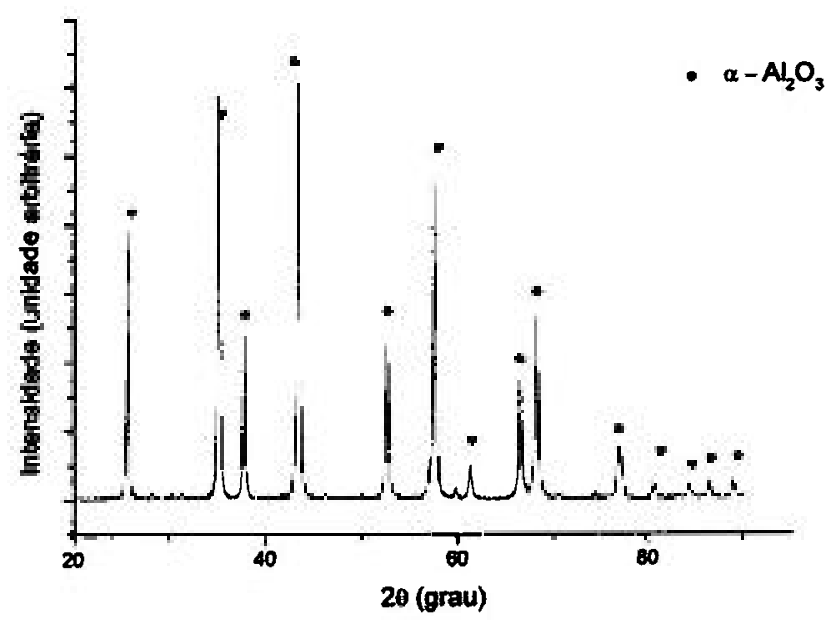

(b) 


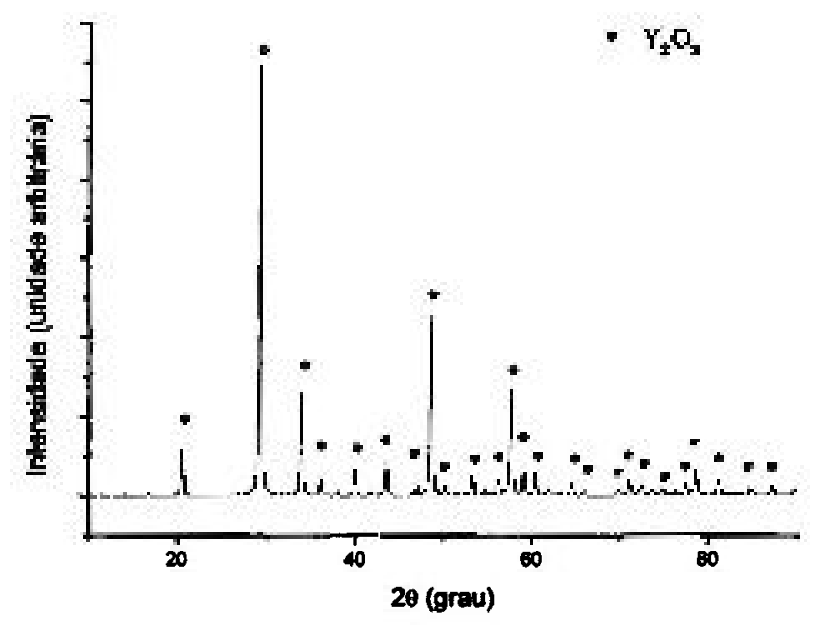

(c)

Figura IV.3- Difratogramas de raios $\mathrm{X}$ dos pós utilizados: (a)- $\mathrm{SiC}$; (b)- $\mathrm{Al}_{2} \mathrm{O}_{3}$; (c)- $\mathrm{Y}_{2} \mathrm{O}_{3}$.

Os difratogramas de raios $\mathrm{X}$ das matérias-primas, Figura IV.3, apresentam picos bem estreitos, indicando que os mesmos apresentam elevado grau de cristalinidade [101].

\section{IV.2 Caracterização dos polímeros}

Como a atmosfera interfere na degradação dos polímeros, foram feitos ensaios por termogravimetria (TG) em três atmosferas, nitrogênio, argônio ou ar sintético [102]. As curvas de perda de massa obtidas por TG dos polímeros PMS, PPS, PMHS: $\mathrm{D}_{4} \mathrm{~V}_{\mathrm{i}}$ e PMHS são mostradas nas Figuras IV.4, IV.5 e IV.6 e IV.7, respectivamente. 


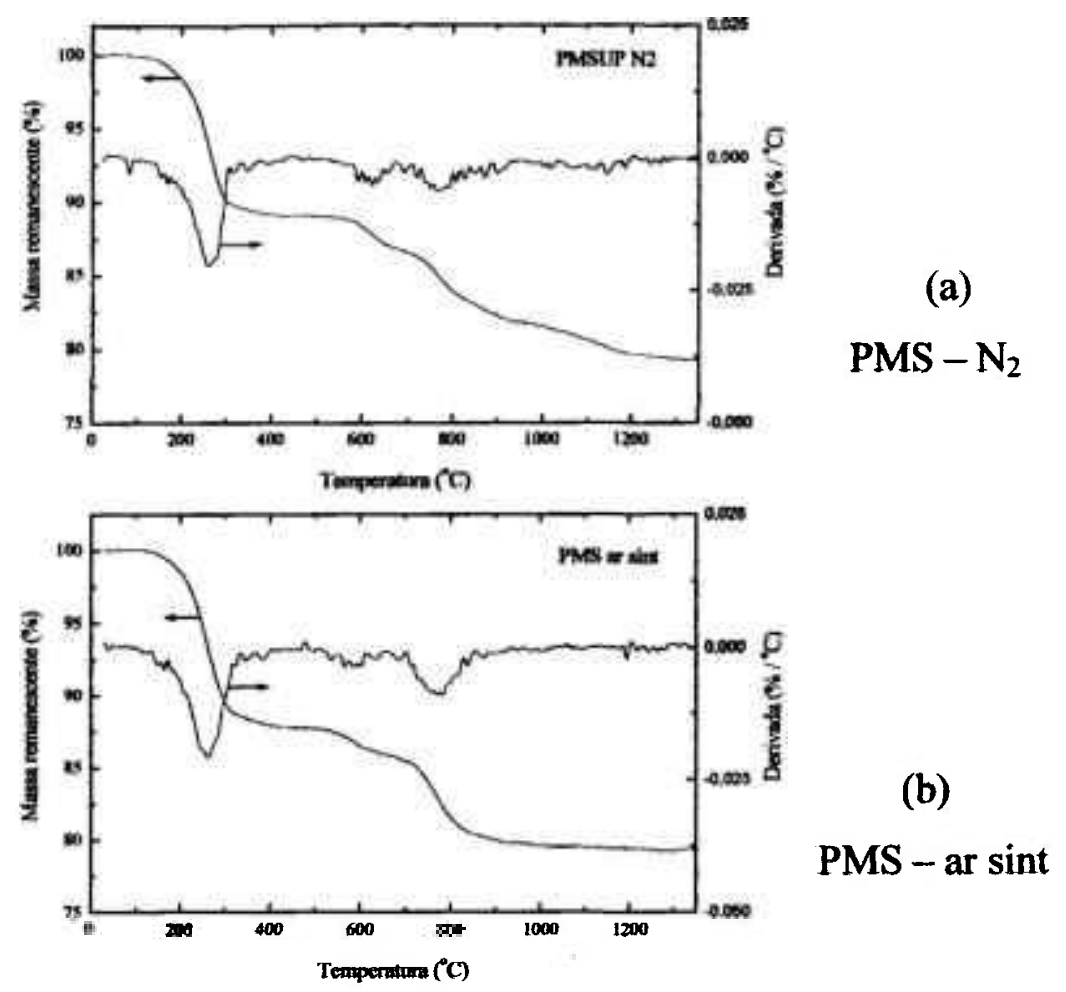

Figura IV.4- Curvas de TG e respectivas derivadas do polímero PMS, em: (a)- nitrogênio; (b)- ar sintético .

As curvas de TG do polímero PMS, Figura IV.4, em ar sintético e nitrogênio são semelhantes, com taxas de perda de massa maiores entre $120^{\circ} \mathrm{C}$ e $320^{\circ} \mathrm{C}$, provavelmente devido à perda de água e etanol, como produtos de reticulação [67]. Portanto, a atmosfera não interferiu nestas curvas.

Acima de aproximadamente $500^{\circ} \mathrm{C}$ o PMS começa a se decompor de acordo com a reação [104]:

$$
\left[\mathrm{CH}_{3} \mathrm{SiO}_{1,5}\right] \rightarrow \mathrm{Si}-\mathrm{O}-\mathrm{C}-\mathrm{H}_{\mathrm{ammorf}}+\mathrm{CH}_{4} \uparrow+\mathrm{H}_{2} \uparrow
$$

Segundo a literatura $[67,72,103]$, a perda de massa em nitrogênio está relacionada à perda de hidrogênio e metano, $\mathrm{CH}_{4}$, resultante da degradação do polímero, quebra de ligações e conseqüente "ceramização" do material. "Ceramização" na pirólise, corresponde à fase do processo na qual ocorre a conversão do material de estrutura polimérica para estrutura amorfa (com repetição da estrutura de curto alcance) ou cristalina (repetição da 
estrutura de longo alcance). $\mathrm{Na}$ TG com atmosfera de nitrogênio, a perda de massa foi acentuada, entre cerca de $600{ }^{\circ} \mathrm{C}$ e $1200{ }^{\circ} \mathrm{C}$, com massa remanescente de $79 \%$ e para o ar sintético, entre aproximadamente $750{ }^{\circ} \mathrm{C}$ e $830{ }^{\circ} \mathrm{C}$, foi mais acentuada e a massa remanescente a $1200{ }^{\circ} \mathrm{C}$ também foi de $79 \%$. Para o PMS as curvas termogravimétricas exibem várias etapas de perda de massa em temperaturas próximas, o processo de decomposição térmica e ceramização são similares independente da atmosfera e, além disso, a perda de massa total é a mesma.

Na Figura IV.5 são mostradas as curvas de TG do polímero PPS e respectivas derivadas, em nitrogênio e em ar sintético.
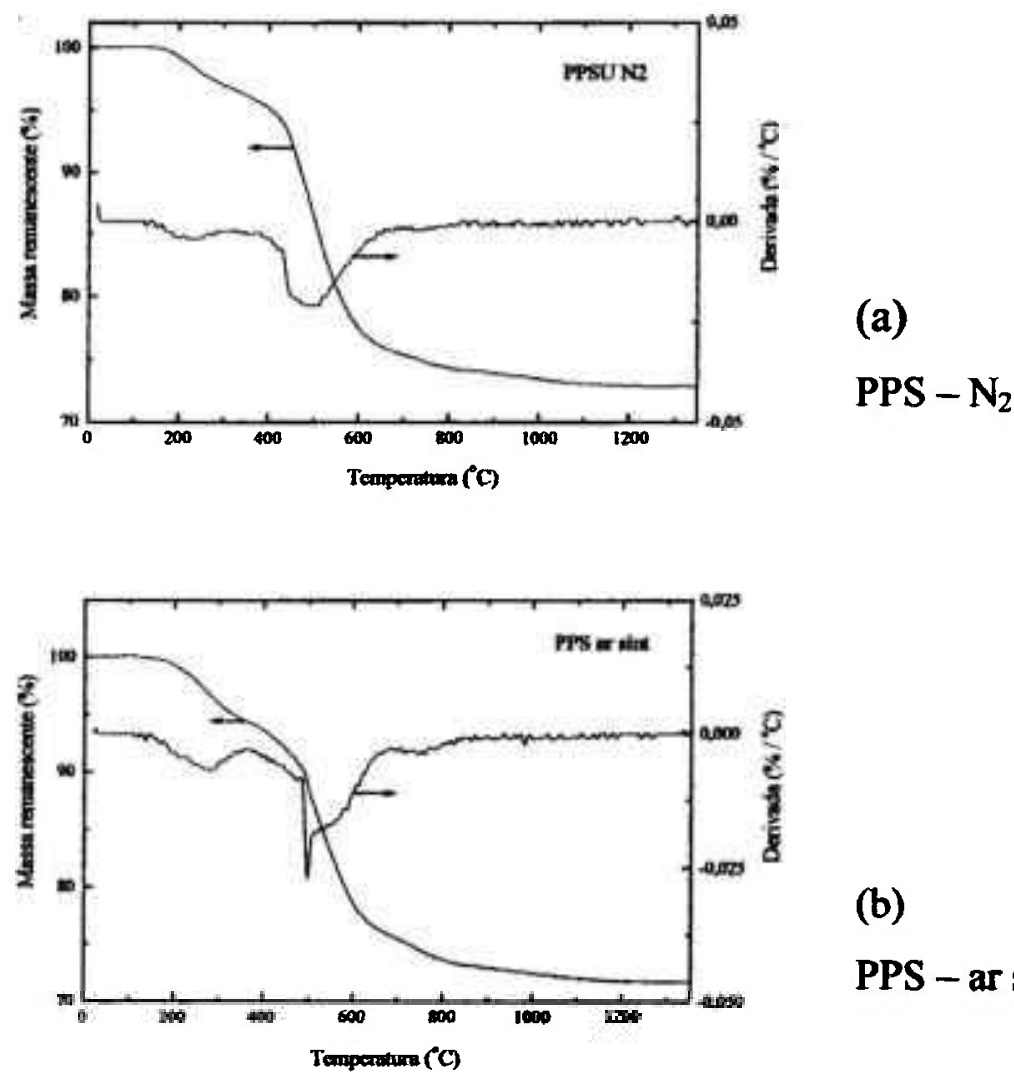

(b)

PPS - ar sint

Figura IV.5- Curvas de TG do polímero PPS e respectivas derivadas, em: (a)- nitrogênio; (b)- ar sintético. 
O polímero PPS, tanto sob atmosfera de nitrogênio quanto de ar sintético, entre $180^{\circ} \mathrm{C}$ e $400^{\circ} \mathrm{C}$ apresenta perda de massa pequena, porém entre $400^{\circ} \mathrm{C}$ e $800{ }^{\circ} \mathrm{C}$ há perda de massa acentuada, Figura IV.5. Neste intervalo de temperatura são quebradas as ligações Si- $\mathrm{C}_{6} \mathrm{H}_{5}$ com liberação de $\mathrm{C}_{6} \mathrm{H}_{6}$ [72]. Há também a liberação de $\mathrm{CH}_{4}$ e $\mathrm{H}_{2}$, com a "ceramizaçăo" do material. As massas remanescentes no caso de atmosfera de nitrogênio e do ar sintético foram $73 \%$ e $72 \%$, respectivamente. Também para o PPS pode-se dizer que as reações de decomposição térmica são semelhantes para as duas atmosferas utilizadas e as perdas de massa, muito próximas.

Na Figura IV.6 são mostradas as curvas de TG do polímero PMHS e respectivas derivadas, em nitrogênio, ar sintético e argônio.

Em relação ao polímero PMHS, Figura IV.6, em nitrogênio, houve perda de massa menor entre $200{ }^{\circ} \mathrm{C}$ e $300{ }^{\circ} \mathrm{C}$ que entre $300{ }^{\circ} \mathrm{C}$ e $500{ }^{\circ} \mathrm{C}$, ocorrendo a "ceramização" do polímero [19]. Há liberação de $\mathrm{CO}_{2}$ e $\mathrm{H}_{2} \mathrm{O}$ e à temperatura superior a 300 ${ }^{\circ} \mathrm{C}$, há quebra de ligação entre $\mathrm{Si}$ e $\mathrm{CH}_{3}$ [104,105]; a massa remanescente foi de aproximadamente $19 \%$. Já para o experimento realizado em ar sintético a perda de massa foi brusca entre cerca de $210^{\circ} \mathrm{C}$ e $470{ }^{\circ} \mathrm{C}$, e a massa remanescente foi bem inferior à primeira situação, 5\%. Em atmosfera de argônio, ocorreu perda de massa brusca entre aproximadamente $200^{\circ} \mathrm{C} \mathrm{e} 400^{\circ} \mathrm{C}$ e perda de massa pequena entre cerca de $400{ }^{\circ} \mathrm{C}$ e 500 ${ }^{\circ} \mathrm{C}$; a massa remanescente foi aproximadamente $18 \%$. Após cerca de $500{ }^{\circ} \mathrm{C}$ o material praticamente não apresentou mais perda de massa. 


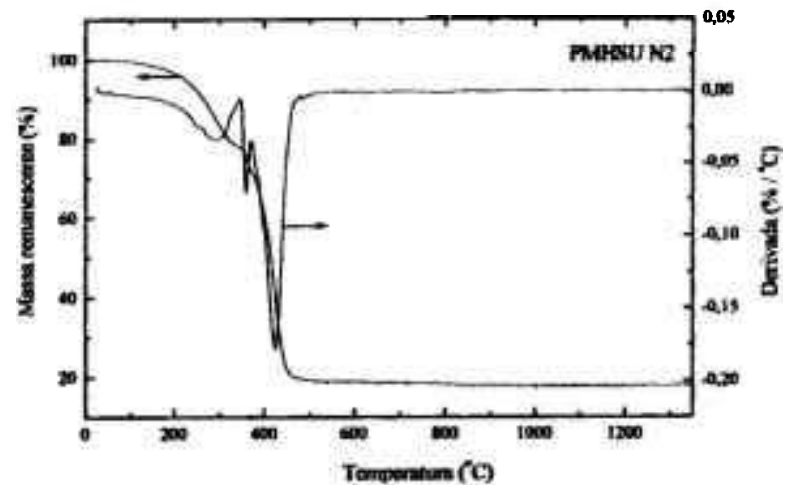

(a)

PMHS $-\mathbf{N}_{2}$

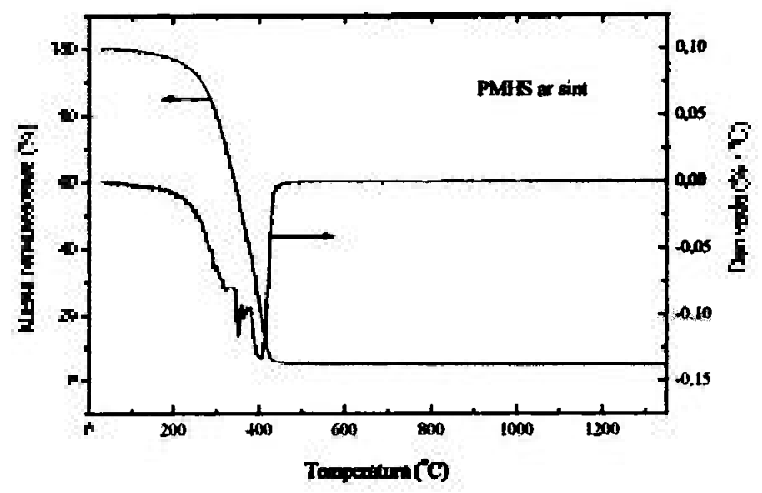

(b)

PMHS - ar sint

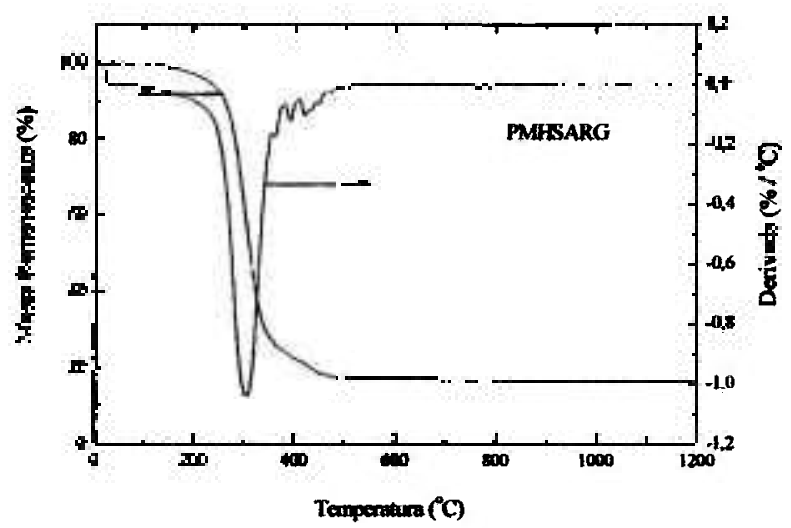

(c)

PMHS - Ar

Figura IV.6- Curvas de TG e respectivas derivadas do polímero PMHS, em: (a)- nitrogênio; (b)- ar sintético; (c)- argônio.

$\mathrm{Na}$ Figura IV.7 são mostradas as curvas de TG do polímero PMHS: $\mathrm{D}_{4} \mathrm{~V}_{\mathrm{i}}$ e respectivas derivadas em atmosfera de nitrogênio e de argônio. 


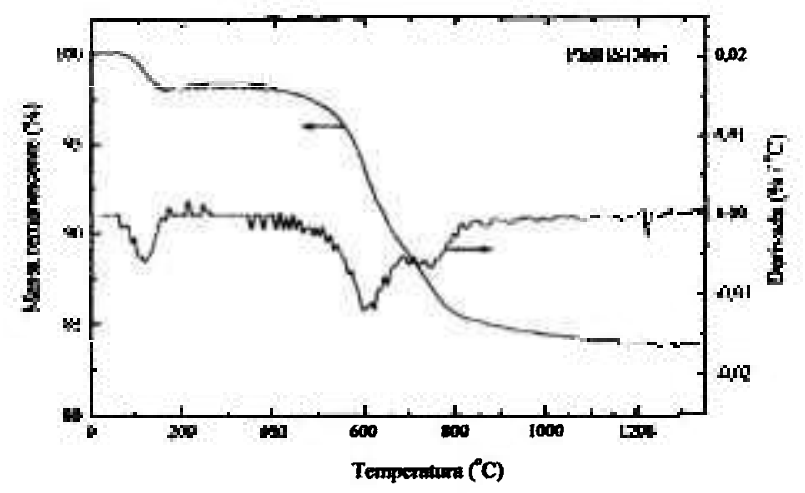

(a)

PMHS: $\mathrm{D}_{4} \mathrm{~V}_{\mathrm{i}}-\mathrm{N}_{2}$

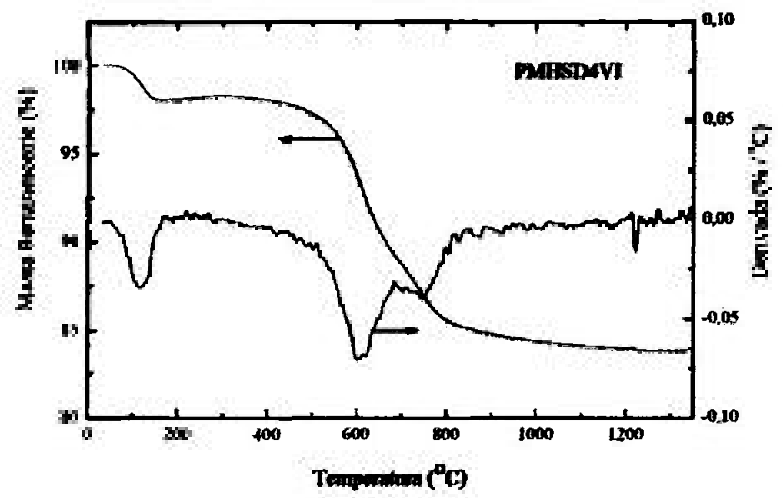

(b)

PMHS:D $\mathbf{D V}_{\mathbf{i}}-\mathbf{A r}$

Figura IV.7- Curvas de TG do polímero PMHS: $\mathrm{D}_{4} \mathrm{~V}_{\mathrm{i}}$ e as respectivas derivadas em diferentes atmosferas: (a)- nitrogênio; (b)- argônio.

As curvas de TG dos polímeros PMHS: $\mathrm{D}_{4} \mathrm{~V}_{\mathrm{i}}$ em nitrogênio e em argônio são muito semelhantes; ocorreram pequenas perdas de massa em aproximadamente $100{ }^{\circ} \mathrm{C}$, provavelmente água fisicamente adsorvida e proeminentes entre $500{ }^{\circ} \mathrm{C}$ e $700{ }^{\circ} \mathrm{C}$, correspondentes à liberação de voláteis orgânicos, como $\mathrm{CH}_{4}$ e $\mathrm{C}_{2} \mathrm{H}_{4}$. A partir de $700^{\circ} \mathrm{C}$ ocorreu o processo de ceramizacaao do material [103,106]. As massas remanescentes foram em torno de 83\%. Misturando-se PMHS e $\mathrm{D}_{4} \mathrm{~V}_{\mathrm{i}}$, proporção de 1:1, o rendimento cerâmico foi maior que considerando apenas PMHS, Figura IV.7.

$O$ início do processo de degradação térmica de polissiloxanos é devido, principalmente, a reações de degradação que ocorrem por meio de rearranjos inter e intracadeias, gerando estruturas voláteis [76].

Na Figura IV.8 são mostrados resultados das análises termogravimétricas dos polímeros utilizados em atmosfera de ar sintético e em nitrogênio. 


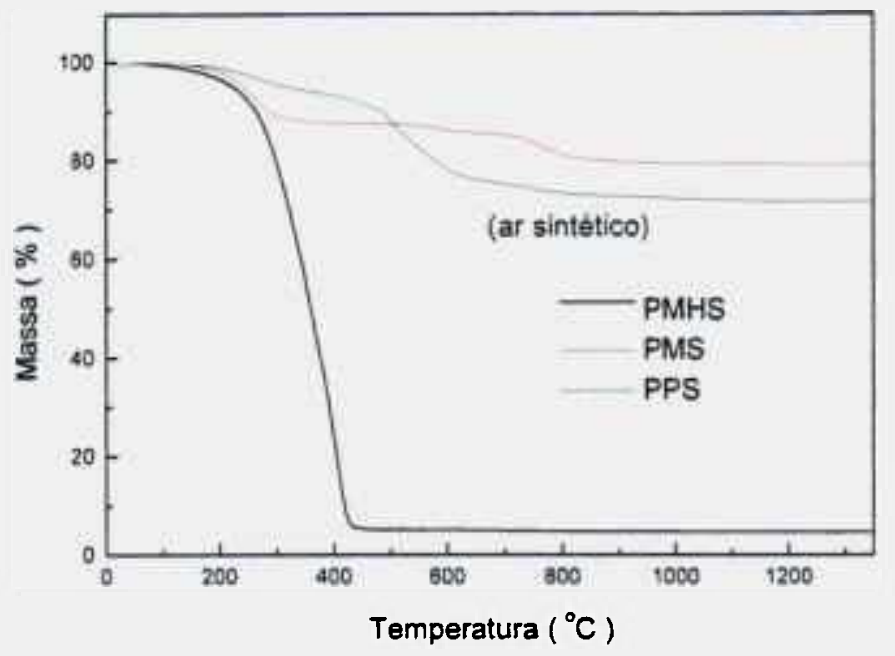

(a)

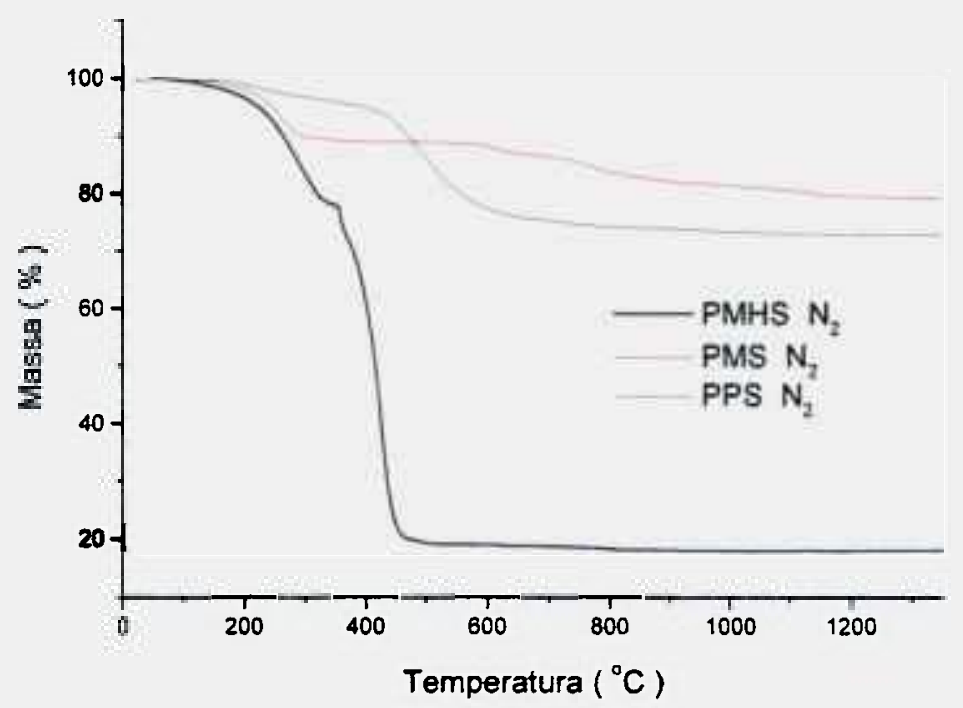

(b)

Figura IV.8 - Curvas de TG dos polímeros utilizados, PMHS, PMS e PPS, com taxa de aquecimento de $10{ }^{\circ} \mathrm{C} / \mathrm{min}$ realizadas em: (a)- atmosfera de ar sintético e (b)nitrogênio. 
Observando a Figura IV.8 (a) e (b) nota-se que o polímero PMHS apresentou perda de massa muito superior ao PMS e PPS. $O$ rendimento cerâmico foi de aproximadamente $5 \%$ para o PMHS, em atmosfera de ar sintético, e aproximadamente $19 \%$, em nitrogênio. $O$ PMS apresentou rendimento de aproximadamente 79\%, tanto em atmosfera de ar sintético, quanto em nitrogênio, e para o PPS o rendimento foi de aproximadamente $73 \%$ para as duas atmosferas utilizadas.

De maneira geral, não aconteceu perda de massa para PMHS após $600^{\circ} \mathrm{C}$, e para os polímeros PMS, PPS e PMHS: $\mathrm{D}_{4} \mathrm{~V}_{\mathrm{i}}$, após $900^{\circ} \mathrm{C}$ a perda de massa é muito pequena.

Os polissiloxanos, em geral, são estáveis em alto vácuo ou em atmosfera inerte entre $350^{\circ} \mathrm{C}$ a $400{ }^{\circ} \mathrm{C}$ [107]. A alta estabilidade térmica dos polissiloxanos é atribuida à alta energia e caráter iônico das ligaç̃es Si-O $(443,7 \mathrm{~kJ} / \mathrm{mol})$ em relação à ligacão de C-C $(345,7 \mathrm{~kJ} / \mathrm{mol})$ [107]. A degradação térmica dos polissiloxanos ocorre principalmente devido à quebra de ligaçð̌es do Si-O, que constituem sua cadeia principal [108].

\section{IV.3- Materiais a base de SiC}

No estudo do efeito da adição de precursores poliméricos à base de $\mathrm{SiC}$ foram utilizados dois materiais: PMHS e PMHS: $\mathrm{D}_{4} \mathrm{~V}_{\mathrm{i}}$.

\section{SiC: $\mathrm{Al}_{2} \mathrm{O}_{3}: \mathbf{Y}_{2} \mathbf{O}_{3}:$ PMHS}

Foram variadas: porcentagens de aditivos poliméricos adicionadas ( $1 \%$ e $5 \%$ ), temperatura de pirólise $\left(500{ }^{\circ} \mathrm{C}\right.$ e $\left.900^{\circ} \mathrm{C}\right)$ e temperatura de sinterização $\left(1850{ }^{\circ} \mathrm{C}\right.$ e $1950^{\circ} \mathrm{C}$ ). Foram calculadas as densidades aparentes pelo método de Arquimedes após sinterizaçăo e as perdas de massa após pirólise e após sinterização. Os resultados estão apresentados na Tabela IV.3. 
Tabela IV.3- Densidade aparente, perdas de massa após pirólise e sinterização das amostras sem polímero, com $1 \%$ e 5\% de PMHS, pirolisadas em atmosfera de argônio a $500^{\circ} \mathrm{C}$ ou $900{ }^{\circ} \mathrm{C}$ e sinterizadas em atmosfera de argônio a $1850^{\circ} \mathrm{C}$ ou $1950^{\circ} \mathrm{C}$.

\begin{tabular}{|c|c|c|c|c|c|c|}
\hline Amostras & $\begin{array}{c}\rho_{\text {a verde }} \\
\left(\mathrm{g} / \mathrm{cm}^{3}\right)\end{array}$ & $\begin{array}{c}\rho_{\text {mpmctu }} \\
\left(\mathrm{g} / \mathrm{cm}^{3}\right)\end{array}$ & $\begin{array}{c}\text { PM } \\
\mathrm{B} \rightarrow \mathrm{A} \\
(\%)\end{array}$ & $\begin{array}{c}\text { PM } \\
\mathrm{C} \rightarrow \mathrm{B} \\
(\%)\end{array}$ & $\begin{array}{c}\mathrm{PM} \\
\mathrm{C} \rightarrow \mathrm{A} \\
(\%)\end{array}$ & $\begin{array}{c}\text { PMP } \\
(\%)\end{array}$ \\
\hline SAY0-1850A & 1,49 & 2,4 & - & - & 6,0 & - \\
\hline SAY0-1950A & 1,57 & 3,1 & - & - & 8,0 & - \\
\hline SAY1H-5A-1850A & 1,57 & 2,4 & 1,8 & 6,6 & 8,4 & 6,8 \\
\hline SAY1H-5A-1950A & 1,56 & 3,0 & 1,2 & 8,8 & 10,0 & 8,7 \\
\hline SAY1H-9A-1850A & 1,52 & 2,4 & 1,4 & 7,3 & 8,7 & 6,8 \\
\hline SAY1H-9A-1950A & 1,56 & 3,0 & 1,3 & 8,5 & 9,8 & 8,7 \\
\hline SAY5H-5A-1850A & 1,78 & 2,4 & 2,2 & 8,2 & 10,4 & 9,8 \\
\hline SAY5H-5A-1950A & 1,83 & 3,1 & 2,2 & 10,8 & 13,0 & 11,7 \\
\hline SAY5H-9A-1850A & 1,82 & 2,4 & 2,1 & 7,4 & 9,5 & 9,8 \\
\hline SAY5H-9A-1950A & 2,01 & 2,9 & 4,4 & 11,3 & 15,7 & 11,7 \\
\hline
\end{tabular}

$\mathbf{A} \rightarrow$ massa antes da pirólise $\quad \mathbf{B} \rightarrow$ massa após pirólise $\quad \mathbf{C} \rightarrow$ massa após sinterização $\mathrm{PM} \rightarrow$ perda de massa

PMP $\rightarrow$ perda de massa prevista

$\mathbf{B} \rightarrow \mathbf{A}$ - perda de massa após pirólise

C $\rightarrow B$ - perda de massa parcial entre pirólise e sinterizaçåo

$\mathbf{C} \rightarrow \mathbf{A}$ - perda de massa total

A amostra SAY5H-9A-1950A apresentou dados discrepantes, principalmente em relação à perda de massa após pirólise, devido ao fato de ter laminado. $O$ valor de densidade aparente do material sinterizado, Tabela III.3, foi $2,4 \mathrm{~g} / \mathrm{cm}^{3}$ para os materiais sinterizados a $1850^{\circ} \mathrm{C}$ e aproximadamente $3,0 \mathrm{~g} / \mathrm{cm}^{3}$ para os corpos-de-prova sinterizados a $1950^{\circ} \mathrm{C}$. As densidades relativas das amostras (\% DT) não foram calculadas, pois não foi possível determinar as porcentagens das fases presentes. Segundo vários pesquisadores [19] para que haja boa densificação de cerâmicas à base de $\mathrm{SiC}$ a temperatura mais adequada é aproximadamente $1950^{\circ} \mathrm{C}$ e dependem dos aditivos utilizados. A temperatura 
de sinterização de $1850^{\circ} \mathrm{C}$ foi baixa para que houvesse boa densificação. A adição da fase polimérica, tanto de $1 \%$ quanto de $5 \%$ praticamente não alterou a densidade para as duas temperaturas utilizadas. As amostras sinterizadas a $1850^{\circ} \mathrm{C}$ apresentaram perda de massa inferior às sinterizadas à $1950^{\circ} \mathrm{C}$. $\mathrm{O}$ aumento da perda de massa das amostras contendo polímeros, em relação às amostras padrões foi expressivo, e é dependente da quantidade de polímero adicionado.

Pode ter formado fases devido a reação entre $\mathrm{SiC}, \mathrm{Al}_{2} \mathrm{O}_{3}$ e $\mathrm{Y}_{2} \mathrm{O}_{3}$ e fases do aditivo de polímero precursor cerâmico e ter ocorrido volatilização das mesmas. Isto indica que o polímero deve ter volatilizado, provavelmente "carregando" outros materiais, já que a diferença de perda de massa é maior que a quantidade de polímero adicionado. $\mathrm{Na}$ análise termogravimétrica do polímero PMHS, em atmosfera de argônio, a massa remanescente foi aproximadamente $19 \%$ para tratamentos térmicos até $1000^{\circ} \mathrm{C}$.

Negita [108] sugeriu, baseado em dados termodinâmicos, que um número limitado de óxidos não provocam a decomposição do SiC durante a sinterização, já que os dados obtidos por Omori [21] foram empíricos. $\mathrm{Al}_{2} \mathrm{O}_{3}, \mathrm{Y}_{2} \mathrm{O}_{3}$, e outras terras raras são aditivos efetivos para sinterização de SiC. Negita [108] se baseou na análise da reatividade do SiC com vários compostos, da mesma forma que havia sido feito por ele para $\mathrm{Si}_{3} \mathrm{~N}_{4}$. Estes resultados, para óxidos metálicos, são apresentados na Figura IV.9. Entretanto, a presenfa de $\mathrm{SiO}_{2}$ na forma de óxido superficial nas partículas de pó de $\mathrm{SiC}$ pode prejudicar a performance deste material [26]. Segundo vários pesquisadores $[98,109]$ a quantidade de aditivos mais apropriada para materiais à base de $\mathrm{SiC}$ é aproximadamente $10 \%$ em peso.

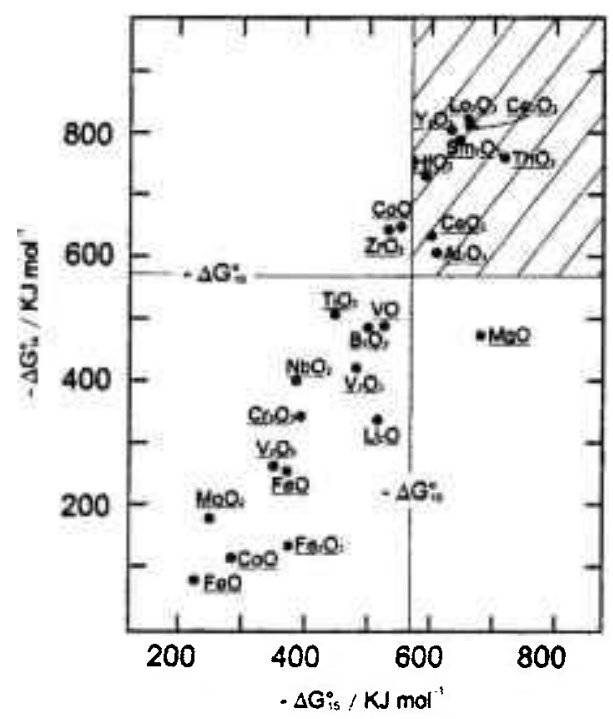

Figura IV.9- Óxidos metálicos efetivos como aditivos de sinterização do SiC [109]. 
Difratogramas das amostras sinterizadas a $1850^{\circ} \mathrm{C}$ e a $1950^{\circ} \mathrm{C}$ são mostrados nas Figuras IV.10 (a) e (b), respectivamente.

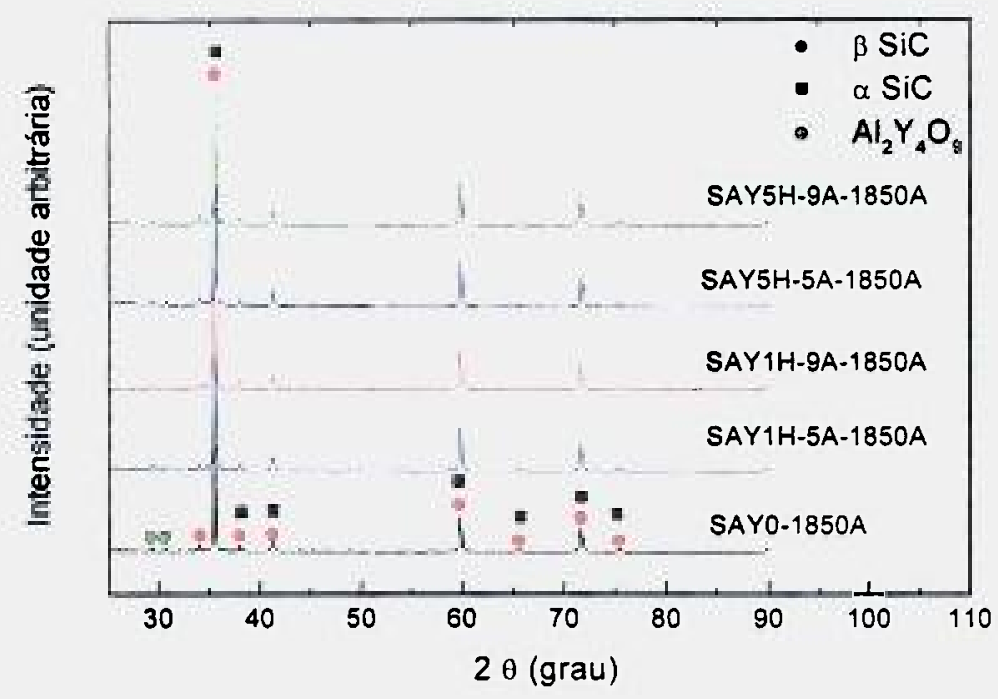

(a)

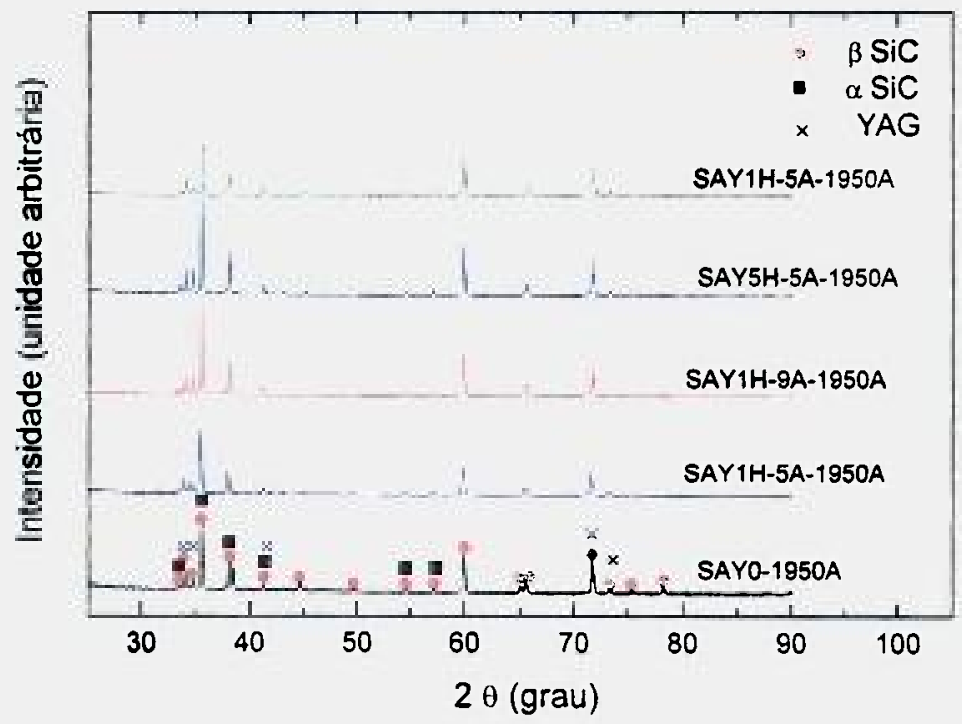

(b)

Figura IV.10- Difratogramas das amostras SAY com aditivo polimérico PMHS, pirolisadas e sinterizadas em atmosfera de argônio: (a) $1850^{\circ} \mathrm{C}$; (b) $1950^{\circ} \mathrm{C}$. 
Embora a identificação de politipos de $\mathrm{SiC}$ seja complexa devido à superposição dos picos de difração, foi constatada a presença de diversos politipos de SiC. Estes politipos indicam que as amostras $\mathrm{SiC}: \mathrm{Al}_{2} \mathrm{O}_{3}: \mathrm{Y}_{2} \mathrm{O}_{3}$ com PMHS possuem $\alpha$-SiC e $\beta$-SiC. Fases secundárias cristalinas foram observadas, como aluminato de ítrio, $\mathrm{Al}_{2} \mathrm{Y}_{4} \mathrm{O}_{9}$, nas amostras sinterizadas a $1850{ }^{\circ} \mathrm{C}$ e $\mathrm{YAG}, \mathrm{Al}_{5} \mathrm{Y}_{3} \mathrm{O}_{12}$, nas sinterizadas a $1950{ }^{\circ} \mathrm{C}$. Dependendo da composição e da temperatura de tratamento térmico utilizados, fatores que afetam a viscosidade da fase líquida formada, tem-se a cristalização de diferentes fases. Não houve diferença nos difratogramas de raios X da Figura IV.10 (a) e (b) para amostras com adição de polímero e sem adição do mesmo e a principal fase formada foi SiC.

A microestrutura das amostras sinterizadas a $18500^{\circ} \mathrm{C}$ e a $1950{ }^{\circ} \mathrm{C}$ pode ser observada nas micrografias obtidas por microscopia eletrônica de varredura, Figura IV.11.

Como as amostras sinterizadas a $1850^{\circ} \mathrm{C}$ não apresentam densidades altas, o polimento foi insatisfatório. Pode-se observar nas Figuras IV.11 (a), (c) e (e), que a distribuição do aditivo à base de ítrio (regiões mais claras) não é homogênea; apenas algumas pequenas regiões foram densificadas.

As amostras sinterizadas a $1950{ }^{\circ} \mathrm{C}$, Figuras IV.11 (b), (d) e (f), possuem microestruturas relativamente homogêneas, poros intergranulares $\mathrm{e}$ fase secundária distribuída entre os grãos de $\mathrm{SiC}$. Nota-se a presença de alguns grãos alongados, identificados nas micrografias (b) e (d).

Para analisar as perdas de massa, que são muito elevadas, foram realizados alguns experimentos, com amostras $\mathrm{SiC}: \mathrm{Y}_{2} \mathrm{O}_{3}: \mathrm{Al}_{2} \mathrm{O}_{3}$ tendo como aditivo o polímero PMHS, modificando as atmosferas do processo de pirólise e de sinterização. Anteriormente as amostras foram pirolisadas e sinterizadas em argônio e posteriormente a pirólise foi realizada em atmosfera de nitrogênio ou argônio e a sinterização em atmosfera positiva de nitrogênio. As densidades aparentes foram obtidas por picnometria de He. 


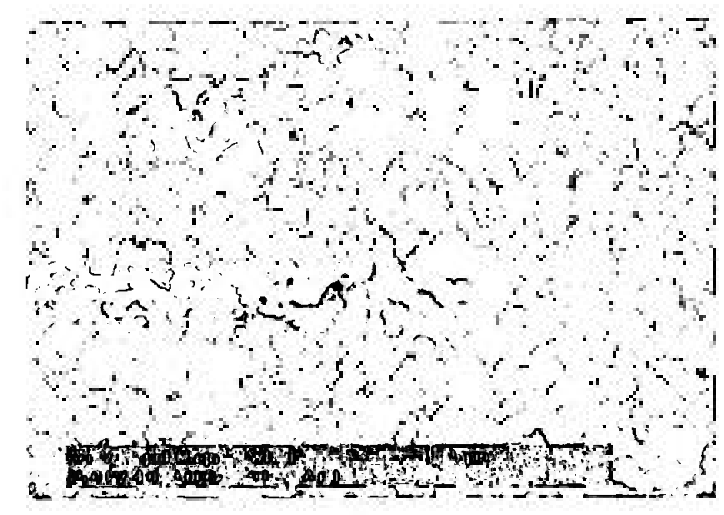

(a)

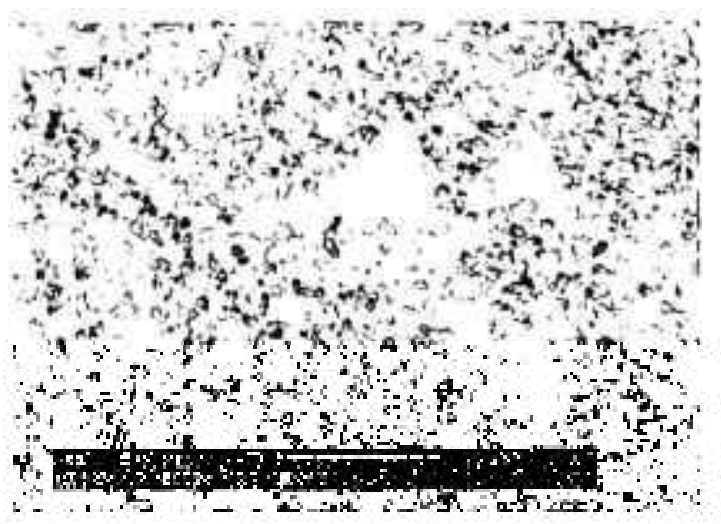

(c)

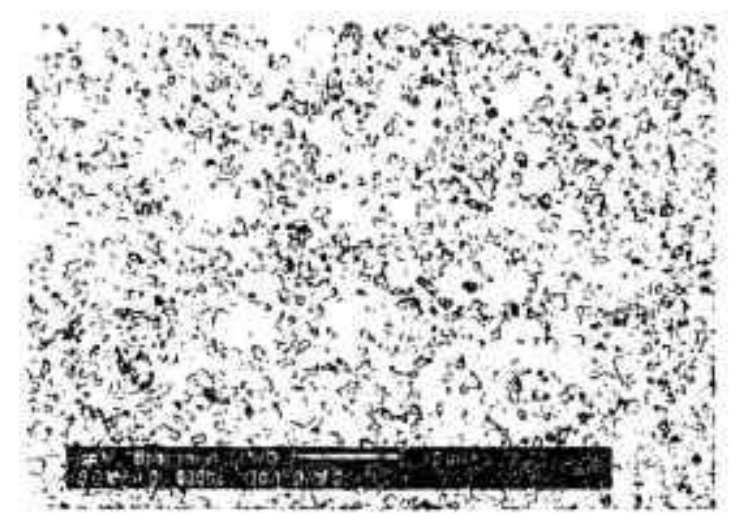

(e)

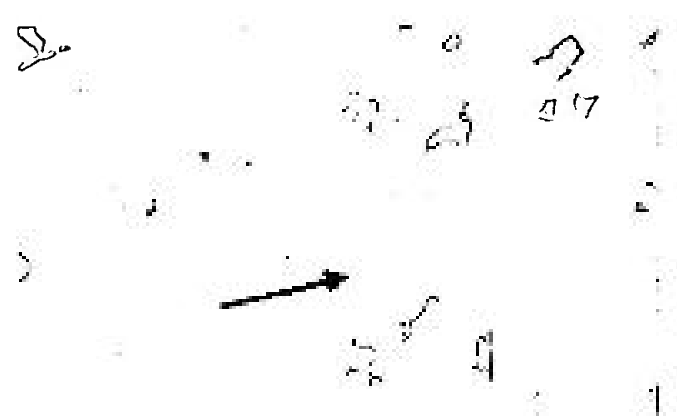

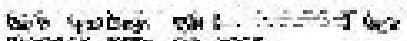

(b)

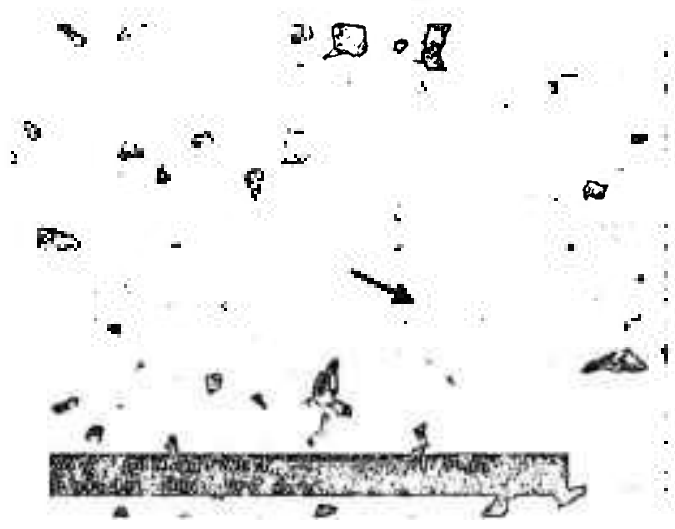

(d)

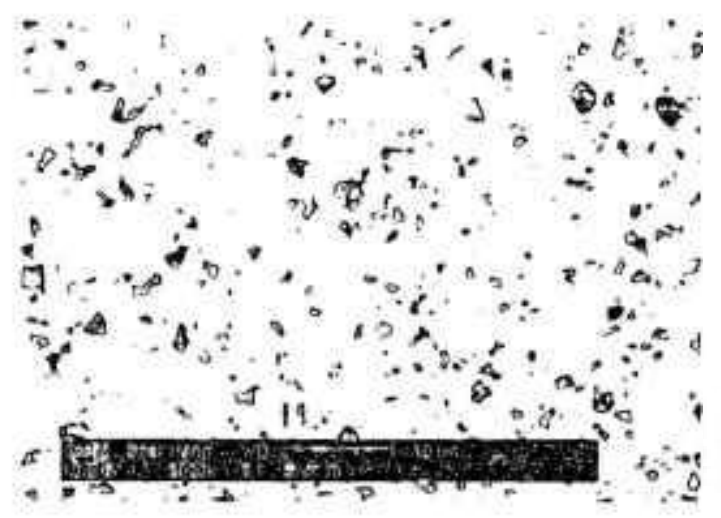

(f)

Figura IV.11- Micrografias de superficies polidas observadas em microscópio eletrônico de varredura: (a)-Amostra SAY0-1850A (padrão), (b)- Amostra SAY0-1950A (padrão), (c)Amostra SAY1H-9A-1850A, (d)- Amostra SAY1H-5A-1950A, (e)- Amostra SAY5H-9A1850A e (f)- Amostra SAY5H-9A-1950A. 
Os valores de perda de massa, em cada etapa, e de densidade após sinterização são apresentados na Tabela IV.4. Foram calculadas as perdas de massa previstas a partir dos dados experimentais obtidos com a amostra padrão SAY0-1950N e análise termogravimétrica até $1350^{\circ} \mathrm{C}$, nas diferentes atmosferas.

Tabela IV.4- Densidades aparentes obtidas por picnometria de He de amostras de $\mathrm{SiC}: \mathrm{Y}_{2} \mathrm{O}_{3}: \mathrm{Al}_{2} \mathrm{O}_{3}$ com PMHS, perdas de massa de amostras pirolisadas a $900{ }^{\circ} \mathrm{C}$ em nitrogênio ou argônio e sinterizadas a $1950^{\circ} \mathrm{C}$ em nitrogênio e perdas de massa previstas.

\begin{tabular}{|c|c|c|c|c|c|}
\hline Amostra & $\begin{array}{c}P_{\text {mirac }} \\
\left(\mathrm{g}^{3} \mathrm{~cm}^{3}\right)\end{array}$ & $\begin{array}{c}\text { PM } \\
\mathrm{B} \rightarrow \mathrm{A} \\
(\%)\end{array}$ & $\begin{array}{c}\mathrm{PM} \\
\mathrm{C} \rightarrow \mathrm{B} \\
(\%)\end{array}$ & $\begin{array}{c}\mathrm{PM} \\
\mathrm{C} \rightarrow \mathrm{A} \\
(\%)\end{array}$ & $\begin{array}{c}\text { PMP } \\
(\%)\end{array}$ \\
\hline SAY0-1950N & $3,01 \pm 0,01$ & - & - & 5,8 & - \\
\hline SAY1H-9N-1950N & $3,11 \pm 0,01$ & 0,7 & 6,3 & 6,9 & 6,5 \\
\hline SAY5H-9N-1950N & $3,15 \pm 0,01$ & 1,4 & 11,9 & 13,2 & 9,6 \\
\hline SAY10H-9N-1950N & $3,09 \pm 0,01$ & 5,0 & 18,3 & 23,3 & 13,3 \\
\hline SAY1H-9A-1950N & $3,03 \pm 0,01$ & 0,8 & 9,0 & 9,8 & 6,5 \\
\hline SAY5H-9A-1950N & $2,93 \pm 0,01$ & 1,2 & 15,6 & 16,8 & 9,6 \\
\hline SAY10H-9A-1950N & $2,64 \pm 0,01$ & 4,6 & 31,3 & 35,9 & 13,4 \\
\hline
\end{tabular}

$\mathbf{A} \rightarrow$ antes da pirólise $\quad \mathbf{B} \rightarrow$ após pirólise $\quad \mathbf{C} \rightarrow$ após sinterização

As densidades das amostras pirolisadas em nitrogênio, $1 \%$ a $10 \%$ de PMHS, foram maiores do que as obtidas por pirólise em argônio, com a mesma quantidade de polímero precursor. As amostras pirolisadas em nitrogênio apresentaram densidades superiores à amostra padrão, inclusive a que possui apenas $1 \%$ de PMHS.

A perda de massa em amostras pirolisadas em atmosfera de argônio foi superior à pirolisada em de nitrogênio, embora para as duas atmosferas tenham sido muito elevadas. A perda de massa foi sempre superior à perda de massa prevista e quanto maior a quantidade de PMHS adicionada, maior a perda de massa.

Embora tenha sido utilizado cadinho fechado e cama protetora para minimizar a perda de massa nos processos de sinterização realizados com $\mathrm{SiC}: \mathrm{Al}_{2} \mathrm{O}_{3}: \mathrm{Y}_{2} \mathrm{O}_{3}$, a perda de massa foi muito alta. Existe a possibilidade dos aditivos poliméricos não estarem mais 
presentes no material após os tratamentos térmicos. As amostras pirolisadas e sinterizadas em nitrogênio apresentaram densidades aparentes mais elevadas e menor perda de massa.

Grande et alii [110], estudaram perda de massa por termogravimetria em amostras de $\mathrm{SiC}$ contendo composição eutética de $7,5 \%$ em peso de $\mathrm{Al}_{2} \mathrm{O}_{3}: \mathrm{Y}_{2} \mathrm{O}_{3}$, para promover sinterização via fase líquida, em atmosfera de argônio. Foi utilizada cama de SiC, em cadinho de grafite aberto, acoplado a uma termobalanca. A perda de massa do SiC sem aditivos foi de $1,4 \%$ em peso, em tratamento térmico a $1870^{\circ} \mathrm{C}$, por $1 \mathrm{~h}$. Em amostras com $7,5 \%$ em peso de $\mathrm{Al}_{2} \mathrm{O}_{3}: \mathrm{Y}_{2} \mathrm{O}_{3}$, sinterizadas a $1920{ }^{\circ} \mathrm{C}$ por $1 \mathrm{~h}$, obteve-se $11 \%$ de perda de massa e densidade de $2,80 \mathrm{~g} / \mathrm{cm}^{3}$ [110].

Segundo os estudos realizados por Grande e colaboradores [110], as reações mais prováveis envolvendo a volatilização de materiais são:

$$
\mathrm{SiC}(\mathrm{s})+2 \mathrm{SiO}_{2}(\mathrm{l}) \leftrightarrow 3 \mathrm{SiO}(\mathrm{g})+\mathrm{CO}(\mathrm{g})
$$

A perda de massa inicial ocorre devido à interação da camada presente na forma de óxidos superficiais nas partículas de SiC. De acordo com dados termodinâmicos esta reacão tem início entre $1300^{\circ} \mathrm{C}$ e $1400^{\circ} \mathrm{C}$. Para temperaturas superiores a $1700^{\circ} \mathrm{C}$ a interação entre $\mathrm{SiC}$ e $\mathrm{Al}_{2} \mathrm{O}_{3}$ ocorre de acordo com a reaça (IV.3):

$$
\mathrm{SiC}(\mathrm{s})+\mathrm{Al}_{2} \mathrm{O}_{3}(\mathrm{~s}) \leftrightarrow \mathrm{Al}_{2} \mathrm{O}(\mathrm{g})+\mathrm{SiO}(\mathrm{g})+\mathrm{CO}(\mathrm{g})
$$

assumindo que praticamente todas as impurezas de oxigênio do SiC tenham sido removidas na reação (IV.3).

$\mathrm{A}$ interação de $\mathrm{SiC}$ e $\mathrm{Y}_{2} \mathrm{O}_{3}$ é considerada viável de acordo com a reaçăo (IV.4), embora faltem dados termodinâmicos para que possa ser avaliada.

$$
\mathrm{SiC}(\mathrm{s})+\mathrm{Y}_{2} \mathrm{O}_{3}(\mathrm{~s}) \leftrightarrow \mathrm{Y}_{2} \mathrm{O}(\mathrm{g})+\mathrm{SiO}(\mathrm{g})+\mathrm{CO}(\mathrm{g})
$$

Segundo Mitra e colaboradores [111] a perda de massa durante o tratamento térmico de $\mathrm{SiC}$ com adiç̋es de $\mathrm{Al}_{2} \mathrm{O}_{3}$ e $\mathrm{Y}_{2} \mathrm{O}_{3}$ também pode ser explicada devido à perda de massa do YAG e outros aluminatos de ítrio, via sublimagão a partir do estado sólido ou evaporação do $\mathrm{Al}$ fundido contendo gases à temperatura superior a $1850^{\circ} \mathrm{C}$. 
Além disso, pode ocorrer oxidação do $\mathrm{SiC}$ por $\mathrm{CO}(\mathrm{g})$, que prevalece à altas temperaturas, de acordo com a reação (IV.5) [111]:

$$
\mathrm{CO}(\mathrm{g})+\mathrm{SiC}(\mathrm{s}) \leftrightarrow 2 \mathrm{C}(\mathrm{s})+\mathrm{SiO}(\mathrm{g})
$$

A formação de $\mathrm{CO}(\mathrm{g})$ e o aumento da pressão parcial durante o tratamento térmico ocorre devido a interação de produtos voláteis com o grafite do forno de acordo com as reações (IV.6) e (IV.7):

$$
\begin{aligned}
& \mathrm{SiO}(\mathrm{g})+2 \mathrm{C}(\mathrm{s}) \leftrightarrow \mathrm{SiC}(\mathrm{s})+\mathrm{CO}(\mathrm{g}) \\
& 2 \mathrm{Al}_{2} \mathrm{O}(\mathrm{g})+3 \mathrm{C}(\mathrm{s}) \leftrightarrow \mathrm{Al}_{4} \mathrm{C}(\mathrm{s})+2 \mathrm{CO}(\mathrm{g})
\end{aligned}
$$

Baud et al. [112] estudaram a perda de massa de $\mathrm{SiC}$ com aditivos óxidos, $\mathrm{Al}_{2} \mathrm{O}_{3}$ e $\mathrm{Y}_{2} \mathrm{O}_{3}$, utilizando dados termodinâmicos, no intervalo de temperatura de $1200 \mathrm{~K}$ a $2200 \mathrm{~K}$, em sistema aberto. De acordo com este estudo as principais espécies gasosas são $\mathrm{Al}(\mathrm{g})$, $\mathrm{Al}_{2} \mathrm{O}(\mathrm{g}), \mathrm{SiO}(\mathrm{g})$ e $\mathrm{CO}(\mathrm{g})$, segundo a reação (IV.8):

$$
2 \mathrm{SiC}(\mathrm{s})+\mathrm{Al}_{2} \mathrm{O}_{3}(\mathrm{~s})+\mathrm{Al}_{2} \mathrm{O}(\mathrm{g}) \leftrightarrow 2 \mathrm{SiO}(\mathrm{g})+2 \mathrm{CO}(\mathrm{g})+4 \mathrm{Al}(\mathrm{g})
$$

Além disso, pode formar em pouca quantidade $\mathrm{Y}(\mathrm{g})$ e $\mathrm{YO}(\mathrm{g})$. Considerando o cadinho de grafite, a pressão parcial de $\mathrm{CO}(\mathrm{g})$ aumenta podendo formar fases como aluminatos, $\mathrm{Al}_{4} \mathrm{O}_{4} \mathrm{C}, \mathrm{Al}_{4} \mathrm{SiC}_{4}$ ou $\mathrm{Al}_{2} \mathrm{OC}$.

A mistura de polimeros inorgânicos, PMHS: $\mathrm{D}_{\mathbf{4}} \mathrm{V}_{\mathrm{i}}$, pode ser usada como precursor cerâmico na formação de vidro de oxicarbeto de silício, em atmosfera de argônio [76]. Decidiu-se utilizar, neste trabalho, PMHS: $\mathrm{D}_{4} \mathrm{~V}_{i}$ como aditivo de sinterização junto com óxidos de alumínio e ítrio.

\section{SiC: $\mathrm{Al}_{2} \mathrm{O}_{3}: \mathbf{Y}_{2} \mathrm{O}_{3}: \mathbf{P M H S}: \mathbf{D}_{\mathbf{4}} \mathbf{V}_{\mathbf{i}}$}

Amostras à base de $\mathrm{SiC}$ foram preparadas usando PMHS: $\mathrm{D}_{4} \mathrm{Vi}$, sendo que os resultados preliminares mostraram um bom rendimento cerâmico até $1350{ }^{\circ} \mathrm{C}$. 
Nesta etapa também variou-se as porcentagens de polímeros precursores adicionadas $\left(1 \%, 5 \%\right.$ e $10 \%$ de PMHS: $\left.\mathrm{D}_{4} \mathrm{~V}_{\mathrm{i}}\right)$, a temperatura de pirólise foi $900{ }^{\circ} \mathrm{C}$, a temperatura de sinterização $1950^{\circ} \mathrm{C}$, e a atmosfera utilizada nos dois tratamentos térmicos foi argônio. As densidades aparentes obtidas por picnometria de hélio e as perdas de massa após sinterização, são apresentadas na Tabela IV.5.

Tabela IV.5- Densidades aparentes obtidas por picnometria de hélio, perdas de massa, perdas de massa previstas após pirólise e sinterização de amostras SAY com 1\%, 5\% e $10 \%$ de $\mathrm{PMHS}: \mathrm{D}_{4} \mathrm{~V}_{\mathrm{i}}$, pirolisadas a $900^{\circ} \mathrm{C}$ e sinterizadas a $1950{ }^{\circ} \mathrm{C}$, em atmosfera de argônio.

\begin{tabular}{|c|c|c|c|c|c|}
\hline Amostra & $\begin{array}{c}\rho_{\text {aparente }} \\
\left(\mathrm{g} / \mathrm{cm}^{3}\right)\end{array}$ & $\begin{array}{c}\text { PM } \\
\mathrm{B} \rightarrow \mathrm{A}(\%)\end{array}$ & $\begin{array}{c}\text { PM } \\
\mathrm{C} \rightarrow \mathrm{B}(\%)\end{array}$ & $\begin{array}{c}\text { PM } \\
\mathrm{C} \rightarrow \mathrm{A}(\%)\end{array}$ & $\begin{array}{c}\text { PMP } \\
(\%)\end{array}$ \\
\hline SAY0-1950A & $3,13 \pm 0,01$ & - & - & 6,5 & \\
\hline SAY1HD-9A-1950A & $2,97 \pm 0,01$ & 1,9 & 20,6 & 22,5 & 6,6 \\
\hline SAY5HD-9A-1950A & $2,94 \pm 0,01$ & 1,5 & 24,4 & 25,5 & 7,0 \\
\hline SAY10HD-9A-1950A & $2,81 \pm 0,01$ & 2,8 & 28,4 & 26,4 & 7,6 \\
\hline
\end{tabular}

$\mathbf{A} \rightarrow$ antes da pirólise $\mathbf{B} \rightarrow$ após pirólise $\mathbf{C} \rightarrow$ após sinterizacão

As densidades dos materiais com polímeros precursores foram inferiores à da amostra de referência. Além disso nota-se que quanto maior a quantidade de polímero PMHS: $\mathrm{D}_{4} \mathrm{~V}_{i}$, menor a densidade obtida. Este fato é devido à diferença entre a densidade do material base e os polímeros adicionados. Estes dados estão de acordo com o trabalho de Schiavon [76]. Porém isto não aconteceu acrescentando somente PMHS, Tabela IV.5, provavelmente pelo fato da amostra não apresentar homogeneidade, como pode se observar nas micrografias da Figura IV.11.

Nota-se que a perda de massa é expressiva apesar das análises por TG indicarem menor perda de massa para a mistura destes polímeros. De acordo com a análise termogravimétrica, a massa remanescente do polímero $P M H S: D_{4} V_{i}$, em atmosfera de argônio é aproximadamente $83 \%$, em temperatura de até $1350^{\circ} \mathrm{C}$. Os valores de perda de massa são consideravelmente superiores aos previstos utilizando perda de massa de SAY0$1950 \mathrm{~A}$ e resultados de análise termogravimétrica. 
Difratogramas das amostras SAY0, SAY1HD-9A-1950A, SAY5HD-9A-1950A e SAY10HD-9A-1950A, após pirólise a $900{ }^{\circ} \mathrm{C}$ e sinterização a $1950{ }^{\circ} \mathrm{C}$ por 1 hora são mostrados na Figura IV.12.

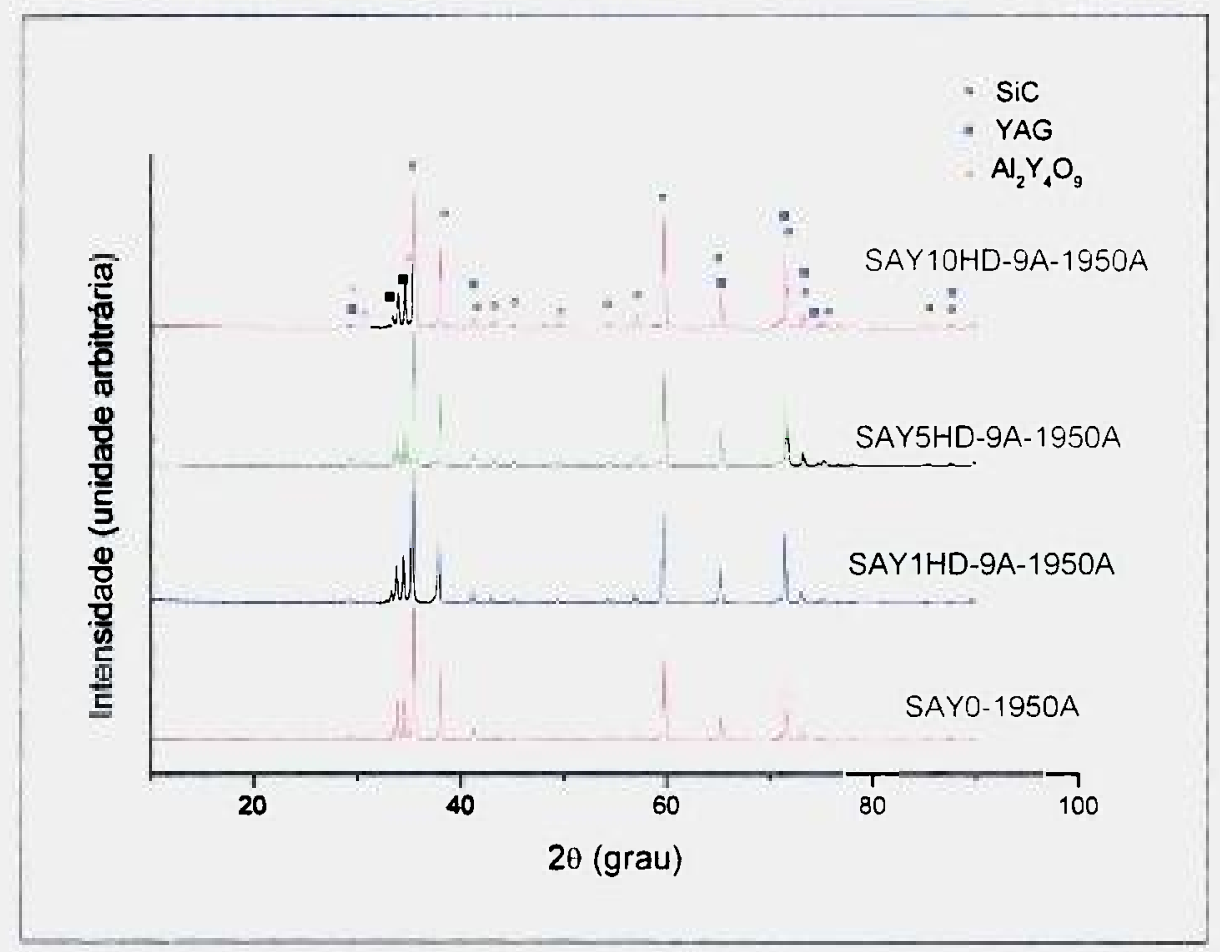

Figura IV.12- Difratogramas referentes aos compósitos SAY0-1950A, SAY1HD-9A1950A, SAY5HD-9A-1950A e SAY10HD-9A-1950A, após pirólise a $900{ }^{\circ} \mathrm{C}$ e sinterização a $1950^{\circ} \mathrm{C}$ por 1 hora, em atmosfera de argônio.

Além da presença dos politipos de $\mathrm{SiC}$ foi observada também a presença de $\mathrm{Al}_{2} \mathrm{Y}_{4} \mathrm{O}_{9}$ e YAG, $\mathrm{Al}_{5} \mathrm{Y}_{3} \mathrm{O}_{12}$, em todas as amostras analisadas. Portanto, independente da concentração de PMHS: $D_{4} V_{i}$ adicionada, as fases formadas foram as mesmas. Os materiais à base de $\mathrm{SiC}$ com apenas $\mathrm{PMHS}$, sinterizados a $1850^{\circ} \mathrm{C}$ também apresentaram $\mathrm{Al}_{2} \mathrm{Y}_{4} \mathrm{O}_{9}$ (óxido de alumínio e ítrio); já os sinterizados a $1950^{\circ} \mathrm{C}$ verificou-se somente $\mathrm{SiC}$ e YAG (Figura IV.12). Verifica-se, no diagrama de equilibrio $\mathrm{Al}_{2} \mathrm{O}_{3}-\mathrm{Y}_{2} \mathrm{O}_{3}$, Figura IV.13, as fases $\mathrm{Al}_{2} \mathrm{Y}_{4} \mathrm{O}_{9}$, e $\mathrm{Al}_{5} \mathrm{Y}_{3} \mathrm{O}_{12}, \mathrm{YAG}$. 


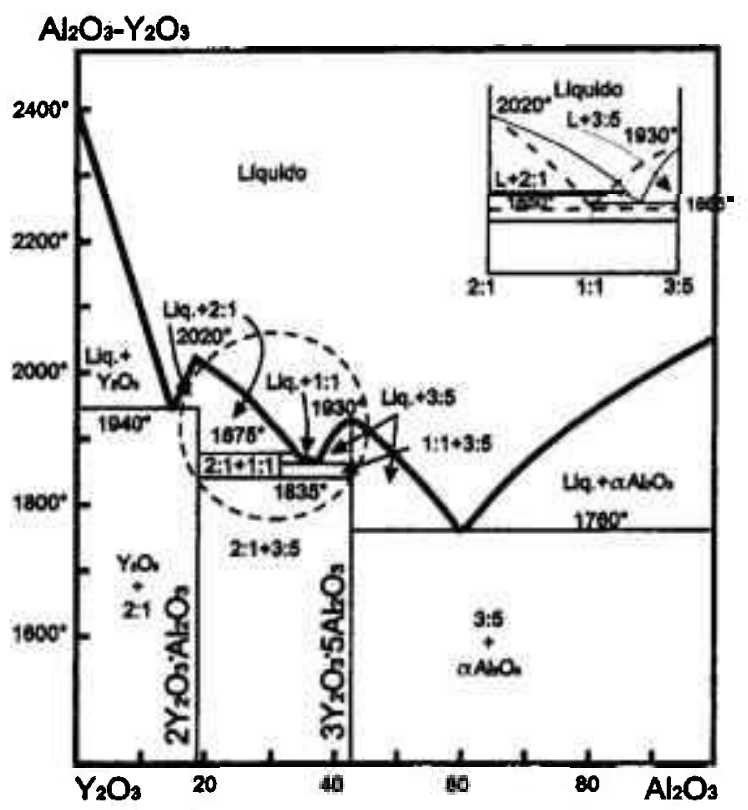

Figura IV.13- Diagrama de fases $\mathrm{Al}_{2} \mathrm{O}_{3}-\mathrm{Y}_{2} \mathrm{O}_{3}$ [113].

Segundo o diagrama de equilibrio, são formadas duas fases a partir do líquido devido à sinterizacão via fase líquida:

$\mathrm{Al}_{2} \mathrm{Y}_{4} \mathrm{O}_{9}$ e $\mathrm{Al}_{5} \mathrm{Y}_{3} \mathrm{O}_{12}$ (YAG):

Líquido $\rightarrow \mathrm{Al}_{2} \mathrm{Y}_{4} \mathrm{O}_{9}$ e $\mathrm{Al}_{5} \mathrm{Y}_{3} \mathrm{O}_{12}$

Estas fases foram identificadas também por difração de raios $X$ para amostras SAY0-1950A, SAY1HD-9A-1950A, SAY5HD-9A-1950A e SAY10HD-9A-1950A.

As microestruturas das amostras SAY0-1950A, SAY1HD-9A-1950A, SAY5HD9A-1950A e SAY10HD-9A-1950A são mostradas na Figura IV.14. 


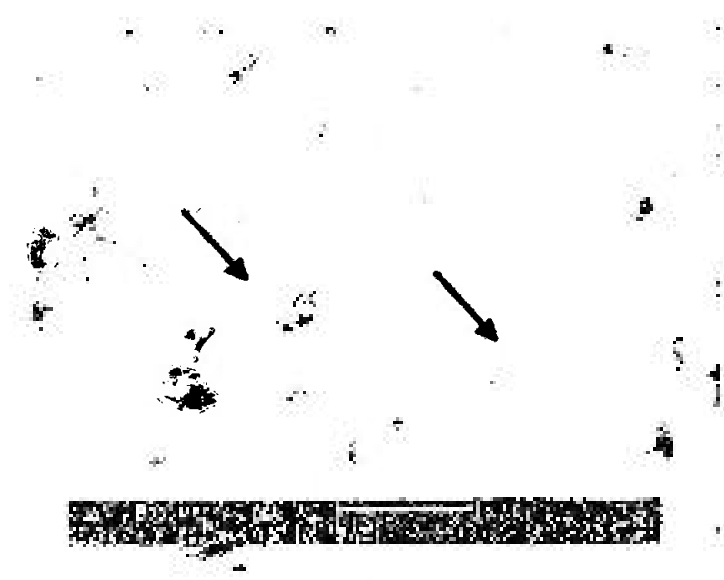

(a)

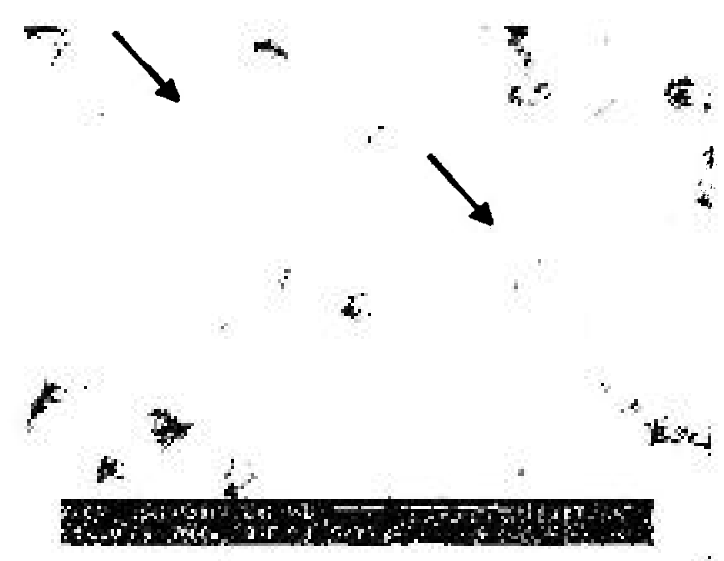

(b)

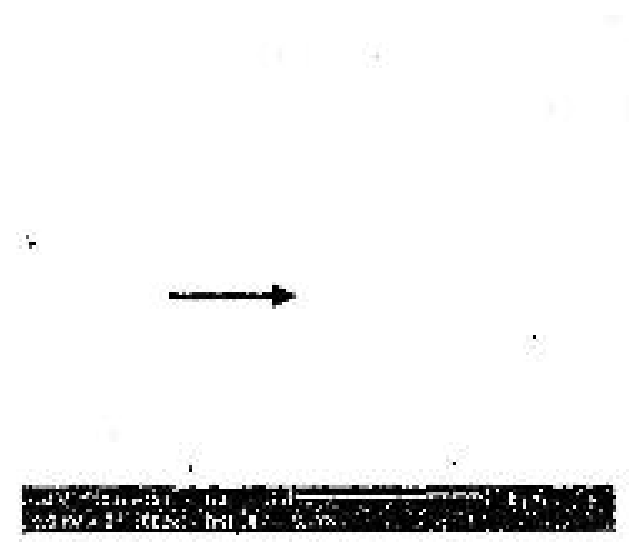

(c)

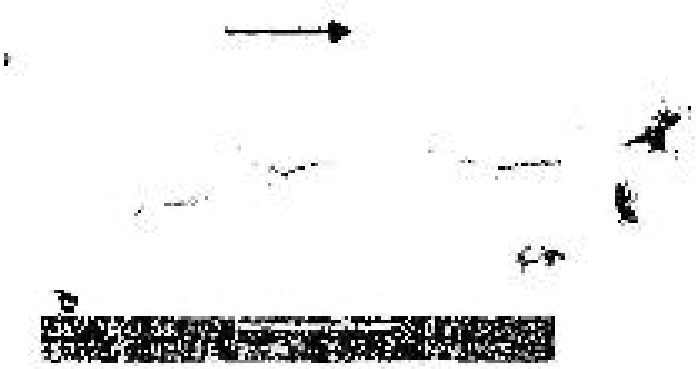

(d)

Figura IV.14- Micrografias obtidas por microscopia eletrônica de varredura: (a)- Amostra SAY0-1950A; (b)- Amostra SAY1HD-9A-1950A; (c)- Amostra SAY5HD-9A-1950A; (d)- Amostra SAY10HD-9A-1950A.

Em todas as amostras sinterizadas a $1950^{\circ} \mathrm{C}$ os pontos triplos são, em geral, constituídos de fase secundária com ângulo diedro pequeno $\left(60^{\circ}\right)$, o que indica boa molhabilidade durante a sinterização [86].

Apesar de não terem sido revelados detalhes da microestrutura, pode-se observar na na Figura IV.14, "linhas retas relativamente extensas" devidas aos contornos de grãos alongados de $\mathrm{SiC}$, indicados por setas. Na Figura IV.14 (d) também há grãos alongados, identificados nas micrografias, podendo observar trincas entre os grãos, introduzidas 
durante ensaio de impressão Vickers, "cortando" alguns deles. O mecanismo de tenacificação predominante é por deflexão de trincas, que é o mais comum para cerâmicas à base de $\mathrm{SiC}$, embora possa inferir que, provavelmente, tem-se, também, o mecanismo por ponteamento na cauda da trinca.

Na Tabela IV.6 são apresentados os valores de dureza Vickers das amostras SAY01950A, padrão, SAY1HD-9A-1950A, SAY5HD-9A-1950A e SAY10HD-9A-1950A.

Tabela IV.6- Valores de dureza Vickers das amostras SAY0-1950A, SAY1HD-9A-1950A, SAY5HD-9A-1950A e SAY10HD-9A-1950A.

\begin{tabular}{|c|c|}
\hline Amostra & $\begin{array}{c}\mathrm{H}_{\mathrm{v}} \\
(\mathrm{GPa})\end{array}$ \\
\hline SAY0-1950A & $20,5 \pm 1,8$ \\
\hline SAY1HD-9A-1950A & $17,4 \pm 1,1$ \\
\hline SAY5HD-9A-1950A & $18,7 \pm 1,2$ \\
\hline SAY10HD-9A-1950A & $18,6 \pm 1,4$ \\
\hline
\end{tabular}

Os valores de dureza para amostras SAY com $1 \%, 5 \%$ e $10 \%$ de PMHS: $\mathrm{D}_{4} \mathrm{~V}_{\mathrm{i}}$, foram próximos, o que significa que a quantidade de aditivos não interferiu na dureza do material. Porém foram inferiores à dureza obtida para amostra padrão, SAY0-1950A.

Na Figura IV.15 é mostrada a indentação da amostra SAY1HD-9A-1950A, e algumas trincas saindo de diagonais, indicadas na micrografia.

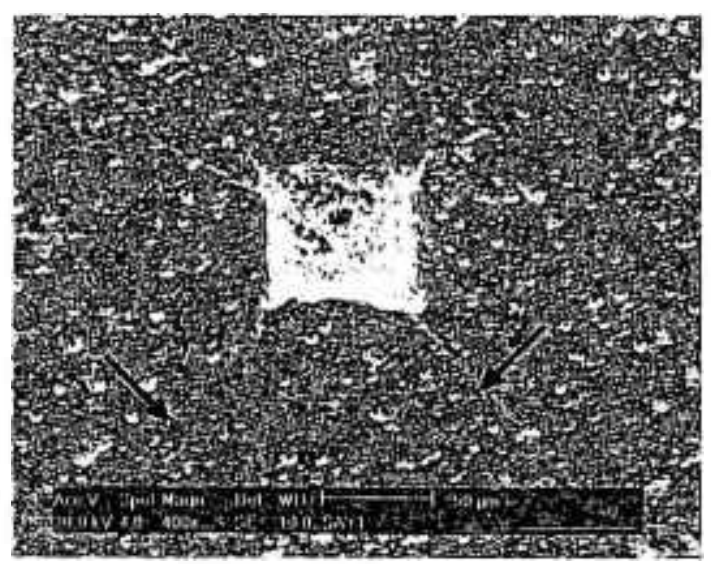

Figura IV.15 - Indentação e trincas da amostra SAY1HD-9A-1950A. 
Em pesquisa realizada por J. Marchi [114], sobre sinterização via fase líquida de cerâmicas à base de $\mathrm{SiC}$ com aditivos óxidos, para amostras de $\mathrm{SiC}: \mathrm{Al}_{2} \mathrm{O}_{3}: \mathrm{SiO}_{2}: \mathrm{Y}_{2} \mathrm{O}_{3}$, sinterizadas a $1950^{\circ} \mathrm{C}$ por 1 hora em argônio, obteve-se densidade média de $94 \%$ D.T. e dureza Vickers de aproximadamente $21,3 \mathrm{GPa}$.

Segundo She e Ueno [115] em trabalho à base de $\mathrm{SiC}$ com $\mathrm{Al}_{2} \mathrm{O}_{3}$ e $\mathrm{Y}_{2} \mathrm{O}_{3}$ como aditivos, sinterização à $1950^{\circ} \mathrm{C}$ por 1 hora em argônio, eles obtiveram aproximadamente 97,5\% D.T e aproximadamente 18,2 GPa de dureza Vickers.

Cerâmicas à base de $\mathrm{SiC}$ sem polímeros precursores são normalmente sinterizadas em argônio, obtendo densidades elevadas. Neste trabalho foram feitos tratamentos térmicos em nitrogênio obtendo-se densidades maiores que em argônio e, embora a perda de massa tenha sido inferior às obtidas com argônio foram bastante elevadas.

Como os tratamentos térmicos são a temperaturas muito elevadas, há volatilização dos polimeros adicionados, que devem "arrastar" os aditivos óxidos prejudicando a densificação.

Como os prováveis produtos formados teriam composiça similar à da amostra de SiC năo foi possível determinar se houve formação de fase cerâmica a partir do precursor polimérico.

Diante destes fatos resolveu-se estudar $\mathrm{Al}_{2} \mathrm{O}_{3}$ com polímeros precursores cerâmicos.

\section{IV.4- Materiais à base de $\mathrm{Al}_{2} \mathrm{O}_{3}$}

No estudo de materiais à base de $\mathrm{Al}_{2} \mathrm{O}_{3}$ foram adicionados três polímeros precursores cerâmicos, PMHS, PMS e PPS (1\%, 5\% e 10\%). Estes materiais foram pirolisados a $900{ }^{\circ} \mathrm{C}$, em argônio ou nitrogênio, e sinterizados a $1650^{\circ} \mathrm{C}$, em nitrogênio.

\section{Amostra de $\mathrm{O}_{-} \mathrm{Al}_{2} \mathrm{O}_{3}$ - padrũo}

A amostra padrão apresenta crescimento anormal de grãos e alguns poros intergranulares, Figura IV.16 (a) e (b). 


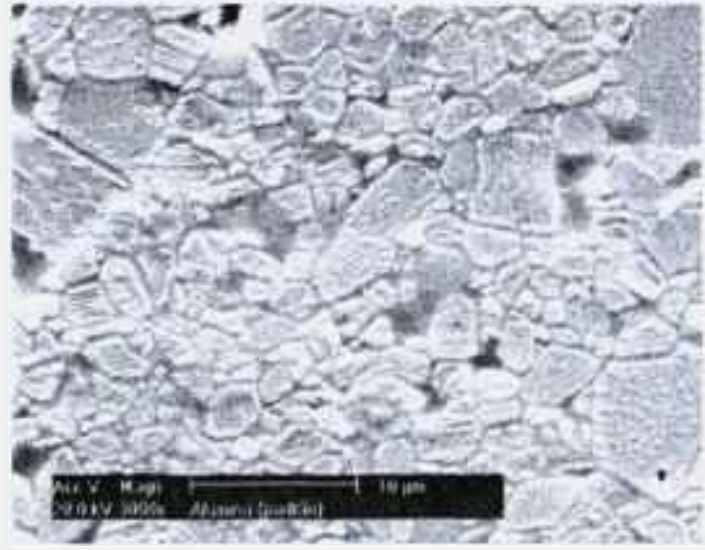

(a)

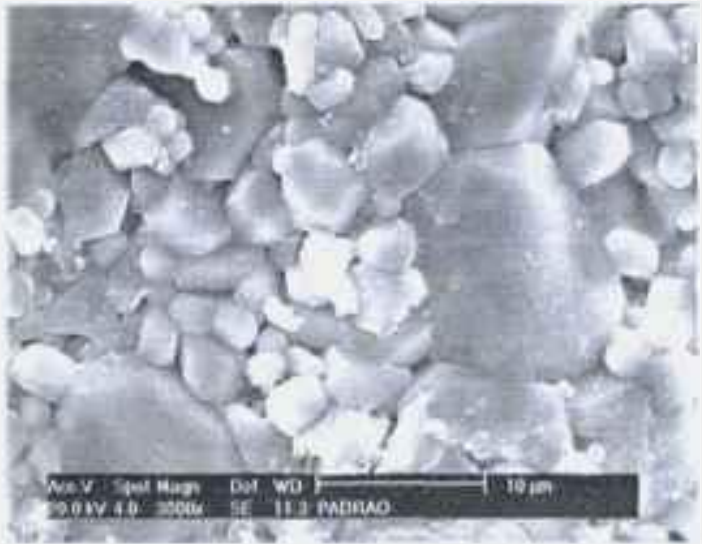

(b)

Figura IV.16- Micrografias da amostra padrão de alumina, A0-1650N: (a)- Após ataque térmico a vácuo a $1550^{\circ} \mathrm{C}$, por 15 min.; (b)- Superficie de fratura.

O tamanho de grão varia bastante, de aproximadamente $1 \mu \mathrm{m}$ a cerca de $15 \mu \mathrm{m}$. A densidade deste material é $3,87 \mathrm{~g} / \mathrm{cm}^{3}$, Tabela IV.7, que corresponde a $97,2 \%$ da densidade teórica da alumina.

As amostras de $\mathrm{Al}_{2} \mathrm{O}_{3}$ prensadas com os polímeros são brancas, com diâmetro de $2,4 \mathrm{~cm}$. Após compactação uniaxial a quente e pirólise, as mesmas apresentam coloração acinzentada, com leve retração, cerca de $8 \%$, e após a sinterização, tornam-se pretas, provavelmente devido às reações químicas e formação de fases a partir dos polímeros, que contém $\mathrm{Si}$ e carbono. Na Figura IV.17 encontram-se fotografias de amostras após compactação e após pirólise.
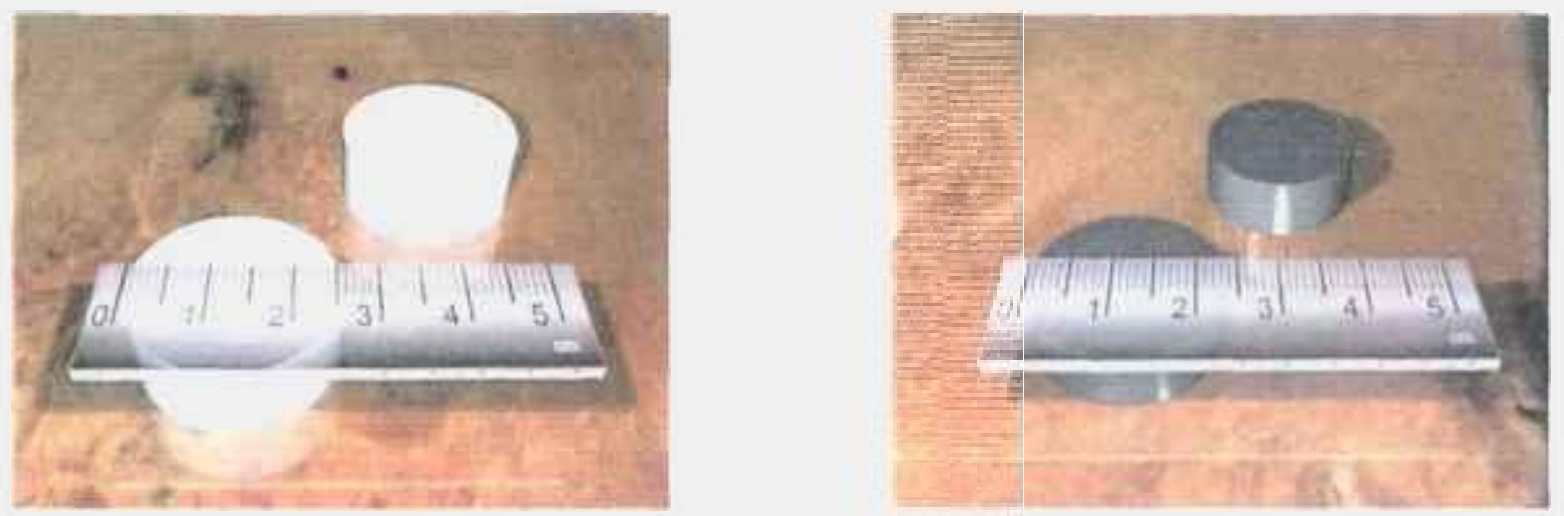

Figura IV.17 - Aparência da amostra antes e após pirólise, A10H-9A-1650A. 
Nas Figuras IV.18, IV.19 e IV.20 são mostrados difratogramas de raios $\mathrm{X}$ de amostras de $\mathrm{Al}_{2} \mathrm{O}_{3}: 10 \%$ PMHS, $\mathrm{Al}_{2} \mathrm{O}_{3}: 10 \%$ PMS e $\mathrm{Al}_{2} \mathrm{O}_{3}: 10 \%$ PPS, após pirólise.

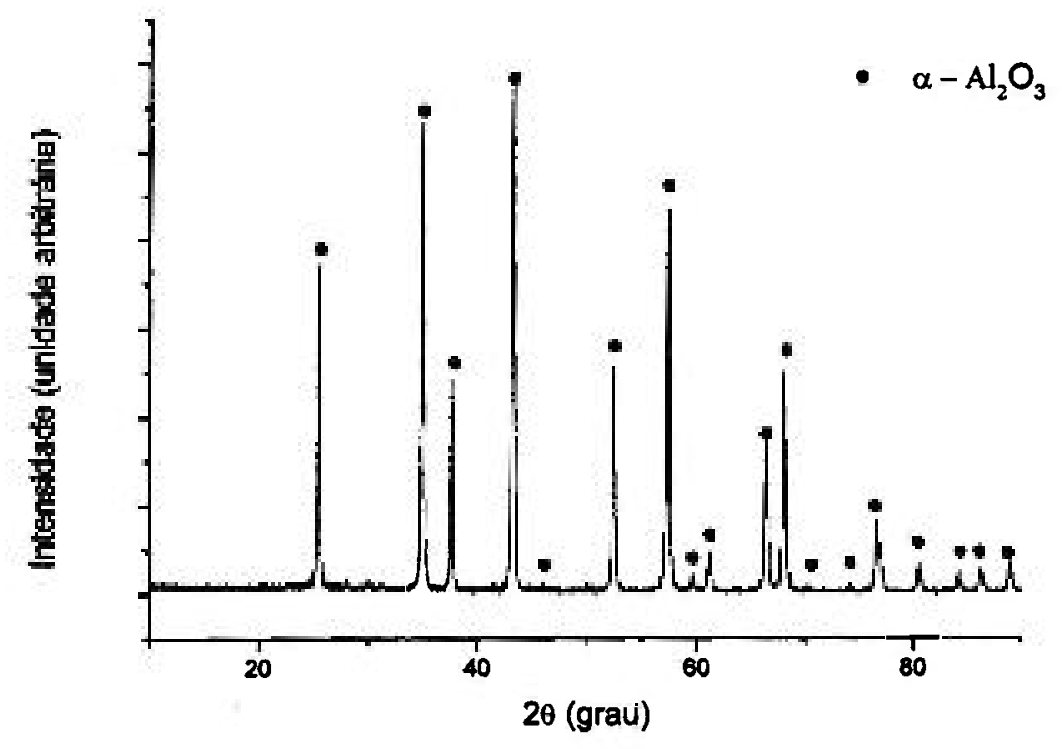

Figura IV.18 - Difratograma de raios $\mathrm{X}_{\text {de }} \mathrm{Al}_{2} \mathrm{O}_{3}: 10 \%$ PMHS após pirólise $\left(900{ }^{\circ} \mathrm{C} / 1 \mathrm{~h}\right)$.

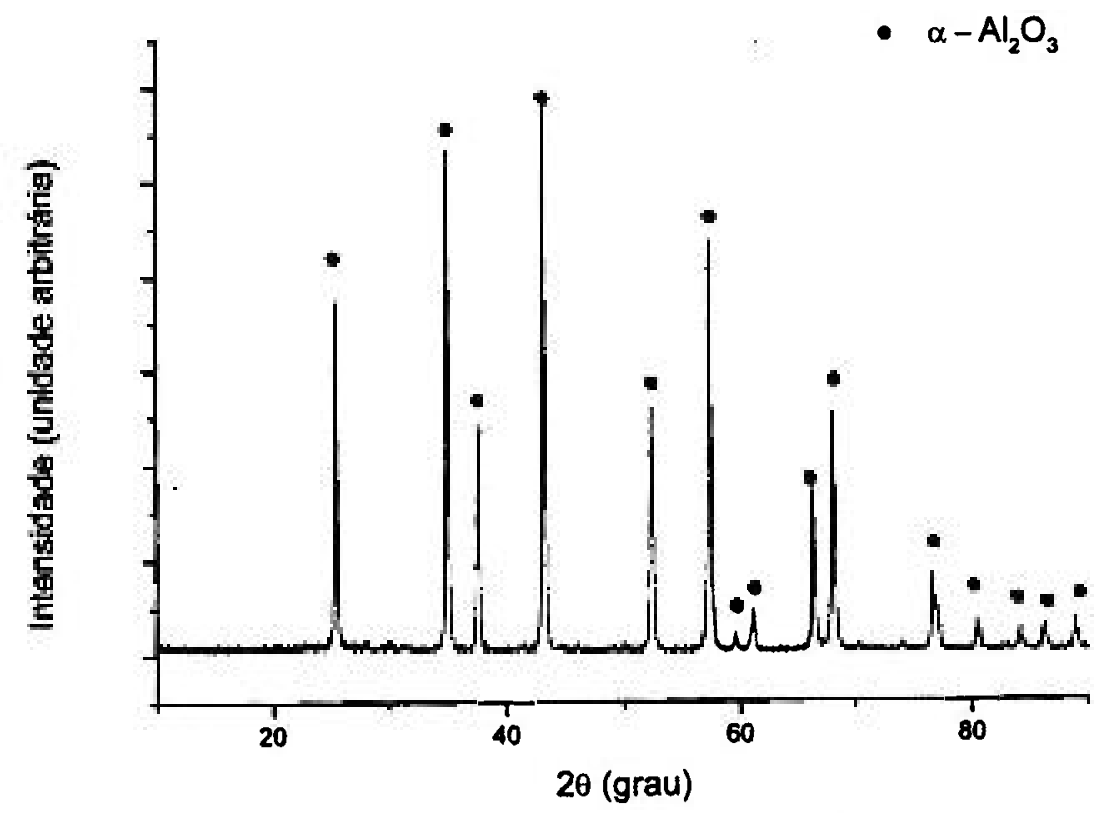

Figura IV.19 - Difratograma de raios $\mathrm{X}$ de $\mathrm{Al}_{2} \mathrm{O}_{3}: 10 \%$ PMS após pirólise $\left(900{ }^{\circ} \mathrm{C} / 1 \mathrm{~h}\right)$. 


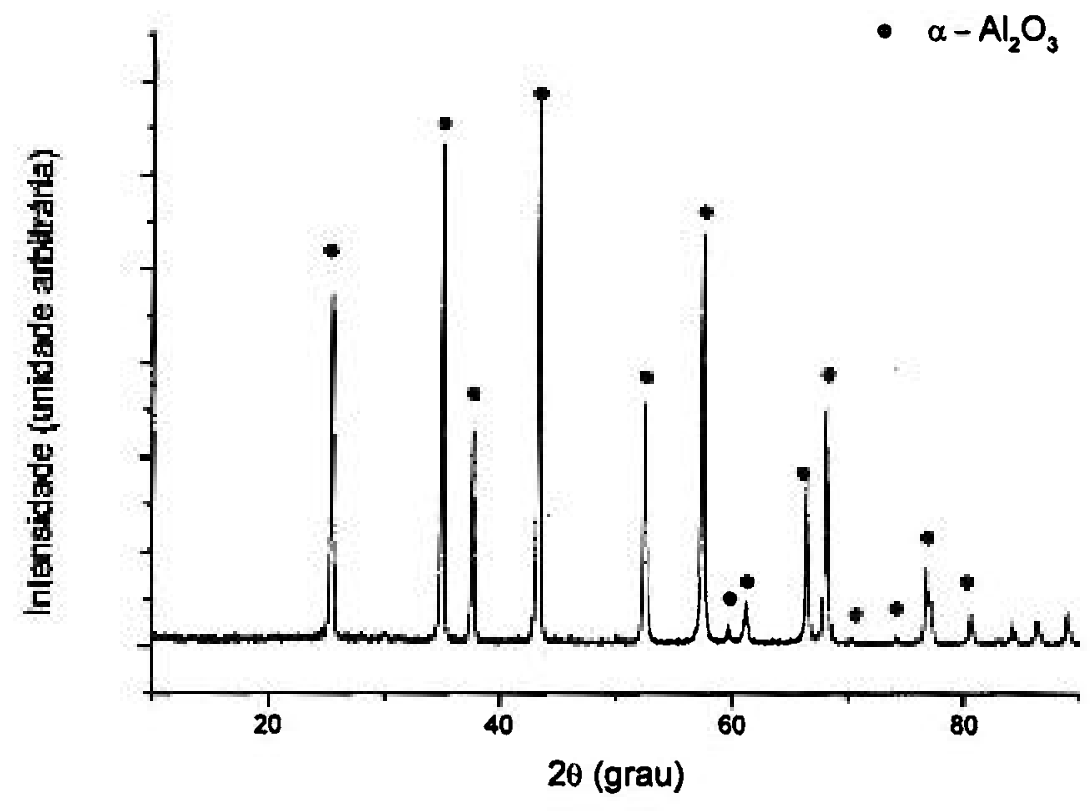

Figura IV.20 - Difratograma de raios $\mathrm{X}$ de $\mathrm{Al}_{2} \mathrm{O}_{3}: 10 \%$ PPS após pirólise $\left(900^{\circ} \mathrm{C} / 1 \mathrm{~h}\right)$.

Nota-se somente a presença de $\mathrm{Al}_{2} \mathrm{O}_{3}$ já que não é possivel detectar por difração de raios $\mathrm{X}$ o restante do polimero que está retido na amostra. $\mathrm{A}$ esta temperatura ocorreu volatilização de alguns materiais, e não foi suficiente para que houvesse formação de fases cristalinas a partir dos precursores poliméricos. Com a decomposição dos polissiloxanos durante a pirólise há formação de fase vítrea como oxicarbeto de silício, SiCO. A transição entre orgânicos e inorgânicos e formação de SiCO ocorre entre $700^{\circ} \mathrm{C} \mathrm{e} 800^{\circ} \mathrm{C}$ [116].

Para o estudo da sinterização de $\mathrm{Al}_{2} \mathrm{O}_{3}$ contendo o polímero PMHS como aditivo foram feitos testes em relação à atmosfera de pirólise (argônio ou nitrogênio), enquanto na sinterização foi utilizado nitrogênio. Este procedimento foi adotado para verificar a perda de massa em amostras de alumina e a influência da atmosfera na formação de fases.

\section{$\mathrm{Al}_{2} \mathrm{O}_{3}:$ PMHS}

Para o estudo da cinética de sinterização foi realizado experimento em dilatômetro, onde se constata que a retração linear da amosta teve inicio em aproximadamente $120{ }^{\circ} \mathrm{C}$; em $\sim 1400{ }^{\circ} \mathrm{C}$ constatou-se um ponto de inflexão, provavelmente devido à formação de 
fases e a partir desta temperatura, além de possiveis mudanģas de fases, deve haver alterações nos mecanismos de sinterização. No patamar de 1 hora a $1650^{\circ} \mathrm{C}$ houve pequena retracão, sendo a retracăo máxima de aproximadamente $14,2 \%$. A partir dos resultados de dilatometria foi resolvido fazer estudos de densificacăo utilizando a composiça de alumina com $1 \%, 5 \%$ e $10 \%$ de precursor polimérico, PMHS. A temperatura de pirólise foi $900^{\circ} \mathrm{C}$ em atmosferas de nitrogênio ou argônio. A sinterizacăo foi a $1650^{\circ} \mathrm{C}$, em nitrogênio.

Os valores de densidade aparente das amostras pirolisadas e sinterizadas em nitrogênio e pirolisadas em argônio e sinterizadas em nitrogênio são apresentados na Tabela IV.7. Para o cálculo das \%DT, foi utilizada, como referência, a densidade teórica da alumina, $\left(3,98 \mathrm{~g} / \mathrm{cm}^{3}\right)$.

Para verificar a presença de carbono, ou seja, se parte do polímero ficou retido na alumina, foi feito ensaio em analisador de carbono total na amostra A1H-9N-1650N. A amostra analisada possui aproximadamente $0,02 \% \mathrm{em}$ peso de carbono. Por outro lado, os resultados da análise semi-quantitativa por espectrometria de fluorescência de raios $\mathrm{X}$ por dispersão de comprimento de onda do $\mathrm{Al}_{2} \mathrm{O}_{3}$ (Tabela IV.1), não indica a presença de carbono, o que reforça o fato do $\mathrm{C}$ presente nas amostras sinterizadas ser proveniente do polimero.

Na Figura IV.21 é mostrada a curva de dilatometria da amostra A10H-9N-1650N.

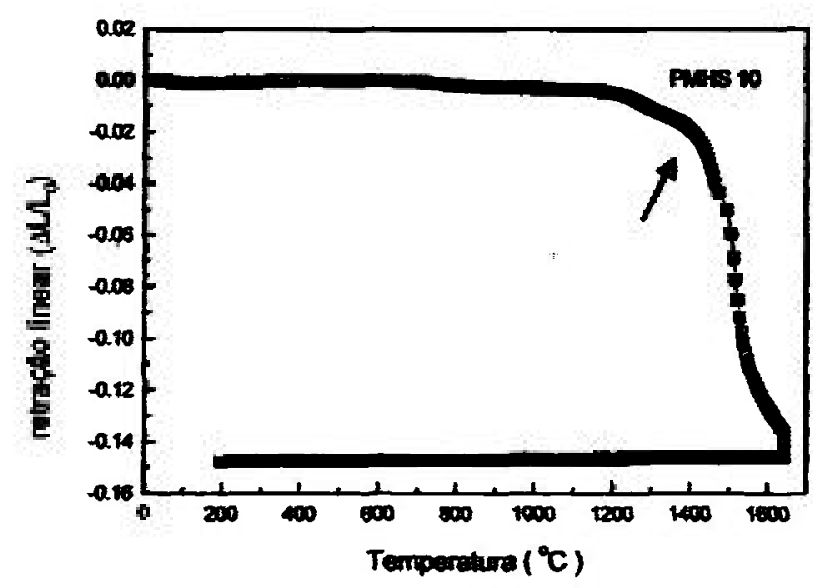

Figura IV.21- Curva de dilatometria das amostras A10H-9N-1650N: retração linear em funçăo da temperatura. 
Tabela IV.7- Densidades aparentes, por picnomentria de He, valores de \%D.T. e perdas de massa das amostras $\mathrm{Al}_{2} \mathrm{O}_{3}: \mathrm{PMHS}$ pirolisadas a $900{ }^{\circ} \mathrm{C}$, em nitrogênio ou argônio, e sinterizadas a $1650^{\circ} \mathrm{C}$ em nitrogênio.

\begin{tabular}{|c|c|c|c|c|c|c|}
\hline Amostras & $\begin{array}{c}\rho_{\text {aparente }} \\
\left(\mathrm{g} / \mathrm{cm}^{3}\right)\end{array}$ & \%D.T. & $\begin{array}{c}\text { PM } \\
\mathrm{B} \rightarrow \mathrm{A}(\%)\end{array}$ & $\begin{array}{c}\text { PM } \\
\mathrm{C} \rightarrow \mathrm{B}(\%)\end{array}$ & $\begin{array}{c}\text { PM } \\
\mathrm{C} \rightarrow \mathrm{A}(\%)\end{array}$ & $\begin{array}{c}\text { PMP } \\
(\%)\end{array}$ \\
\hline A0-1650N & $3,87 \pm 0,01$ & 97,2 & - & - & 1,9 & - \\
\hline A1H-9N-1650N & $3,77 \pm 0,01$ & 94,7 & 1,2 & 0,7 & 1,9 & 2,7 \\
\hline A5H-9N-1650N & $3,66 \pm 0,01$ & 92,0 & 2,5 & 1,1 & 3,6 & 5,9 \\
\hline A10H-9N1650N & $3,76 \pm 0,01$ & 94,5 & 5,0 & 1,0 & 6,9 & 9,8 \\
\hline A1H-9A-1650N & $3,82 \pm 0,01$ & 96,0 & 0,3 & 1,3 & 1,6 & 2,7 \\
\hline A5H-9A-1650N & $3,65 \pm 0,01$ & 91,7 & 3,2 & 2,1 & 5,3 & 5,9 \\
\hline A10H-9A-1650N & $3,70 \pm 0,01$ & 93,0 & 7,3 & 1,6 & 8,9 & 9,9 \\
\hline
\end{tabular}

$\mathbf{A} \rightarrow$ antes da pirólise $\mathbf{B} \rightarrow$ após pirólise $\mathbf{C} \rightarrow$ após sinterizacãa

$B \rightarrow A$ - perda de massa durante pirólise

C $\rightarrow B$ - perda de massa parcial entre pirólise e sinterização

C $\rightarrow$ A - perda de massa total

De maneira geral, as densidades das amostras de $\mathrm{Al}_{2} \mathrm{O}_{3}: \mathrm{PMHS}$ pirolisadas e sinterizadas em nitrogênio foram próximas às densidades das amostras pirolisadas com argônio, Tabela IV.7.

As amostras pirolisadas e sinterizadas com nitrogênio apresentaram, em geral, menor perda de massa em relação às pirolisadas em argônio, portanto, para as próximas amostras foi utilizada esta atmosfera. Possivelmente o nitrogênio reage com os produtos de decomposição do polímero, retendo o mesmo.

Os difratogramas das amostras pirolisadas em nitrogênio, AlH-9N-1650N, AlH9N-1650N, A10H-9N-1650N, e pirolisadas em argônio, A1H-9A-1650N, A5H-9A-1650N, A10H-9A-1650N, são mostrados nas Figuras IV.22 (a) e (b), respectivamente. 

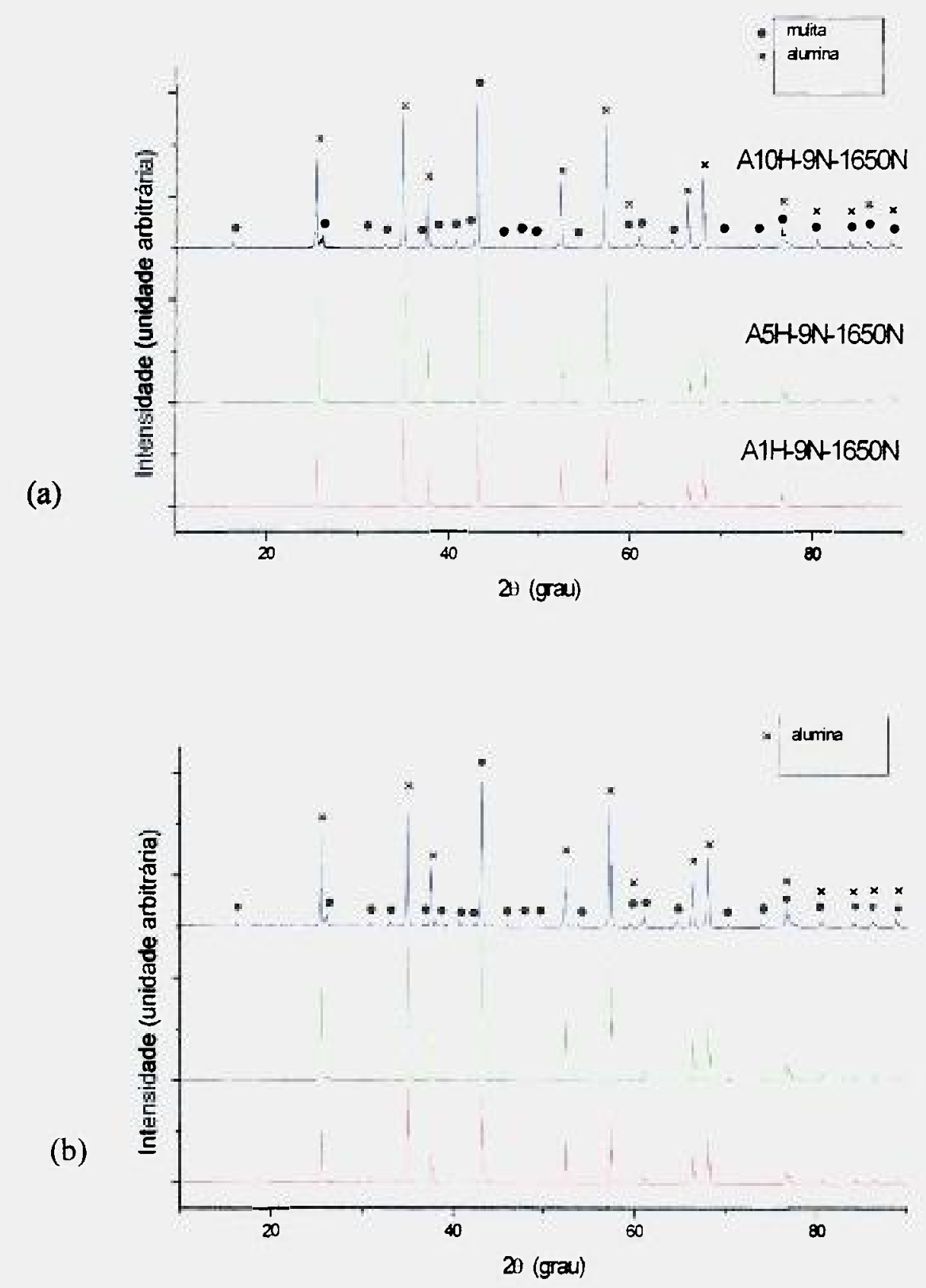

Figura IV.22- Difratogramas mostrando as fases cristalinas presentes nas amostras: (a) AlH-9N-1650N, A1H-9N-1650N e A10H-9N-1650N, (b) AlH-9A-1650N, A5H-9A$1650 \mathrm{~N}$ e $\mathrm{A} 10 \mathrm{H}-9 \mathrm{~A}-1650 \mathrm{~N}$. 
Foi constatado nos difratogramas das amostras de $\mathrm{Al}_{2} \mathrm{O}_{3}: \mathrm{PMHS}$, pirolisadas em argônio e em nitrogênio, a presença de $\mathrm{Al}_{2} \mathrm{O}_{3}$ e mulita ( $\left.\mathrm{Al}_{4} \mathrm{SiO}_{8}\right)_{1,2}$, fícha JCPDS 73-1389, mostrando que o $\mathrm{Si}$ e $\mathrm{O}$ do polímero reagem com o $\mathrm{Al}_{2} \mathrm{O}_{3}$. Esta fase provavelmente foi formada pela reação entre $\mathrm{Al}_{2} \mathrm{O}_{3}$ e $\mathrm{SiO}_{2}$ resultante da oxidação de partículas de $\mathrm{Si}$ ou a partir da decomposiçăo do polímero [116]. A fase formada foi independente da atmosfera utilizada. Segundo Su e Sternitzke, a oxidacão do Si presente no polímero precursor pode ser responsável pela formação de mulita [117]. Inicialmente a formaça da mulita ocorre, ao menos parcialmente, por reaçăo no estado sólido entre a cristobalita e a alumina, com consecutiva sinterizafáo na presenca de fase líquida, que é o mecanismo dominante, acima da temperatura do eutético, $1587{ }^{\circ} \mathrm{C}$ no sistema $\mathrm{SiO}_{2}-\mathrm{Al}_{2} \mathrm{O}_{3}$ [27]. Segundo vários pesquisadores, em trabalhos com $\mathrm{Al}_{2} \mathrm{O}_{3}$ e silica, ao ar, derivada de polidimetilsiloxano, $\mathrm{Al}_{2} \mathrm{O}_{3}$ e SiC provenientes de polimetilsiloxano [117] e sintese "in situ" de compósitos de $\mathrm{Al}_{2} \mathrm{O}_{3}$ e SiC [105], em argônio, a "mulitizaçăo" inicia entre $1400^{\circ} \mathrm{C}$ e $1500{ }^{\circ} \mathrm{C}$. Segundo Harshe et alli [118], quando $\mathrm{Al}_{2} \mathrm{O}_{3}$ e $\mathrm{SiO}_{2}$ são usados para formaça de mulita, a densificação é obtida quando o $\mathrm{SiO}_{2}$ toma-se viscoso. Depois da densificação inicial a reação entre estes compostos forma mulita em temperatura normalmente acima de $1600^{\circ} \mathrm{C}$.

Na Figura IV.23 é mostrado o diagrama de equilibrio $\mathrm{Al}_{2} \mathrm{O}_{3}-\mathrm{SiO}_{2}$.

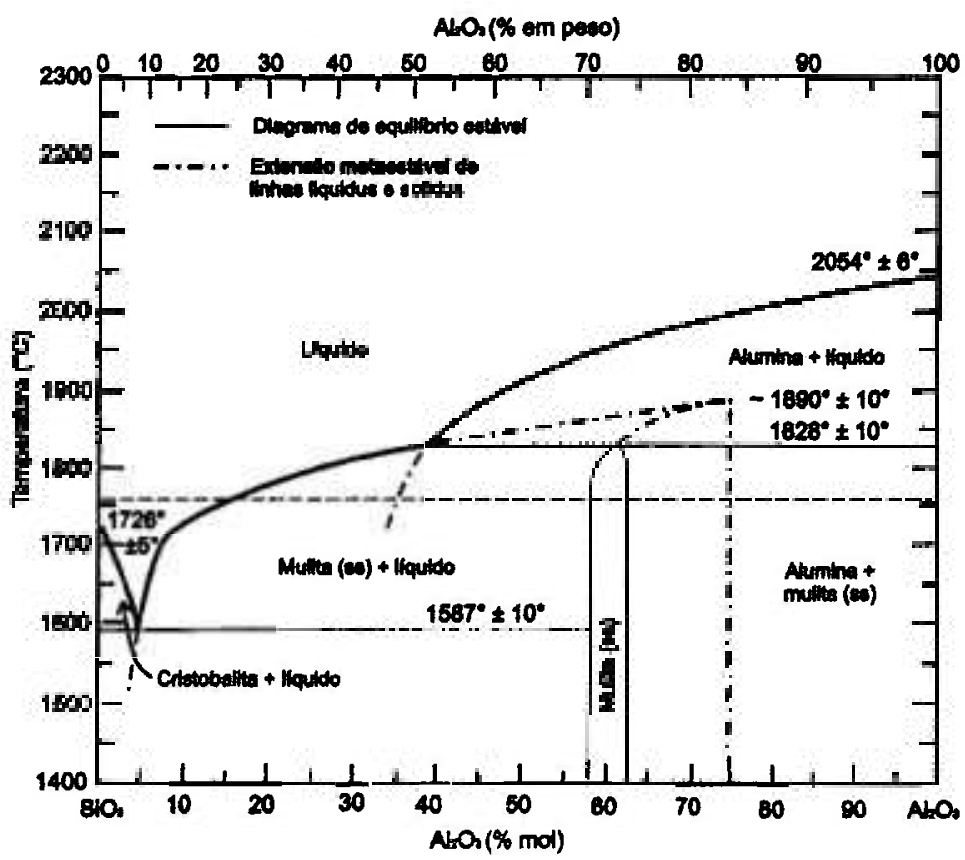

Figura IV.23- Diagrama de fases $\mathrm{Al}_{2} \mathrm{O}_{3}-\mathrm{SiO}_{2}[27]$. 
Observa-se no diagrama de fases $\mathrm{Al}_{2} \mathrm{O}_{3}-\mathrm{SiO}_{2}$ que, com as composiçøes utilizadas entre alumina e polímero $\left(1 \%, 5 \%\right.$ e $10 \%$ em peso), sinterizadas a $1650{ }^{\circ} \mathrm{C}$, pode haver formação de mulita em equilíbrio formando alumina + mulita. Estes materiais são termodinamicamente compatíveis. Além disso, têm potencial para utilização como cerâmica estrutural a altas temperaturas, pelo fato da mulita ter resistência mecânica elevada. Tanto a alumina quanto a mulita são muito utilizadas como refratário, cadinho, mobilia para fornos [104].

Na Figura IV.24 é mostrada a quantidade de carbono em função da quantidade de polímero após sinterização de A1H-9N-1650N, A5H-9N-1650N e A10H-9N-1650N. Os dados para obtenção desta curva foram obtidos utilizando-se a técnica de análise de carbono total.

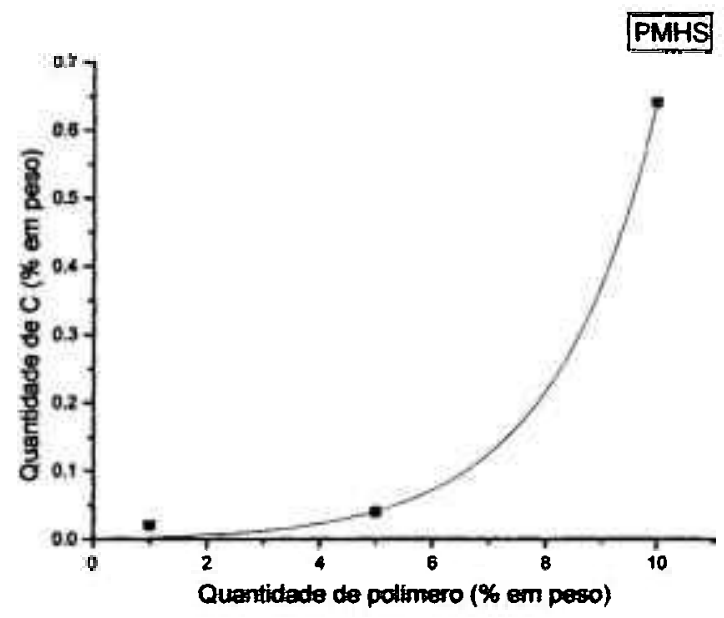

Figura IV.24- Análise de carbono total após sinterização das amostras A1H-9N-1650N, A5H-9N-1650N e A10H-9N-1650N.

Pode-se observar que à medida que a quantidade de polímero adicionado aumenta, a quantidade de carbono também aumenta, atingindo cerca de $0,65 \%$ em peso, para uma adição de $10 \%$ em peso de PMHS. 


\section{Amostras de $\mathrm{Al}_{2} \mathrm{O}_{3}: 1 \%$ PMHS pirolisadas em argônio}

Na Figura IV.25 é mostrada a micrografia de uma amostra atacada, o espectro de EDS e a superficie de fratura da amostra A1H-9A-1650N.

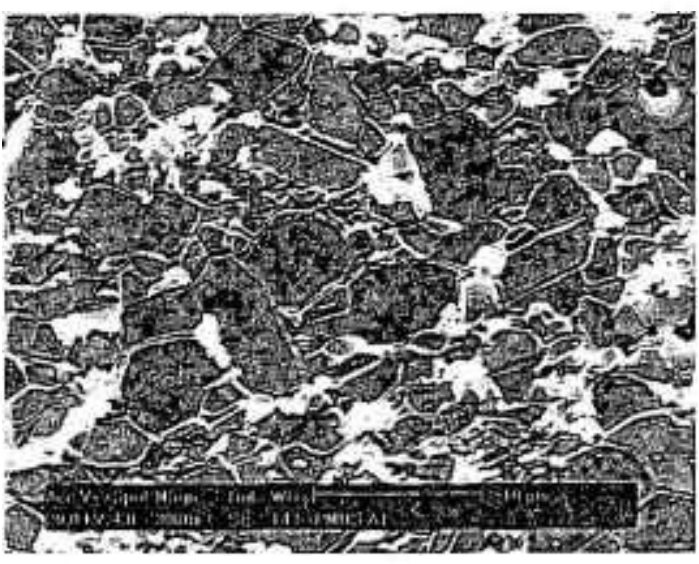

(a)

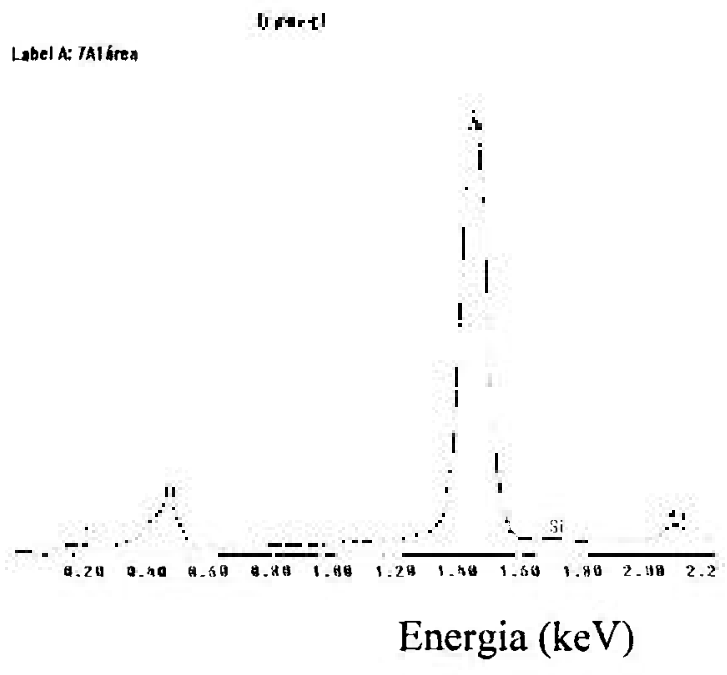

(b)

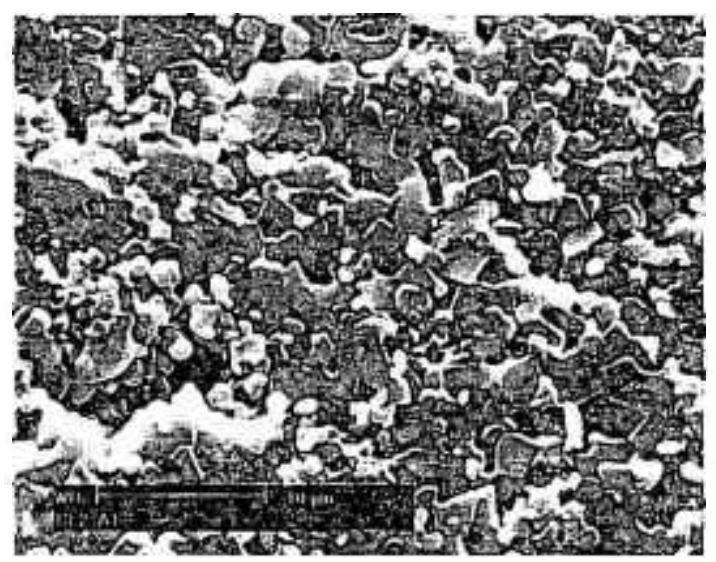

(c)

Figura IV.25- Amostra A1H-9A-1650N: (a)- Micrografia após ataque térmico a vácuo a $1550{ }^{\circ} \mathrm{C}$, por $15 \mathrm{~min}$; (b)- Espectro de EDS, correspondente à micrografia (a); (c)Superficie de fratura. 
Nota-se, na micrografia da amostra polida e atacada, Figura IV.25 (a), alguns grăos menores e arredondados, grăos facetados, grăos alongados e poros. As "partículas" claras sobre as amostras são provavelmente provenientes da fase que se encontra nos contomos de grão. Como o ataque foi feito em temperatura relativamente alta, $1550{ }^{\circ} \mathrm{C}$, este material pode ter amolecido, migrado para a superficie e cristalizado durante o resfriamento. É, possivelmente, resultante da reacão do resíduo do polímero com a alumina. Fazendo-se uma análise por EDS, da área da Figura IV.25 (a), foram detectados elementos da matriz, com discretas relevâncias nas posiçoes correspondentes às energias dos picos de Si e do C. O pico relativo ao Au é devido ao recobrimento. A faixa de tamanho de grăo é larga, variando de aproximadamente $1 \mu \mathrm{m}$ a $9 \mu \mathrm{m}$. $\mathrm{Na}$ micrografia da superficie de fratura, Figura IV.25 (c), pode-se observar maior número de grãos arredondados, e maior quantidade de poros.

\section{Amostras de $\mathrm{Al}_{2} \mathrm{O}_{3}: 5 \%$ PMHS pirolisadas em argônio}

Na Figura IV.26 são mostradas a micrografia de amostra polida e atacada termicamente, espectro de EDS e superfície de fratura da amostra A5H-9A-1650N.

Nota-se, na micrografia da amostra polida, grăos arredondados, grãos alongados e alguns poros. Fazendo-se uma análise por EDS, foram detectados os elementos $\mathrm{C}$ e $\mathrm{Si}$ melhor definidos que na amostra A1H-9A-1650N. Há um pico espúrio. Este pico, denominado pico de soma ("sum peak") está presente quando dois fótons entram no detector de raios $\mathrm{X}$, do EDS, praticamente ao mesmo tempo e o analisador registra a energia correspondente à soma das energias dos dois fótons; este tipo de artefato depende da taxa de contagens utilizadas. $O$ tamanho de grăo varia de aproximadamente 2 $\mu \mathrm{m}$ a $9 \mu \mathrm{m}$. Na micrografia da superficie de fratura, Figura IV.26 (c), observa-se uma quantidade maior de poros. 


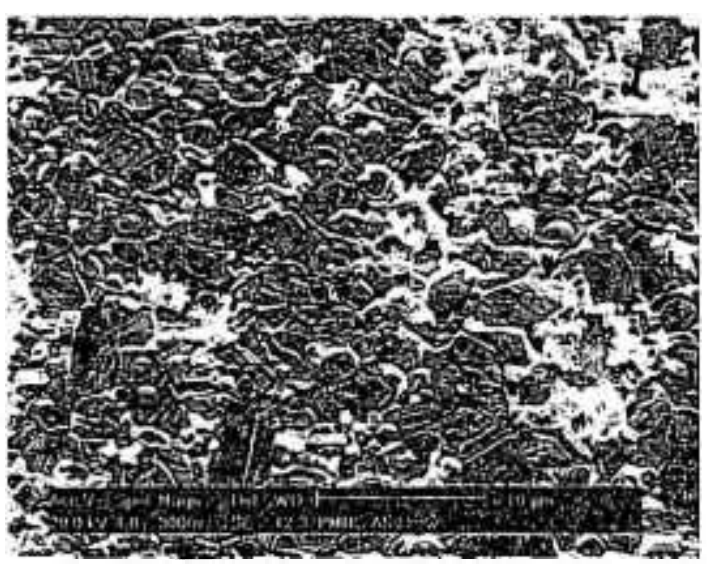

(a)

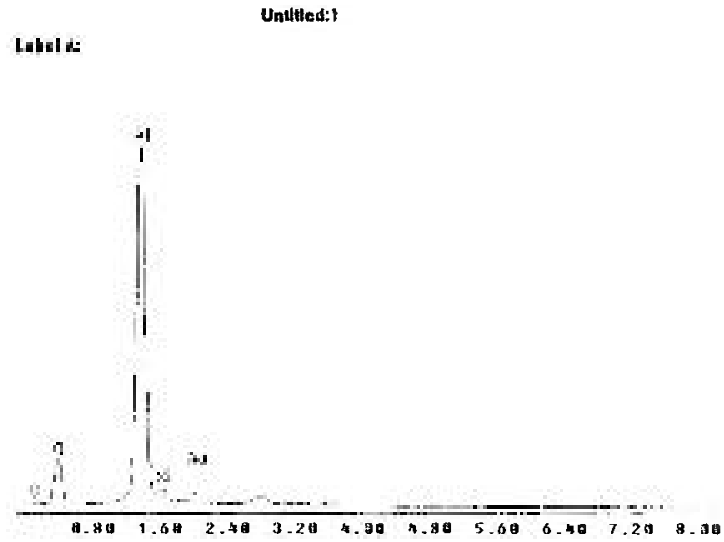

Energia (keV)

(b)

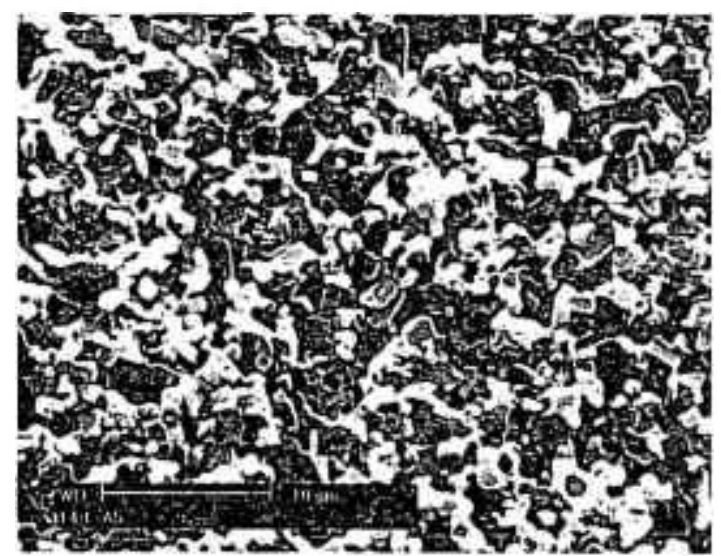

(c)

Figura IV.26- Amostra A5H-9A-1650N: (a)- Microestrutura da amostra após ataque térmico a vácuo a $1550{ }^{\circ} \mathrm{C}$, por $15 \mathrm{~min}$; (b)- Espectro de EDS; varredura da área apresentada no item (a); (c)- Superficie de fratura da amostra.

\section{Amostras de $\mathrm{Al}_{2} \mathrm{O}_{3}: 10 \%$ PMHS pirolisadas em argônio}

Na Figura IV.27 é mostrada a micrografia de amostra polida e atacada termicamente, espectro de EDS e superficie de fratura da amostra A10H-9A-1650N. 


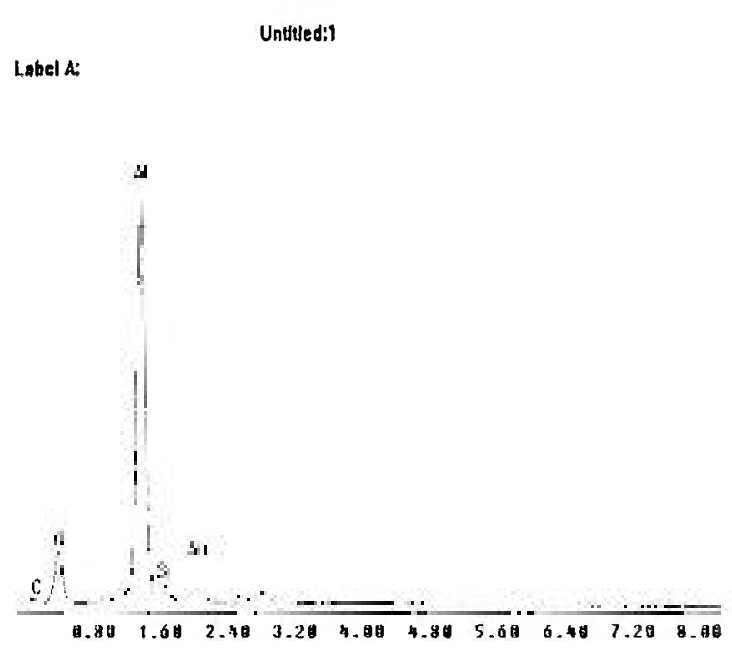

Energia (keV)

(a)

(b)

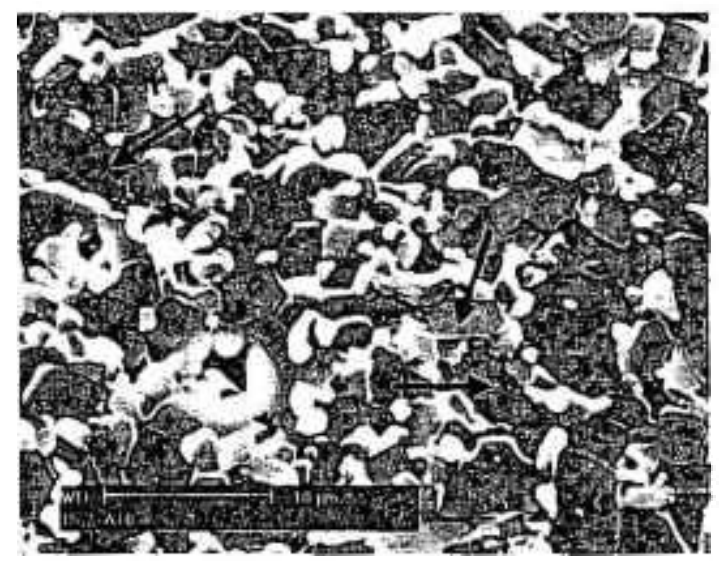

(c)

Figura IV.27- Micrografias de amostras A10H- 9A-1650N; (a) Amostra após ataque térmico a vácuo a $1550^{\circ} \mathrm{C}$, por 15 min.; (b) Espectro de EDS, varredura em área da região apresentada no item (a); (c) Superfície de fratura.

A amostra polida foi atacada e apresenta uma certa rugosidade provavelmente devido ao excesso de ataque, Figura IV.27 (a). Na análise por EDS observa-se picos de C e $\mathrm{Si}$ bem definidos, além do $\mathrm{Al}$ e $\mathrm{O}$ provenientes do $\mathrm{Al}_{2} \mathrm{O}_{3}$. Nota-se a presença de $\mathrm{Au}$ devido ao recobrimento. Neste caso, a faixa de tamanho de grãos varia entre aproximadamente $0,3 \mu \mathrm{m}$ e $5 \mu \mathrm{m}$. Na superfície de fratura há alguns grãos arrendondados e outros alongados, típicos da alumina, identificados com setas na Figura IV.27 (c). 
As micrografias obtidas por MEV da amostra AlH-9N-1650N, são mostradas na Figuras IV.28. Foram feitas também análises de espectometria de raios $\mathrm{X}$ por dispersão de energia.
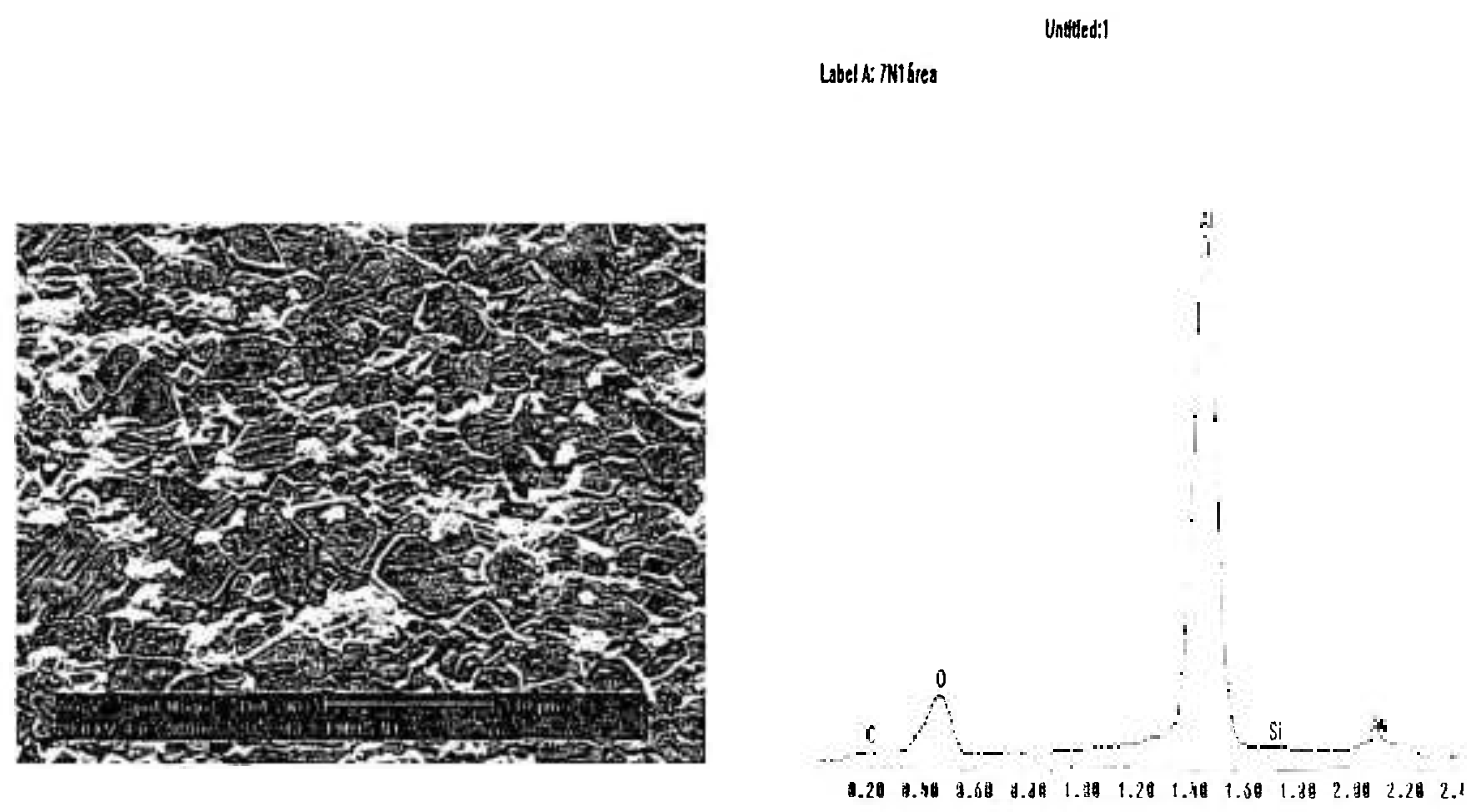

(a)

(b) Energia (keV)

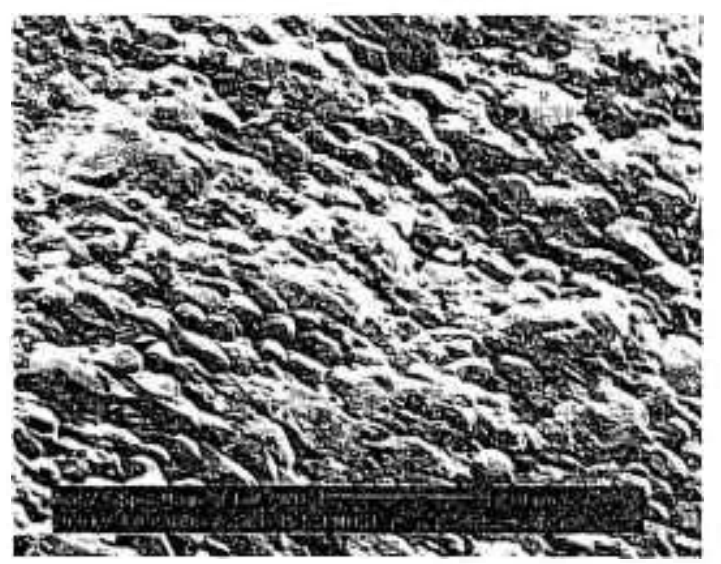

(c)

Figura IV.28-Amostra A1H-9N-1650N: (a)- Micrografia de amostra após polimento e ataque térmico; (b)- Espectro de EDS, varredura em área da região apresentada no item (a); (c)- Superficie de fratura. 
Na Figura IV.28 (a) é mostrada a micrografia de amostra polida e atacada. $\mathrm{O}$ espectro de EDS é relativo à área da Figura IV.28 (a) e mostra pequenas relevâncias de C e $\mathrm{Si}$, provenientes do polímero precursor. $\mathrm{O}$ tamanho de grão varia de cerca de $1 \mu \mathrm{m}$ a aproximadamente $6 \mu \mathrm{m}$. A fratura observada nas Figura IV.28 (c) é intergranular.

\section{Amostras de $\mathrm{Al}_{2} \mathrm{O}_{3}: 5 \%$ PMHS pirolisadas em nitrogênio}

As micrografias obtidas por MEV da amostra A5H-9N-1650N, são mostradas na Figuras IV.29. Foram feitas também análises de espectometria de raios $\mathrm{X}$ por dispersão de energia.

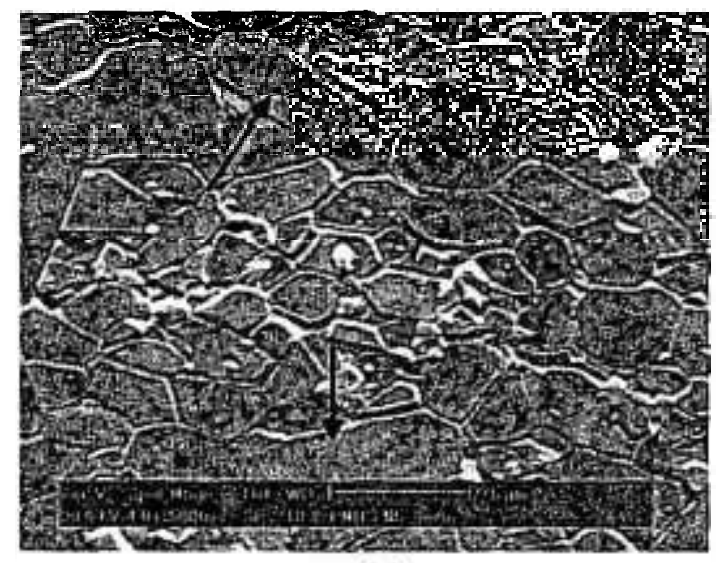

(a)

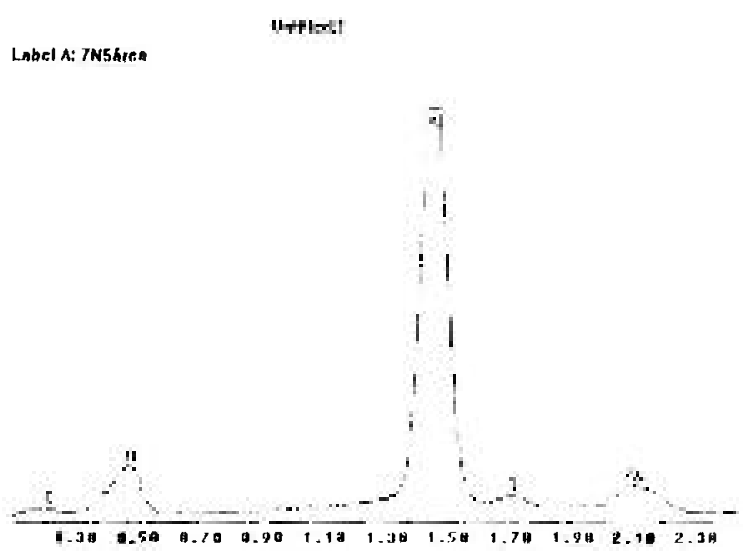

(b) Energia (keV)

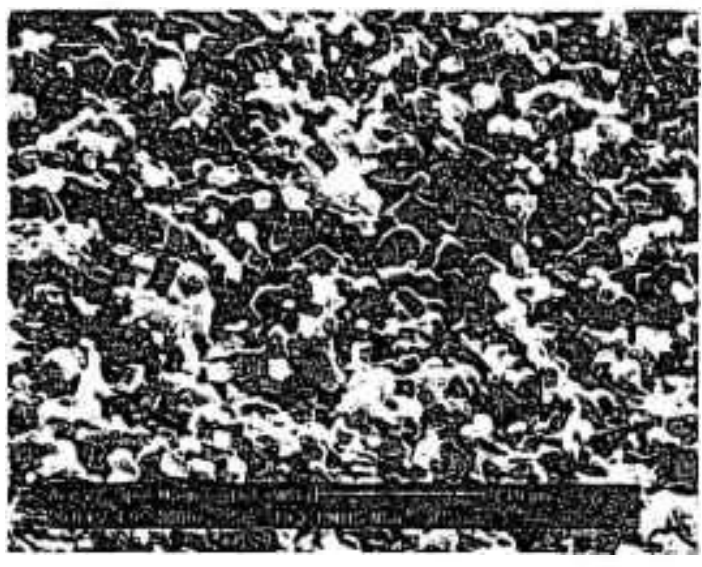

(c)

Figura IV.29- Amostra A5H-9N-1650N: (a)- Micrografia após polimento; (b)- Espectro de EDS, varredura em área da região apresentada no item (a), (c)-Superficie de fratura.

A amostra polida apresenta alguns grãos alongados, outros facetados. O espectro de EDS da micrografia (a) apresenta $\mathrm{C}, \mathrm{O}$, e Si provenientes do polímero. De uma maneira 
geral, os espectros de EDS são do tipo mostrado na Figura IV.29 (b). Observando a amostra polida e a superfície de fratura pode-se estimar que os grãos variam de aproximadamente $1 \mu \mathrm{m}$ a cerca de $5 \mu \mathrm{m}$.

\section{Amostras de $\mathrm{Al}_{2} \mathrm{O}_{3}: 10 \%$ PMHS pirolisadas em nitrogênio}

Nas Figuras IV.30 e IV.31 são mostradas as micrografias de MEV da amostra A10H-9N-1650N.

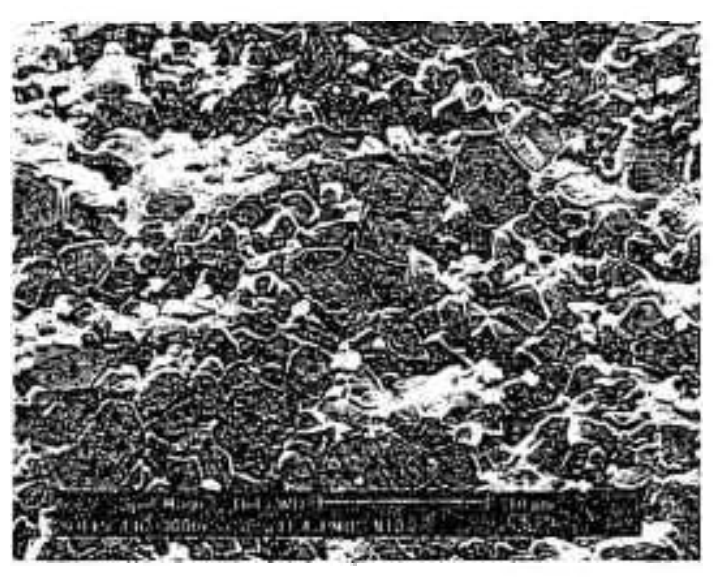

(a)

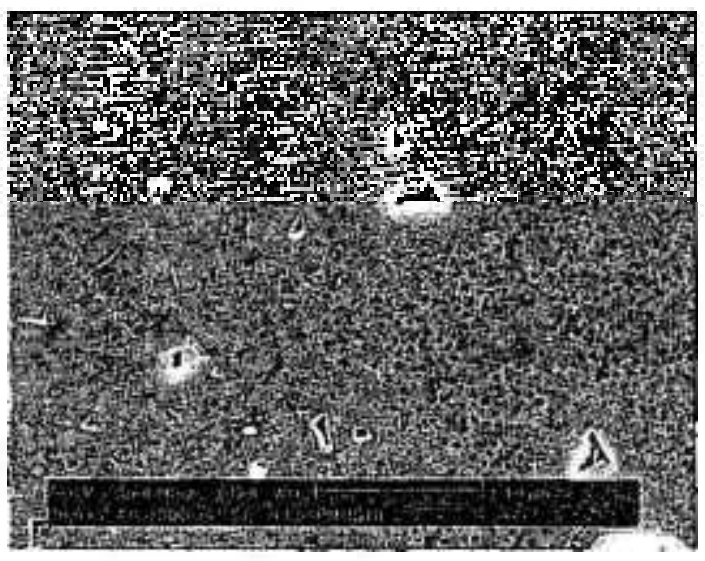

(c)

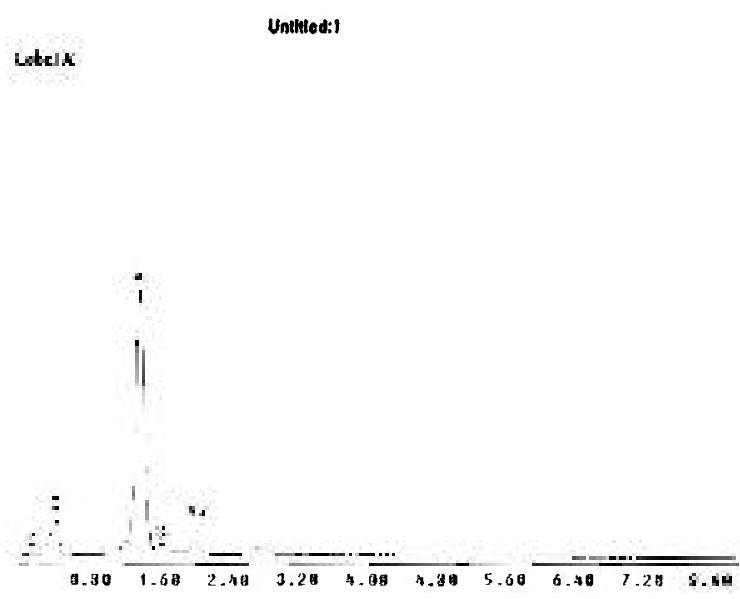

(b) Energia (keV)

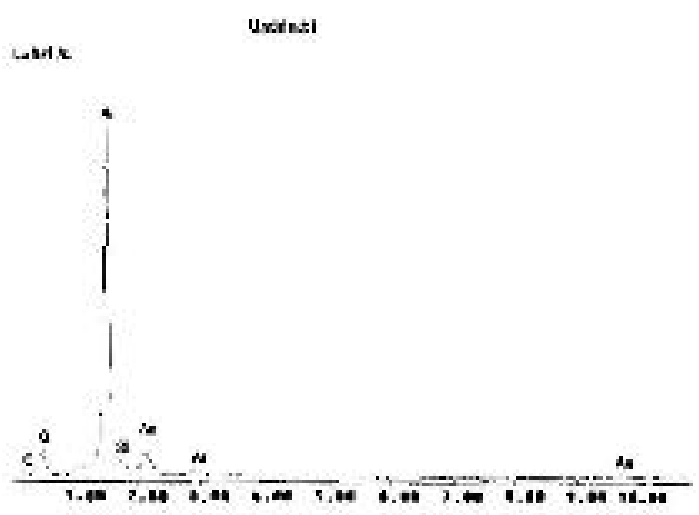

(d) Energia (keV)

Figura IV.30- Amostra A10H-9N-1650N: (a)- Superficie polida e atacada; (b)- Espectro de EDS, da região apresentada em (a); (c)- Superficie sem ataque; (d)- Espectro de EDS da região (c). 


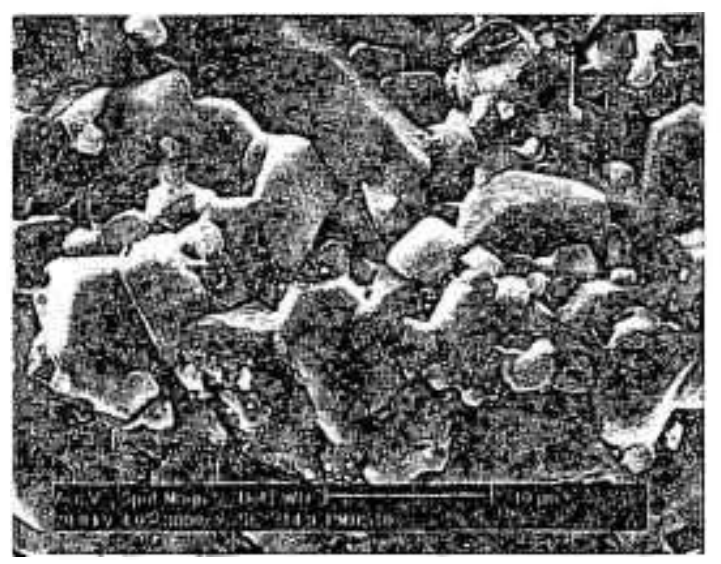

(a)

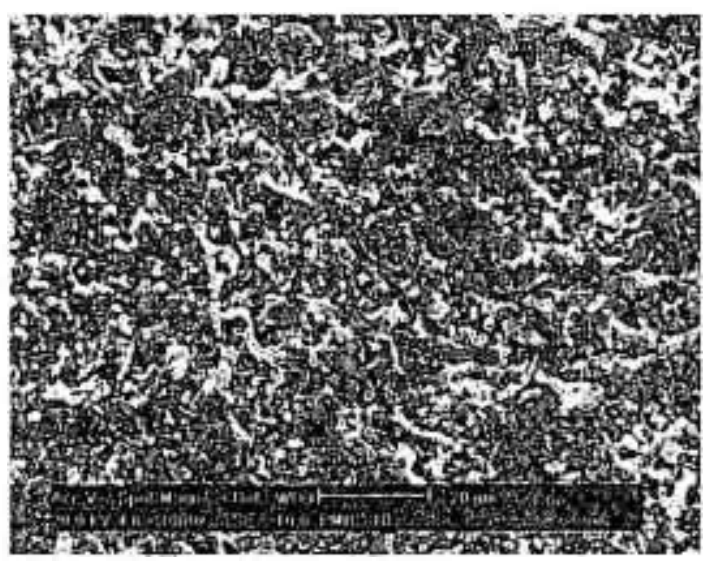

(b)

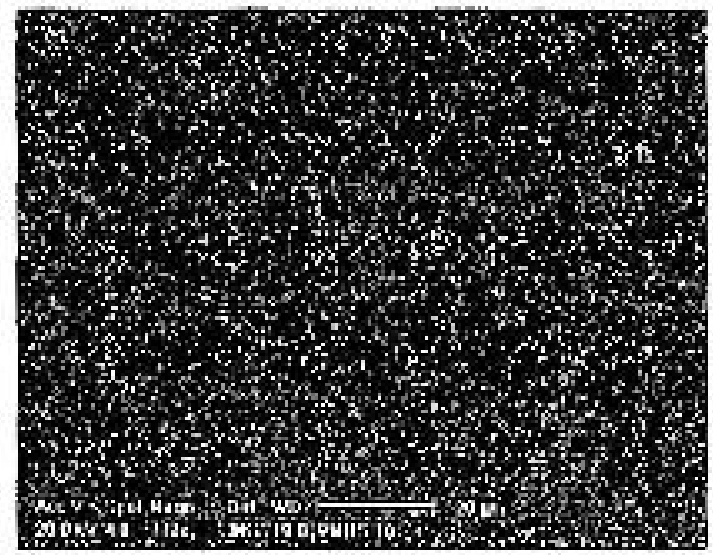

(c)

Figura IV.31- Amostra A10H-9N-1650N: (a)- Superficie de fratura; (b)- Superficie polida e atacada; (c)- Mapeamento de raios X do elemento Si.

O tamanho de grão varia de $\sim 1 \mu \mathrm{m}$ a cerca de $7 \mu \mathrm{m}$, como pode ser observado na Figura IV.30 (a) e Figura IV.31 (a). Para o espectro de EDS, Figura IV.30 (b), foi feita varredura em área da região apresentada na micrografia da Figura IV.30 (a). A superficie sem ataque, Figura IV.30 (c), mostra a presença de segunda fase que, de acordo com os resultados de EDS, Figura IV.30 (d), apresenta C, O Al, e Si. Comparando com os resultados de difração de raios $X$, a segunda fase provavelmente é mulita. A Figura IV.31 (b) mostra o mapeamento de raios $X$ da superficie polida e atacada, Figura IV.31 (a), onde 
os pontos claros representam $\mathrm{Si}$, que podem também estar associados à presença de mulita. Nota-se distribuição homogênea dessa fase na matriz de alumina.

As microestruturas das amostras observadas em MEV apresentam alguns poros devido, principalmente, à volatilização dos produtos orgânicos durante a pirólise [73, 105, 118], e as densidades são relativamente altas, levando-se em conta a densidade teórica da alumina.

Em todos os espectros de EDS observa-se pico de Si e de C, além do Al e do oxigênio. Este fato demonstra que o $\mathrm{Si}$ e o $\mathrm{C}$ do polímero PMHS estão presentes nas amostras e são mais evidentes nas amostras com adições de 5\% e 10\% de PMHS.

A amostra A10H-9N-1650N foi observada em microscópio eletrônico de transmissão. O objetivo da utilização desta técnica é um estudo mais detalhado da microestrutura do material identificando-se fases presentes e sua localização por espectroscopia de raios $\mathrm{X}$ por dispersão de energia.

Na Figura IV.32 são mostradas micrografias gerais da microestrutura da amostra A10H-9N-1650N, com aumentos relativamente baixos.

Nesta análise foram observados elementos característicos da microestrutura como o tamanho dos grãos, poros, pontos triplos, presença ou não de fase amorfa, contornos de grão. Nota-se que há grande variação no tamanho dos grãos de alumina, presença de poucos poros e ausência de fase amorfa.

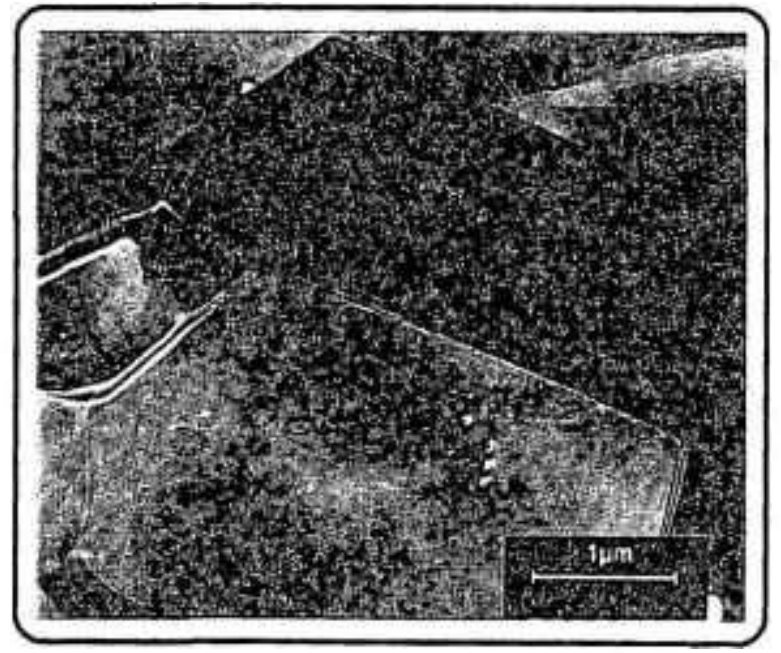




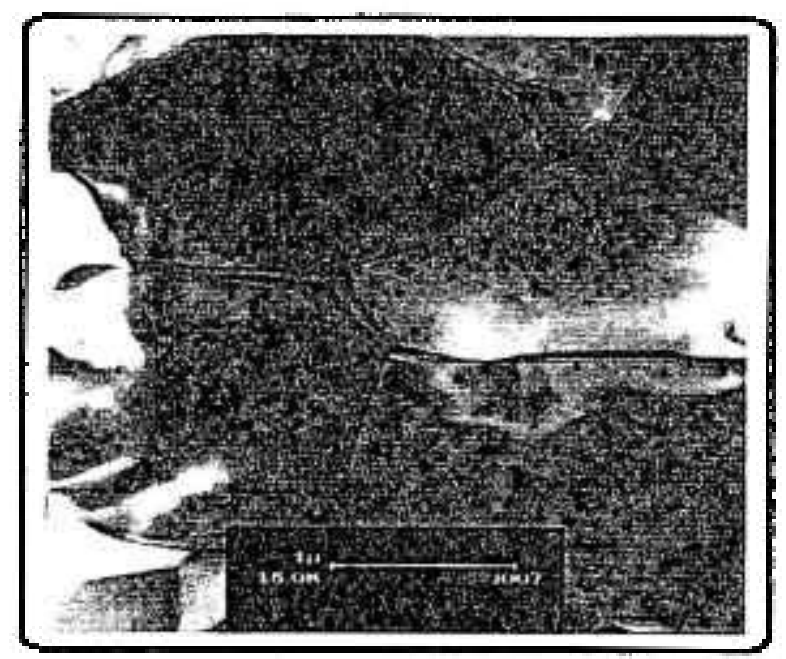

(b)

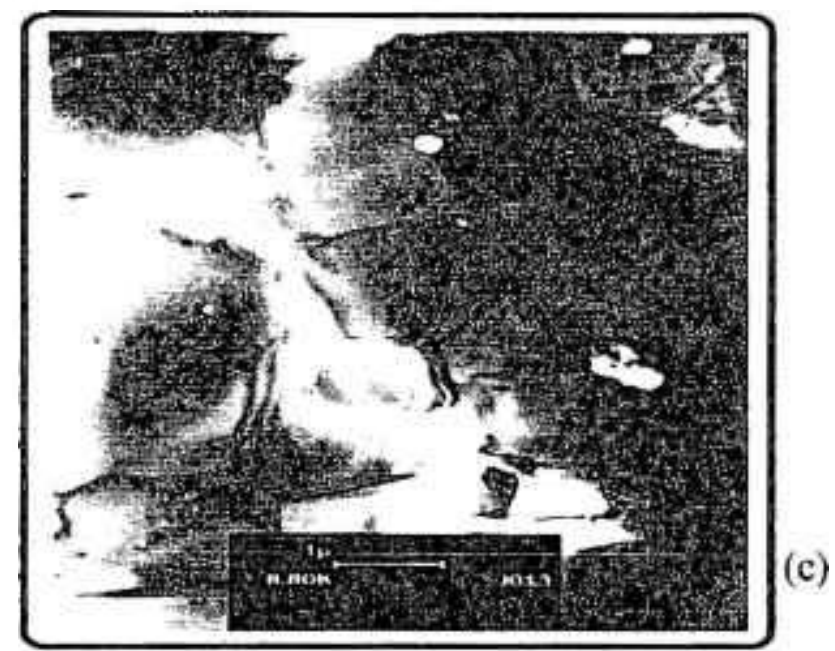

Figura IV.32- Micrografias de MET da amostra A10H-9N-1650N.

Para a análise de fases foram utilizadas a técnica de EDS, na amostra A10H-9N1650N, Figura IV.33. Foram feitas análises de vários grãos, sendo apresentadas algumas micrografias representativas das fases determinadas. 


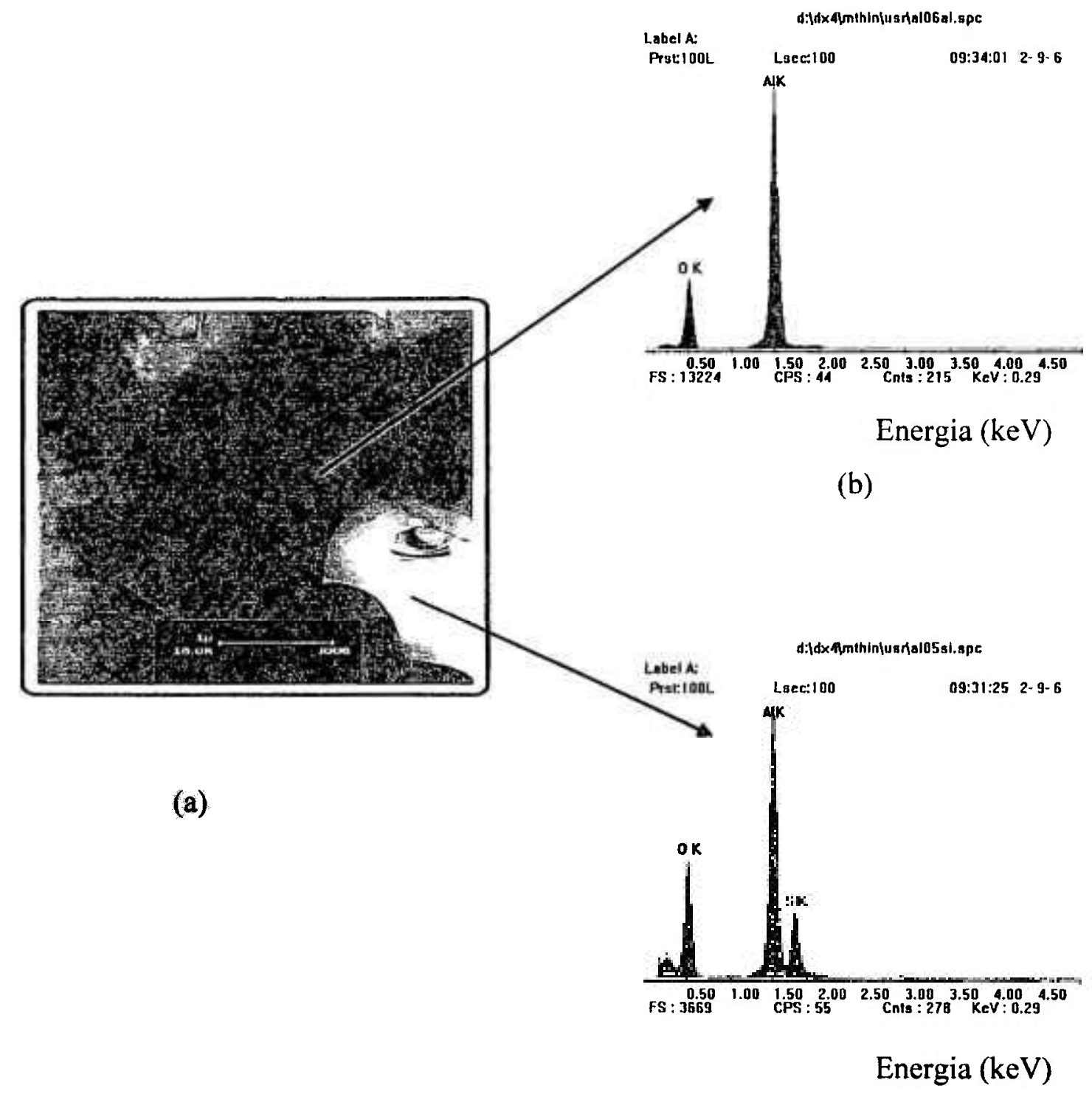

(c)

Figura IV.33- (a)- Micrografia da amostra Al0H-9N-1650N; (b) e (c); EDS correspondentes à análise de grãos.

Na Figura IV.33 nota-se no espectro de EDS, item (b), a presença de Al e O, correspondente a um grão de alumina. $O$ espectro de EDS, item (c), observa-se a presença de $\mathrm{Al}, \mathrm{O}$ e Si evidenciando a presença de mulita (grão claro). 
Na Figura IV.34 é mostrada a micrografia da amostra A10H-9N-1650N e EDS correspondente à análise de grão.

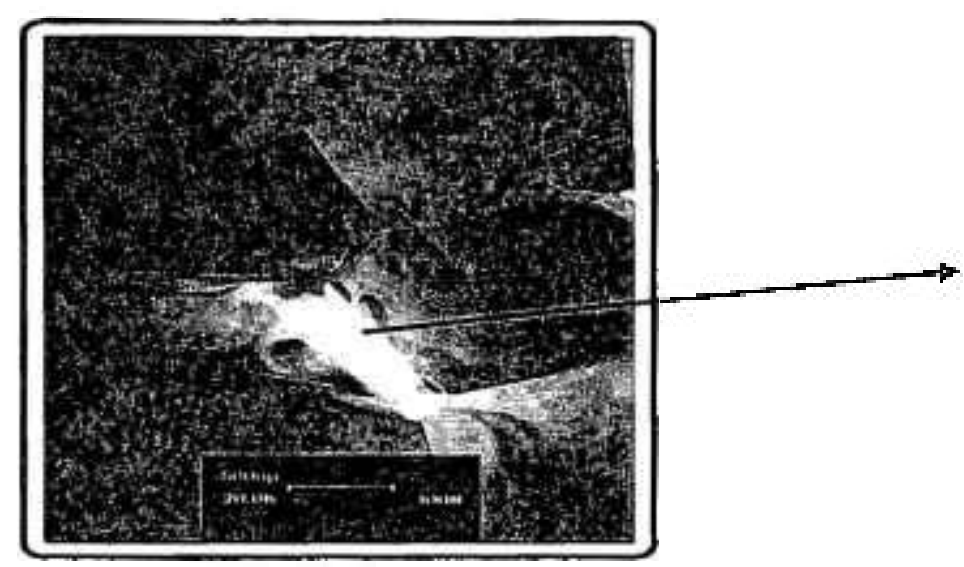

(a)

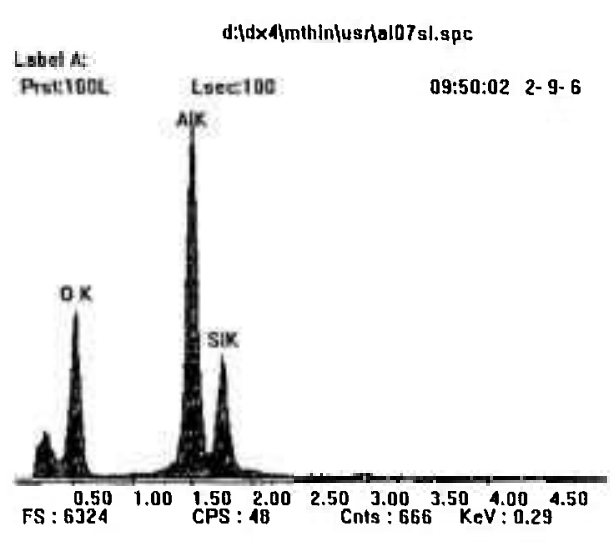

Energia (keV)

(b)

Figura IV.34- (a)- Micrografia da amostra A10H-9N-1650N; (b); EDS correspondente à análise de grão.

Quanto à micrografia da Figura IV.34 (a), os grãos mais escuros são de $\mathrm{Al}_{2} \mathrm{O}_{3}$ e o mais claro, como mostra o EDS, (b), é de mulita, também de acordo com resultados do difratograma, Figura IV.22 (a).

Na Tabela IV.8 são apresentdos os valores de dureza Vickers e tenacidade à fratura das amostras A1H-9A-1650N, A5-9A-1650N e A10H-9A-1650N. 
Tabela IV.8- Dureza Vickers e tenacidade à fratura das amostras A1H-9A-1650N, A5-9A$1650 \mathrm{~N}$ e A10H-9A-1650N.

\begin{tabular}{|c|c|c|}
\hline Amostras & $\begin{array}{c}\mathrm{H}_{\mathrm{v}} \\
(\mathrm{GPa})\end{array}$ & $\begin{array}{c}\mathrm{K}_{\mathrm{IC}} \\
\left(\mathrm{MPa} \cdot \mathrm{m}^{1 / 2}\right)\end{array}$ \\
\hline A0-1650N & $14,9 \pm 0,6$ & $3,72 \pm 0,18$ \\
\hline A1H-9N-1650N & $15,9 \pm 0,3$ & $3,47 \pm 0,10$ \\
\hline A5H-9N-1650N & $15,7 \pm 0,6$ & $3,48 \pm 0,10$ \\
\hline A10H-9N-1650N & $16,3 \pm 0,6$ & $3,45 \pm 0,11$ \\
\hline A1H-9A-1650N & $15,5 \pm 0,3$ & $3,56 \pm 0,10$ \\
\hline A5H-9A-1650N & $13,0 \pm 0,3$ & $3,95 \pm 0,18$ \\
\hline A10H-9A-1650N & $14,9 \pm 0,4$ & $3,86 \pm 0,12$ \\
\hline A10H-9N-1650N & $16,3 \pm 0,6$ & $3,45 \pm 0,11$ \\
\hline
\end{tabular}

Os valores de dureza Vickers nas amostras com duas condições de pirólise foram relativamente próximos, estando dentro de uma faixa que varia de 13,0 GPa e 16,3 GPa. Os valores de tenacidade à fratura determinados variam de $3,45 \mathrm{MPa} \cdot \mathrm{m}^{1 / 2}$ a 3,95 $\mathrm{MPa} \cdot \mathrm{m}^{1 / 2}$.

Na Figura IV.35 são mostradas as micrografias típicas de indentações de amostras de $\mathrm{Al}_{2} \mathrm{O}_{3}$ com PMHS utilizadas para medidas de dureza e trincas para medidas de tenacidade à fratura.

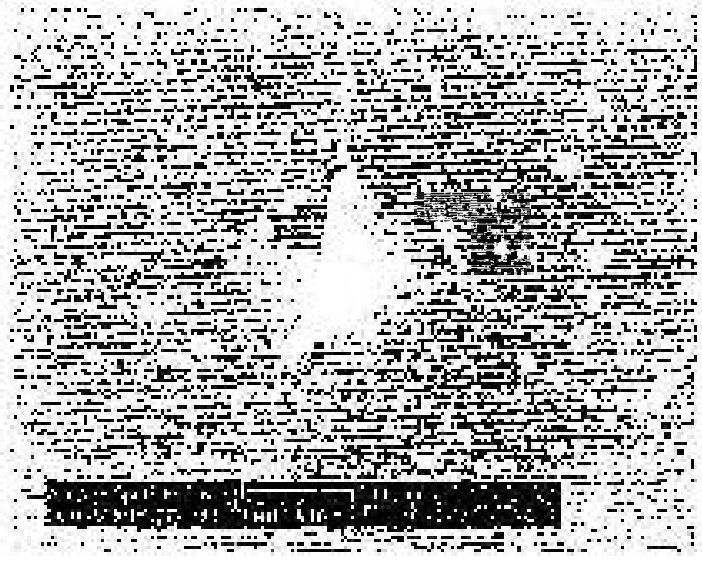

(a)

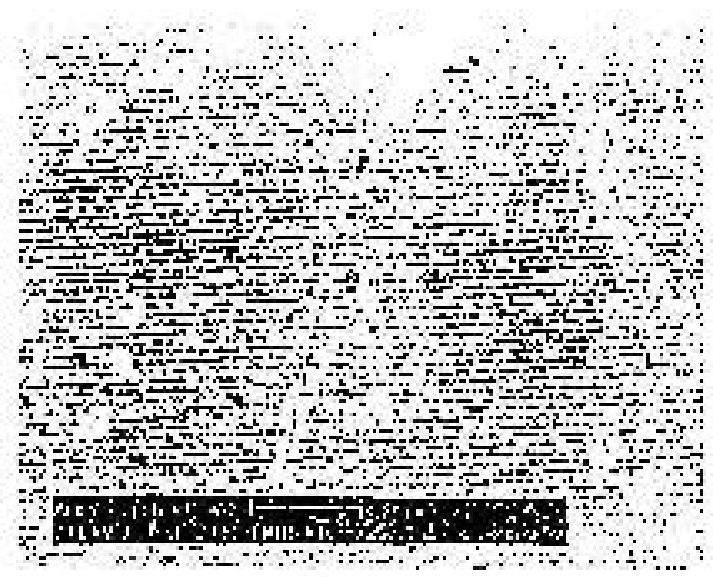

(b) 


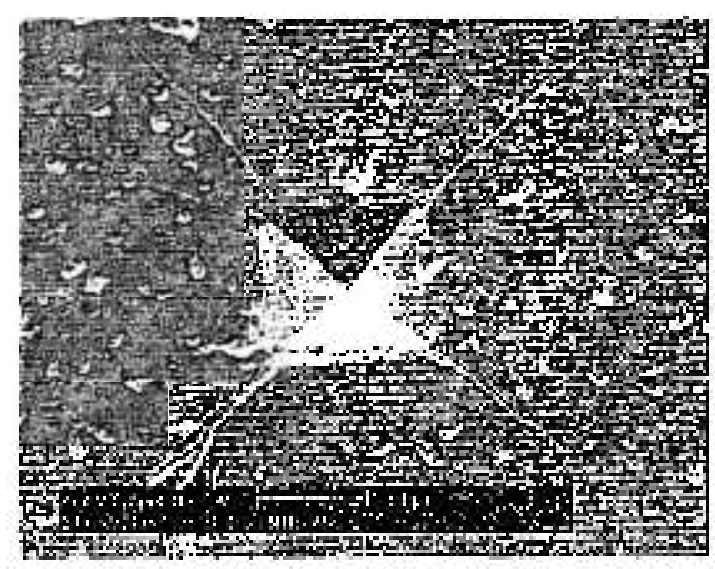

(c)

Figura IV.35- Micrografias de indentações; (a)- Amostra A10H-9N-1650N, indentação; (b)- Amostra A10H-9N-1650N, trinca; (c)- Amostra A5H-9A-1650N, indentação.

Uma visão geral da indentação da amostra $\mathrm{A} 10 \mathrm{H}-9 \mathrm{~N}-1650 \mathrm{~N}$ pode ser vista na Figura IV.35 (a). Observa-se, com maior detalhe, na Figura IV.35 (b), uma trinca típica para medidas de $\mathrm{K}_{\mathrm{lc}} \mathrm{Na}$ indentação da amostra A5H-9A-1650N, pode-se ver claramente as trincas radiais, e poros, Figura IV.35 (c).

$\mathrm{O}$ método utilizado para medidas do $\mathrm{K}_{\mathrm{lc}}$ é prático para materiais frágeis com baixa tenacidade à fratura, uma vez que é simples e rápido.

Além do polímero PMHS, foram estudadas também as adições de PMS e PPS em $\alpha-\mathrm{Al}_{2} \mathrm{O}_{3}$, pirolisadas e sinterizadas em nitrogênio.

Depois de realizados os testes das amostras de $\mathrm{Al}_{2} \mathrm{O}_{3}$ com PMHS com diferentes atmosferas de pirólise, decidiu-se pirolisar o $\mathrm{Al}_{2} \mathrm{O}_{3}$ com PMS e com PPS em nitrogênio. A sinterização foi realizada a $1650^{\circ} \mathrm{C}$, em nitrogênio.

\section{$\mathrm{Al}_{2} \mathrm{O}_{3}: \mathrm{PMS}$}

Na Figura IV.36 é mostrada a curva de dilatometria da amostra A10M-9N-1650N. $\mathrm{Na}$ curva de retração linear observa-se um ponto de inflexão em aproximadamente $700{ }^{\circ} \mathrm{C}$, que pode ser devido a volatilização de polímeros ou formação de fase. A partir de aproximadamente $1200^{\circ} \mathrm{C}$ ocorre retração alta, com possivel formação de fases cristalinas e alterações no processo de sinterização. A retração máxima foi de cerca de $11 \% \mathrm{e}$ no patamar de 1 hora a $1650^{\circ} \mathrm{C}$ houve pequena retração. 
Nesta etapa do trabalho foram utilizadas composições de alumina com $1 \%, 5 \%$ e $10 \%$ de precursor polimérico, PMS. A temperatura de pirólise foi $900^{\circ} \mathrm{C}$, em atmosfera de nitrogênio. A sinterização foi feita a $1650^{\circ} \mathrm{C}$, em nitrogênio.

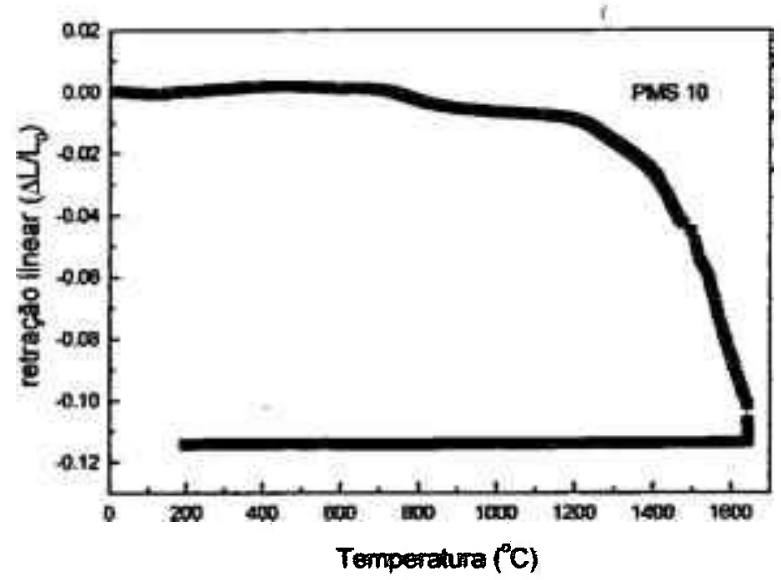

Figura IV.36- Curvas de dilatometria das amostras A10M-9N-1650N: retração linear, em função da temperatura.

As densidades aparentes das amostras, determinadas por picnometria de He, \% D.T. e perdas de massa das amostras de alumina contendo PMS, são apresentadas nas Tabela IV.9.

Tabela IV.9- Densidades aparentes, \% D.T. e perdas de massa de A0-1650N, A1M- 9N$1650 \mathrm{~N}, \mathrm{~A} 5 \mathrm{M}-9 \mathrm{~N}-1650 \mathrm{~N}$ e A10M-9N-1650N.

\begin{tabular}{|c|c|c|c|c|c|c|}
\hline Amostra & $\begin{array}{c}\rho_{\text {aparnie }} \\
\left(\mathrm{g} / \mathrm{cm}^{3}\right)\end{array}$ & $\begin{array}{c}\% \\
\text { D.T. }\end{array}$ & $\begin{array}{c}\text { PM } \\
\mathrm{B} \rightarrow \mathrm{A}(\%)\end{array}$ & $\begin{array}{c}\text { PM } \\
\mathbf{C} \rightarrow \mathrm{B}(\%)\end{array}$ & $\begin{array}{c}\text { PM } \\
\mathrm{C} \rightarrow \mathrm{A}(\%)\end{array}$ & $\begin{array}{c}\text { PMP } \\
(\%)\end{array}$ \\
\hline A0-1650N & $3,96 \pm 0,03$ & 99,5 & - & - & 1,2 & - \\
\hline A1M-9N-1650N & $3,88 \pm 0,07$ & 97,5 & 1,1 & 0,1 & 1,2 & 1,4 \\
\hline A5M-9N-1650N & $3,78 \pm 0,03$ & 95,0 & 1,8 & 1,1 & 2,9 & 2,2 \\
\hline A10M-9N-1650N & $3,72 \pm 0,04$ & 94,0 & 3,1 & 1,5 & 4,7 & 3,3 \\
\hline
\end{tabular}

$A \rightarrow$ antes da pirólise $B$ após pirólise $\mathbb{C} \rightarrow$ após sinterização

B $\rightarrow$ A - perda de massa durante pirólise

C $\rightarrow$ B - perda de massa parcial entre pirólise e sinterizaçåo

$C \rightarrow A$ - perda de massa total 
As densidades aparentes das amostras PMS diminuem com o aumento da quantidade de polímero.

Em relação às amostras $\mathrm{Al}_{2} \mathrm{O}_{3}$ :PMS, a amostra padrão e $\mathrm{Al}_{2} \mathrm{O}_{3}$ com $1 \%$, obtiveram menor perda de massa. Por outro lado as perdas de $\mathrm{Al}_{2} \mathrm{O}_{3}: \mathrm{PMS}$, com $5 \%$ e $10 \%$ de polímero precursor, apresentaram valores menores que a perda de massa prevista. Comparando com as amostras $\mathrm{Al}_{2} \mathrm{O}_{3}$ :PMHS, as mesmas apresentaram perdas de massa superiores às amostras $\mathrm{Al}_{2} \mathrm{O}_{3}$ :PMS.

Na Figura IV.37 são mostrados os difratogramas das amostras com adições de PMS e sinterizadas a $1650^{\circ} \mathrm{C}$.

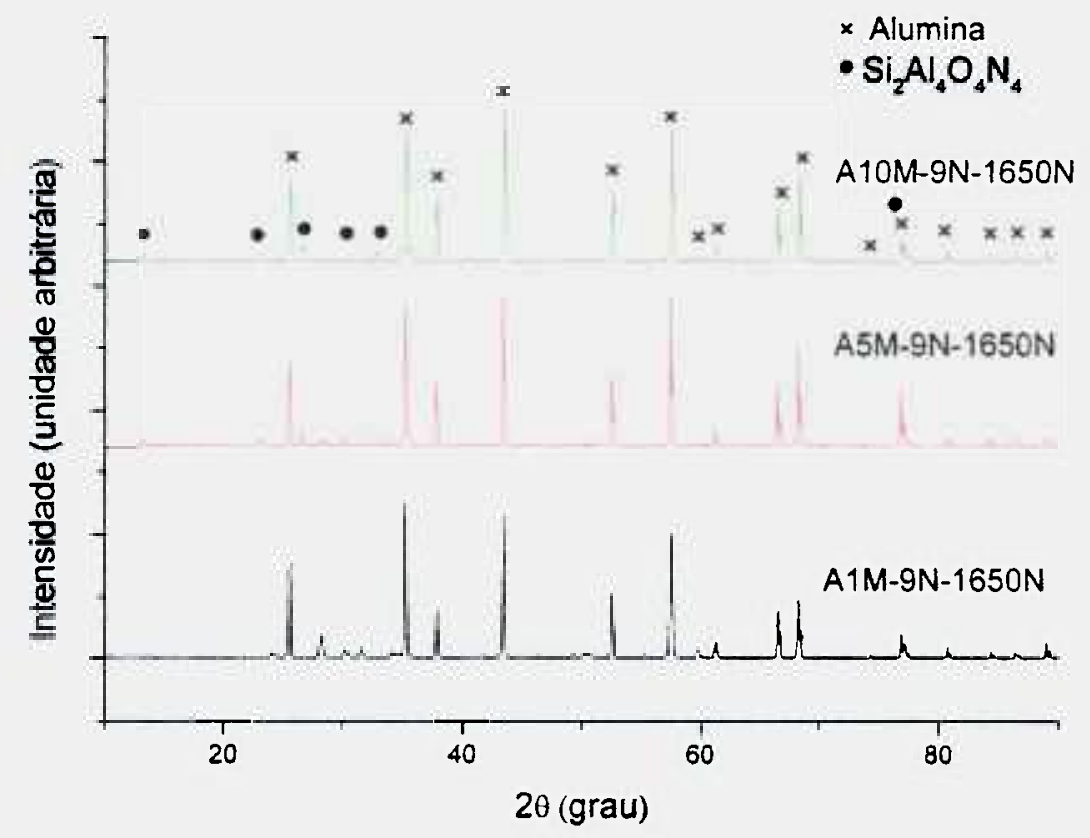

Figura IV.37- Difratogramas de raios X das amostras A1M-9N-1650N, A5M-9N-1650N e A10M-9N-1650N.

Os difratogramas de raios $\mathrm{X}$ das amostras de $\mathrm{Al}_{2} \mathrm{O}_{3}: \mathrm{PMS}$ sinterizadas apresentam pelo menos duas fases, alumina e $\mathrm{Si}_{2} \mathrm{Al}_{4} \mathrm{O}_{4} \mathrm{~N}_{4}$, ficha JCPDS 76-598. Há alguns picos cujas fases não foi possivel identificar.

Na Figura IV.38 é mostrada a quantidade de carbono em função da quantidade de polímero após sinterização de $\mathrm{Al}_{2} \mathrm{O}_{3}: 1 \%$ PMS, $\mathrm{Al}_{2} \mathrm{O}_{3}: 5 \%$ PMS e $\mathrm{Al}_{2} \mathrm{O}_{3}: 10 \%$ PMS. Os dados para obtenção desta curva foram obtidos utilizando-se a técnica de análise de carbono total. 


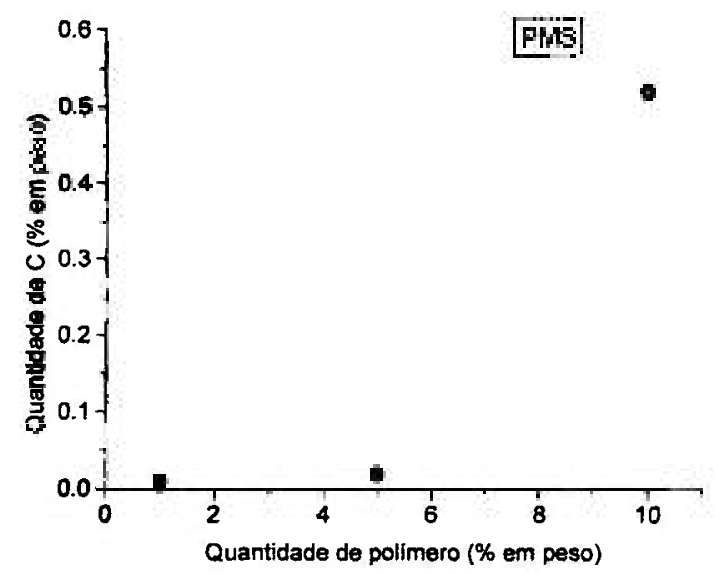

Figura IV.38- Análise de carbono total após sinterização das amostras AlM-9N-1650N, A5M-9N-1650N e A10M-9N-1650N.

Observa-se nesta curva exponencial que à medida que aumenta a quantidade de polimero, a quantidade de carbono retido também aumenta, atingindo aproximadamente $0,52 \%$ em peso.

\section{Amostra de $\mathrm{Al}_{2} \mathrm{O}_{3}: 1 \%$ PMS}

Micrografias de superficies de fratura da amostra AlM- $9 \mathrm{~N}-1650 \mathrm{~N}$, obtidas por MEV, são mostrados na Figura IV.39.

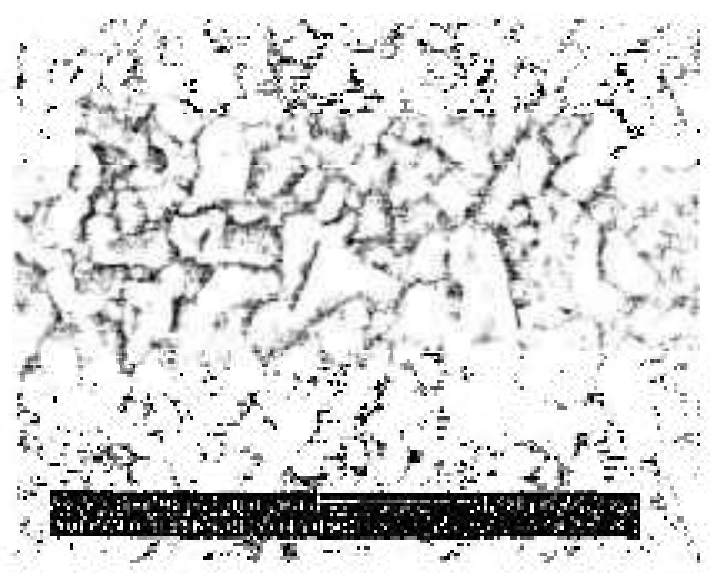

(a)

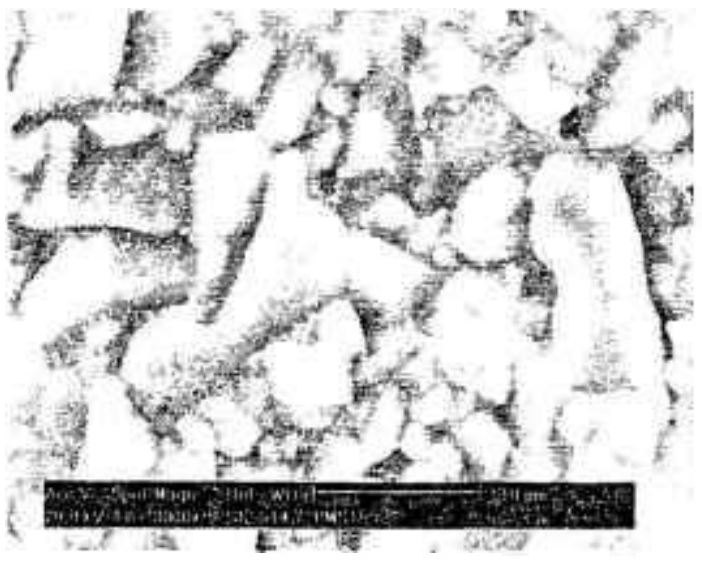

(b)

Figura IV.39- Micrografias de amostra de $\mathrm{Al}_{2} \mathrm{O}_{3}$ com $1 \%$ de PMS, pirolisada a $900{ }^{\circ} \mathrm{C}$ e sinterizada a $1650^{\circ} \mathrm{C}$, em atmosfera de nitrogênio, A1M- 9N-1650N: (a) e (b)- Superficies de fratura. 
Nestas micrografias, amostra A1M- 9N-1650N, pode-se observar grãos pequenos e arredondados, e alguns alongados. O tamanho de grão apresenta larga distribuição e, fazendo-se uma estimativa, varia de aproximadamente $1 \mu \mathrm{m}$ a cerca de $15 \mu \mathrm{m}$.

Em trabalho de Schiavon et alli, sobre caracterização microestrutural de compostos de matriz cerâmica a partir de polissiloxano e pó de SiC [106], obteve-se micrografias, semelhantes à algumas obtidas neste trabalho, como exemplo, Figura IV.40. Na Figura IV.40 é mostrado o composto de matriz cerâmica a partir de polissiloxano e pó de SiC.

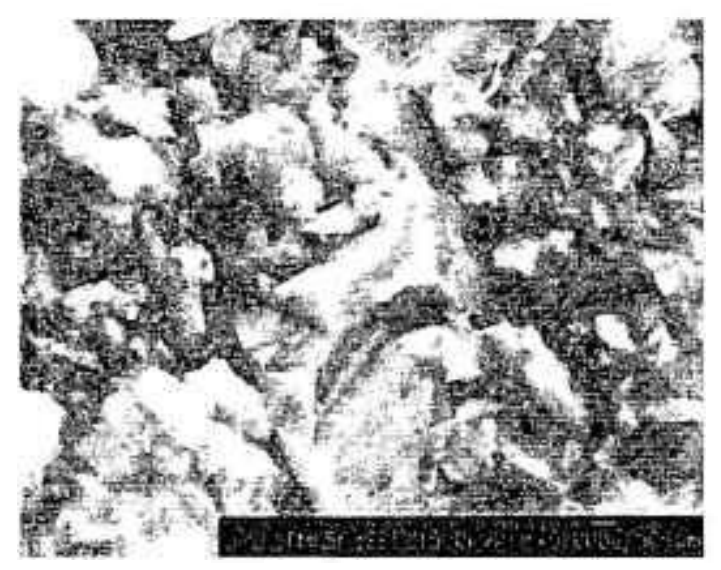

Figura IV.40- Composto de matriz cerâmica a partir de polissiloxano e pó de SiC [106].

\section{Amostra de $\mathrm{Al}_{2} \mathrm{O}_{3}: 5 \%$ PMS}

Na Figura IV.41 são mostradas as micrografias da amostra A5M- 9N-1650N obtidas por MEV. 


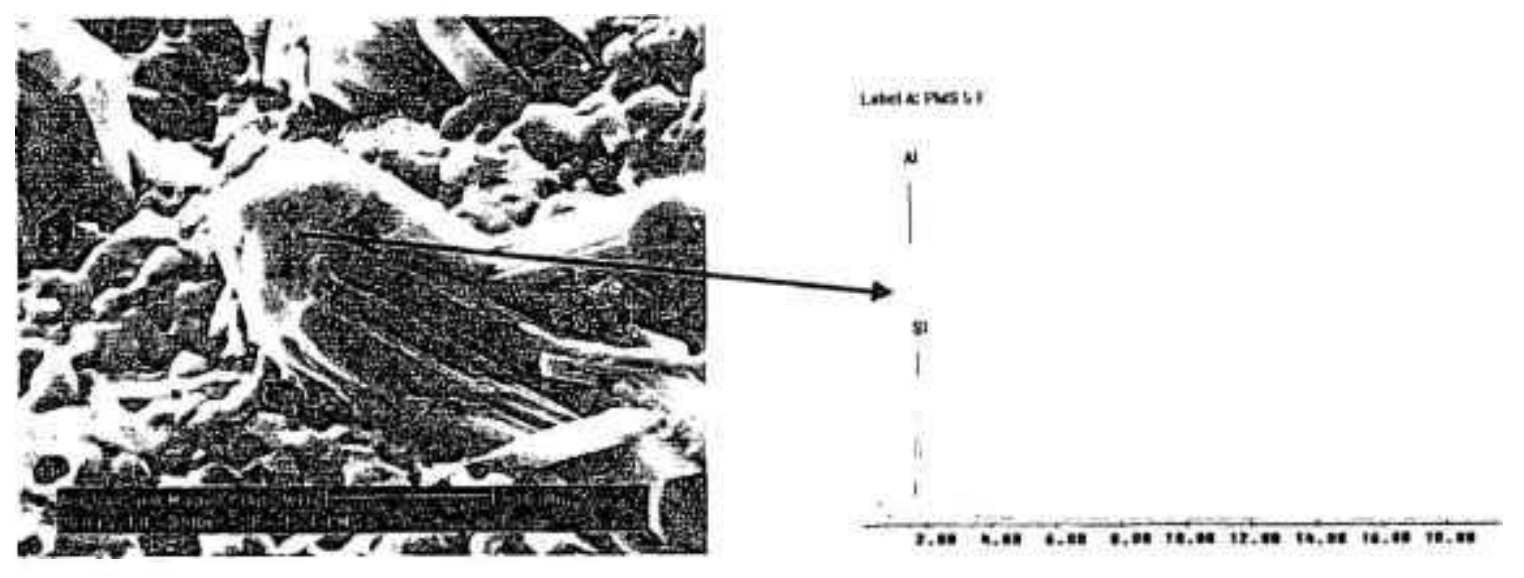

Energia (keV)

(a)

(b)

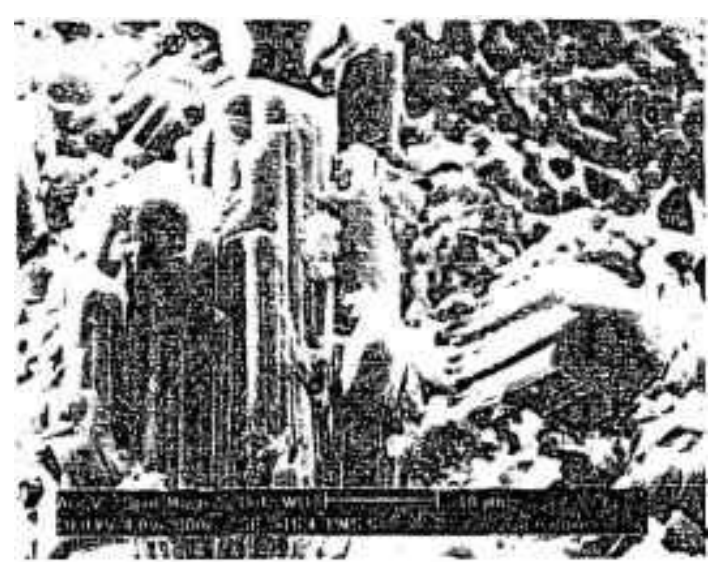

(c)

Figura IV.41- Micrografias da amostra A5M-9N-1650N: (a), (c)- Superficies de fratura, (b)- Espectro de EDS.

Nas Figuras IV.41 (a) e (b), observa-se fratura intergranular. Nestas micrografias pode-se notar a presença de alguns poros e grãos secundários com forma alongada. $O$ espectro de EDS apresenta os elementos $\mathrm{Si}, \mathrm{Al}$ e $\mathrm{O}$. Os grãos alongados, embora com dimensões maiores, de certa forma parecem "whiskers", que são normalmente utilizados como reforço em $\mathrm{Si}_{3} \mathrm{~N}_{4}$, SiC. Se estes grãos forem dispersos na matriz podem acionar mecanismos de tenacificação. 


\section{Amostra de $\mathrm{Al}_{2} \mathrm{O}_{3}: 10 \%$ PMS}

Nas Figuras IV.42 e IV.43 são mostradas as micrografias obtidas por MEV da amostra A10M-9N-1650N.

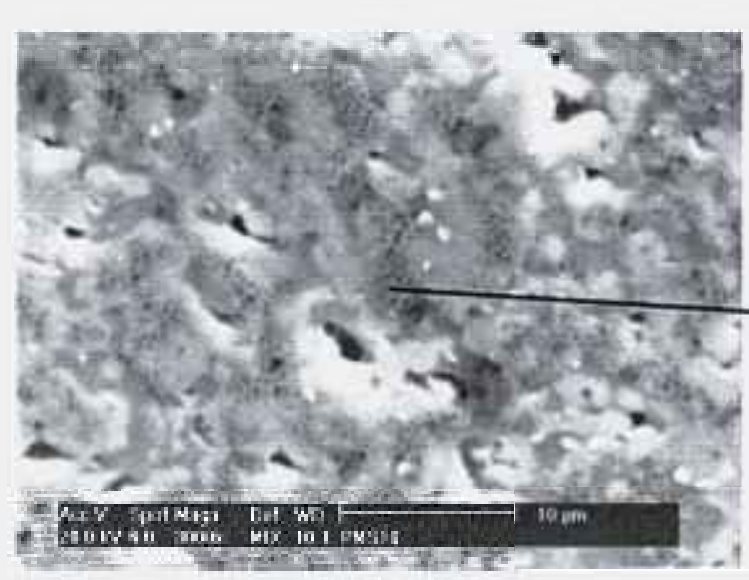

(a)

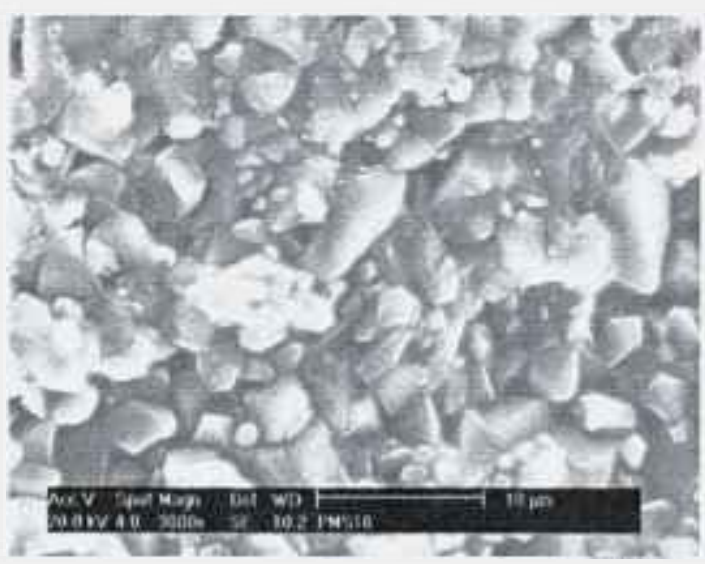

(c)
Latri A: PMSIO FASE CINZA

Lestee:

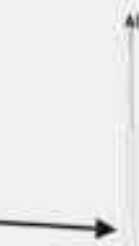

(b)

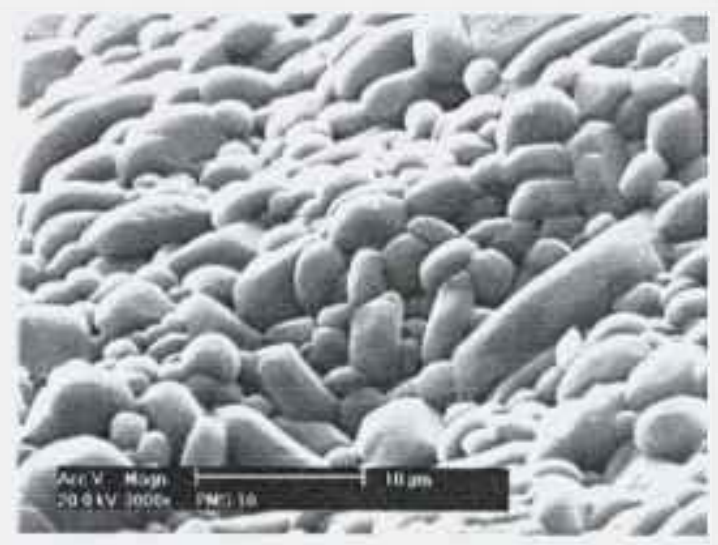

(d)

Figura IV.42- Micrografias obtidas por MEV da amostra A10M-9N-1650N: (a)- Amostra sem ataque; (b)- EDS da região cinza escuro da amostra do item (a); (c) e (d)- Superfícies de fratura. 


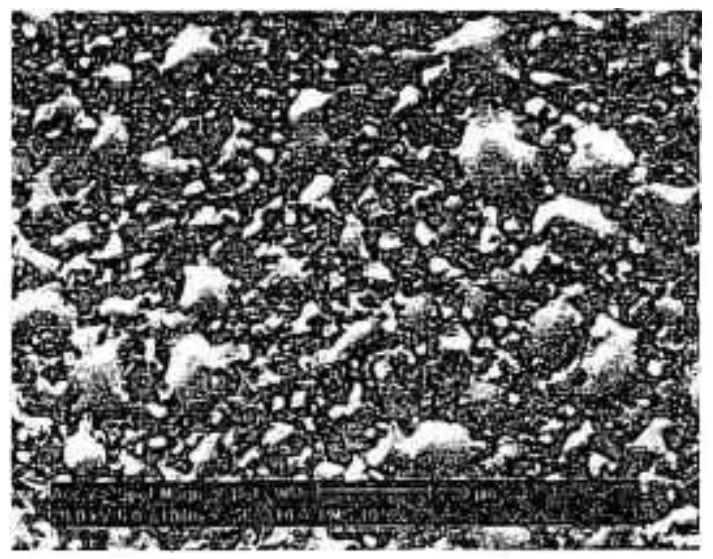

(a)

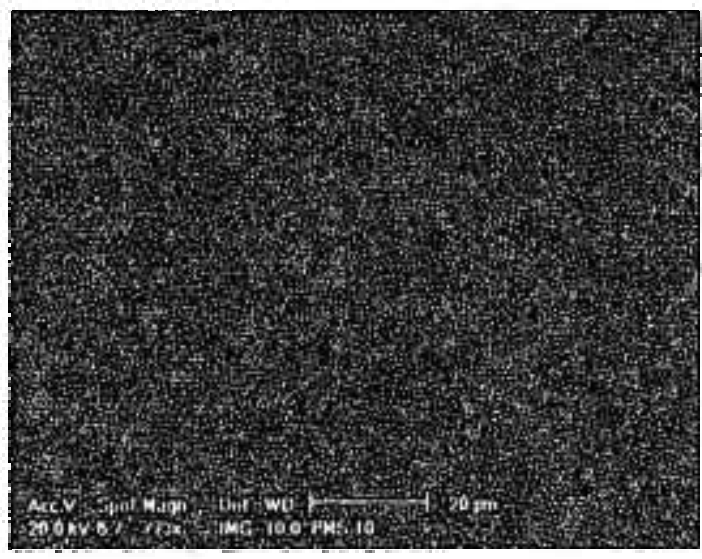

(b)

Figura IV.43- Micrografias obtidas por MEV da amostra A10M-9N-1650N: (a)- Superfície atacada; (b)-mapeamento de raios $\mathrm{X}$ do elemento $\mathrm{Si}$.

$\mathrm{Na}$ amostra que não foi submetida a ataque, Figura IV.42 (a), pode-se observar regiões escuras que, de acordo com análise por EDS, Figura IV.42 (b), contém os elementos $\mathrm{Si}$, Al e $\mathrm{O}$, podendo ser oxinitreto de alumínio e silício, $\mathrm{Si}_{2} \mathrm{Al}_{4} \mathrm{O}_{4} \mathrm{~N}_{4}$, o que estaria de acordo com resultados do difratograma. A superficie de fratura, IV.42 (c), é intergranular. Após limpeza da amostra de A10M-9N-1650N, com solução fraca de HF, obteve-se micrografias de fratura intergranular com grãos bem definidos, característicos da alumina, Figura IV.42 (d). O tamanho dos grăos varia de aproximadamente 1,5 $\mathrm{m}$ a cerca de $15 \mu \mathrm{m}$.

A amostra da Figura IV.43 (a) foi submetida a ataque a $1550^{\circ} \mathrm{C}$ por $15 \mathrm{~min}$. Nota-se a presença de bolhas, que pode ser uma fase contendo Si. O mapeamento de raios X, Figura IV.42 (f), mostra um aumento da concentração de Si em regiões coincidentes com as bolhas.

Na Figura IV.44 é mostrada uma visão geral por MET da amostra A10M-9N$1650 \mathrm{~N}$, podendo-se observar características das microestruturas, como tamanho de grão e contomos de grão. 

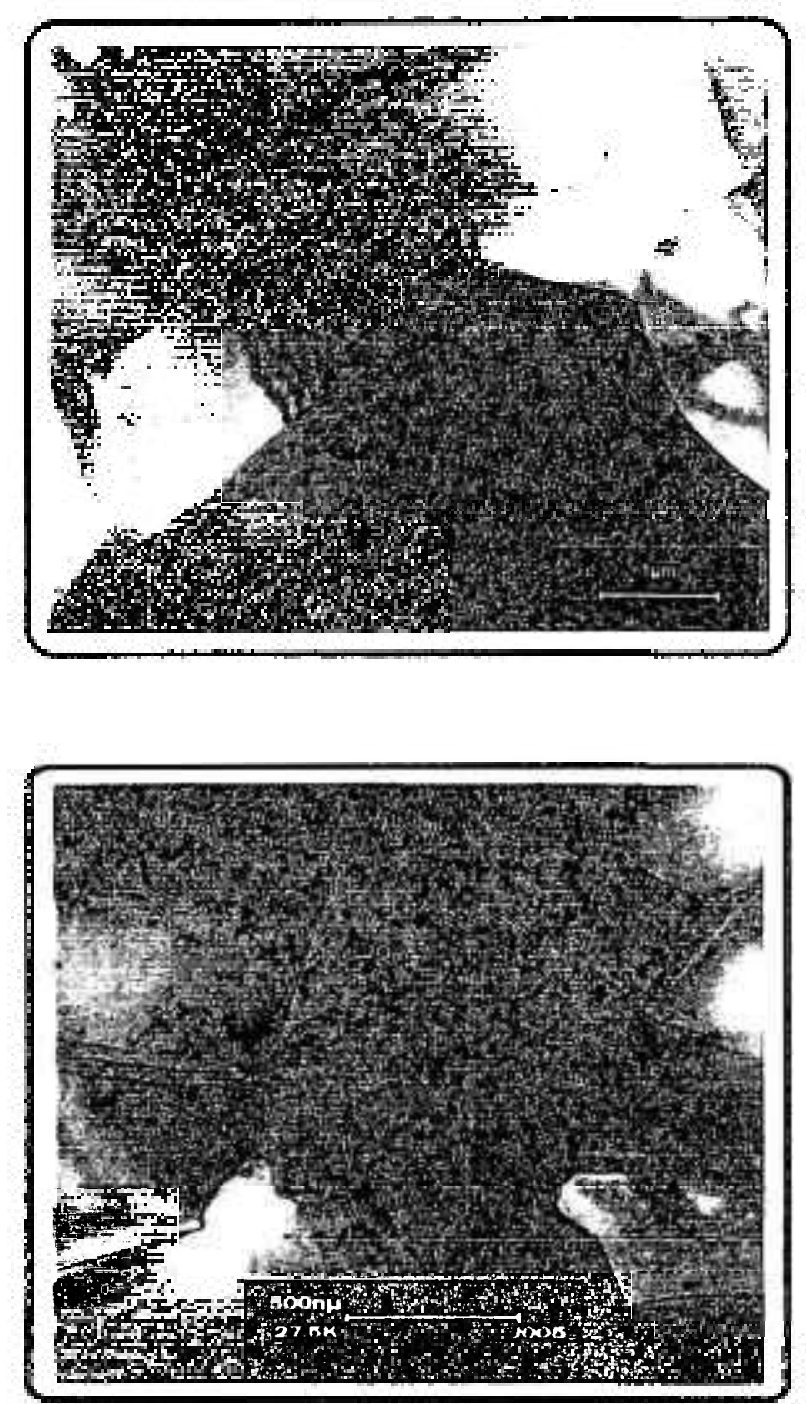

Figura IV.44- Visão geral da amostra A10M-9N-1650N.

Nota-se que há grande variação no tamanho dos grãos de alumina e não foi observada a presença de poros, nem a presença de fase amorfa.

Foram feitas determinações da estrutura cristalina de vários grãos, sendo apresentadas algumas micrografias representativas das fases determinadas na Figura IV.45 e Figura IV.46. 


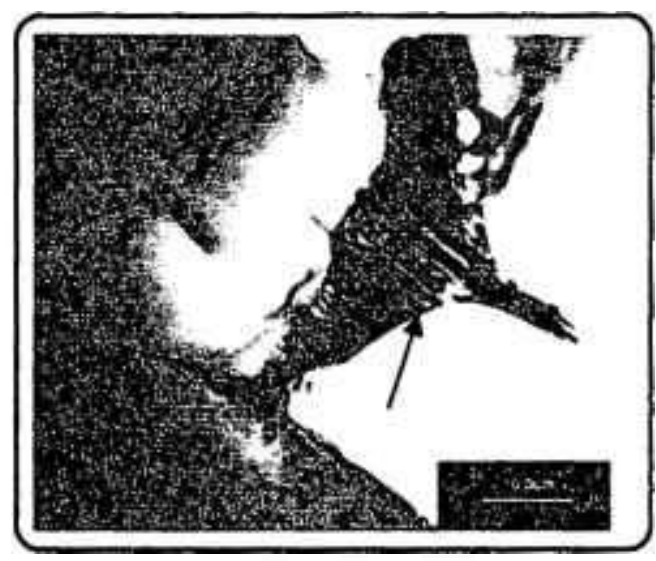

(a)

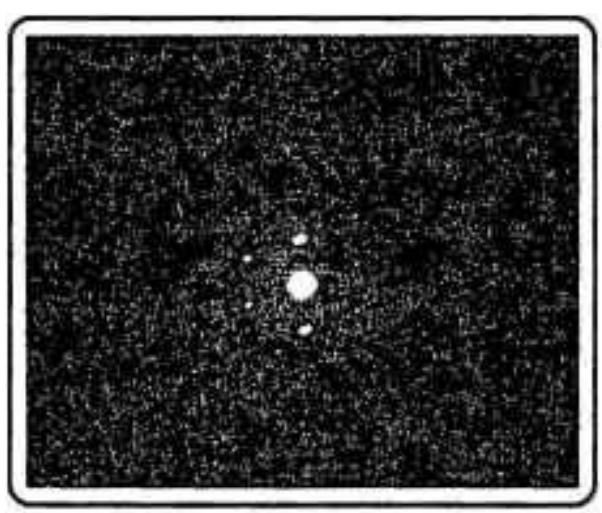

(c)

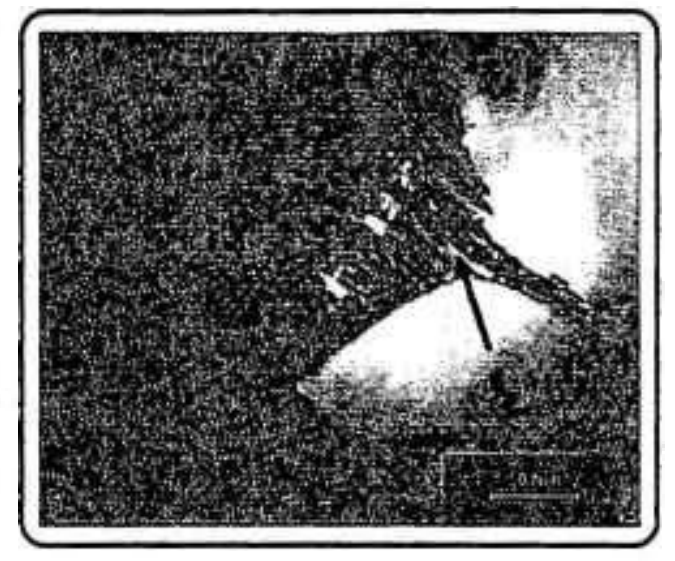

(b)

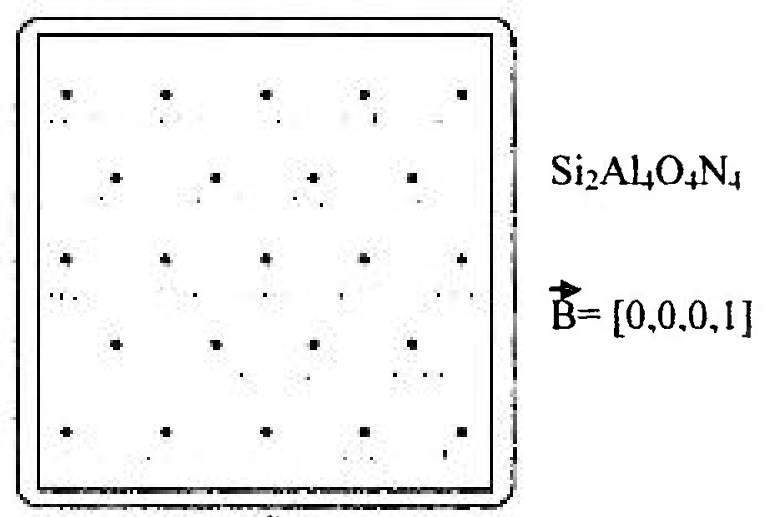

(d)

Figura IV.45- Micrografias da amostra A10M-9N-1650N, (a), (b)- (a)- Micrografia da amostra, campo claro; (b)- Micrografia da amostra, campo escuro; (c)- Padrão de difração eletrônico (d)- Indexação por DIFPAT.

Nas micrografias da amostra A10M-9N-1650N, (a), campo claro e (b), campo escuro, foi feito padrão de difração eletrônico (c) e a indexação foi feita pelo programa DIFPAT, (d). Esta amostra apresentou as seguintes fases identificadas: $\mathrm{Al}_{2} \mathrm{O}_{3}$ de estrutura hexagonal com parâmetro de rede $a=b=0,476 \mathrm{~nm}$ e $c=1,299 \mathrm{~nm}, \mathrm{Si}_{2} \mathrm{Al}_{4} \mathrm{O}_{4} \mathrm{~N}_{4}$, estrutura hexagonal com parâmetro de rede $a=b=7,692 \mathrm{~nm} \mathrm{e} c=2,99 \mathrm{~nm}$. Estes resultados estão em concordância com os resultados de difração de raios X, Figura IV.37. 


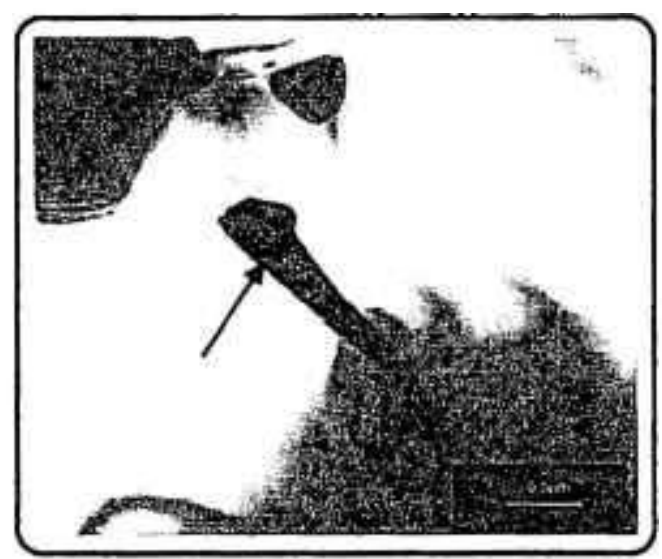

(a)

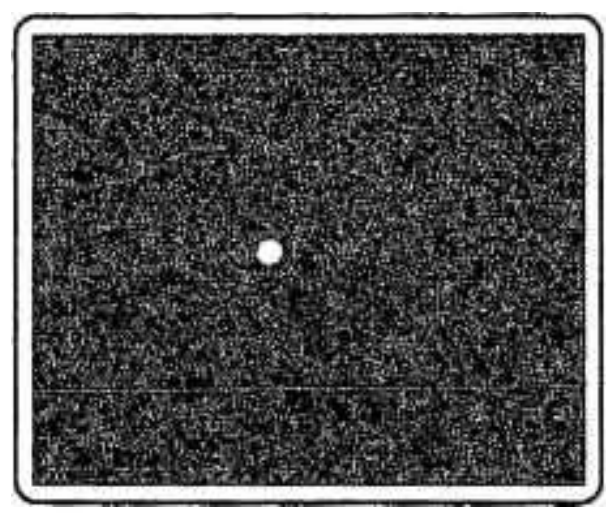

(c)

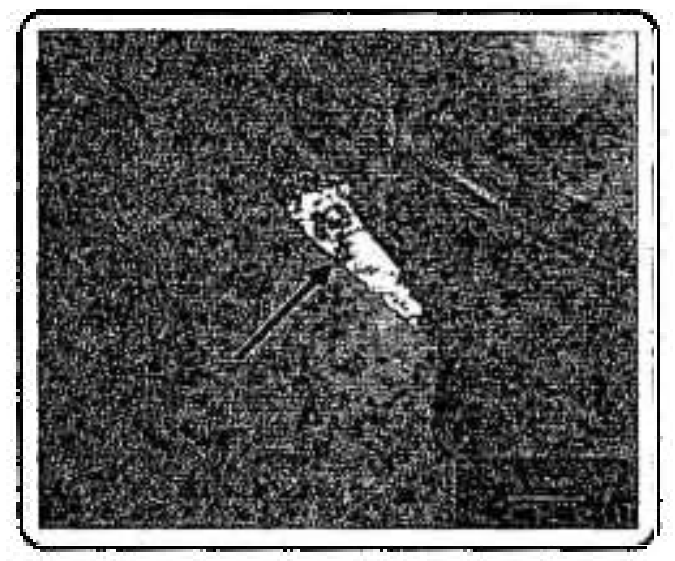

(b)

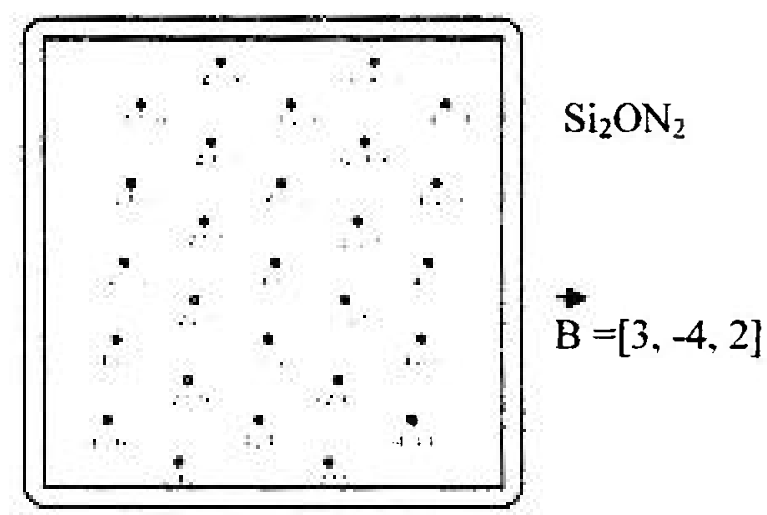

(d)

Figura IV.46- Micrografias da amostra A10M-9N-1650N, (a)- Micrografia da amostra, campo claro; (b)- Micrografia da amostra, campo escuro; (c)- Padrão de difração eletrônico; (d)- Indexação por DIFPAT.

Para esta região, foi adotado o mesmo procedimento da região anterior, Figura IV.45. Nesta região da amostra foram observadas as seguintes fases: $\mathrm{Al}_{2} \mathrm{O}_{3}$ de estrutura hexagonal com parâmetro de rede $a=b=0,476 \mathrm{~nm}$ e $c=1,299 \mathrm{~nm}, \mathrm{Si}_{2} \mathrm{ON}_{2}$, de estrutura 
ortorrômbica, com parâmetro de rede $a=5,49 \mathrm{~nm}, b=8,88 \mathrm{~nm}$ e $c=4,85 \mathrm{~nm}$. Esta fase não havia sido detectada por difração de raios $X$.

Para a análise de fases, além dos padrões de difração eletrônico foi utilizada a técnica de EDS, na amostra A10M-9N-1650N, Figura IV.47.

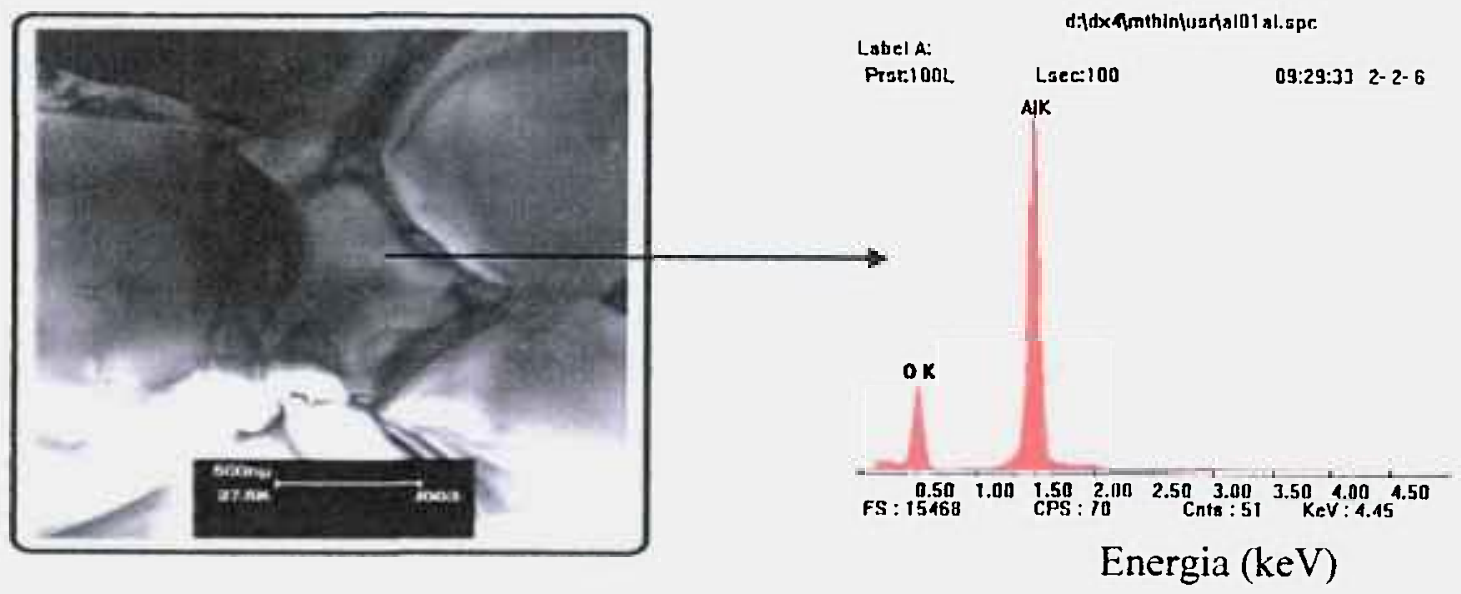

(a)

(b)

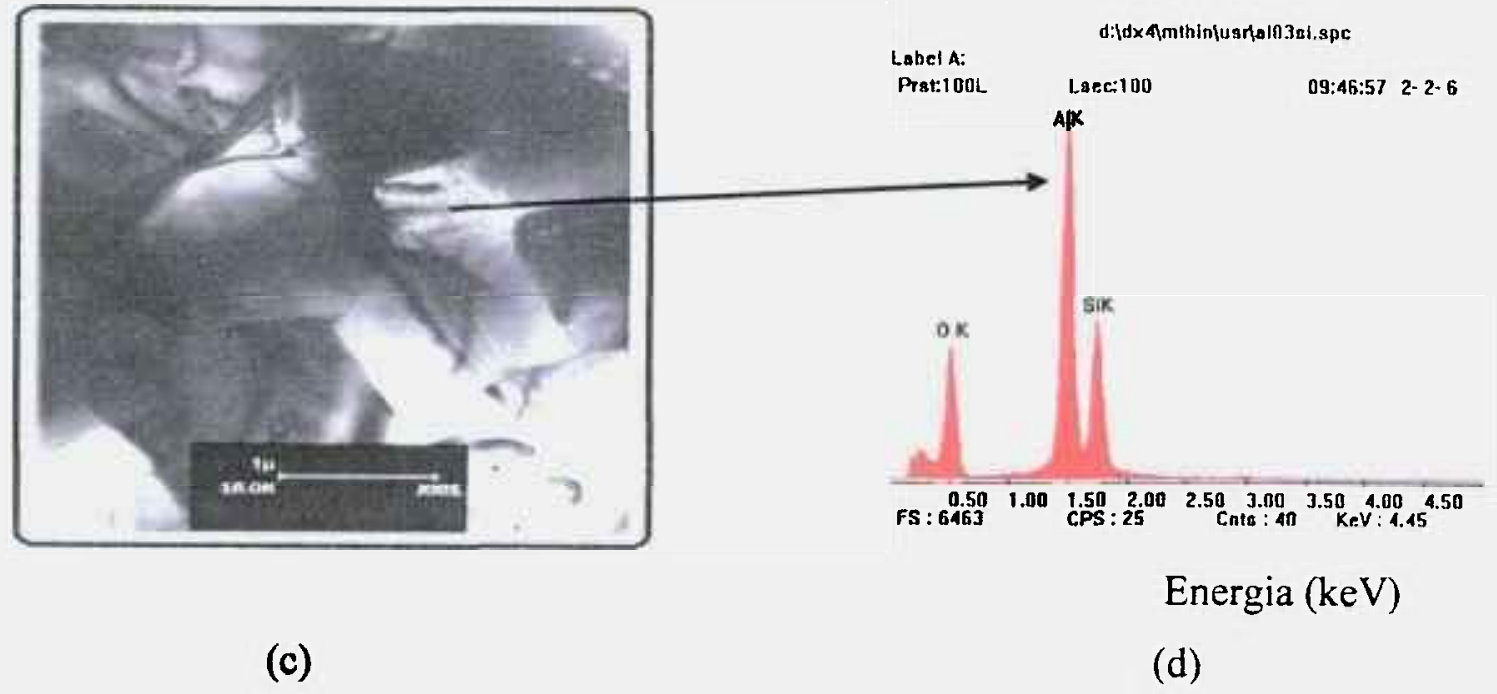

Figura IV.47- (a), (c)- Micrografias da amostra A10M-9N-1650N; (b), (d)- EDS correspondentes à análise de grãos. 
Nota-se no espectro de EDS, (b), somente os picos de $\mathrm{Al}$ e $\mathrm{O}$, indicando a presença de grão de $\mathrm{Al}_{2} \mathrm{O}_{3}$. Em relação ao grão um pouco mais claro a análise por EDS indica, além de $\mathrm{Al}$, e $\mathrm{O}$, a presença de $\mathrm{Si}$, podendo-se inferir que é $\mathrm{Si}_{2} \mathrm{Al}_{4} \mathrm{O}_{4} \mathrm{~N}_{4}$ ou $\mathrm{Si}_{2} \mathrm{ON}_{2}$.

Os valores de dureza e tenacidade à fratura das amostras A0-1650N, A1M- 9N1650N, A5M- 9N-1650N e A10M- 9N-1650N são apresentados na Tabela IV.10. Seus valores foram próximos, levando em conta o desvio padrão, inclusive para a alumina padrão. A dureza variou de $14,9 \mathrm{GPa}$ a $16,5 \mathrm{GPa}$ e a tenacidade à fratura variou de 3,72 GPa a $4,47 \mathrm{GPa}$.

Tabela IV.10- Dureza Vickers e tenacidade à fratura de A0-1650N, AIM-9N-1650N, A5M- 9N-1650N e A10M- 9N-1650N.

\begin{tabular}{|c|c|c|}
\hline Amostra & $\begin{array}{c}\mathrm{H}_{\mathrm{v}} \\
(\mathrm{GPa})\end{array}$ & $\begin{array}{c}\mathrm{K}_{\mathrm{lc}} \\
\left(\mathrm{MPa}^{1 / 2}\right)\end{array}$ \\
\hline A0-1650N & $14,9 \pm 0,6$ & $3,92 \pm 0,11$ \\
\hline A1M-9N-1650N & $15,6 \pm 0,6$ & $4,47 \pm 0,18$ \\
\hline A5M-9N-1650N & $16,3 \pm 0,7$ & $4,11 \pm 0,17$ \\
\hline A10M-9N-1650N & $16,5 \pm 0,7$ & $3,72 \pm 0,13$ \\
\hline
\end{tabular}

\section{$\mathbf{A l}_{2} \mathbf{O}_{3}: \mathbf{P P S}$}

Na Figura IV.48 é mostrada a curva de retracão linear em função da temperatura, obtida por dilatometria, da amostra A10P-9N-1650N.

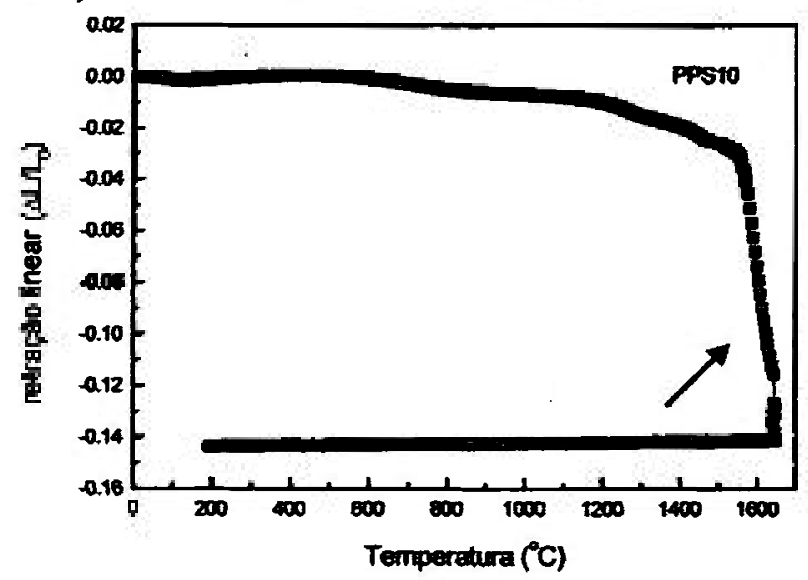

Figura IV.48- Curva de dilatometria da amostra A10P-9N-1650N: retração linear, em função da temperatura. 
Observando esta curva, nota-se um pequeno declive em tomo de $600^{\circ} \mathrm{C}$, que pode ser devido à volatilização de precursores poliméricos. Em aproximadamente $1200^{\circ} \mathrm{C}$ temse o início a retracăo, com um ponto de inflexăo em cerca de $1520^{\circ} \mathrm{C}$, que significa que houve formação de fase e alteraçes nos mecanismos de sinterizaçăo. Na região de patamar $\left(1650^{\circ} \mathrm{C} / 1 \mathrm{~h}\right)$ o material ainda está retraindo. A retrafão máxima foi de aproximadamente $14 \%$.

As densidades aparentes, \% D.T. e valores de dureza das amostras A0-1650N, A1P9N-1650N, A5P-9N-1650N e A10P- 9N-1650N são apresentadas na Tabela IV.11.

Tabela IV.11- Densidades aparentes, \% D.T. em perdas de massa de A0-1650N, A1P9N-1650N, A5P-9N-1650N e A10P-9N-1650N.

\begin{tabular}{|c|c|c|c|c|c|c|}
\hline Amostra & $\begin{array}{c}\rho_{\text {apare }} \\
\left(\mathrm{g} / \mathrm{cm}^{3}\right)\end{array}$ & $\%$ D.T. & $\begin{array}{c}\text { PM } \\
\mathrm{B} \rightarrow \mathrm{A}(\%)\end{array}$ & $\begin{array}{c}\text { PM } \\
\mathrm{C} \rightarrow \mathrm{B}(\%)\end{array}$ & $\begin{array}{c}\text { PM } \\
\mathrm{C} \rightarrow \mathrm{A}(\%)\end{array}$ & $\begin{array}{c}\text { PMP } \\
(\%)\end{array}$ \\
\hline A0-1650N & $3,96 \pm 0,03$ & 99,5 & - & - & 1,2 & - \\
\hline A1P-9N-1650N & $3,84 \pm 0,04$ & 96,5 & 0,1 & 1,0 & 1,1 & 1,4 \\
\hline A5P-9N-1650N & $3,71 \pm 0,05$ & 93,2 & 1,3 & 1,6 & 2,9 & 2,5 \\
\hline A10P-9N-1650N & $3,78 \pm 0,04$ & 95,0 & 2,3 & 3,9 & 6,1 & 3,8 \\
\hline
\end{tabular}

$\mathrm{A} \rightarrow$ antes da pirólise $\mathrm{B} \rightarrow$ após pirólise $\mathrm{C} \rightarrow$ após sinterização

$\mathbf{B} \rightarrow \mathbf{A}$ - perda de massa após pirólise

C $\rightarrow$ B - perda de massa parcial entre pirólise e sinterização

$\mathbf{C} \rightarrow \mathbf{A}$ - perda de massa total

A alumina pura, material de referência, possui densidade superior às obtidas com amostras preparadas com polímeros precursores. Isto acontece devido ao fato da densidade da alumina ser superior às densidades da mulita e do $\mathrm{Si}_{2} \mathrm{Al}_{4} \mathrm{O}_{4} \mathrm{~N}_{4}$ e foi tomada apenas a densidade do $\mathrm{Al}_{2} \mathrm{O}_{3}$ como referência, já que não foi possivel quantificar as outras fases presentes. Em trabalho feito por Borsa e Brook [37] comparando nanocompósitos de $\mathrm{Al}_{2} \mathrm{O}_{3}$ - SiC obtidos por polímero precursor e pelo método convencional, sendo $1700{ }^{\circ} \mathrm{C}$ a temperatura de sinterizaça, a densidade do material preparado com polímero foi ligeiramente inferior à do nanocompósito obtido pelo método tradicional, dados estes que estão de acordo com os resultados deste trabalho. 
Tanto as perdas de massa das amostras $\mathrm{Al}_{2} \mathrm{O}_{3}: \mathrm{PMHS}$, pirolisadas em argônio ou nitrogênio, quanto as perdas de massa previstas foram superiores às perdas de massa e PMP dos polímeros $\mathrm{Al}_{2} \mathrm{O}_{3}:$ PMS e $\mathrm{Al}_{2} \mathrm{O}_{3}$ :PPS.

Com relação à porosidade, embora tenha feito análise de porosimetria de $\mathrm{Hg}$ apenas para uma amostra, A10P-9N-1650N, cujo resultado foi $6 \%$, valor compatível com o dado da densidade aparente, Tabela IV.12; observando as densidades e as micrografias, pode-se concluir que as amostras não têm muitos poros. Materiais cerâmicos possuem, normalmente, uma fração de poros residual devido à limitação do processo de densificação [40].

Na Figura IV.49 são mostrados os difratogramas das amostras A1P-9N-1650N, A5P- $9 \mathrm{~N}-1650 \mathrm{~N}$ e $\mathrm{A} 10 \mathrm{P}-9 \mathrm{~N}-1650 \mathrm{~N}$.

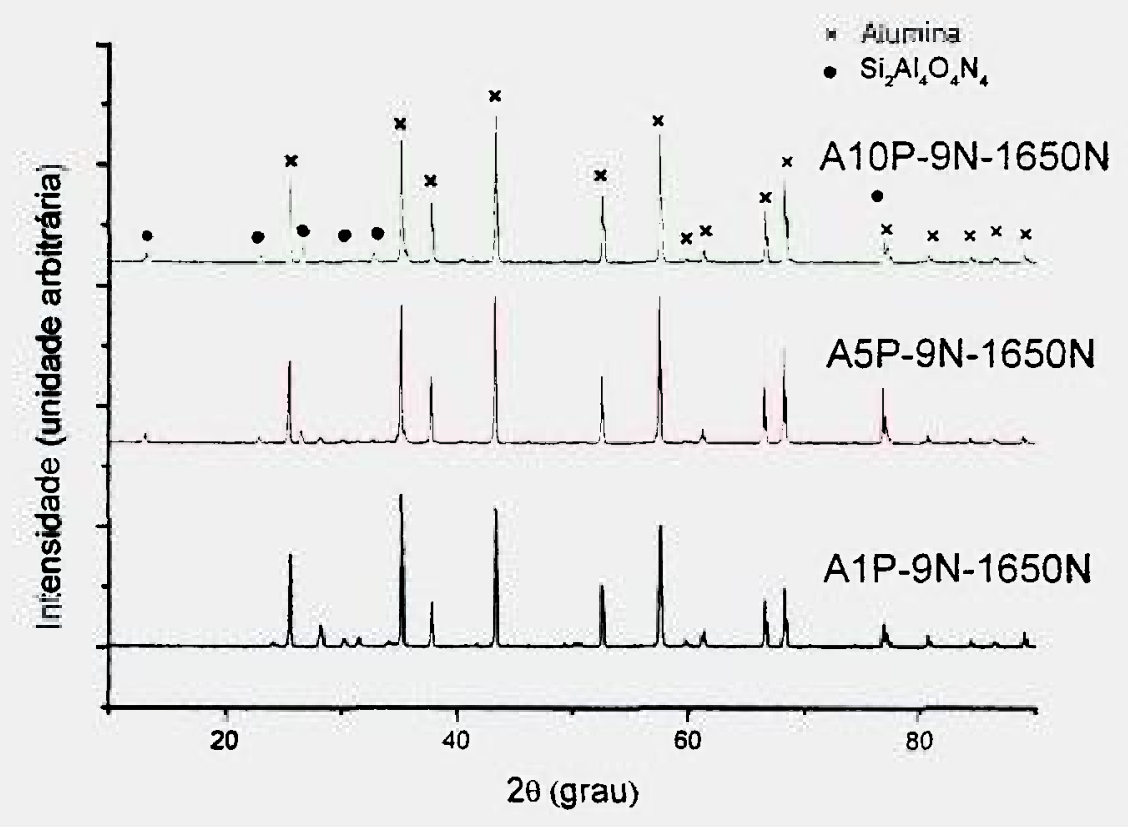

Figura IV.49- Difratogramas de raios $\mathrm{X}$ das amostras A1P-9N-1650N, A5P-9N-1650N e A $10 \mathrm{P}-9 \mathrm{~N}-1650 \mathrm{~N}$.

Foram identificadas as fases $\mathrm{Al}_{2} \mathrm{O}_{3}$ e $\mathrm{Si}_{2} \mathrm{Al}_{4} \mathrm{O}_{4} \mathrm{~N}_{4}$ (JCPDS 76-598), nas amostras contendo PPS, assim como havia sido observado nas amostras $\mathrm{Al}_{2} \mathrm{O}_{3}:$ PMS. A presença de $\mathrm{Si}_{2} \mathrm{Al}_{4} \mathrm{O}_{4} \mathrm{~N}_{4}$ pode estar relacionada às características fisicas da $\mathrm{Al}_{2} \mathrm{O}_{3}$. Este pó é fino, 
portanto reativo, possibilitando a ocorrência de reaçes entre $\mathrm{Al}_{2} \mathrm{O}_{3}$ e os produtos de decomposigăo dos polímeros, como $\mathrm{Si}, \mathrm{O}$ e atmosfera de $\mathrm{N}_{2}$, gerando novas fases [67].

Nos difratogramas das amostras de $\mathrm{Al}_{2} \mathrm{O}_{3}$ peparadas com PMHS, PMS e PPS não foi detectado carbono, que pode estar distribuído pela matriz como solução sólida, como nanopartículas ou como carbono livre, que não é ligado na rede tridimensional do material [119].

A quantidade de carbono remanescente para todas as amostras foi pequena, o que é um ponto positivo já que o mesmo pode produzir poros fechados devido a volatilização do gás $\mathrm{CO}$, formado pela reação entre $\mathrm{SiO}_{2}$ e $\mathrm{C}$ que prejudica a sinterização destes materiais [75]. $\mathrm{O}$ carbono livre pode também inibir a sinterizacão reagindo com a matriz de $\mathrm{Al}_{2} \mathrm{O}_{3}$ a altas temperaturas [75]. $O$ comportamento e o papel desempenhado pelo carbono livre que aparece durante a pirólise de polissiloxanos tem sido pouco estudado e as discussões são muito controversas [119,120]. Na Figura IV.50 é mostrada a quantidade de carbono em função da quantidade de polímero após sinterizacão, de amostras A1P-9N-1650N, A5P-9N$1650 \mathrm{~N}$ e A1OP-9N-1650N.

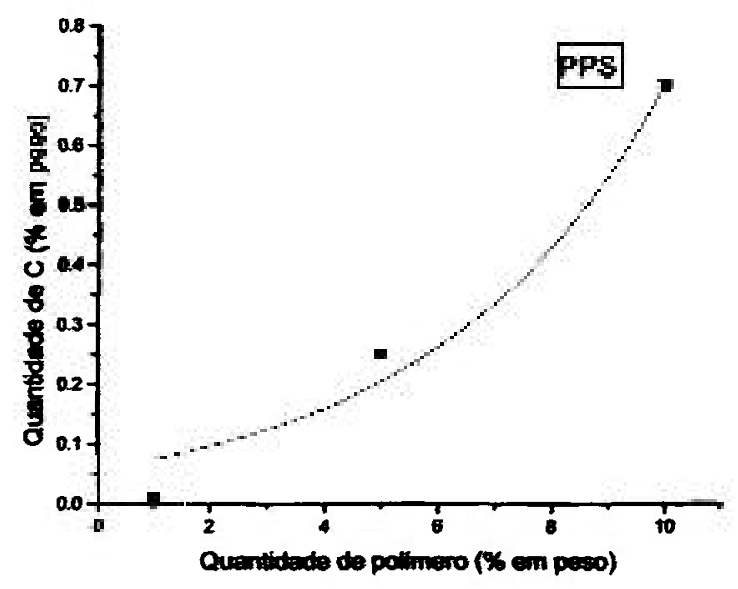

Figura IV.50- Análise de carbono total após sinterizaçăo das amostras A1P-9N-1650N, A5P-9N-1650N e A10P-9N-1650N.

Pode-se observar que à medida que a quantidade de polímero aumenta, a quantidade de carbono também aumenta, atingindo cerca de $0,7 \%$ em peso para a amostra A10P- 9N$1650 \mathrm{~N}$. 


\section{Amostra de $\mathrm{Al}_{2} \mathrm{O}_{3}: 1 \%$ PPS}

$\mathrm{Na}$ Figura IV.51 são mostradas as micrografias obtidas por MEV da amostra A1P$9 \mathrm{~N}-1650 \mathrm{~N}$.

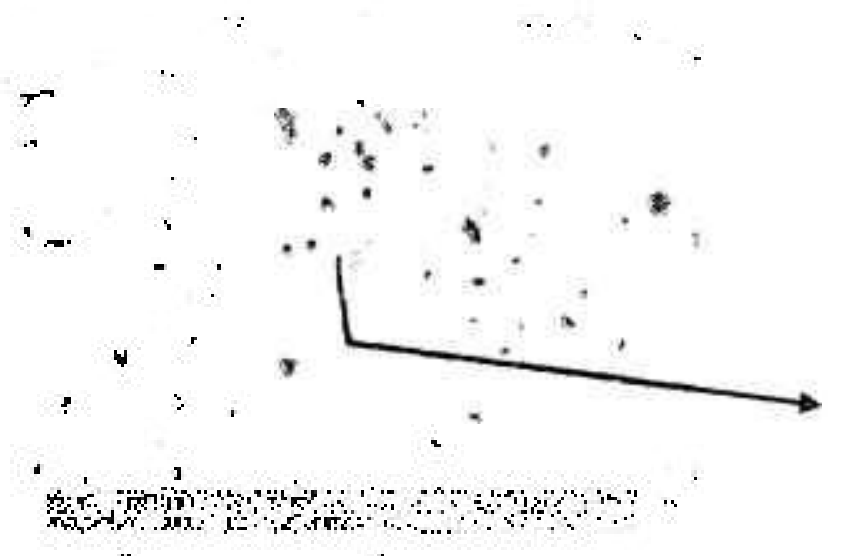

(a)

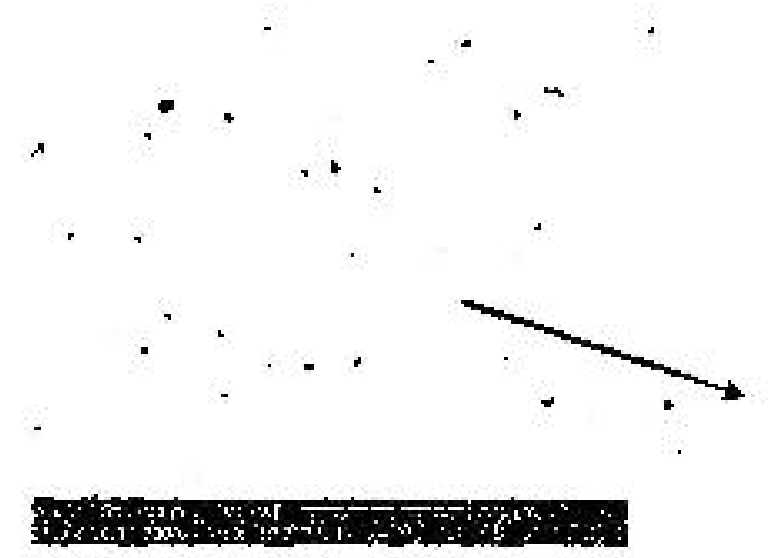

(c)
Label A PPST FASE CINZA

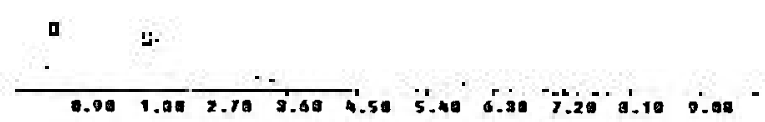

(b) Energia (keV)

Labol A PPSTMATRIZ

A

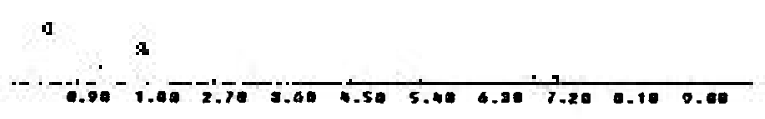

(d) Energia (keV)

(e)

Figura IV.51- Micrografias obtidas por MEV da amostra A1P-9N-1650N: (a)- Amostra sem ataque; (b)- EDS da região marcada com setas, apresentada no item (a); (c)- Amostra sem ataque; (d)- EDS da matriz; (e)- Superficie de fratura. 
$O$ espectro de raios $X$ da região cinza escuro (b), correspondente ao item (a) da Figura IV.51, apresenta picos de $\mathrm{Si}, \mathrm{O}, \mathrm{Al}$, que sugere a presença de $\mathrm{Si}_{2} \mathrm{Al}_{4} \mathrm{O}_{4} \mathrm{~N}_{4}$, fases distribuídas de maneira relativamente homogênea na matriz. Já o espectro relativo à matriz, Figura IV.51 (d), tem picos principalmente de $\mathrm{Al}$ e $\mathrm{O}$, indicando $\mathrm{Al}_{2} \mathrm{O}_{3}$. Pode-se observar na Figura IV.51 (e) provavelmente uma fase secundária envolvendo os grãos. O tamanho de grão varia de aproximadamente $1 \mu \mathrm{m}$ a cerca de $8 \mu \mathrm{m}$. Nota-se alguns poros nas superficies sem ataque.

\section{Amostra de $\mathrm{Al}_{2} \mathrm{O}_{3}: 5 \%$ PPS}

Na Figura IV.52 são mostradas as micrografias obtidas por MEV da amostra A5P$9 \mathrm{~N}-1650 \mathrm{~N}$.

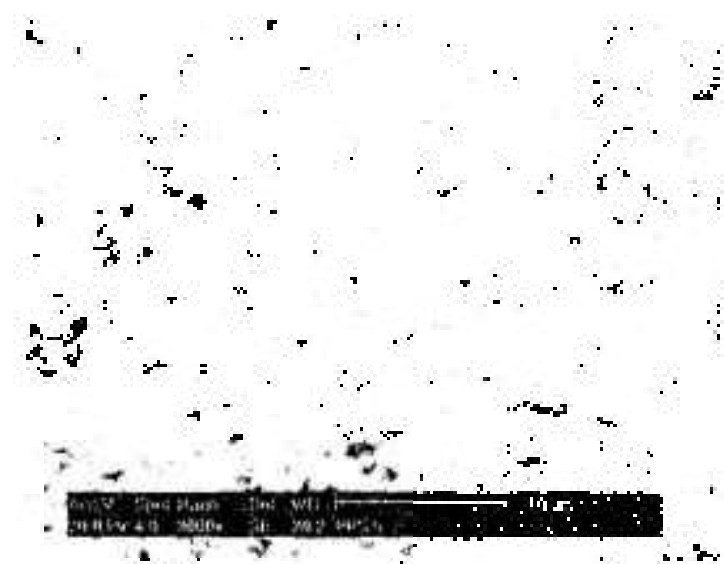

(a)

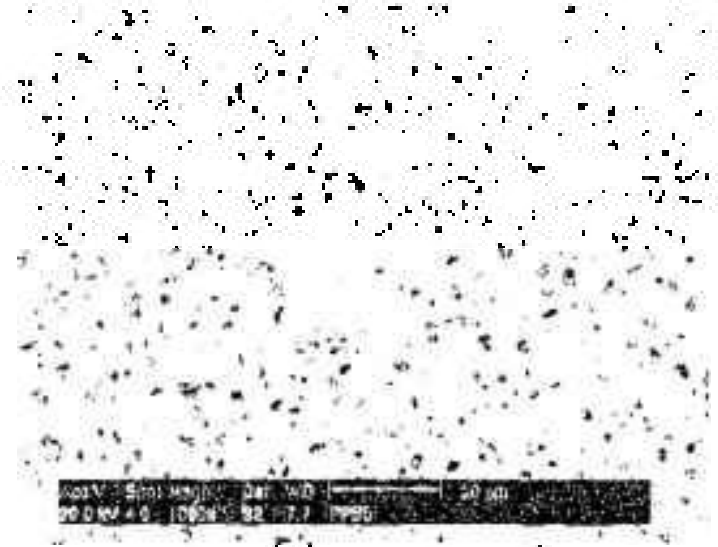

(b)

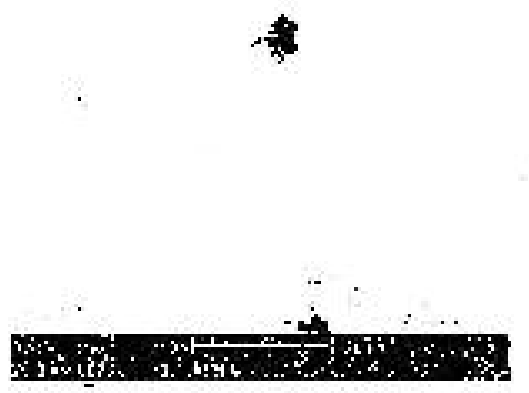

(c)

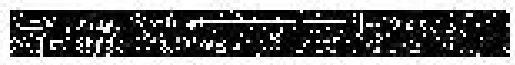

(d)

Figura IV.52- Micrografias obtidas por MEV da amostra A5P-9N-1650N: (a),(b)Superficies polidas e atacadas; (c), (d)- Superficies de fratura. 
Nas Figuras IV.52 (a) e (b) apresentam superficies polidas, atacadas a vácuo, a $1550{ }^{\circ} \mathrm{C}$ por $15 \mathrm{~min}$, nas quais observam-se poros e arrancamento devido ao polimento. Nas Figuras IV.52 (c) e (d) têm-se superficies de fratura, aparentemente com fase secundária e alguns poros. $O$ tamanho de grão varia de aproximadamente $1 \mu \mathrm{m}$ a $8 \mu \mathrm{m}$.

\section{Amostra de $\mathrm{Al}_{2} \mathrm{O}_{3}: 10 \%$ PPS}

Na Figura IV.53 são mostradas micrografias obtidas por MEV, EDS e mapeamento de raios $X$ da amostra A10P-9N-1650N.

$\mathrm{Na}$ Figura IV.53 (b) é mostrado o espectro de raios $\mathrm{X}$ da região mais densa na micrografia (a), mostrando pico bem definido de $\mathrm{Si}$, portanto deve estar associado a presença de fases ricas em $\mathrm{Al}, \mathrm{Si}$ e $\mathrm{O}$, provavelmente $\mathrm{Si}_{2} \mathrm{Al}_{4} \mathrm{O}_{4} \mathrm{~N}_{4}$, de acordo com resultados de difração de raio X, Figura IV.49. Nesta Figura, (d), pode-se observar mapeamento de raios $\mathrm{X}$ do $\mathrm{Si}$, referente à região da amostra apresentada em (c). Nota-se que no mapeamento de raios $\mathrm{X}$, há áreas ricas em $\mathrm{Si}$, que coincidem com as áreas mais densas da micrografia. Conclui-se, portanto, que a fase à base de Si não está distribuída uniformemente na matriz, mas sim na forma de aglomerados. Na Figura IV.53 (f) é mostrado o espectro de raios $X$ da região da micrografia (e), podendo se observar o pico de Si.

As amostras não são homogêneas, como a série de micrografias apresentadas evidencia. De acordo com a literatura $[17,55,118,120]$, a composição química do produto final e a microestrutura é fortemente influenciada pela composiçăo do polímero empregado e, devido à termólise, há volatilização de orgânicos causando perda de massa, o que está de acordo com este trabalho. 

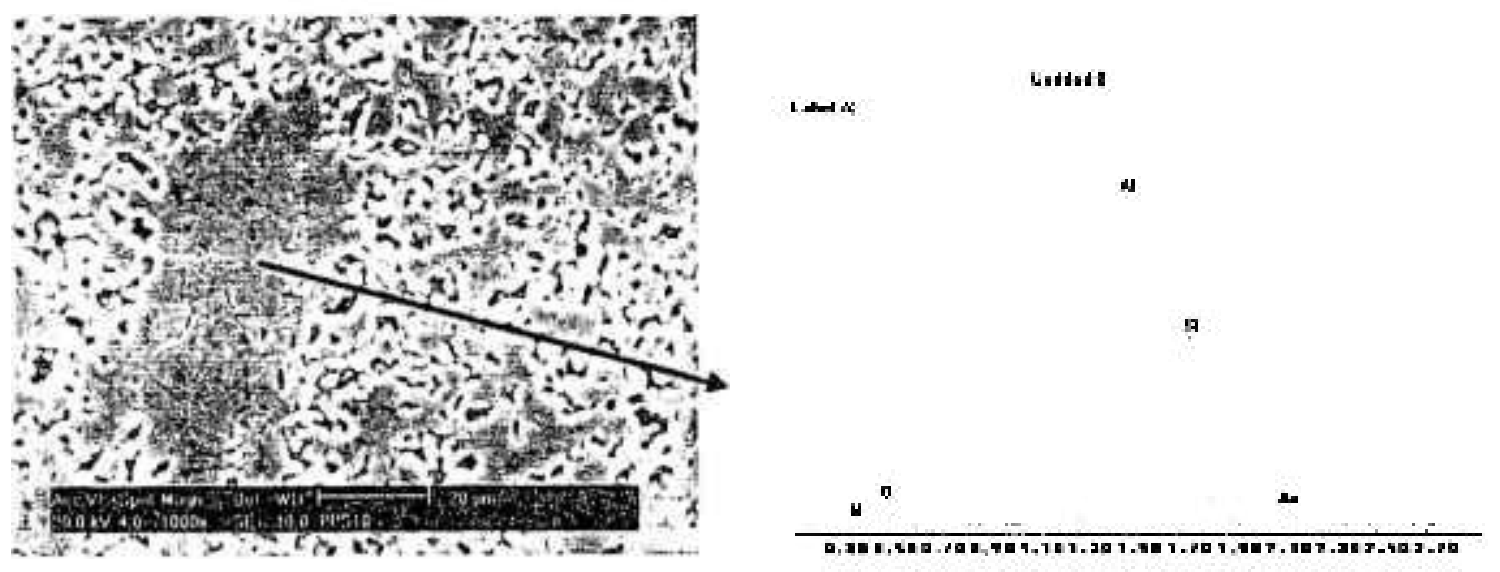

(a)

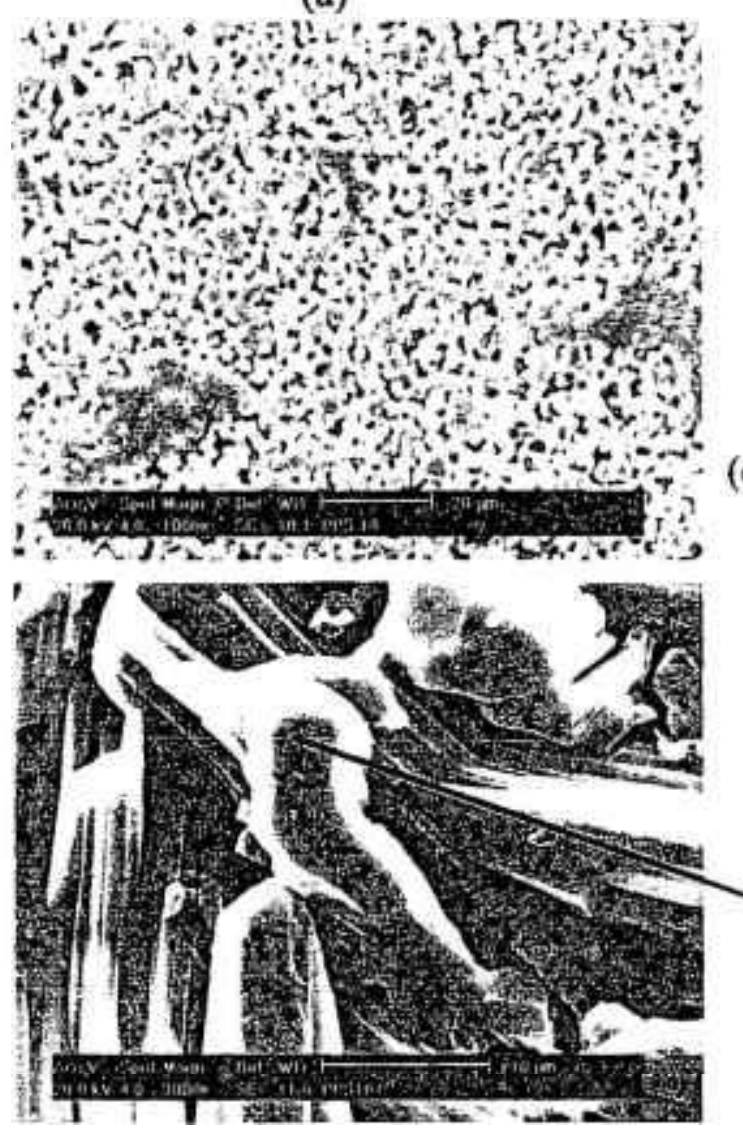

(e)

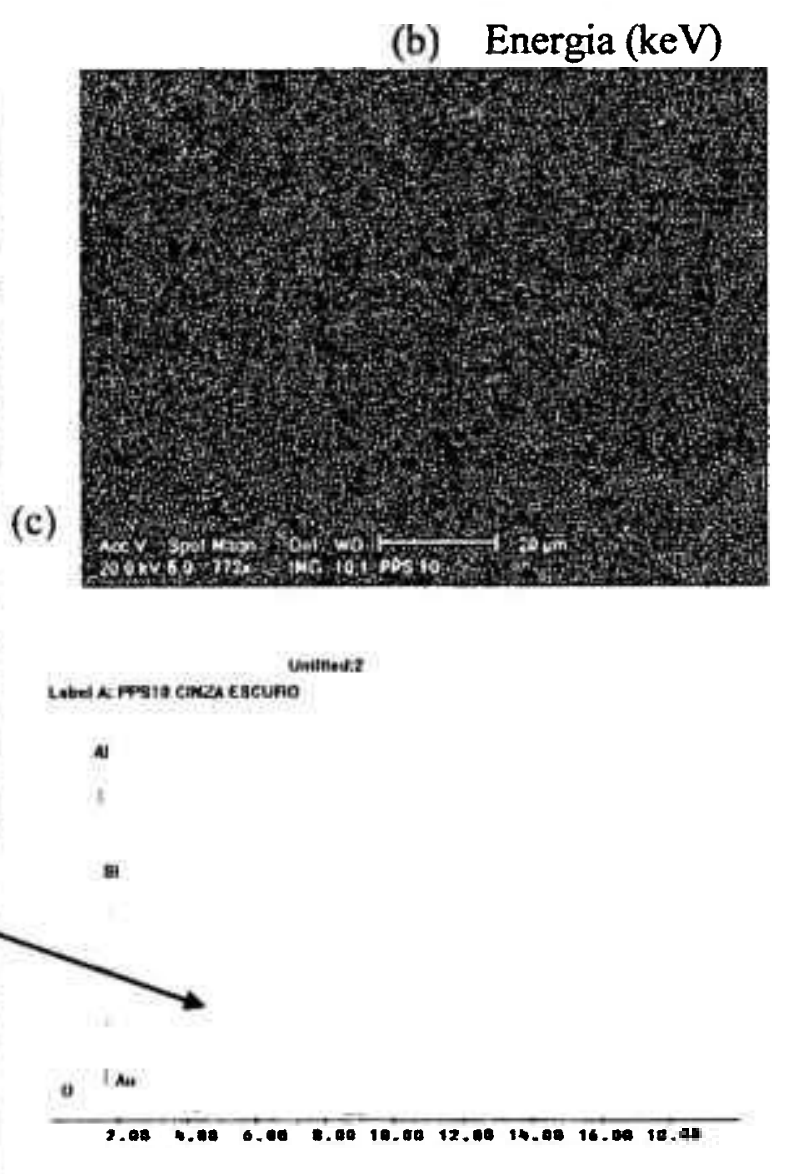

(f) Energia (keV)

(d)

Figura IV.53- Micrografias obtidas por MEV da amostra A10P-9N-1650N: (a)- Amostra polida e atacada; (b)- Espectro de EDS da região sem poros, item (a); (c)-Amostra polida e atacada; (d)- Mapeamento de raios X de Si da região apresentada no item (c); (e)Superficie de fratura; (f)- Espectro de EDS da amostra apresentada no item (e), varredura em área. 
A microestrutura das amostras depende de vários fatores como grupos funcionais dos polímeros precursores, condiçóes da pirólise [73,121,122] e da sinterização, ou seja, basicamente da temperatura, da atmosfera e do tempo de tratamento térmico. Uma característica comum a todas amostras é a presenca de poros devido, principalmente, à volatilização dos produtos orgânicos durante a pirólise [73]. No presente trabalho as amostras não apresentaram quantidade elevada de poros, pois a porcentagem de polímero adicionada não foi grande e a taxa de aquecimento no processo de pirólise foi bem lenta.

Na Tabela IV.12 são apresentados os valores de dureza Vickers e tenacidade à fratura das amostras A0P-1650N, AIP-9N-1650N, A5P-9N-1650N e A10P-9N-1650N.

Tabela IV.12- Valores de dureza e de tenacidade à fratura das amostras A0-1650N, AIP9N-1650N, A5P-9N-1650N e A10P-9N-1650N.

\begin{tabular}{|c|c|c|}
\hline Amostra & $\begin{array}{c}\mathbf{H}_{\mathbf{v}} \\
(\mathrm{GPa})\end{array}$ & $\begin{array}{c}\mathbf{K}_{\mathbf{d c}} \\
\left(\mathrm{MPa} . \mathrm{m}^{1 / 2}\right)\end{array}$ \\
\hline A0-1650N & $14,9 \pm 0,6$ & $3.95 \pm 0,13$ \\
\hline A1P-9N-1650N & $15,4 \pm 0,8$ & $3,81 \pm 0,15$ \\
\hline A5P-9N-1650N & $15,2 \pm 0,6$ & $4,11 \pm 0.13$ \\
\hline A10P-9N-1650N & $12,8 \pm 1,3$ & $3.99 \pm 0,18$ \\
\hline
\end{tabular}

A dureza da amostra padrão foi inferior às durezas das amostras A1P- $9 \mathrm{~N}-1650 \mathrm{~N}$ e A5P-9N-1650N, porém superior à dureza da A10P-9N-1650N.

Em relação à tenacidade à fratura a amostra A5P-9N-1650N apresentou um valor maior que as outras amostras, inclusive em relaçåo à amostra padrão.

As curvas de retraçăo linear, em funçăo da temperatura, das amostras A10H-9N1650N, A10M-9N-1650N e A10P-9N-1650N, sinterizadas em dilatômetro, são mostradas na Figura IV.54. As amostras A10H-9N-1650N e A10P-9N-1650N apresentaram retração linear próximas e superiores à retracio da amostra A10M-9N-1650N. 


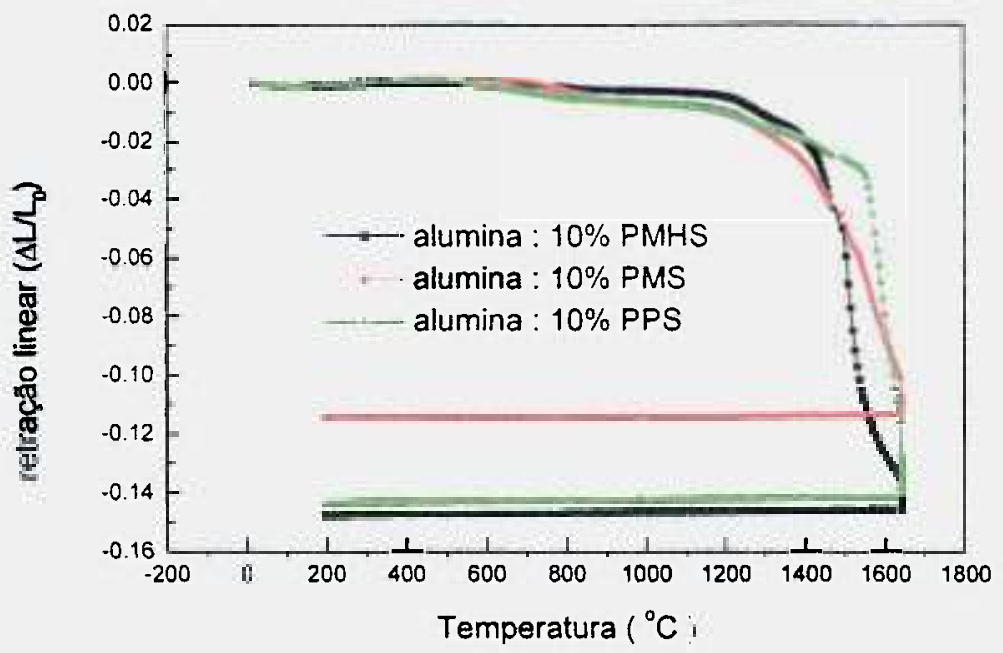

Figura IV.54- Curvas de retração linear em função da temperatura das amostras A $10 \mathrm{H}-9 \mathrm{~N}-1650 \mathrm{~N}$, A10M-9N-1650N e A10P-9N-1650N.

As amostras com adições de PMS apresentaram menores perdas de massa do que amostras com adições iguais de PMHS, o que não era esperado a partir das análises dos polímeros em TG.

Comparando as densidades das amostras $\mathrm{Al}_{2} \mathrm{O}_{3}$ :PMS com as das amostras $\mathrm{Al}_{2} \mathrm{O}_{3}$ :PPS, nota-se que seus valores foram um pouco maiores. Quanto às densidades do $\mathrm{Al}_{2} \mathrm{O}_{3}$ :PMHS, seus valores foram, em geral, inferiores aos das amostras com PMS e PPS. As densidades das amostras padrões foram superiores às amostras com PMHS, PMS e PPS.

Os valores de dureza variaram na faixa de $12,8 \mathrm{GPa}$ a $16,5 \mathrm{GPa}$. De acordo com a literatura, Tabela II.4, os valores de dureza do $\mathrm{Al}_{2} \mathrm{O}_{3}$ variam muito, de $18,0 \mathrm{GPa}$ a $23 \mathrm{GPa}$, dependendo do processamento.

Comparando as durezas da amostra padrão, amostras de $\mathrm{Al}_{2} \mathrm{O}_{3}$ :PMHS, $\mathrm{Al}_{2} \mathrm{O}_{3}$ :PMS e $\mathrm{Al}_{2} \mathrm{O}_{3}: \mathrm{PPS}$, levando-se em conta os desvios padões, conclui-se que são muito próximas e os precursores poliméricos não exerceram influência nesta propriedade. A dureza depende essencialmente da porosidade e do tamanho de grão do material. Esta propriedade é influenciada, também. por defeitos e micro-trincas que possam estar sob o indentador [94].

Em relação à tenacidade à fratura variaram de $3,45 \mathrm{MPa} \cdot \mathrm{m}^{1 / 2}$ a $4,47 \mathrm{MPa} \cdot \mathrm{m}^{1 / 2}$, considerando-se, inclusive, a amostra padrão. Segundo a Tabela II.4, a tenacidade à fratura da alumina varia de $2,5 \mathrm{MPa} \cdot \mathrm{m}^{1 / 2}$ a 4,5 MPa.m $\mathrm{m}^{1 / 2}$. 
Os valores de $\mathrm{K}_{\mathrm{K}}$ para $\mathrm{Al}_{2} \mathrm{O}_{3}: \mathrm{PMS}$ e $\mathrm{Al}_{2} \mathrm{O}_{3}: P P S$ são próximos, porém superiores à tenacidade das amostras $\mathrm{Al}_{2} \mathrm{O}_{3}:$ PMHS.

Em trabalho realizado por Rice [44] foi estudada a microestrutura e propriedades mecânicas de nanocompósitos de $\mathrm{Al}_{2} \mathrm{O}_{3} / \mathrm{SiC}$ preparados com policarbossilano, PCS. Foram preparadas amostras de $\mathrm{Al}_{2} \mathrm{O}_{3}$ com diferentes concentrações de $\mathrm{SiC}$ (2,5\% vol, $5 \%$ vol e 7,5\% vol). O PCS foi misturado ao pó de $\mathrm{Al}_{2} \mathrm{O}_{3}$, foi feita a cura, pirólise $\left(1500^{\circ} \mathrm{C}\right.$ por $2 \mathrm{~h}$, em Ar) e prensagem a quente $\left(1700^{\circ} \mathrm{C}\right.$ por $1 \mathrm{~h}$, a $25 \mathrm{MPa} \mathrm{em}$ Ar). A densidade média obtida foi $3,90 \pm 0,04 \mathrm{~g} / \mathrm{cm}^{3}$, de dureza Vickers foi $18,4 \pm 0,5 \mathrm{GPa}$ e de tenacidade à fratura 2,99 $\pm 0,05 \mathrm{MPa}^{1 / 2}$. As trincas formadas no ensaio de impressão Vickers foram do tipo radial-mediana. Variando significativamente a concentracãa de $\mathrm{SiC}$ os valores de densidade, dureza e tenacidade à fratura não variam muito, resultados que estão em concordância com este trabalho.

A técnica de preparaçào de materiais com polímeros precursores tem o potencial para que as fases formadas tenham distribuiça uniforme na matriz de alumina mas, como pode ser observado nas micrografias, espectros de raios $X$ e nos mapeamentos de raios $X$, isto não acontece para os três polimeros empregados. As amostras preparadas com PMHS apresentaram a distribuição de Si mais uniforme. $O$ mesmo nåo aconteceu com amostras preparadas com PMS e PPS, que apresentam aglomerados à base de Si, AI, O e N. Além disso, independentemente das microestruturas, das densidades das amostras com PMHS, PMS, PPS, bem como a quantidade destes polímeros, os valores de dureza Vickers são próximos, levando-se em conta os desvios padrões. Uma maneira que, possivelmente, possa contornar este problema é trabalhar com alumina mais fina, fazer uma mistura deste pó com o polímero e catalisador deixando mais tempo no agitador magnético, de modo que haja maior homogeneidade entre os componentes.

Uma das vantagens de preparar materiais por este método é que a conformaçáo é fácil, já que no processo de obtenção das amostras é formada uma mistura levemente pastosa, que possibilita verter o material em matrizes de diferentes formas. Filmes finos foram obtidos por intermédio de síntese de SiC com policarbossilano [51]. O polímero precursor misturado com catalisador foi depositado em uma superficie ainda na forma de uma mistura pastosa, e pirolisado para obtenção da fase cerâmica. Com este processo é possível recobrir superficies grandes e objetos com superficies irregulares. Este processo pode ser feito utilizando $\mathrm{Al}_{2} \mathrm{O}_{3}: \mathrm{PMHS}, \mathrm{Al}_{2} \mathrm{O}_{3}: \mathrm{PMS}$ e $\mathrm{Al}_{2} \mathrm{O}_{3}: \mathrm{PPS}$. 
$\mathrm{Na}$ Tabela IV.13 são apresentados os valores de densidade, dureza e tenacidade à fratura para as amostras $\mathrm{Al}_{2} \mathrm{O}_{3}: P M H S, \mathrm{Al}_{2} \mathrm{O}_{3}: \mathrm{PMS}$ e $\mathrm{Al}_{2} \mathrm{O}_{3}: \mathrm{PPS}$.

Tabela IV.13- Valores de densidade, dureza e tenacidade à fratura para as amostras $\mathrm{Al}_{2} \mathrm{O}_{3}: \mathrm{PMHS}, \mathrm{Al}_{2} \mathrm{O}_{3}: \mathrm{PMS}$ e $\mathrm{Al}_{2} \mathrm{O}_{3}: \mathrm{PPS}$.

\begin{tabular}{|c|c|c|c|}
\hline Amostra & $\rho$ & $\mathrm{H}_{\mathrm{v}}$ & $\mathrm{K}_{\mathrm{lc}}$ \\
\hline A0H-1650N & $3,87 \pm 0,01$ & $14,9 \pm 0,6$ & $3,72 \pm 0,18$ \\
\hline A1H-9N-1650N & $3,77 \pm 0,01$ & $15,9 \pm 0,3$ & $3,47 \pm 0,10$ \\
\hline A5H-9N-1650N & $3,66 \pm 0,01$ & $15,7 \pm 0,6$ & $3,48 \pm 0,10$ \\
\hline A10H-9N-1650N & $3,76 \pm 0,01$ & $16,3 \pm 0,6$ & $3,45 \pm 0,11$ \\
\hline A0M-1650N & $3,96 \pm 0,03$ & $14,9 \pm 0,6$ & $3,92 \pm 0,11$ \\
\hline A1M-9N-1650N & $3,88 \pm 0,07$ & $15,6 \pm 0,6$ & $4,47 \pm 0,18$ \\
\hline A5M-9N-1650N & $3,78 \pm 0,03$ & $16,3 \pm 0,7$ & $4,11 \pm 0,17$ \\
\hline A10M-9N-1650N & $3,72 \pm 0,04$ & $16,5 \pm 0,7$ & $3,72 \pm 0,13$ \\
\hline A0P-1650N & $3,96 \pm 0,03$ & $14,9 \pm 0,6$ & $3,92 \pm 0,13$ \\
\hline A1P-9N-1650N & $3,84 \pm 0,04$ & $15,4 \pm 0,8$ & $3,81 \pm 0,15$ \\
\hline A5P-9N-1650N & $3,71 \pm 0,05$ & $15,2 \pm 0,6$ & $4,11 \pm 0,13$ \\
\hline A10P-9N-1650N & $3,78 \pm 0,04$ & $12,8 \pm 1,3$ & $3,99 \pm 0,18$ \\
\hline
\end{tabular}

Amostras de $\mathrm{Al}_{2} \mathrm{O}_{3}:$ PMHS, $\mathrm{Al}_{2} \mathrm{O}_{3}: \mathrm{PMS}$ e $\mathrm{Al}_{2} \mathrm{O}_{3}: \mathrm{PPS}$ foram sinterizadas a $1700^{\circ} \mathrm{C}$, nas mesmas condiçðes das amostras sinterizadas a $1650^{\circ} \mathrm{C}$, com o intuito de verificar possíveis diferenças nas densidades.

As densidades aparentes foram feitas por picnometria de He e os resultados para as amostras $\mathrm{Al}_{2} \mathrm{O}_{3}: \mathrm{PMHS}, \mathrm{Al}_{2} \mathrm{O}_{3}: \mathrm{PMS}$ e $\mathrm{Al}_{2} \mathrm{O}_{3}: \mathrm{PPS}$ encontram-se na Tabela IV.14, juntamente com a porcentagem da densidade teórica, considerando apenas a densidade da alumina. 
Tabela IV.14- Densidade aparente por picnometria de He e \% D.T. de amostras de $\mathrm{Al}_{2} \mathrm{O}_{3}: \mathrm{PMHS}, \mathrm{Al}_{2} \mathrm{O}_{3}: \mathrm{PMS}$ e $\mathrm{Al}_{2} \mathrm{O}_{3}: \mathrm{PPS}$ pirolisadas a $900^{\circ} \mathrm{C}$ e sinterizadas a $1700{ }^{\circ} \mathrm{C}$, em atmosfera de nitrogênio.

\begin{tabular}{|c|c|c|}
\hline Amostras & $\begin{array}{c}P_{\text {mpmec }} \\
\left(\mathrm{g} / \mathrm{cm}^{3}\right)\end{array}$ & \% D.T. \\
\hline A0-1700N & $3,85 \pm 0,01$ & 96,7 \\
\hline AlH-9N-1700N & $3,79 \pm 0,01$ & 95,2 \\
\hline A5H-9N-1700N & $3,70 \pm 0,01$ & 93,0 \\
\hline A10H-9N-1700N & $3,71 \pm 0,01$ & 93,2 \\
\hline A1M-9N-1700N & $3,77 \pm 0,01$ & 94,7 \\
\hline A5M-9N-1700N & $3,81 \pm 0,01$ & 95,7 \\
\hline A10M-9N-1700N & $3,73 \pm 0,01$ & 93,7 \\
\hline A1P-9N-1700N & $3,77 \pm 0,01$ & 94,7 \\
\hline A5P-9N-1700N & $3,81 \pm 0,01$ & 95,7 \\
\hline A10P-9N-1700N & $3,73 \pm 0,01$ & 93,7 \\
\hline
\end{tabular}

As amostras $\mathrm{Al}_{2} \mathrm{O}_{3}: \mathrm{PMHS}, \mathrm{Al}_{2} \mathrm{O}_{3}: \mathrm{PMS}$ e $\mathrm{Al}_{2} \mathrm{O}_{3}: \mathrm{PPS}$ pirolisadas a $900{ }^{\circ} \mathrm{C}$ em nitrogênio e sinterizadas a $1700{ }^{\circ} \mathrm{C}$ em nitrogênio, apresentaram densidades muito próximas às amostras com mesmas composições sinterizadas a $1650^{\circ} \mathrm{C}$, o que é um indicativo que a temperatura de sinterização utilizada inicialmente foi adequada. 


\section{V- CONCLUSÕES}

No processamento de amostras de $\mathrm{SiC}: \mathrm{Al}_{2} \mathrm{O}_{3}: \mathrm{Y}_{2} \mathrm{O}_{3}$ com adição de polímeros $(1 \%$ a $10 \%$ em peso, PMHS, polimetilhidrogenossiloxano e PMHS: $\mathrm{D}_{4} \mathrm{~V}_{i}$ - 1, 3, 5, 7- tetrametil-1, 3, 5, 7- tetravinilciclotetrassiloxano) houve elevada perda de massa, principalmente quando a atmosfera de sinterização foi argônio. As amostras à base de carbeto de silício, com adição de polímeros atingiram densidade de aproximadamente $3,0 \mathrm{~g} / \mathrm{cm}^{3}$ quando pirolisada a $900{ }^{\circ} \mathrm{C}$, em argônio e sinterizadas a $1950{ }^{\circ} \mathrm{C} / 1 \mathrm{~h} / \mathrm{Ar}$ e $2,4 \mathrm{~g} / \mathrm{cm}^{3}$ para sinterização realizada a $1850^{\circ} \mathrm{C} / 1 \mathrm{~h} / \mathrm{Ar}$. Em geral, a atmosfera mais adequada para sinterização de cerâmicas à base de carbeto de silício é o argônio, mas devido à elevada perda de massa, as amostras foram sinterizadas em atmosfera de nitrogênio. As amostras pirolisadas e sinterizadas em nitrogênio sofreram perda de massa menor, mas ainda muito elevada. A amostra que atingiu maior densidade foi a que possuía adição de $5 \%$ em peso de PMHS, foi pirolisada e sinterizada em atmosfera de nitrogênio, $3,15 \mathrm{~g} / \mathrm{cm}^{3}$.

No estudo de densificação em dilatômetro de amostras à base de alumina, contendo $10 \%$ em massa de polímeros precursores cerâmicos (PMHS, PMS, polimetilsilsesquioxano, e PPS, polifenilmetilvinilhidrogenosilsesquioxano) até a temperatura de $1650^{\circ} \mathrm{C}$, a retração foi de aproximadamente $14 \%$. Nos estudos de sinterização utilizando patamar de $1650^{\circ} \mathrm{C} / 1 \mathrm{~h}$ em fornos com atmosfera de $\mathrm{N}_{2}$, os melhores valores de densidade foram obtidos com a utilização de PMS $\left(3,7\right.$ a $\left.3,9 \mathrm{~g} / \mathrm{cm}^{3}\right)$.

Os elementos químicos $\mathrm{Si}$ e $\mathrm{C}$ originários dos precursores cerâmicos foram detectados por técnicas de análise de elementos, e as fases cristalinas formadas, determinadas por difração de raios X e/ou por DIFPAT foram: mulita - para adições de PMHS e $\mathrm{Si}_{2} \mathrm{Al}_{4} \mathrm{O}_{4} \mathrm{~N}_{4}$ e $\mathrm{Si}_{2} \mathrm{ON}_{2}$ para adições de PMS e PPS, em sinterizações com atmosfera de nitrogênio.

Em relação à microestrutura, as amostras à base de alumina sinterizadas a $1650^{\circ} \mathrm{C} / 1 \mathrm{~h}$ apresentam crescimento anormal de grão. Dentre as amostras com aditivos poliméricos, as amostras contendo PMHS apresentaram a microestrutura mais homogênea, com distribuição da fase secundária formada, mulita, em posições intergranulares. Nas amostras contendo PMS ou PPS a distribuição das fases formadas, $\mathrm{Si}_{2} \mathrm{Al}_{4} \mathrm{O}_{4} \mathrm{~N}_{4}$ e $\mathrm{Si}_{2} \mathrm{ON}_{2}$ é bastante heterogênea.

A obtenção de compósitos cerâmicos utilizando pequenas adições de polímeros precursores cerâmicos mostrou-se viável para materiais à base de alumina, sendo uma rota simples de conformação com grande potencial para a obtenção de peças com geometria complexa. 


\section{VI- PROPOSTAS PARA TRABALHOS FUTUROS}

- Estudar a influência da viscosidade do polímero precursor cerâmico durante o processamento, visando melhorar a distribuição das fases formadas nas amostras à base de alumina.

- Confecção de peças à base de alumina utilizando aditivos poliméricos precursores cerâmicos por diferentes processos, visando a obtenção de geometrias complexas.

- Estudo de resistência a choque térmico e a oxidação dos compósitos obtidos. 


\section{REFERÊNCIAS BIBLIOGRÄFICAS}

[1]- FERRANTE, M. Seleção de Materiais, UFSCar, 1996.

[2]- CARTER, H.C.; TSVETKOV, F.V.; GLASS, C.R.; HENSHALL, D.; BRADY, M.; MÜLLER, S.G.; KORDINA, O.; IRVINE, K.; EDMOND, A.J.; KONG, S.H.; SINGH, R.; ALLEN, T.S.; PALMOUR, W.J. Progress in SiC: from material growth to commercial device development, Mat. Sci. Eng., v.61, p.1-8, 1999.

[3]- PAGE, T.T. The physics and chemistry of carbides, nitrides and borides, edited by R. Freer, Kluwer Acad. Publishes, Netherlands, p.197-214, 1990.

[4]- CHO, M.S.; KIM, B.H.; KONG, J.I.; SUNG, A.Y.; WOO, A.Y.S. Synthesis, catalytic Si-Si dehydrocoupling, and thermolysis of polyvinylsilanes $\left[\mathrm{CH}_{2} \mathrm{CH}\left(\mathrm{SiH}_{2} \mathrm{X}\right)\right]_{\mathrm{n}}(\mathrm{X}=\mathrm{H}, \mathrm{Ph})$, J. Organomet. Chem., v.685, p.99-106, 2003.

[5]- SCHMIDT, H.; BUHLER, P.; GREIL, P. Pyrolitic conversion of poly(methylsiloxane) to silicon (oxy)carbide, Conference of ECRS, Riccione, Italy, 1995.

[6]- SORARÙ, G.D.; KLEEBE, H.J.; CECCATO, R.; PEDERIVA, L. Development of mullite-SiC nanocomposites by pyrolysis of filled polymethilsiloxane gels, J. Eur. Ceram. Soc., v.20, p.2509-2517, 2000.

[7]- YAMADA, K.; MOHRI, M. Properties and applications of silicon carbide ceramics. In: Somiya, S.; Inomata, Y. Silicon Carbide Ceramics - 1: Fundamental and solid reaction. Elsevier Science, London, p.13-44, 1991.

[8]- LAUGHTON, D; Silicon Carbide, Am. Ceram. Soc. Bulh, p.76-77, 1999.

[9]- IZHEVSKYI, V.A.; GENOVA, L.A.; BRESSIANI, A.H.A.; BRESSIANI, J.C. Liquid phase sintered $\mathrm{SiC}$. Processing and transformation controlled microstructure tailoring, Mater. Res., v.3, n.4, p.131-138, 2000.

[10]- IZHEVSKYI, V.A.; GENOVA, L.A.; BRESSIANI, J.C.; BRESSIANI, A.H.A. Liquid-phase sintering of SiC-based ceramics, Key Eng. Mater., v.189, p.173-180, 2001.

[11]- KNIPPENBERG, W.F. Philips research reports, v.18, p.161-274, 1963. 
[12]-Siceram high tech ceramic products, 1999.

[13]- NEUDECK, P.G. Recent progress in silicon carbide semiconductor eletronics technology, NASA Lewis Research Center, USA, 1999.

[14]- IZHEVSKYI, V.A.; GENOVA, L.A.; BRESSIANI, J.C.; BRESSIANI , A.H.A. Review: silicon carbide, structure, properties and processing, Cerâmica, v.46; p.4-14, 2000.

[15]- RAMSDELL, R.S. Studies on silicon carbide, Am. Min., v.32, p.64-82, 1947.

[16]- BRESSIANI, A.H.A. Das verdichtungsverhalten von $\beta$-SiC beim heisspressen mit verchiedenen sinterhilfen, Institut für Netallkunde der Universität Stuttgart, Deutchland, 1984.

[17]- ZHOU, Y.; HIRAO, K.; TORIYAMA, M.; TANAKA, H. Silicon carbide ceramics prepared by pulse electric current sintering of $\beta-\mathrm{SiC}$ and $\alpha-\mathrm{SiC}$ powders with oxide and nonoxide additives, J. Mater. Res., v.14, n. 8, p.3363-3368, 1999.

[18]- PROCHAZKA, S.; Scanlau, R.M. Effect of boron and carbon on sintering of SiC, J. Am. Ceram. Soc., v.58, n. 1-2, p.72, 1975.

[19]- LANGE, F.F. Hot-pressing behaviour or silicon carbide powders with additions of aluminium oxide, J. Mater. Sci, v.10, p.314-320, 1975.

[20]- BÖCKER, W.D.G.; STORM, R.S.; CHIA, K.Y. Silicon carbide bodies having high toughness and fracture resistence and methods of making the same, European Patent Application n. 90 310, p.329-339, 1990. apud Nader, M.; ALDINGER, F.; HOFFMANN, M.J. Influence of the $\alpha / \beta-\mathrm{SiC}$ phase transformation on microstructural development and mechanical properties of liquid phase sintered silicon carbide, J. Mater. Sci., v.34, p.11971204, 1997. 
[21]- SIGL, L.S.; KLEEBE, H.J., Core/rim structure of liquid-phase silicon carbide, J. Am. Ceram. Soc., v.76, n³, p.773- 776, 1993, apud OMORI, M. and TAKEI, H., Pressureless sintering of SiC, J. Am. Ceram. Soc., v.65, c-92, 1982.

[22]- NADER, M.; ALDINGER, F.; HOFFMANN, M.J. Influence of the $\alpha / \beta$-SiC phase transformation on microstructural development and mechanical properties of liquid phase sintered silicon carbide, J. Mater. Sci, v.34, p.1197-1204, 1997.

[23]- KIM, J.Y.; KIM, Y.W.; MITOMO, M.; ZHAN, G.D.; LEE, J.G. Microstructure and mechanical properties of $\alpha$-silicon carbide sintered with yttrium-aluminum garnet and silica, J. Am. Ceram. Soc., v.82, n.2, p.441-444, 1999.

[24]- CHO, D.H.; KIM, Y.W.; KIM, W. Strength and fracture toughness of in situtoughened silicon carbide, J. Mater. Sci., v.32, p. 4777-4782, 1997 apud Kim, Y.W.; LEE, J.G., J. Mater. Sci, v. 27, p.4746, 1992.

[25 ]- KIM, Y.W.; MITOMO, M.; HIROTSURU, H., Microstructural development of silicon carbide containing large seed grains, J. Am. Ceram. Soc., 80, n.1, p.99-105, 1997.

[26]- DÖRRE, E.; HÜBNER, H. Alumina, Processing, Properties, and Applications, Ilschner and N.M. Grant, Springer - Verlag, Germany, 1984.

[27]- CHIANG, Y.M.; BIRNIE, D.P.; KINGERY, W.D. Physical ceramics- Principles for ceramic science and engineering, The MIT Series in Material Science and Engineering Series Statement, John Wiley \& Sons, USA, 1997.

[28]- HART, L.D. Alumina chemicals; science and technology handbook, In: Production processes, properties, and applications for calcined and high-purity aluminas, T.J. Carbone, p.99-108, The American Ceramic Society, Inc., 1990.

[29]- GITZEN, W. Alumina as a Ceramic Material, The American Ceramic Society, Inc, USA, 1970.

[30]- GOMES, U.U. Tecnologia dos Pós: Fundamentos e Aplicaçôes, UFRN, editora Universitária, RN, p.117, 1995. 
[31]- VAN VLACK, L.H. Propriedades dos Materiais Cerâmicos, Edgard Blücher, editora da Universidade de São Paulo, 1973.

[32]- BJÖRKLUND, H. Grain Morphology and Intergranular Structure of $\mathrm{Si}_{3} \mathrm{~N}_{4}$ and $\mathrm{Al}_{2} \mathrm{O}_{3}$ Based Ceramics, Tese de Doutorado, Chalmers University of Technology, 1996.

[33]- ANSTIS, G.R.; CHANTIKUL, P.; LAWN, B.R.; MARSHALL, D.B. A critical evaluation of indentation techniques for measuring fracture toughness: I, Direct crack measurements, J. Am. Ceram. Soc., v.64, n.9, p.533-538, 1981.

[34]- ZHAO, S.; ZHANG, J.; ZHAO, S.; LI, W.; LI, H. Comp. Sci. Tech., v.63, Issue 7, p.1009-1014, 2003.

[35]- KINGERY, W.D. Structure and Properties of $\mathrm{MgO}$ and $\mathrm{Al}_{2} \mathrm{O}_{3}$ Ceramics, Advances in Ceramics, v.10, The American Ceramic Society, USA, 1984.

[36]- RICHERSON, D. Modern ceramic engineering, properties, processing and use in design, Marcel Dekker, 1992.

[37]- BORSA, C.E.; BROOK, R.J. Fabrication of $\mathrm{Al}_{2} \mathrm{O}_{3} / \mathrm{SiC}$ nanocomposites using a polymeric precursor, Ceramic processing science and technology, Ceramic transactions, v.51, H. Hausner, G.L. Messing, S.Hirano, The American Ceramic Society, p. 653-657, 1995.

[38]- STERNITZKE, M.; DERBY, B.; BROOK, R.J. Alumina/silicon carbide nanocomposites by hybrid polymer/powder processing: microstructures and mechanical properties, J. Am. Ceram. Soc., v.81, n.1, p.41-48, 1998.

[39]- CHANG, S.; DOREMUS, R.H.; SCHADLER, L.S.; SIEGEL, R.W. Hot-pressing of nano-size alumina powder and the resulting mechanical properties, Int. Appl Ceram. Technol. v.1, p.172-179, 2004. 
[40]- YOSHIMURA, H.N.; MOLISANI, A.L.; SIQUEIRA, G.R.; CAMARGO, A.C.; NARITA, N.E.; CESAR, P.F.; GOLDENSTEIN, H. Efeito da porosidade nas propriedades mecânica de uma alumina de elevada pureza, Cerâmica, v.51, p.239-251, 2005.

[41]- NIIHARA, K. New design concept of structural ceramic-ceramic nanocomposites, J. Ceram. Soc. Jpn., v.99, p.974-992, 1991.

[42]- JEONG, Y.K.; NAKAHIRA, A.; NIIHARA, K. Effects of additives on microstructure properties of alumina/silicon carbide nanocomposites, J. Am. Ceram. Soc., v.82, p.3609$3612,1999$.

[43]- DENG, Z.Y.; ZHOU, Y.; BRITO, M.E.; TANAKA, Y.; OHJI, T. Effects of rare earth dopants on grain boundary bonding in alumina-silicon carbide composites, J. Eur. Ceram. Soc., v.24, p.511-516, 2004.

[44]- RICE, R. Ceramics from polymer pyrolysis, opportunities and needs- A material perspective, Am. Ceram. Soc. Bull., v.62, n.8, p.889-892, 1983.

[45]- LEE, J.S.; YANO, T. Fabrication of short-fiber-reinforced $\mathrm{SiC}$ composites by polycarbosilane infiltration, J. Eur. Ceram. Soc., v.24, p.25-31, 2004.

[46]-COLOMBO, P.; MODESTI, M. Silicon oxycarbide ceramic foams from a preceramic polymer, J. Am. Cer. Soc., v.3, n.6, p.573-578, 1999.

[47]- COLOMBO, P.; GAMBARYAN-ROISMAN, T.; SCHEFFLER, M.; BUHLER, P.; GREIL, P. Conductive ceramic foams from preceramic polymers, Ultahigh-temperature ceramics, J. Am. Ceram. Soc, v.84, n.10, p.2265-2268, 2001.

[48]- ADE, M.; HAUBELT, J. Electroconductive ceramic composites with low-to-zero shrinkage during sintering, J. Eur. Ceram. Soc., v.23, p.1979-1986, 2003.

[49]- COLOMBO, P.; PERINI, K.; BERNARDO, E.; CAPETElletI, T.; MACCAGNAN, G. Ceramic microtubes from preceramic polymers, J. Am. Cer. Soc., v.86, n.6, p.1025-1027, 2003. 
[50]- GOERKE, O.; FEIKE, E.; HEINE, T.; TRAMPERT, A.; SCHUBERT, H. Ceramic coatings processed by spraying of siloxane precursors (polymer-spraying), J. Eur. Ceram. Soc., v.24, p.2141-2147, 2004.

[51]- COLOMBO, P.; PAULSON, T.E.; PANTANO, C.G. Synthesis of silicon carbide thin films with polycarbosilane (PCS), J. Am. Ceram. Soc., v.80, p. 2333-2400, 1997.

[52]- SCHIAVON, M.A.; SORARÙ, G.D.; YOSHIDA, I.V.P. Poly(borosilazanes) as precursores of Si-B-C-N glasses: synthesis and high temperature properties, J. Non-Cryst. Solids, v.348, p.156-161, 2004.

[53]- GREIL, P. Active-filler-controlled pyrolysis of preceramic polymers, J. Am. Ceram. Soc., v.78, p.835-848, 1995.

[54]- SCHIAVON, M.A.; REDONDO, S.U.A.; PINA, S.R.O.; YOSHIDA, I.V.P. Investigation on kinetics of thermal decomposition in polysiloxane networks used as precursors of silicon oxycarbide glasses, J. Non-Cryst. Solids, v.304, p.92-100, 2002.

[55]- WANG, Z.C.; ALDINGER, F.; RIEDEL, R. Novel silicon-boron-carbon-nitrogen materials thermally stable up to $2200^{\circ} \mathrm{C}$, Ultrahigh-Temperature Ceramics, J. Am. Ceram. Soc., v.84, p.2179-2183, 2001.

[56]- KAKIMOTO, K.; WAKAI, F.; BILL, J.; ALDINGER, F. Synthesis of Si-C-O bulk ceramics with various chemical compositions from polycarbosilane, J. Am. Ceram. Soc, v.82, n. 9, p.2337-2341, 1999.

[57]- MONTHIOUX, M.; DELVERDIER, O. Thermal behavior of (organosilicon) polymer-derived ceramics. V: Main facts and trends, J. Eur. Ceram. Soc, v.16, p.721-737, 1996. 
[58]- DERNOVSEK, O; BRESSIANI, J.C.; BRESSIANI, A.H.A.; ACCHAR, W.; GREIL, P. Reaction bonded niobium carbide ceramics from polymer-filler mixtures, J. Mater. Sci, v. 35, p.2201-2207, 2000.

[59]- ICHIKAWA, H. Recent advances in nicalon ceramic fibres including HI-Nicalon Types, Ann.Chi. Sci. Mat., v.25, p.523-528, 2000.

[60]- ROUXEL, T.; SANGLEBOEUF, J.C.; GUIN, J.P.; KERYVIN, V.; SORARÙ, G.D. Surface damage resistance of gel-derived oxycarbide glasses: hardness, toughness and scratchability, Ultrahigh-temperature ceramics, J. Am. Ceram. Soc., v.84, n.19, p.22202224, 2001.

[61]- WAN, J.; GASCH, M.; MUKHERJEE, K. In situ densification behavior in the pyrolysis consolidation of amorphous Si-N-C bulk ceramics from polymer precursors, Ultrahigh-temperature ceramics, J. Am. Ceram. Soc., v.84, n.10, p.2165-2169, 2001.

[62]- HE, J.; SCARLETE, M.; HARROD, J. Silicon nitride and silicon carbonitride by the pyrolysis of poly(methylsiladiazane), J. Am. Ceram. Soc., v.78, n.11, p.3009-3017, 1995.

[63]- YAJIMA, S.; HAYASHI J.; OMORI, M. Continuous silicon carbide fiber of high tensile strengh, Chem. Leth, p.931, 1975.

[64]- BILL, J.; ALDINGER, F. Precursor - derived covalent ceramics: Synthesis, Structures and High Temperature Mechanical Properties, J.Bill, F. Wakai, F. Aldinger, Wiley-VCH, Weinheim, Germany, p.35, 1999.

[65]- RAHIMI, A.; SHOKOLAHI, P. Application of inorganic polymeric materials, Int. J. Inorg. Mat, v.3, p.843-847, 2001.

[66]- WILLS, R.R.; MARKLE, R.A.; MUKHERJEE, S.P. Siloxanes, silanes and silazanes in the preparation of ceramics and glasses, Am. Ceram.Soc. Bull., p.904-912, 1983.

[67]- ROCHA, R.M. Obtenção e Caracterização de Cerâmicas no Sistema Si-Al-O-N-C Empregando Pirólise de Misturas de Polissiloxano e Cargas, Tese de Doutorado, Instituto 
de Pesquisas Energéticas e Nucleares, Autarquia Associada à Universidade de São Paulo, 2004.

[68]- HARDMAN, B; TORKELSON, A. Silicones. In: Encyclopedia of polymer science and engineering, edited by, Kroschvitz J. I., USA, John Wiley \& Sons, v.15, p.205-308, 1989.

[69]- CZOSNEK, C.; WOLSZEZAK, J.; DRYGÁS M.; GÓRA, M.,; JANIK, J.F. Nano$\mathrm{SiC}$ implantation into the structure of carbon/graphite materials made by pyrolysis (carbonization) of the precursor system coal tar pitch/poly(dimethilsiloxane), J. Phys. Chem. Solids, v.65, p.647-653, 2004.

[70]- GREIL, P. Polymer derived engineering ceramics; Adv. Eng. Mater., p.339, 2000.

[71]- ERNY, T.; SUTTOR, D.; GREIL, P. Properties of novel polymer derived ceramic composites, th Europ. Ceram. Soc. Conf., Italy, Oct. 1995.

[72]- CORDELAIR, J.; GREIL. P. Electrical conductivity measurements as a microprobe for structure transitions in polysiloxane derived Si-O-C ceramics, J. Eur. Ceram. Soc., v.20, p.1947-1957, 2000.

[73]- HÖRZ, M.; ZERN, A.; BERGER, F.; HAUG, J.; MÜLLER, K.; ALDINGER, F.; WEINMANN, M. Novel polysilazanes as precursors for silicon nitride/silicon carbide composites without "free" carbon, J. Eur. Ceram. Soc, v.25, p.99-110, 2005.

[74]- MICHALET, T.; PARLIER, M.; ADDAD, A.; DUCLOS, R.; CRAMPON, J. Formation at low temperature with low shrinkage of polymer/ $\mathrm{Al} / \mathrm{Al}_{2} \mathrm{O}_{3}$ derived mullite, Ceram. Int, v.27, p.315-319, 2001.

[75]- HA, J.S.; LIM, C.S.; KIM, C.S.; CHEONG, D.S. A new process for $\mathrm{Al}_{2} \mathrm{O}_{3} / \mathrm{SiC}$ nanocomposite by polycarbosilane infiltration, Met Chem. Physics, p.241-245, 2002. 
[76]- SCHIAVON; M.A. Polissiloxanos e polissilazanos como precursors de materiais cerâmicos e suas aplicaçōes na obtenção de compósitos de matriz cerâmica; Tese de Doutorado, Instituto de Química, Universidade Estadual de Campinas, 2002.

[77]- CALLISTER, W. D. Materials Science and Engineering-An Introduction, John Wiley \& Sons, INC, Third Edition, USA, 1994.

[78]- GERMAN, R. Sintering theory and practice, John Wiley \& Sons, ${ }^{\text {st }}$ ed. 1996.

[79]- GERMAN, R.M. Sintering, In: Powder Metallurgy Science, edited by K.H. Roll, USA, 1984.

[80]- SHAW, N.J. Densification and coarsening during solid state sintering of ceramics: A review of the models- I: Densification, Powder Metall Intern, v.31, p.16-21, 1989.

[81]- ASHBY. M. F. A first report on sintering diagrams. Acta Metall., v.22, 1984.

[82]- KOPFSTAD, P. Electrochemical transport defet - Dependent processes. In: Kopfstad, P.; Nonstoichiometry, diffusion and electrical conductiviy in binary metal oxides, Wiley, USA, chapter 6, 1972.

[83]- THÜMMLER, F.; THOMMA, W. The Sintering Process, Metall. Rev., v.12, p.69108, 1967.

[84]- TEBCHERAN, S.M.; VARELA, J.A.; BRANKOVIC S.; BRANKOVIC G.; SPAGNOL, P.D.; CILENSE, M.; PERASOLLI L.; LONGO, E. Cinética de sinterização para sistemas à base de $\mathrm{SnO}_{2}$ por taxa de aquecimento constante, Cerâmica, v.49, p.99-109, 2003.

[85]- VARELA, J.A.; LONGO, E. Princípios de sinterização em estado sólido. Parte I: modelos teóricos, Cerâmica, v.32, p.69-101, 1984.

[86]- GERMAN, R. Liquid phase sintering, Plenum Press, USA, 1985. 
[87]- BALBO, A.; SCITI, D.; MELANDRI, C.; COSTA, A.L.; BELLOSI, A. Processing and characterization of liquid phase sintered silicon carbide, Proceedings of the $4^{\text {th }}$ International Conference on Science, Technology, and Applications of Sintering, Grenoble, France, August 29-September 1, p.33-40, 2005.

[88]- SOUZA, S.A. Ensaios Mecânicos de Materiais Metálicos, Editora Edgard Blücher Ltda., 1974.

[89]- QUINN, J.B.; QUINN, G.D. Indentation brittleness of ceramics: a fresh approach, $J$. Mater. Sci, v.32, p.4331-4346, 1997.

[90]- PONTON, C.B.; RAWLINGS, R.D. Vickers indentation fracture toughness test. Part I: Review of literature and formulation of standardized indentation toughness equations, Mater. Sci. Tech., v.5, p.865-871, 1989.

[91]- MCCOLM, I.J. Ceramic Hardness, p.160, edited by Plenum Press, USA, 1990.

[92]- MENEZES, C.A.B. Estudo da Influência do teor de elementos de terras raras leves nas cerâmicas de zircônia-céria-ítria, Tese de Doutorado, Instituto de Pesquisas Energéticas e Nucleares, Autarquia Associada à Universidade de São Paulo, 2001.

[93]- WARREN, R. Ceramic-Matrix Composites, Chapman and Hall, Inc., USA, 1992.

[94]- CARTER, H.C.; TSVETKOV, F.V.; GLASS, C.R.; HENSHALL, D.; BRADY, M.; MÜLLER, S.G.; KORDINA, O.; IRVINE, K.; EDMOND, A.J.; KONG, S.H.; SINGH, R.; ALLEN, T.S.; PALMOUR, W.J. Progress in SiC: from material growth to commercial device development, Mat. Sci. Eng., v. 61, p.1-8, 1999.

[95]- SIERGIEJ, R.R.; CLARKE, C.R.; SRIRAM, S.; AGARWAL, K.A.; BOJKO, J.R.; MORSE, W.A.; BALAKRISHNA, V.; MACMILLAN, F.M.; BURK, A.A.; BRANDT, D.C. Advances in $\mathrm{SiC}$ materials and devices; an industrial point of view, Mat. Sci. Eng., v. 61, p.9-17, 1999.

[96]- GENOVA, L.A. Efeito das variáveis de processamento nas características microestruturais e mecânicas do nitreto de silício, Tese de Doutorado, Instituto de 
Pesquisas Energéticas e Nucleares, Autarquia Associada à Universidade de São Paulo, 2003.

[97]- REED-HILL, R.E. Physical Metallurgy Principles, W.W. Hagerty, Van Nostrand Reinhold Company, Inc., USA, p. 501, 1972.

[98]- ZHAN, G.D.; XIE, R.J.; MITOMO, M.; KMM, Y.W. Effect of $\beta$-to- $\alpha$ phase transformation on the microstructural development and mechanical properties of finegrained silicon carbide ceramics, J. Am. Ceram. Soc, v.84, p.945-950, 2001.

[99]- IONASHIRO, M.; GIOLITO, I. Nomenclatura, padrões e apresentação dos resultados em análise térmica, Cerâmica, v.26, p.17-24, 1980.

[100]- IONASHIRO, M.; GIOLITO, I. A nomenclatura em análise térmica- Parte II, Cerâmica, v.34, p.163-164, 1988

[101]- CULLITY, B.D. Elements of X-Ray Diffraction, Addison-Wesley Publishing Company, INC, 1967.

[102]- SMITH, A.L. Analysis of Silicones, Wiley, USA, 1974.

[103]- CORDELAIR, J.; GREIL, P. Electrical characterization of polymethylsiloxane/MoSi 2 - derived composite ceramics, J. Am. Ceram Soc, v.84, p.2256-2259, 2001.

[104]- SUTTOR, D.; KLEEBE, H.J.; ZIEGLER, G. Formation of mullite from filled siloxanes, J. Am. Ceram, v.80, n. 10, p.2541-2548, 1997.

[105]- MICHALET, T.; PARLIER, M.; BECLIN, F.; DUCLOS, R.; CRAMPON, J. Elaboration of low shrinkage mullite by active filler controlled pyrolysis of siloxanes, $J$. Eur. Ceram. Soc, v.22, p.143-152, 2002.

[106]- SCHIAVON, M.A.; RADOVANOVIC, E.; YOSHIDA, I.V.P. Microstructural characterization of monolithic ceramic matrix composites from polysiloxane and $\mathrm{SiC}$ powder, Powder Tech., v.123, p.232-241, 2002. 
[107]- JOVANOVIC, J.D.; GOVEDARICA, M.N.; DVORNIC, P.R.; POPOVIC, I.G. The thermogravimetric analysis of some polysiloxanes, Polymer Degradation and Stability, v. 61, p.87-93, 1998.

[108]- NEGITA, K. Effective sintering aids for silicon carbide ceramics: Reactivities of silicon carbide with various additives, J. Am. Ceram. Soc., v.69, c-308-c-310, 1986.

[109]- DIJEN, F.K.; MAYER, E. Liquid phase sintering of silicon carbide, J. Eur. Ceram. Soc., v.16, p.413-420, 1996.

[110]- GRANDE, T.; SOMMERSET, H.; HAGEN, E.; WIIK, K.; EINARSRUD, M.A. Effect of weight loss on liquid-phase-sintered silicon carbide, J. Am Ceram. Soc, v.80, p.1047-1052, 1997.

[111]-MITA, S.; DUTTA, G.; DUTTA, I. J. Am. Ceram. Soc., v.78, p.2385-2390, 1995.

[112]- BAUD, S.; THÉVENOT, F.; PISCH, A.; CHATILLON, C. High temperature sintering of $\mathrm{SiC}$ with oxides additives: $\mathrm{I}$. Analysis in the $\mathrm{SiC}-\mathrm{Al}_{2} \mathrm{O}_{3}$ and $\mathrm{SiC}-\mathrm{Al}_{2} \mathrm{O}_{3}-\mathrm{Y}_{3} \mathrm{O}_{3}$ systems, J. Eur. Ceram. Soc., v.23, p.1-8, 2003.

[113]- TOROPOV, N.A.; BONDAR, I.A.; GALAKHOV, X.S.; NIKOGOSYAN, X.S.; VINOGRADOVA, N.V. Ser. Khim., n.7, p.1162, 1964, apud Phase diagrams for ceramists, The American Ceramic Society, USA, 1969.

[114]- MARCHI J. Sinterização via fase líquida de cerâmicas à base de carbeto de silício com aditivos óxidos utilizando planejamento de experimentos, Tese de Doutorado, Instituto de Pesquisas Energéticas e Nucleares, Autarquia Associada à Universidade de São Paulo, 2003.

[116]- SHE, J.H. UENO, K. Effect of additive content on liquid-phase sintering on silicon carbide ceramics, Mater. Rex. Bull, v.34, p.1629-1636, 1999.

[117]- ROCHA, R.M.; GREIL, P.; BRESSIANI, J.C.; BRESSIANI, A.H.A. Complexshaped ceramic composites obtained by machining compact polymer-filler mixtures, Mater. Rex. v.8, 2005. 
[118]- SU, B.; STERNITZKE, M. A novel processing route for alumina / SiC nanocomposites by Si-polymer pyrolysis, Fourth Euro Ceramics, v.4, p.109-116, A. Bellosi, Gruppo Editoriale Faenza Editrice S. p. A., Italy, 1995.

[119]- HARSHE, R.; BALAN, C.; RIEDEL, R. Amorphous Si(Al)OC ceramic from polysiloxanes: bulk ceramic processing, crystallization behavior and applications, J. Eur. Ceram. Soc., v.24, p.3471-3482, 2004.

[120]- PANTANO, C.G.; SING, A.K.; ZHANG, H. Silicon oxycarbide glasses, J. Sol-Gel Sci. Technol v.14, p.25, 1999.

[121]- TRASSL, S.; MOTZ, G.; RÖSSLER, E.; ZIEGLER, G. Characterization of the freecarbon phase in precursor-derived SiC-C-N ceramics: I, Spectroscopic methods, J. Am. Ceram. Soc, v.85, n.1, p.239-244, 2002.

[122]- WYNNE, K.J.; RICE, R.W. Ceramics via polymer pyrolysis, Ann. Rev. Mater. Sci, v.14, p.297-334, 1984.

[123]- GUMULA, T.; PALUSZKIEWICZ C.; BLAZEWICZ, M. Structural characterization of polysiloxane-derived phases produced during heat treatment, J. Mol. Structure, v.704, p.259-262, 2004. 